PROCESS DEVELOPMENT OF THIN STRIP STEEL CASTING

Final Report

By

A. J. Heckler

R. C. Sussman

A. S. Williarns

December 1990

Work Performed Under Contract Nos. FC07-881D12712

AC07-83ID12443

For

U.S. Department of Energy

Office of Industrlal Technologies

Washington, D.C.

By

Armco, Inc.

Middletown, Ohio 


\section{DISOLAIMER}

This report wat prepared at an accourt of work sponsored hy an agency of the United States Governmem. Neither the United States (iovernment nor ans agency thereof. ner any of then employees, makes any waranty. express or impled. or assumes any legal liabiluy or respomsitrility for the accuracy, completenest. or usefulness of any information, apparatus, profuct, or process disciosed. or represents that its use would not infronge privately owned rights. Reference herein to ant specific commercial product. precess. of service by trade name. trademark, mamufacturer, of otherwise dees not necessarih consutule or imply ats endorsement. recommendanon. or favoring by the Linted States (ioverment or any agency thereot The views and opmons of authors ex. pressed herein do not necessants state or reflect these of the Unted States Cowernment or ans atencs thereof

This report has been reproduced directly from the best available copy.

Avalabie to DOE and DOE contractors from the Office of Scientific and Technical Information, P.O. Box 62, Oak Ridge, TN 37831; prices available from 16151576.8401 , FTS 626.8401.

Available to the public from the National Technical Information Service, U.S. Department of Commerce, 5285 Port Royal Rd., Springfield, VA 22161. 
DE9 1005692

\title{
PROCESS DEVELOPMENT OF THIN STRIP STEEL CASTING
}

\section{Final Report}

December 1990

A. J. Heckler, Program Manager

R. C. Sussman, Prinicipal Investigator

R. S. Williams, Principal Investigator, Westinghouse, Inc.

Work Performed Under Contract DE-FC07-88ID12712

\author{
Prepared for \\ U. S. Department of Energy \\ Idaho Operations Office, Idaho Falls, ID \\ Sponsored by the Office of the Assistant Secretary \\ for Conservation and Renewable Enerc v \\ Office of Industrial Technologies \\ Washington D.C.
}

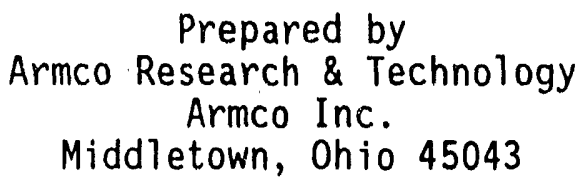


1.0 EXECUTIVE SUMMARY

2.0 DEVELOPMENT OF THIN BTRIP CASTING

3. 0 BACKGROUND

4.0 JUSTIFICATION FOR WORK

5. 0 TECHNICAL APPROACH

6.0 STATEMENT OF WORK

7.0 TASK REPORTS

7.1. Task 1.1 - Water Modeling of Planar Flow Casting Nozzle

7.2 Task 1.2 - Three Dimensional Modeling of Melt Flow in the Melt overflow Tundish

7.3 Heat Transfer and solidification Model

7.4 Task 2.0 - substrate Effects

7.5 Task 3.1 - Melt overflow Casting Experiments 85

7.6 Task 3.2 - Planar Flow Casting

\section{Appendices}

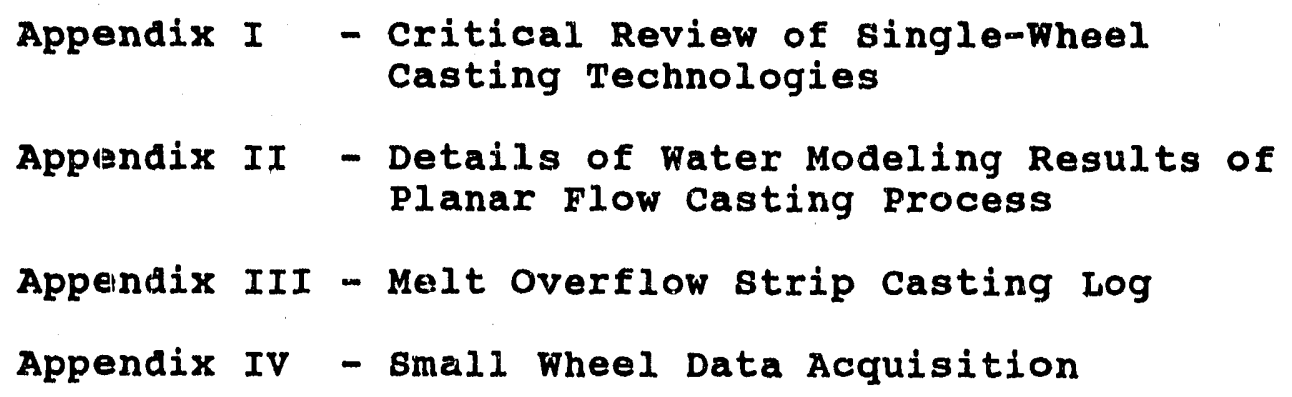




\subsection{EXECUTIVE SUMMARY}

An important new frontier is being opened in steel processing with the emergence of thin strip casting. Casting steel directly to thin strip has enormous benefits in energy savings by potentially eliminating the need for hot reduction in a hot strip mill. This has been the driving force for numerous current research efforts into the direct strip casting of steel.

One of the processes with considerable promise is the casting of steel onto a single cooling substrate. 'The process has already led to the production of thin foil (0.001 to $0.005 \mathrm{in}$. thick) by the planar flow casting process at speeds of up to $75 \mathrm{ft} / \mathrm{sec}$. If a derivative of this process could be developed to cast steel, particularly carbon steel, in the thickness range of $0.030-0.125$ in., a method of thin strip casting might be realized.

The U.S. Department of Energy initiated a program to evaluate the development of thin strip casting in the steel industry. In earlier phases of this program, planar flow casting on an experimental caster was studied by a team of engineers from Westinghouse Electric Corporation and Armco Inc. The results of that program are described in Report DOE/ID/12443-2 (DE88013689). It was concluded by the engineers and the D.O.E. monitors that further work was warranted on both the planar flow casting process and also on a related single wheel technique, the melt overflow casting process, that was briefly investigated at the end of the project. 
A subsequent research program, \#DE-FC07-88I-12712 was designed as a fundamental and developmental study of both casting processes. The goal of the full program was to ascertain the potential of these processes for further research effort on a pilot plant scale. The original experimental plan and focus is shown in Table 1 with a "go/no-go" decision point as Task 4.3 about 9 months into the program. This decision point was extended for 3.5 months when problems developed with the operation of the $7 \mathrm{ft}$. diameter casting wheel and the wheel had to be fully disassembled and redesigned. This report documents the results of the program up to the completion of Task 4.3 .

The planar flow casting was conducted on a nominally $7 \mathrm{ft}$. diameter water-cooled copper wheel casting system. This was designed, fabricated and installed in a dedicated 15,000 sq. ft. foundry facility at Armco Inc., Middletown, ohio. This system is capable of casting 3 in. wide strip and operating at surface speeds of up to $25 \mathrm{ft} / \mathrm{sec}$. Additionally, the facility contains a 16 in. diameter water-cooled wheel with interchangeable casting substrates fabricated from various materials. This small wheel facility has been adapted to utilize the melt overflow process for casting of 3 in. wide strip. These casting facilities are supported by two 500 1b. induction melting furnace and the necessiry liquid steel handling equipment. Techniques have been developed for transportation and filtering of liquid steel without undue temperature loss. The overall foundry facility and associated process technology represents a first-class and relatively unique 
laboratory in which to conduct thin steel strip casting technology development under realistic industrial conditions.

This study was arranged as several separate and distinct tasks which were often completed by different teams of researchers. An early task was to design and build a water model to study fluid flow through different designs of planar flow casting nozzles. A complete and thorough evaluation of various designs was made at various wheel speeds and fluid flow conditions. On the basis of these trials, the best design of the planar flow nozzle was selected for the subsequent trials on the large wheel caster.

Another important task was mathematically modeling of melt overflow casting process. This involved the two dimensional modeling of the flow within the pouring box and at the point of contact of the liquid melt pool with the casting nozzle. The flow patterns predicted by the mathematical modeling were verified by constructing a water model of the meit overflow process and by using liquid dyes and making video tapes of the process. These models can be used in the future to modify the design of the pouring box and the casting nozzle to improve the quality of the solidified strip.

A mathematical solidification model for the formation of the strip in the melt overflow piocess was written. This compared favorably to the actual trial results. This model predicts strip thickness as a function of wheel speed, steel superheat, and melt pool height. 
A study of the material and conditioning of casting substrates was made on the small wheel caster using the melt overflow casting process. The substrates studied included stainless steel, carbon steel, copper and iron electroplated onto copper. All of the different substrates were evaluated with various surface texturing and qualitative relationships were found between the characteristics of the substrate and quality of the strip.

After the water modeling and substrate studies were completed, planar flow casting trials were made on the $7 \mathrm{ft}$. diameter caster. The ideal substrate and nozzle design were used in one of the trials. From the results, it was concluded that the method could not be used successfully for carbon steel without major modifications. A new design of the pouring box and nozzle was conceived and constructed. This combined the best features of the melt overflow and planar flow methods. This design was used on one trial near the end of the program. Continuous strip about 0.045 in. thick was cast at a very high productivity rate, $360 \mathrm{ft} / \mathrm{min}$. Although the strip had a more ripply surface than the strip produced by the melt overflow method on the small wheel caster, the process has definite promise for further investigation.

Sixty-one trial heats were cast to thoroughly evaluate the rnelt overflow casting process on the small wheel caster. The initial strip was very poor in both top and bottom surface quality. other problems encountered were freezing at the melt pool/wheel interface, leakage of liquid steel under the wings of the nozzle, gap control between the nozzle and wheel, and others. Many 
step-by-step improvements were made to overcome these problems. Eventually, the process evolved to the point where silicon-killed carbon steel strip that had very attractive surface quality on both the top and bottom could be consistently produced. This process was chosen for the go/no-go trial heats and five consecutive heats of carbon steel were successfully cast. Equipment and refractory supply limitations restricted the thickness of the strip that could be produced in this phase of the program to a maximum of around $0.035 \mathrm{in.}$ A modest amount of the strip was cold rolled with no apparent quality problems. Cup expansion tests demonstrated very good formability.

The experimental work demonstrated the feasibility of casting carbon steel strip by either the melt overflow process or the modified planar flow process. Further experimental work is needed to increase the thickness of the cast strip, improve top surface quality, gauge control and increase the process productivity. 


\subsection{DEVELOPMENT OF THIN STRIP CASTING}

Prior to beginning this contract, the planar flow casting process (see Figure 1) was investigated for casting of low carbon steel strip in a program funded folntly by U.S. Department of Energy (DOE), Armco Inc., and Westinghouse under DOE Contract No. DE-AC07-83ID12443. The objective of the program was to develop a process for producing cast thicknesses between 0.030 and 0.125 inch with a suitable physical shape and metallurgical structure for cold rolling and annealing to yield a useful product.

During the program, delays in initlating the casting trials occurred due to the recommissioning of the Armco casting facility and in eliminating design and operating problems in the $7 \mathrm{ft}$. diameter casting wheel. At the conclusion of the casting program, the primary technical issues remaining were: the optimization of the liquid steel flow from the feeding system onto the wheel surface; the solidification phenomena occurring at the feeding system-casting wheel interface; and the casting wheel substrate-liquid steel interactions.

Significant progress was made in developing the metal handling system. Ultimately, the liquid steel could be routinely delivered to the casting wheel at the desired temperature and chemistry. The $7 \mathrm{ft}$. casting wheel was modified and proved to be reliable. strip 
ن

舀

款
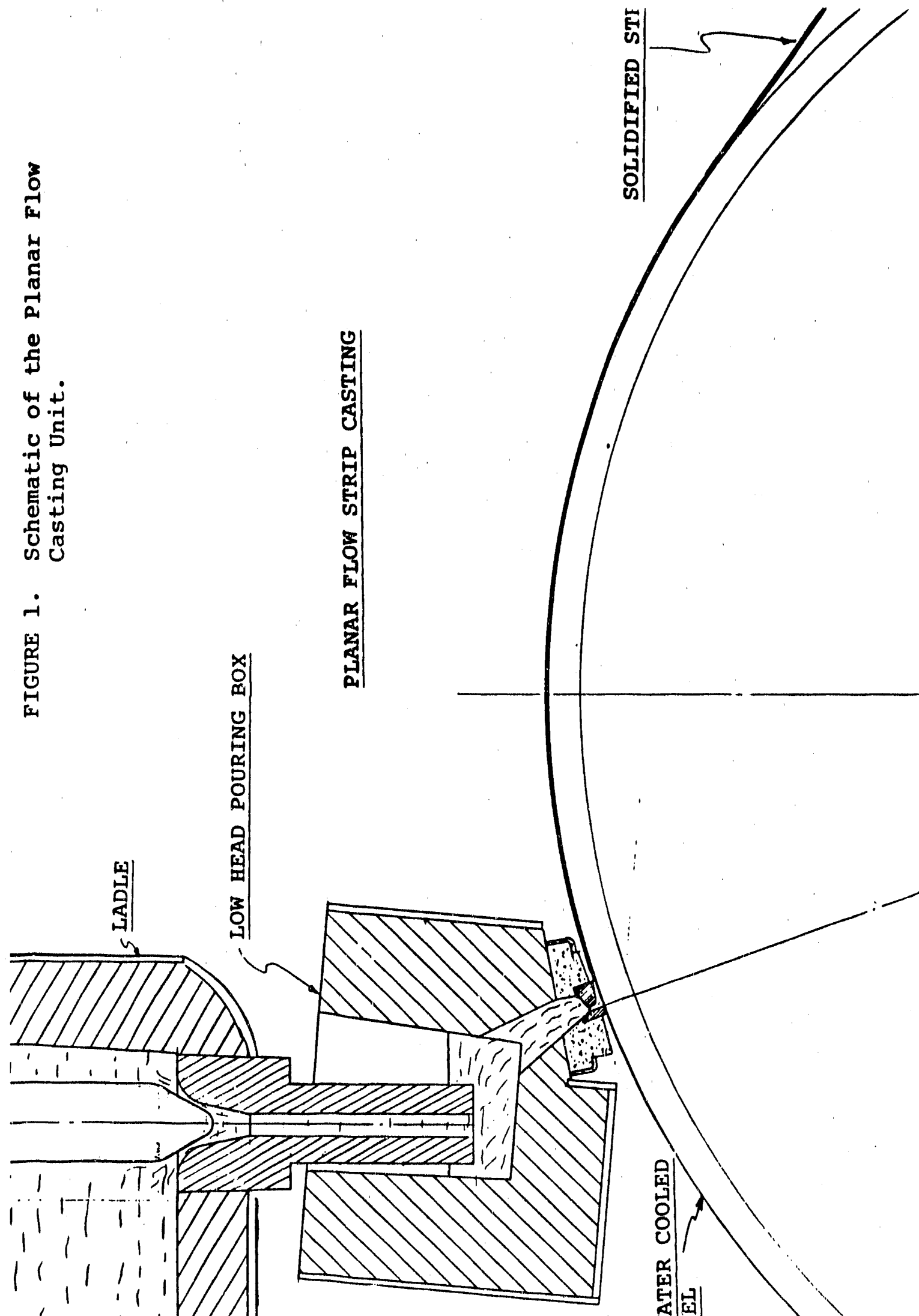

11111

TIIIIII 
up to $0.030 \mathrm{in}$. thick was produced during several trials using planar flow onto the large diameter ( $7 \mathrm{ft.}$ ) casting wheel.

Towards the end of the program, a variant of the melt-overflow method was tried on a small ( 16 in.) diameter wheel (see Figure 2). Several very successful casts were made, producing strip up to $0.020 \mathrm{in.} \mathrm{thick.} \mathrm{It} \mathrm{was} \mathrm{therefore} \mathrm{concluded} \mathrm{that} \mathrm{there} \mathrm{are} \mathrm{two}$ single wheel processes which show promise for the casting of low carbon steel strip.

As most of the equipment design and construction had been completed, Armco Inc. became the Prime contractor for the subsequent program described here to further investigate the planar flow and melt overflow processes. As a subcontractor, Westinghouse $R \& D$ provided technical support from their Metals Process Research Group for the casting trials at Armco. Their design staff also assisted with improvements to the large wheel caster.

The goal of this program was to determine the optimum operating parameters for producing low carbon steel strip, and to establish the feasibility for scale-up to commercial production. The total proposed program was intended to cover $: 7$ months and a total effort of 22,500 man-hours. As the attached statement of work details, a critical go/no-go milestone was established after the first eight months. This milestone was extended three and one-half months principalıy due to delays with design changes to the large wheel 


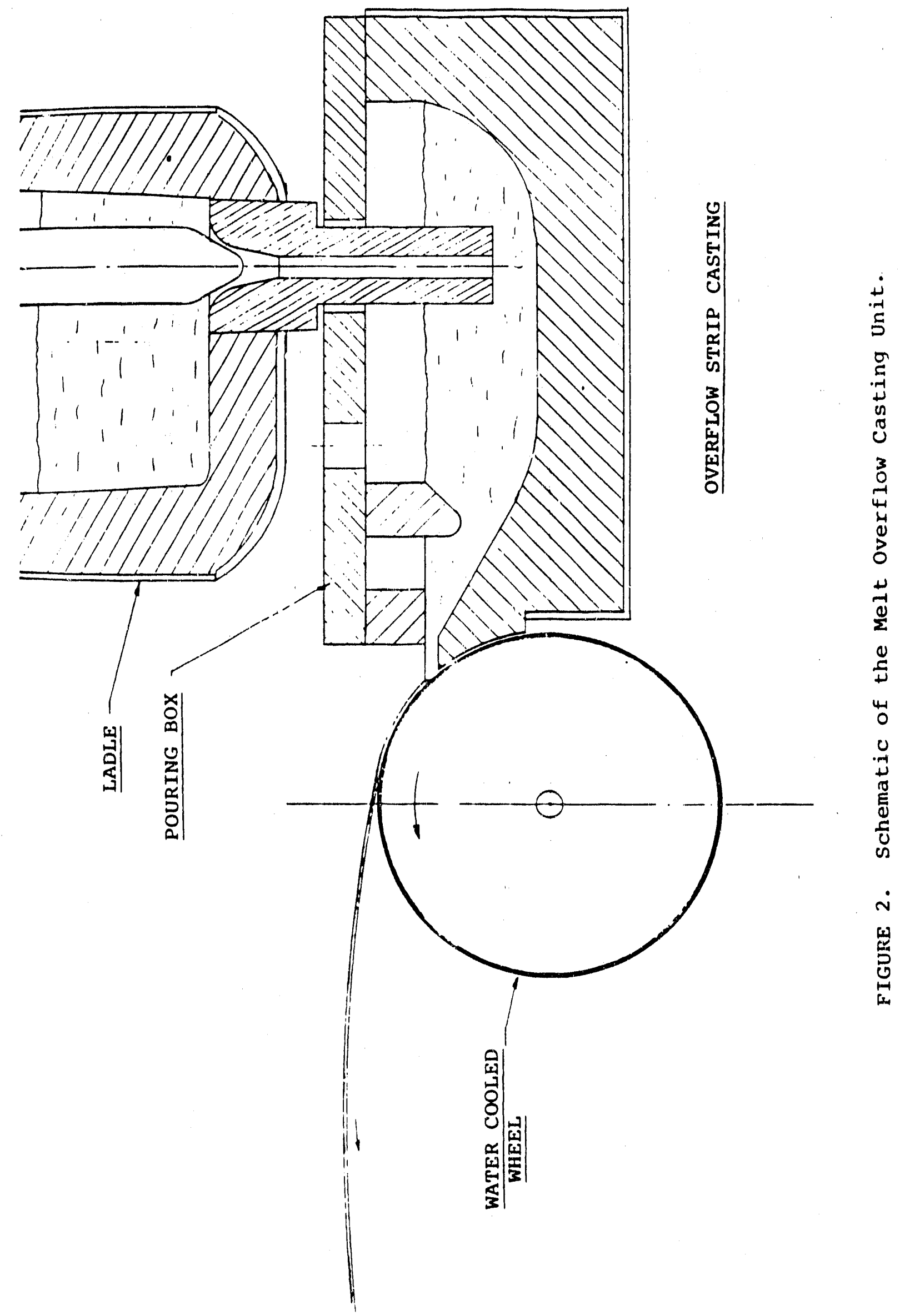




\subsection{BACKGROUND}

\section{Previous Work}

Planar flow casting was determined in Phase $I$ of contract \#DOE-AC07-83ID12443 to be a prime candidate for commerclal direct strip casting of low carbon steels. Accordingly, a major experimental phase II program was initiated to explore the feasibility of the process. During the course of this study, a unique experimental facility was established. Two fully equipped and monj.tored casters were constructed: a 16 in. diameter caster for evaluation of selected chill block (substrate) materials; and a $7 \mathrm{ft}$. diameter wheel. for planar flow casting experiments. Both systems can cast up to $3 \mathrm{in.} \mathrm{wide} \mathrm{strip.} \mathrm{Two} 500 \mathrm{lb}$. melting furnaces were recommissioned, and numerous ladles and pouring boxes were constructed to supply molten metal to the casters. An extensive computerized system was developed to control the casting units and to collect and analyze data from the trials.

Two separate casts on the large wheel yielded roughiy $4001 \mathrm{bs}$. of low carbon steel strip, with an average thickness of somewhat less than $0.030 \mathrm{in}$. In many other trials, discontinuous pieces or chips of steel strip with up to 0.090 in. thick were produced. In these latter trials, the amount and velocity of the liquid steel metered onto the wheel through the nozzle was excessive, causing a portion of the steel to remain unsolidifiec as it traveled over the top of the wheel. The thickness of the liquid steel streams and problems of the strip lifting off the wheel prevented adequate heat 
extraction rates to the wheel, thus much of the material exited the wheel still molten. These results suggested that if the fluid flow could be controlled so that the resulting solidifying strip was flat, adhered to the wheel, and was no greater thickness than that which could be completely solidified on the wheel, continuous strip within the desired range of dimensions could be produced.

Concurrent with the planar flow casting on the 71 wheel, a variant of the melt overflow method was investigated using the 16 in. diameter casting wheel. These trials yielded several hundred pounds of 0.015 to 0.020 in. strip of reasonably good surface quality. The advantage of the melt overflow process is that the amount of material removed from the molten pool is determined by the degree of solidification, and thus it always produces fully solidified material. This process showed promise, but there were concerns as to whether quality strip of sufficient thickness could be produced.

These results from both the planar flow method and the melt overflow method indicated that one or both of these processes were potentially viable for casting steel strip in the thicknesses required for cold rolling. Unfortunately, the period of the program over which significant experimental trials could be conducted was limited to only seven months. Technical problems were associated with the construction of the state-of-the-art cooling system for the large diameter wheel and were solved during the contract period. The results of this program were reported in Report 87-9D4-STRIP-R4 . 


\section{Current Program}

The new program, contract \#DE-FC07-88ID12712 was intended to evaluate both the melt overflow and planar flow casting process with the goal of selecting one of the two processes for continued study. The technical research progr: I was designed to give approximately equal weight to both processes. A go/no-go criteria was established for continuation of the work after eight months. This was later amended to add 3.5 months, largely due to problems in implementing design changes of the large wheel needed to solve several mechanical problems identified during the previous experimented program. Other than the go/no-go criteria, other factors used to evaluate the processes include:

- Maximum thickness achievable strip surface quality Metallurgical quality Óverall energy content and economics Equipment required and cost to proceed to pilot scale 


\subsection{JUSTIFICATION FOR WORK}

The cost reduction potential for any direct thin steel strip casting technique includes at least. three important areas:

- Energy and yield savings

- operating cost savings

- Process capital cost savings

If the proposed direct strip casting process using a single water cooled quench wheel can be successfully developed from a technical and operational standpoint, it has potential for cost savings over conventional hot rolled strip production practice in each of the three areas.

Extensive detail on cost reduction and energy assessment for direct steel strip casting is contained in the Armco Inc. proposal for this program, "Process Development of Thin strip steel Casting," Volume I - Technical Proposal, March 27, 1987. 


\subsection{TECHNICAL APPROACH}

The overall technical approach was to develop a basic understanding of obstacies to success in buth the planar finw and melt overflow casting processes in order to evaluate both casting processes. The phase was 11.5 months long and was intended to provide the information needed to select te most promising casting process.

As with conventional continuous casting processes, it is essential that the steel be thoroughly deoxidized. The choice of deoxidants basically resides with either of two elements, silicon or aluminum. The steel grade chosen for investigation in this phase of the program was carbon si-killed steel, based on experience gained in the previous program. Si-killed steels are easier to handle and reduce the problem of nozzle clogging. Once the thickness and shape requirements are met for commercial Quality grade of steel, the trials will proceed to the casting of aluminum killed steel in an attempt to produce grades of Deep Drawing Quality steels. In early trials of the previous program, ceramic filters above the nozzle area were found to be very effective in removing the $\mathrm{Al}_{2} \mathrm{O}_{3}$ inclusions and preventing nozzle blockage. Thus there is confidence that once an optimized process is in place for Si-killed steel, we will be able to cast Al-killed steels with minor modifications to the system.

The casting trials on the large wheel during the previous program had identified several technical obstacles to planar flow 
casting of steel strip. It was clear that design of the pouring box and nozzle was critical to obtaining the proper smooth, even flow of metal onto the wheel. Video tapes of the casting trials, along with data on the strip temperature and heat extraction confirmed the dramatic effect of nozzle designs on the flow pattern and solidification characteristics. Toward the end of the 40 or so planar flow trials, nozzle design had improved markedly, but time and funding constraints prevented full optimization. Additionally, inadequate adhesion of the strip to the substrate appeared to limit the deg. . CE solidification achieved, even for good flow patterns.

To en 1-rge the fundamental knowledge and to reduce the number of casting trials required on the large wheel, the current program began with the design and construction of a water model of the planar flow pouring box and nozzle. The design was flexible in order to study numerous concepts with the particular intention of finding the design which gave consistent smooth flow without crossover currents and pinching in at the sides of the flow, phenomena that were observed in previous trials on the large wheel. The water model effort was completed before actual trials of planar flow casting were reinitiated on the large wheel so that the results could be incorporated in the nozzle design.

A backgroud literature review was also done of published information on the single wheel casting processes. This review is included in Appendix I. 
Mathematical modeling was used to supplement the water modeling and to compile the casting parameters for an efficient statistical matrix of experiments. Without great expense in computer time or manpower, dimensionless numbers for the fluid flow and heat transfer parameters were calculated following the principles of chemical engineering Combining the parameters into dimensionless numbers, such as Prandl, Weber and Reynolds numbers, generates information on the inter-relationship of the geometric and analytical parameters, and allows for a more efficient design of the statistical matrix of experiments by eliminating redundant and illogical experiments.

More extensive mathematical modeling was conducted for melt overflow casting, concentrating on methods to produce thicker strip. For this process, the heat transfer from the molten pool to the wheel was modeled to improve our understanding of the key operating parameters. Also, mathematical modeling of fluid flow in the pouring box and in the melt pool at the point of contact with the wheel was completed. Extensive two dimensional plots were made of fluid flow in both the horizontal and vertical planes. Professor Sahai from onio state University assisted us in all of the mathematical analysis.

The other essential study to improve the direct strip casting process was on the influence of steel-to-substrate effects in the heat transfer to the wheel. Parameters such as the chemistry, roughness, and temperature of the substrate were studied with trials on the small wheel. Wheels made of copper, carbon steel and 
stainless steel were used for the small 16 in. diameter wheel to determine the wetability and adhesion properties of the steel to the different substrates. Residence time on the wheel was used as a me isure of the effective heat transfer. Also, a wheel with iron electroplated onto copper was construsted and evaluated on the small wheel caster.

The melt overflow method was developed concurrently with the substrate studies on the 16 in. diameter casting wheel in Task 3.1 . The nature of the technology of this process permitted very useful experiments on the small wheel. The main emphasis of the melt overflow experiments was to produce thicker strip while still maintaining good surface quality. The crucial parameters for increased thickness appear to be wheel speed, wheel chemistry and melt puddle control. The experiments were designed to study these effects, as well as improve pouring box and nozzle designs and refractories for better control and longer life.

Using the knowledge gained by water modeling (Task 1.1) mathematical modeling (Task 1.2) and substrate experiments (Task 2), planar flow trials were reinitiated on the large wheel as Task 3.2. The trials used silicon killed steel and evaluated the critical operating parameters of wheel speed, pouring box head height and wheel temperature. 
After 11.5 months, a "go no-go" decision cr.teria was established on the basis of demonstrated achievement of casting a si-killed low carbon steel composition in strip form and meeting the following criteria:

- Average cast thickness in exress of $0.03 \mathrm{in}$.

- Visible holes totaling $1 \%$ or less of strip area

- Achieve above results with a success rate of $80 \%$ over five consecutive casts

The original time line is shown in Table $I$. 
Table I

\section{PROCESS DEVELOPHENT OF THIN STRIP STEEL CASTIM}

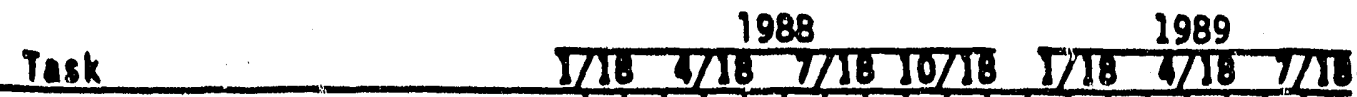

1. Invest fgate Fundamental Casting Parameters 1.1 Water Modeling of Planar Ffow Nozzle 1.2 Anclytical Investigation of Planar flow and Overflow feeding Systems

2. Establish the Effects of Casting theel Substrate

3. Design and Perform Preliminary Casting Experiments for Screening Purposes

3.1 Melt Overfiow Casting Experiments

3.2 Planar flow Casting Experiments

4. Go/No Go Decision and Selection of Candidate Process for Final Evaluation

4.1 Establish Criteria for Making Go/No Go Decision and for Candidate Process Approval

4.2 Go/No Go Decision

4.3 Selection of Candidate Process

5. Optimization of Candidate Process and Evaluation of Electromagnetic Casting Devices
5.1 Development of Experimental Plan
5.2 Investigation of Electromagnetic Enhancement of Nozzle Erit Flow

5.3 Conduct Casting Experiments

6. Processing Characterization of Cast Material 6.1 Development of Experimental Plan

6.2 Characterization of As-Cast Material

6.3 Characterization of Processed Material

7. Techno-Economic Analys is of Candidate Process

8. Specification of Scaled-Up Technology

8.1 Specification of Scaled-Up Equipment and Facility Size

8.2 Conceptual Design of Scaled-Up Equipment

8.3 F.stablish Program Costs to Evaluate Scaled-Up Process

9. Project Management

9.1 Management Plan

9.2 Program Management

9.3 Reporting

9.4 Review Meetings

9.5 Technology Transfer

9.6 Critical Review of Single-Whee?

Casting Technologies

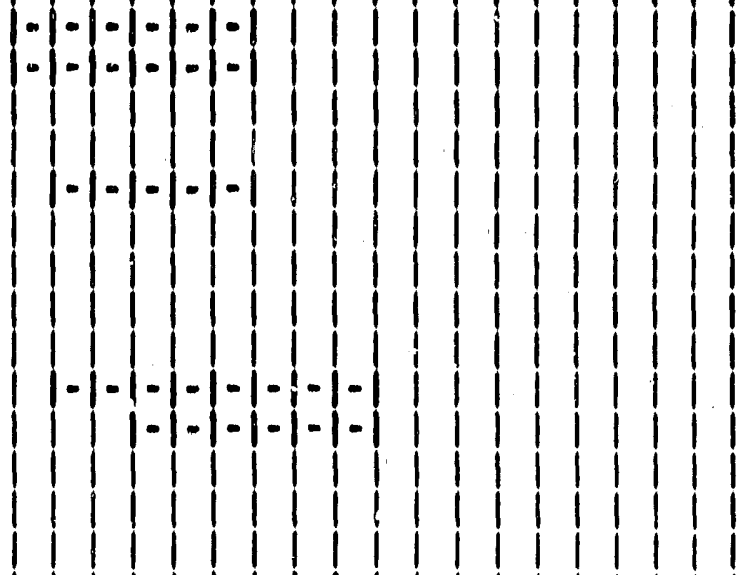

$1191,1-1,191911$

111111101111111111

111919191911

19919919191919

111111111111111111

$11111111-1-1 \mid 1111111$

$1111111-1-1-1-1-1-1-1-11$

$1111111,1-1-1-1-1-1-1-1-1$

1111111111111111111

1111111111111111

$11111-1-1-1-1-1-1-1\} 111$

$111111111-1-1-1-1-1-1-1-1$

111111111111111

$111111111111-1-1-1111$

1111111111111111111

111111111111111111

$1111111111-11111111$

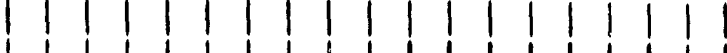

$1119111,1-1-1-1-1 \mid 1$

1111111.111111111111

1111111111111111111

111111111111111111

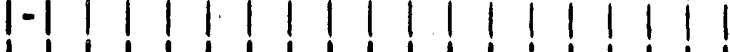

$1-1-1-1-1-1-1-1-1-1-1-1-1-1-1-1-1-1-1$

$1-1-1-1-1-1-1-1 \cdot 1-1-1-1-1-1-1-1-1-1-1$

$1-1-1-1-1-1-1-1-1-1-1-1-1-1-1-1-1-1-1$

$1111111111111111-1-1-1$

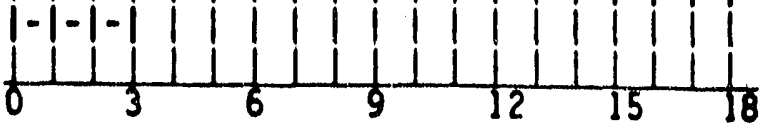




\subsection{STATEMENT OF WORK}

\section{Detailed Description of Tasks}

\section{Task 1 - Investigate Fundamental Casting Parameters}

Task 1.1 Water Modeling of Planar Flow Nozzle: Develop an experimental plan and subsequently design, bulld, and run trials with a water model that can evaluate the flow of fluid onto the wheel during planar flow casting as a function of casting parameters, nozzle design, and pouring box design.

Task 1.2 Analytical Investigation of Planar Flow and overflow Feeding systems: Utilize appropriate computer model to assist in optimum nozzle parameter definition in planar flow casting and heat transfer for both the planar flow and overflow feeding systems. The results obtained in the DOE Thin-section Casting program shall be obtained and utilized, if appropriate, in order to reduce the effort required for this task.

\section{Task 2 - Establish the Effects of Casting wheel substrate}

Task 2.1 Develop an experimental plan and subsequently investigate the effects of substrate material, roughness, and surface preparation on a small casting wheel. 
Task 3 - Design and Perform Preliminary Casting Experiments for

\section{screening purposes}

Task 3.1 Melt overflow Casting Experiments: Develop an experimental plan and subsequently conduct experiments to evaluate the melt overflow casting process on a small. casting wheel. In this regard, the results from Tasks 1.2 and 2.1 shall be utilized if appropriate. The proress parameters that control strip thickness and quality shall be investigated semi-quantitatively. If low carbon steel can be cast successfully, casts shall be conducted on the large casting wheel to more fully characterize the process.

Task 3.2 Planar Flow Casting Experiments: Develop an experimental plan and subsequently conduct experiments to evaluate the planar flow casting process on the large casting wheel. As appropriate, the results from Tasks $1.1,1.2$, and 2.1 shall be utilized. The process parameters that control. strip thickness and quality shall be investigated semi-quantitatively.

Task 4 - "Go/No-Go" Decision and selection of Candidate process for Final Evaluation

Task 4.1 Establish criteria for making "Go/No-Go" decision and for candidate process approval: Develop criteria for the continuation decision and for selecting the candidate process that reflect the technical, economic, and 
intellectual property (Task 9.6) aspects of the process. Obtain DOE approval for these criteria.

Task 4.2 "Go/NO-Go" Decision: on the basis of the results from Tasks 1, 2, and 3, the criterla developed in Task 4.1, and in conjunction with DOE, make decision to proceed or discontinue testing.

Task 4.3 Selection of Candidate Process: on the basis of a "GO" decision in Task 4.2, choose the candidate process with DOE concurrence and continue the program.

\section{Task 5 - Optimization of Candidate process}

Task 5.1 Development of an experimental Plan: Develop an experimental plan with principal objectives being to establish the effects of major process variables on strip thickness and quality in an efficient manner. Obtain DOE approval for this plan.

Task 5.2 I. vestigation of Electromagnetic Enhancement of Nozzle Exit Flow: Employ the existing electromagnetic equipment with a new coil design to shape the metal flow at the exit of the nozzle of the candidate process in an attempt to improve surface quality, heat transfer, and flow control. The design and construction of the device shall be effected by Westinghouse. The nature of these experiments shall be incorporated in the experimental design developed under Task 5.1. 
Task 5.3 Conduct Casting Experiments: Conduct casting experiments based on the experimental design developed in Task 5.1.

\section{Task 6 - Processing and Characterization of Cast Material}

Task 6.1 Development of an Experimental Plan: Develop an experimental plan for characterizing as-cast and processed steels macroscopically and microscopically, including microstructural analysis and standard mechanical properties. Obtain DOE approval for this plan.

Task 6.2 Characterization of As-Cast Material: Characterize as-cast material in accordance with the plan developed in Task 6.1. Ascertain whether the material has potential for commercial applications.

Task 6.3 Characterization of Processed Material. Characterize material that is subjected to thermal-mechanical processing in accordance with the plan developed in Task 6.1. Ascertain whether the material has potential for commercial applications.

\section{Task 7 - Techno-Economic Analysis of Candidate Process}

Task 7.1 Conduct a techno-econornic analysis of the candidate process that includes, but is not limited to, the following estimated items: product quality, process economics (product yield, maintenance, consumables, 
capital, labor, casting rate, and energy costs;, scalability, and existing and competitive technologies.

\section{Task 8 - Specification of scaled-Up Technology}

Task 8.1 Specification of scaled-up equipment and facility size: If the analysis conducted under Task 7.1 is encouraging, ascertain the desired size of the scaled-up technology and review these conclusions with the DOE.

Task 8.2 Specification of Scaled-Up Equipment: Develop a conceptual design for scaled-up equipment.

Task 8.3 Establish program and costs to evaluate scaled-up process: Develop a plan and associated costs to evaluate the scaled-up process that can serve as a basis for the future development of the technology.

\section{Task 9 - Project Management}

Task 9.1 Management Plan: A Management Plan that includes the following shall be submitted to the DOE Project Manager for approval within 30 days afier the contract is awarded: the project organization showing key individuals, the project management philosophy, the negntiated Statement of Work; a Task Schedule; a Milestone Schedule and log; Quality control and Environmental protection criteria; a cost plan; and an initial Federal Assistance Management summary Report. The Managemerit Plan shall be updated as requested by the 
DOE if significant changes occur in program content, schedule, or costs.

Task 9.2 Program Management: Perform necessary project management functions to keep projects budget and schedule as specified in Management Plan. Maintain communication with all project participants.

Task 9.3 Reporting: prepare and submit reports in accordance with the Reporting Requirements and Distribution Checklists. specifically, project status, cost and schedule shall be reported quartorly to the DOE through the project status Report and the Federal Assistance Management summary Report. A final report that covers all asperts of the project shall be prepared and issued. Technical and project progress shall be reported verbally at frequent intervals for review by the DOE. Also, DOE and/or its designated representatives shall be advised of significant events as they occur.

Task 9.4 Review Meetings: A schedule for review meetings with the DOE shall be developed on the basis of the timing for the research tasks. Attendees shall receive an agenda of the meeting at least five days in advance of the meeting. A meeting shall be scheduled in conjunction with the "Go/no-go" decision and candidate process selection of Task 4. Additional meetings may be requested by either 
Armco or the DOE as required during the course of the project.

Task. 9.5 Technology Transfer: Develop a plan to transfer the technology to the appropriate persons and institutions at the appropriate times relative to the stutus of development. Submit the plan to DOE for information prior to implementation but not prior to the "go/no-go" decision to be made in Task 4.2 .

Task 9.6 Critical Review of Single-Wheel Casting Technologies: A critical review of patents (domestic and foreign) already issued and the open literature on existing single-wheel casting technologies shall be conducted in order to ensure that existing technologies are appropriately applied to the project. Results of this review shall also be used to develop the intellectual property criteria referred to in Task 4.1. A report regarding this review shall be submitted to the DOE within three months after the cooperative agreement is awarded. 


\subsection{TASK REPORTS}

\subsection{Task 1.1. Water Modeling of Planar Flow Casting Nozzle}

\section{Introduction}

Planar flow casting (PFC) is a method presently being studied for application in the production of low carbon steel strip. Aim strip thicknesses of $.030-.125$ inches at casting rates of 2-15 $\mathrm{ft} / \mathrm{sec}$ are desired. To provide a thorough yet inexpensive means of studying the numerous variables associated with PFC, a full scale water model of the planar flow caster was constructed. A series of experiments were then run, providing a very satisfactory visual representation of the fluid dynamics of PFC casting.

\section{Discussion}

\section{Experimental setup:}

Three dimensionless numbers were deemed to portray the fluid flow characteristics for planar flow casting:

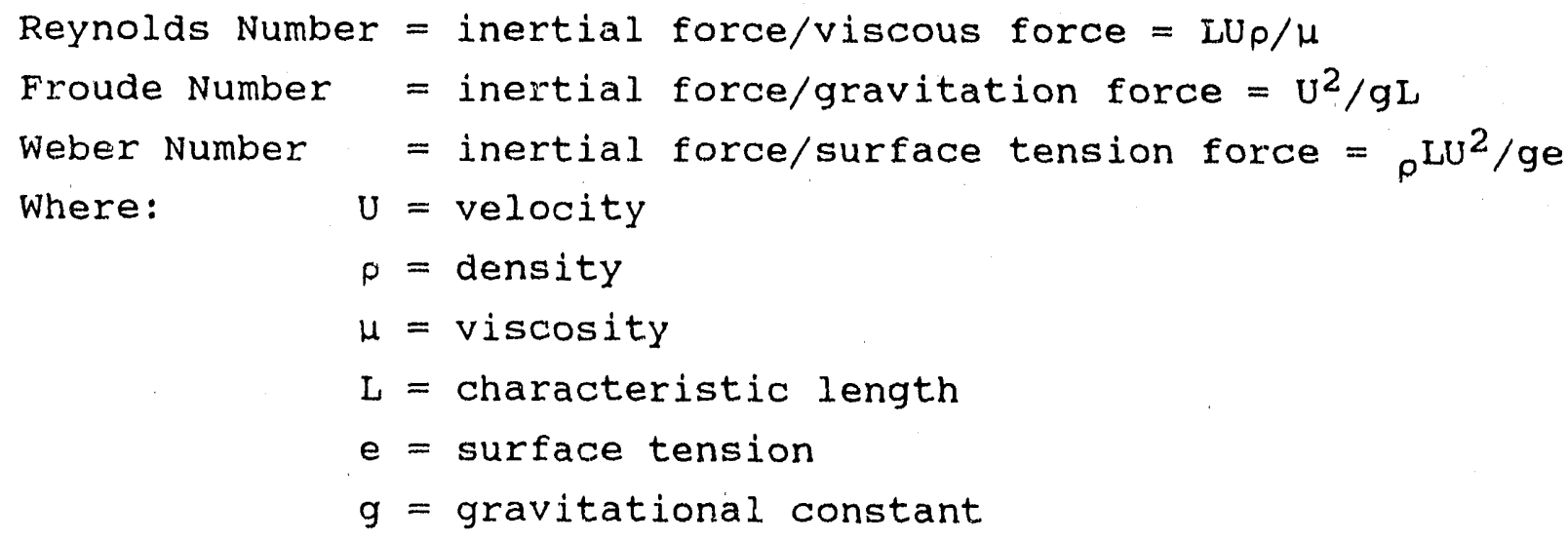


For any arrangement of the water model, only two out of the three dimensionless numbers could be made similar between steel and water systems.

The experiments were designed for Reynolds No. - Froude No. similarity between the water model and liquid steel systems, achieved by having a l:1 dimensional similarity and using $80^{\circ} \mathrm{F}$ water. Later trials were run under Reynolds No. - Weber No. and Froude No. - Weber No. similarity conditions to check for agreement with the Reynolds No. - Froude No. trials.

The entire PFC system was duplicated using plexiglas, including ladle, pouring box, and nozzle. As in the actual steel caster, the water model nozzle width was 3 inches. A simulated wheel was constructed using a continuous belt moving over an arc constructed from stainless steel and Plexiglas. An elevation of the model is shown in Figure 3. A variable speed motor was used to drive the belt from $2-20 \mathrm{ft} / \mathrm{sec}$.

Initial experiments focused on the nozzle and how the liquid distributes itself onto the moving belt. Referring to Figure 4 , the following variables were identified. They are divided into two groups. Those which are time consuming to change and those which are easily changed:

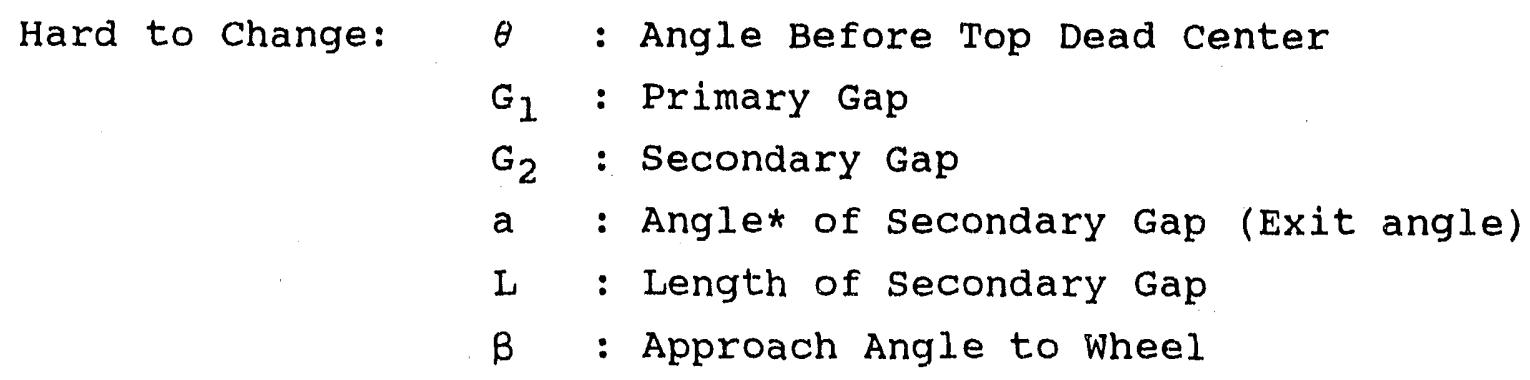




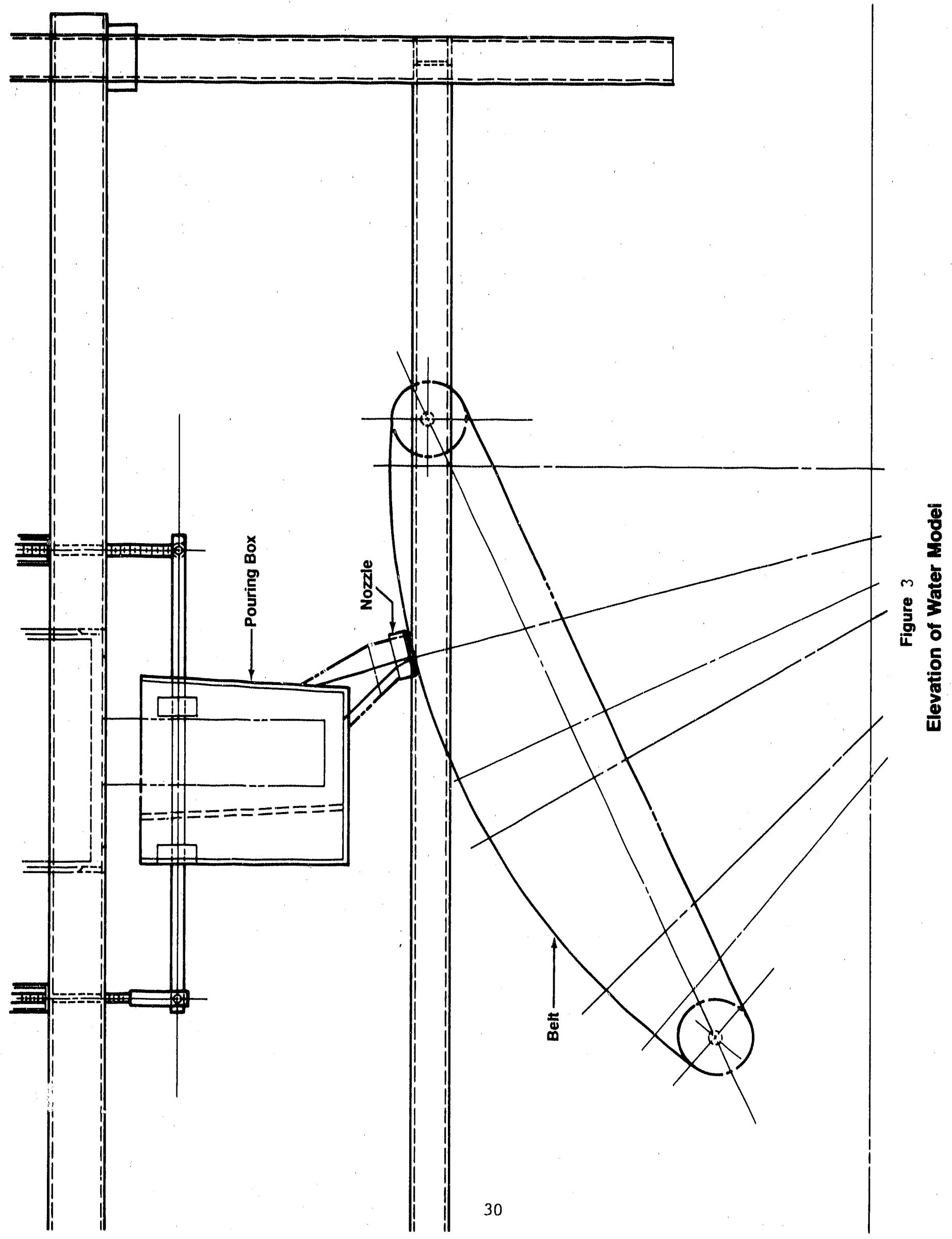




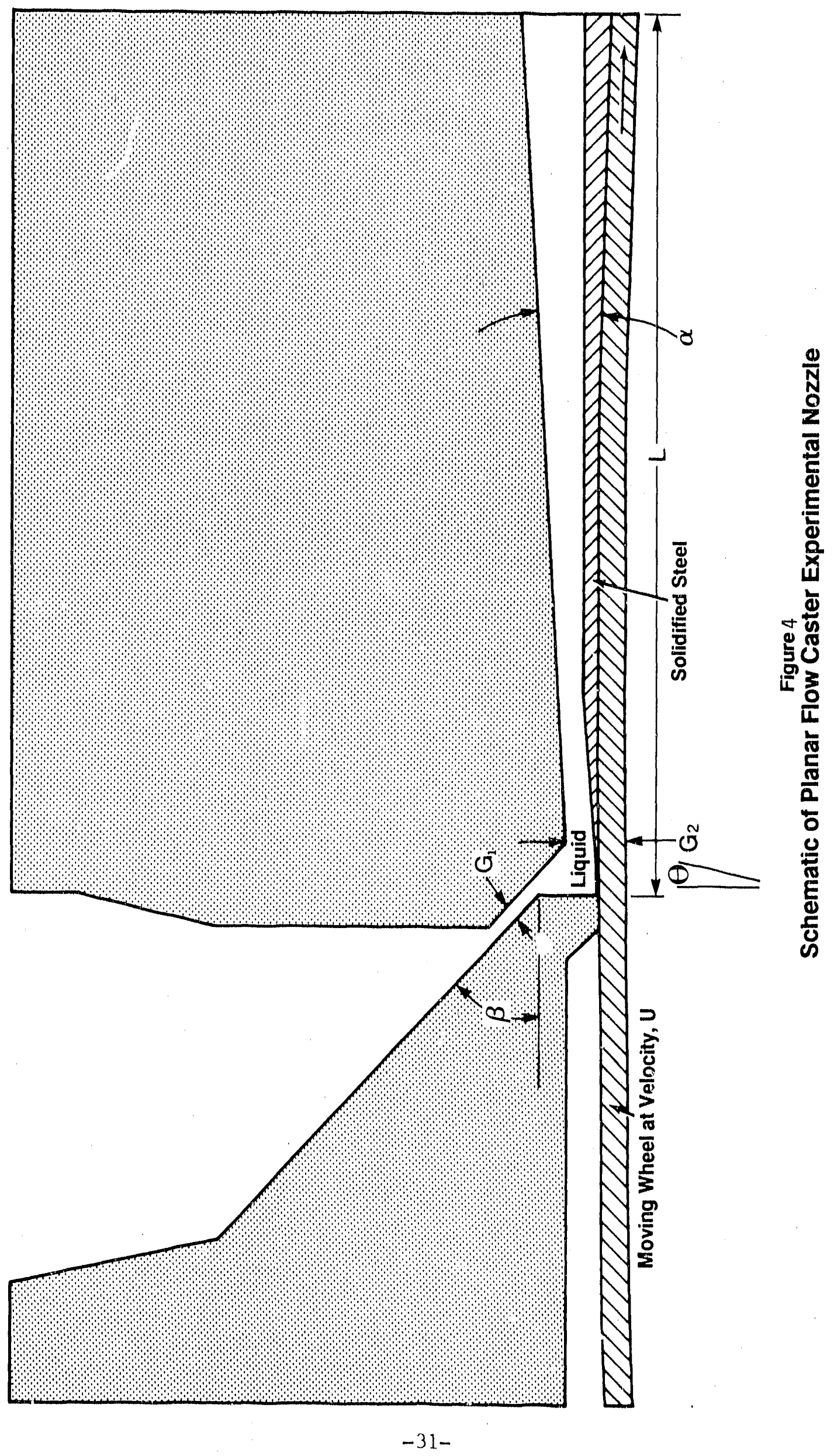


Easy to Change: $H \quad$ : Head pressure

$\mathrm{v}_{\mathbf{s}}$ : substrate velocity.

* (t) : diverging exit angle, (-) : converging exit angle.

Due to the large number of variables, it was impossible to look at all combinations of geometries. A statistically designed matrix of experiments was therefore developed to minimize the total number of trials needed to reveal general irends in the parametric relationships. Allowing i to remain constant at $1 "$, acceptable upper and lower limits were selected for the hard-to-change variables giving five variables with two data points to be studied. Table II represents a one-half replicate of a $2 / 5$ fractional. experiment. $G_{1}, H$, and $V_{S}$ were varied with each one of the runs to determine the optimum conditions for the hard-to-change variables.

\section{Table II \\ schedule of Runs fol water Model}

\begin{tabular}{|c|c|c|c|c|}
\hline Run & $\theta^{\circ}$ & $B^{\circ}$ & $\mathrm{G}_{2}$ (in) & $\alpha^{\circ}$ \\
\hline 1 & 15 & 90 & 0.05 & +5 \\
\hline 2 & 15 & 90 & 0.05 & -5 \\
\hline 3 & 15 & 60 & 0.15 & +5 \\
\hline 4 & 15 & 60 & 0.05 & +5 \\
\hline 5 & 15 & 60 & 0.15 & -5 \\
\hline 6 & 15 & 60 & 0.05 & -5 \\
\hline 7 & 15 & 90 & 0.15 & -5 \\
\hline 8 & 15 & 90 & 0.15 & +5 \\
\hline 9 & 45 & 60 & 0.05 & +5 \\
\hline 10 & 45 & 60 & 0.05 & -5 \\
\hline 11 & 45 & 90 & 0.05 & -5 \\
\hline 12 & 45 & 60 & 0.15 & -5 \\
\hline 1.3 & 45 & 90 & 0.15 & +5 \\
\hline 14 & 45 & 60 & 0.15 & +5 \\
\hline 15 & 45 & 90 & 0.05 & +5 \\
\hline 16 & 45 & 90 & 0.15 & -5 \\
\hline
\end{tabular}

For each of the sixteen runs, $G_{1}$ was set at two values:

A. $G_{1}=2 \times G_{2} ;\left(G_{1} / G_{2}=.20 * / .15, .10 / .05\right)$ *due to size limitations.

B. $\mathrm{G}_{1}=1 / 2 \times \mathrm{G}_{2} ;\left(\mathrm{G}_{1} / \mathrm{G}_{2}=.075 / .15, .025 / .05\right)$ 
Based on the results from these initial sixteen runs, the nozzle configuration observed to provide the most satisfactory flow pattern was 10A. This nozzle configuration was modified over a second series of runs to optimize the nozzle flow characteristics, Table III. Runs 17, 18, and 19 were designed to further investigate the relationship between $G_{1}$ and $G_{2}$ with $G_{1} / G_{2}$ ratios of $1.0,1.5$, and 2.0 respectively. The additional nozzle parameter listed in Table III was for the secondary gap extension, EXT, introduced during these runs. The secondary gap extension was formed by extending $G_{2}$ past the front of the nozzle a distance equal to $\mathrm{G}_{2} \times \cos \beta$. This extension apparently helped to smooth out the stream exiting the nozzle.

The remaining four runs listed in Table III were variations of run 18 , in which $G_{1} / G_{2}$ ratio of 1.5 exhibited the better flow pattern. Since it was apparent from runs 17 through 19 that the nozzle extension proved beneficial to achieving a stabler stream, the extension was increased to .115" for runs 20 through 23 . In addition, the increased extension spanned the entire width of the nozzle past the edges of $\mathrm{G}_{1}$.

Run 21 used $140^{\circ} \mathrm{F}$ water to model the steel flow through the nozzle based on the Weber and Reynolds numbers, the previous twenty test having been modeled based on the Reynolds and Froude numbers.

In run 22, the nozzle was modified by tapering out the sides of $G_{2}$ in order to retain the same cross sectional area through $G_{2}$ as it converged towards the exit. As with the first twenty runs, 
run 22 was performed under Reynolds No. - Froude No. onnditions with the water temperature maintained at $80^{\circ} \mathrm{F}$.

For run $23, G_{1}$ and $G_{2}$ were both reduced by $44 \%$, maintaining the same $G_{1} / G_{2}$ ratio of $3 / 2$ used in Run 18 . This was done in order to model the steel flow based on the Weber and Froude numbers.

Table III

Schedule of Additional Runs for Water Model

\begin{tabular}{lllllll} 
Run & $\theta^{\circ}$ & $B^{\circ}$ & $\begin{array}{c}\mathbf{G}_{2} \\
(\mathbf{i n})\end{array}$ & $\mathbf{a}^{\circ}$ & $\begin{array}{c}\mathbf{G}_{1} \\
(\mathbf{i n})\end{array}$ & $\begin{array}{c}\mathrm{EXT} \\
(\mathbf{I})\end{array}$ \\
\hline 17 & 45 & 60 & 0.05 & -5 & 0.05 & 0.025 \\
18 & 45 & 60 & 0.05 & -5 & 0.075 & $0.0375^{\circ}$ \\
19 & 45 & 60 & 0.05 & -5 & 0.10 & 0.050 \\
20 & 45 & 60 & 0.05 & -5 & 0.075 & 0.115 \\
21 & 45 & 60 & 0.05 & -5 & 0.075 & 0.115 \\
223 & 45 & 60 & 0.05 & -5 & 0.075 & 0.115 \\
234 & 45 & 60 & 0.028 & -5 & 0.042 & 0.115
\end{tabular}

1. Increased Extension Test

2. Weber Reynolds Number Test

3. Diverging Gap Walls Test

4. Froude Weber Number Test

\section{Observation:}

Observations were made of the flow characteristics using visual inspection and video tape over a range of belt speeds from 0 FPS to 20 FPS for each nozzle configuration at heads of $5.5 "$ and $11.5 "$. For test 9 through 23 observations were also made with a 3.5 " head. Figure 5 is an illustration of the various flow characteristics observed during the twenty-three tests. Predominate characteristics were spreading of the stream upon exiting the nozzle, formation of standing wave patterns, particularly the 


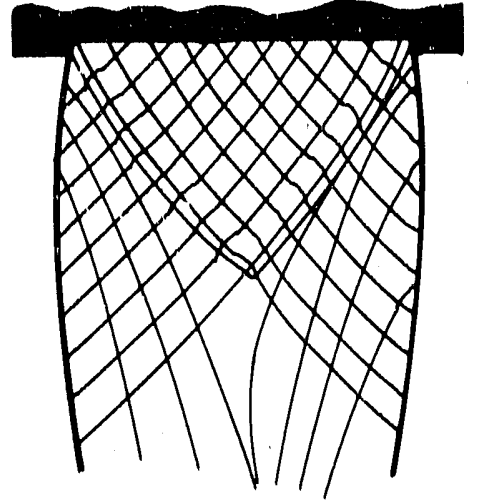

A) Raised V-Shaped Plateau with Quilted Interiors and Sloping Edges

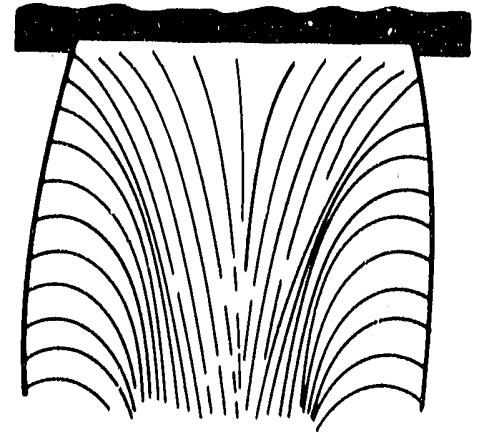

C) Rolling Crests Along Stream Edges

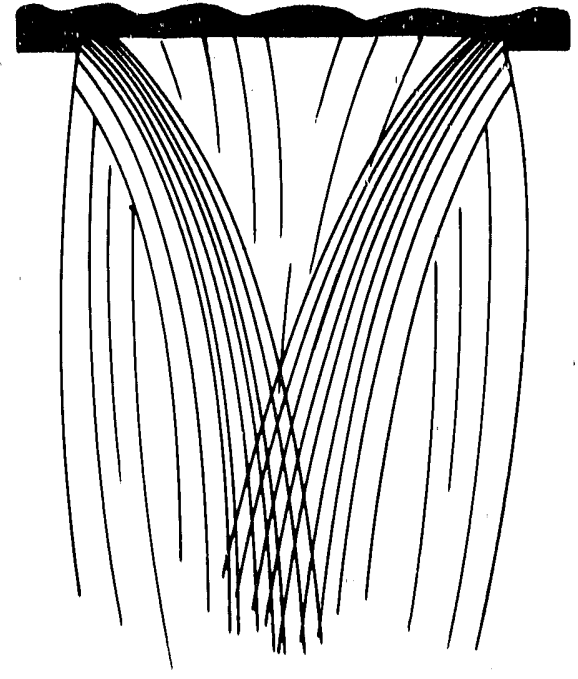

B) Roping of Stream Center

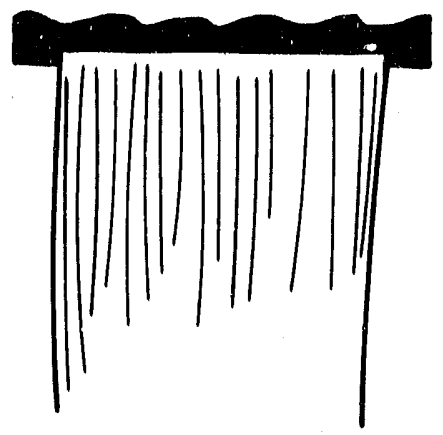

D) Straight, Flat Streamline Flow

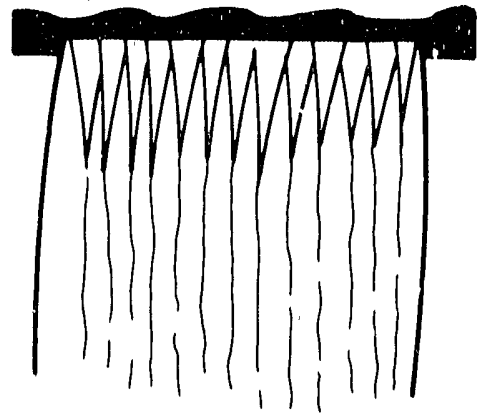

F) Multiple Small "V"

Figure 5

Water Model Fluid Flow Patterns 
formation of "V" shaped waves and a crisscrossing quilted wave pattern, rolling of the stream edges, and the formation of a raised stream center. Not all of these characteristios were observed during every test. Also noted was the flow race through the nozzle at a belt speed of 10 FPS, $Q_{10}$ FPS. Each test was started with a belt speed of 10 FPS. Table IV lists the measured flow rates noted at 10 FPS during the tests.

Distinct variations in the stream characteristics were observed over the series of tests. A written description of each of the 23 runs can be found in Appendix I. These are lllustrated in Figures $5(a-f)$. Generally, the stream pattorn consisted of two standing waves forming at the nozzle's edges and crossing along the stream's centerline. This produced the $\mathrm{V}$ pattern depicted in Figure $5 \mathrm{a}$. As the $V$ was formed the edges tended to spread causing a slope to be formed from the wave front outward. The interior of the $i$ appeared as a raised plateau laced with multiple smaller V's. The interlacing of these smaller V's created a quilted pattern over the surface of the plateau. The edge of the stream appeared concave as it exited the nozzle with the profile sloping up to form the plateau. As the stream moved away from the nozzle, the edge became convexed and expanded inwards as the volume of water shifted from the raised plateau to the edges. How the water flowed through the nozzle greatly affected the character of this general pattern. Increased flow towards the center produced severe roping of the stream at the center, Figure 5b. Water flowed in from the edges as the center pulled up in a high turbulent crest. Increased flow 
TABLE IV

Nozzle Flow Rates at Belt speeds equal to $10 \mathrm{eps}^{+}$

\begin{tabular}{|c|c|c|c|c|c|c|}
\hline \multirow[t]{2}{*}{ Run } & \multicolumn{6}{|c|}{ Head Level (In) } \\
\hline & 3.5 & 5.5 & 10.0 & 11.5 & 2.5 & 4.5 \\
\hline $1 \mathrm{~A}$ & & 3.5 & & 5.0 & & \\
\hline IB & & 1.2 & & 2.2 & & \\
\hline $2 \mathrm{~A}$ & & 2.5 & & 3.3 & & \\
\hline $2 B$ & & 1.1 & & 3.3 & & \\
\hline $3 A$ & & 5.4 & & 7.5 & & \\
\hline $3 B$ & & 3.1 & & 4.6 & & \\
\hline $4 \mathrm{~A}$ & & 4.1 & & 7.0 & & \\
\hline $4 B$ & & 0.9 & & & & \\
\hline $5 A$ & & 6.5 & & $9.3 *$ & & \\
\hline $5 B$ & & 3.5 & & 4.5 & & \\
\hline $6 A$ & & 2.5 & & 4.2 & & \\
\hline $6 \mathrm{~B}$ & & 1.3 & & 2.6 & & \\
\hline $7 \mathrm{~A}$ & & 6.7 & & $9.3 *$ & & \\
\hline $7 \mathrm{~B}$ & & 3.4 & & 5.0 & & \\
\hline $8 \mathrm{~A}$ & & 5.1 & & $9.5 *$ & & \\
\hline $8 B$ & & 3.4 & & 4.6 & & \\
\hline $9 A$ & 4.5 & 4.5 & 6.5 & & & \\
\hline $9 \mathrm{~B}$ & 1.5 & 1.5 & 1.3 & & & \\
\hline $10 A$ & 2.5 & 2.5 & & & & \\
\hline $10 B$ & 1.0 & & 2.0 & & & \\
\hline $11 A$ & 2.0 & & 3.5 & & & \\
\hline $11 B$ & 1.2 & 1.5 & 1.7 & & & \\
\hline $12 \mathrm{~A}$ & 4.2 & 5.4 & 7.6 & & & \\
\hline $12 \mathrm{~B}$ & 3.3 & 3.5 & 4.9 & & & \\
\hline $13 \mathrm{~A}$ & & 6.1 & & & & \\
\hline $13 \mathrm{~B}$ & 2.2 & 2.7 & 3.7 & & & \\
\hline $14 \mathrm{~A}$ & & & & & & \\
\hline $14 \mathrm{~B}$ & 2.6 & 4.0 & 4.2 & & & \\
\hline $15 \mathrm{~A}$ & 1.7 & & 2.3 & & & \\
\hline $15 \mathrm{~B}$ & 0.8 & 1.2 & 1.6 & & & \\
\hline $16 \mathrm{~A}$ & 5.0 & 6.0 & 9.0 & & & \\
\hline $16 \mathrm{~B}$ & & 2.7 & 5.5 & & & \\
\hline 17 & 1.2 & 1.5 & 2.7 & & & \\
\hline 18 & 2.0 & 2.3 & 3.0 & & & \\
\hline 19 & 2.3 & 2.5 & & & & \\
\hline 20 & 2.1 & 2.5 & 3.4 & & & \\
\hline 21 & 1.6 & 2.3 & 3.0 & & & \\
\hline 22 & 2.3 & 2.3 & 3.2 & & & \\
\hline 23 & & & & & $<1$ & 1.0 \\
\hline
\end{tabular}

* Unable to sustain desired head level.

+ Flow is gpm, $1 \mathrm{gpm}$ is equivalent to .010 thick strip at $10 \mathrm{fps}$. 
towards the edges, likewise, resulted in the formation of rolling crest along the edges of the stream, Figure 5c. In both instances, flattening of the stream, as it rode up the belt entailed increased spreading of the steam across the belt. In the latter case, the spreading of the edges towards the center created a $V$ pattern similar to the general pattern except the $V$ contained a sunken trough instead of a plateau. Starving of the stream with respect to the quantity of water being removed by the belt produced a very flat stream with very straight steamlines, Figure $5 d$. Other variations of the general flow were multiple rivulets and small $\mathrm{V}$ emerging from the nozzle, Figures $5 e$ and $5 \mathrm{f}$, with and without the formation of a larger $V$ standing wave.

Raising the head of water in the pouring box increased the flow out the nozzle. The increased flow tended to accent the flow pattern present at the lower head. Turbulent flow worsened, standing waves became more defined, and spreading broadened. On the other hand, accelerating the speed of the belt tended to sweep away the flow patterns. As the belt increased in speed, it increased the rate at which it carried away the water being supplied by the nozzle. In doing so the flow pattern became more spread out along the length of the belt. Thus, V's were elongated, turbulent flow flattened, and spreading restricted. For the most part, slowing the speed of the belt returned the stream to the same state it was in prior to acceleration to the higher speed. It was observed that for certain nozzle designs, the flow did not return to its initial state, tests $14 \mathrm{~A}, 14 \mathrm{~B}$, and $16 \mathrm{~B}$. In these tests 
acceleration to a high belt speed broke the surface of the stream away from the roof of $G_{2}$. Upon returning to lower speed, $G_{2}$ would remain unfilled and the overall flow was less than the original flow.

The effect of moving the nozzle from $15^{\circ}$ to $45^{\circ}$ back from top dead center was an increase in the back pressure the stream exerted on the flow exiting the nozzle. This increased pressure was the direct result of gravity pulling the stream back down the belt to the nozzle as the friction of the moving belt pulled the stream away from the nozzle. If the force of the stream exiting the nozzle was not sufficient to propel its mass of water up the belt, keeping unidirectional flow of the stream as it is pulled along by the belt, the gravitational forces acting on the water caused the stream to spread and possibly flow back onto the nozzle. A nozzle which allowed a high flow of water was more susceptible to back flow than a more restricted nozzle. The increased flow created a thicker stream which was more prone to shearing. Raising the head or increasing the speed of the belt reduced the tendency for the stream to back flow by increasing the force behind the stream or increasing the rate which the water was being removed by the belt, respectively.

Comparisons of flow from nozzles incorporating an approach angle, $B$, of $60^{\circ}$ with flows from nozzles with a $90^{\circ}$ indicated very little effect due to the change in approach angle. The flow, however, did appear to be slightly smoother exiting from a nozzle with $B$ of $60^{\circ}$. 
Employing a $G_{1}$ smaller than $G_{2}$ also tended to reduce the tendency for back flow. The tighter primary gap produced a thinner stream, reducing the opportunity for the stream to shear. Thus, not as much force was required to maintain the stream. $A G_{1}$ smaller than $G_{2}$ also decreased the contact of the stream with the roof of the secondary gap. This decreased contact resulted in an increase in stream surface texture. Since $G_{1}$ was smaller than $G_{2}$, the secondary gap was not being fully supplied, leaving a gap between the surface of the stream and the roof of the secondary gap. Fluctuations in the stream adhered to the roof caused small rivulets and V's to form across the width of the stream as $1 t$ exited the nozzle.

Reducing $G_{2}$ also restricted the flow of water out the nozzle and produced a thinner stream. The restricted flow reduced the tendency of the stream to spread. It also reduced the amount of roping observed at the center and edges of the stream. Roping is an effect of surface tension. Center roping was caused by a high flow region towards the center of the nozzle. The large volume of water at this point allowed the stream to roll up in order to reduce its surface tension. Restricting the flow prevented the build up of the volume of water required to allow the stream to form a rope. Edge roping, similar to center roping, occurred as the stream tried to reduce its surface tension. The edges of the stream were built up as the center $V$ wave form created by nozzle edge effects narrowed. If a sufficient volume of water was present 
the edges roped. Again, the restricted flow prevented the ropes from forming even though stream edge effects were still present.

In comparing stream characteristics attributed to either diverging and converging nozzle designs, it was observed that a converging nozzle produced a more unfform flow. A diverging nozzle allowed the stream to roll up either at the center or at the edges. As the gap between nozzle and belt grew wider, the stream would lose contact with the nozzle. Surface tension would then start to pull the stream in on itself. If contact was maintained, the widening gap actually pulled the water up into a rope. A converging nozzle forced the stream to remain flat, maintaining contact with the water until it exited the nozzle. Though other factors, such as a large $G_{2}$, caused the stream to rope, streams on a whole appeared better controlled exiting from a converging nozzle than from a matching diverging nozzle.

As stated above, test IOA's nozzle configuration exhibited the most satisfactory flow characteristics of the initial trials. This configuration was a $5^{\circ}$ converging nozzle with a $60^{\circ}$ approach angle, a 0.100 in. $G_{1}$, a .050 in. $G_{2}$, and positioned $45^{\circ}$ back on the belt from top dead center. Tests 17,18 and 19 used $G_{1}$ 's of .050 in.,.075 in., and $.100 \mathrm{in.,}$ respectively, to access the relationship between $G_{1}$ and $G_{2}$. Since the same Plexiglas nozzle model was used for each of these tests, as $G_{1}$ was increased the roof of $G_{2}$ was extended outward by $G_{1} * \cos \beta$ or $0.5 * G_{1}$ for an $\beta$ of $60^{\circ}$. The outcome of these tests indicated that a slightly larger $G_{1}$ is required to supply $G_{2}$. With a $G_{1}$ equal to $G_{2}$, test 17 , the 
supply of water was somewhat restricted. Though the stream was smooth and streamlined, $G_{2}$ did not appear to be completely filled. Increasing $G_{1}$ lessened this restriction, filling $G_{2}$ and producing the characteristic standing wave pattern. With $G_{1}$ equal to twice $\mathrm{G}_{2}$, test 19 , the increased supply reinforced the standing wave to the extent that the smoothness of the stream was jeopardized. Hence, test 18 gave the most acceptable results.

During tests 17,18 , and 19 , it was noted that the extension of the roof of the nozzle's secondary gap alded in keeping the stream under control. This was further validated by test 20 in which an extension of .115 in. was attached across the width of the nozzle used in test 18 .

Test 21 used $140^{\circ} \mathrm{F}$ water to model the steel flow through test $20^{\prime} \mathrm{s}$ nozzle based on the Weber and Reynolds numbers. The previous twenty tests were modeled based on Reynolds and Froude numbers. The increased water temperature did not drastically effect the stream characteristics, appearing much as it did in test 20. Flow rates at the various heads tested were slightly lower with the hotter water and the stream spreading tended to increase slightly.

Modifications were made to the nozzle in test 22 . By tapering out the sides of $G_{2}$, the same cross sectional area was retained along $\mathrm{G}_{2}$ as it converged toward the exit. This reduced the restriction on the flow imposed by the converging nozzle. Water temperature was maintained at $80^{\circ} \mathrm{F}$. As a result of the outward momentum 
derived from the tapered sides, spreading of the stream was worsened. This concept was therefore rejected.

The last test to be performed was one in which the flow was modeled based on a Weber No. - Froude No. relationship. That is to say, surface tension, gravitational, and inertial forces were included and the viscous forces were neglected. For test $23, \mathrm{G}_{1}$ and $G_{2}$ were both reduced by $44 \%$, maintaining the same ratio as in test 18. The flow of water from the nozzle was greatly restricted, producing a very smooth, straight stream. At very low heads, $0.5 "$, the stream appeared to have a mirror finish. A V shaped standing wave became more apparent as the head was increased.

\section{Comparison of Water Model Runs to Actual Liquid steel Casts:}

Virtually all of the steel casts performed in the experimental strip casting facility at Armco Inc. in Middletown, ohio during the previous program had matching nozzle configurations and conditions tested during the water model trials. The similarity between the steel and water for the same geometry was amazingly close. It is not possible in this report to discuss all of the results, but three examples can be discussed in more detail.

\section{Test I}

Nozzle geometries used in both the water model, run 5B, and steel cast, $\mathrm{D} 86024$, tested converging nozzle with $\mathrm{G}_{1}$ less than $\mathrm{G}_{2}$. In both cases, the flow was shown to be very "ropey", pulling in from the edges and forming very narrow but thick flow, very 
irregular, unstable and completely unacceptable for planar flow casting. The flow pattern consisted of the standing $V$ wave and quilted pattern with rolling of the edges. slowing the speed increased the wandering in the stream 1 ines and broadened the stream.

\section{Test II}

The flow patterns in both the water model run, $4 \mathrm{~B}$ and the steel cast, D86042, were extremely complex. The stream tended to form a rope towards the centers of the casting wheel, $G_{2}$ seemed to f111 then unfill with the fluctuation of the roping action of the stream. Lowering the speed only seemed to aggravate the instability and spreading of the flow.

\section{Test III}

with $G_{1}>G_{2}$, both the water model, run $10 A$, and the steel cast, D87001, showed excellent flow characteristics. There was very little spreading of the streams and the steel flow was very flat. Injecting ink revealed straight stream lines in the water with only a slight $V$ standing wave. The two edges remained very stable and the flow was stable and consistent throughout the runs. 


\section{summary and conclusion}

The full soale plexiglas water model is an excelient tool for qualitatively analyzing the fluld flow in and at the exit of the planar flow nozzle. The appearance of the flow exiting the nozzle in the water system was very much akin to the flow observed using like nozzles in the liquid steel system. The obvious advantages in using the water model to study nozzle designs are the relative safety, ease, and low cost associated in using the $80^{\circ} \mathrm{F}$ water in place of $2900^{\circ} \mathrm{F}$ molten steel.

Employing a Reynolds No. - Froude No. relationship, an experimental matrix consisting of 32 different nozzle geometries was generated to study planar flow casting. Based on this study, a nozzle geometry consisting of a .100 in. primary gap with a $60^{\circ}$ approach angle and a $5^{\circ}$ converging .050 in. secondary gap, positioned $45^{\circ}$ back from the top dead center of the wheel was found to yield the satisfactory flow characteristics. Additional tests showed that the flow characteristics could be improved by reducing the primary gap to $.075 \mathrm{in}$. and extending the roof of the secondary gap $115 \mathrm{in}$. out in front of the nozzle.

Incraasing the water temperature to $140^{\circ} \mathrm{F}$ allowed the Plexiglas water model to be modified to simulate planar flow casting of liquid steel based on a Reynolds No. - Weber No. relationship. The increased water temperature did not drastically effect the stream characteristics, appearing much as it did in Test 20. 
Reducing the primary and secondary gaps by $44 \%$ allowed for testing to be done under a weber No. - Froude No. relationship. The flow of water from the nozzle was greatly restricted, producing a very smooth, straight stream. At very low heads, $0.5 "$, the stream appeared to have a a mirror finish. A V-shaped standing wave became more apparent as the head was increased. 


\subsection{Task 1.2 Three Dimensional Modeling of Melt Flow In the Melt}

overflow Tundish

\section{Introduction}

It is now well known that the fluid flow plays a very critical role in production of a good quality strlp. For the past decade or so, extensive physical and mathematical modeling have been used to understand and improve melt flow in continuous casting tundishes of large sections such as slabs and billets. Hcwever, very little work is avallable in the published literature on the modeling of melt flow in shallow tundishes for production of thin strip.

The purpose of this work has been to develop a threedimensional mathematical model to represent the hydrodynamics of strip casting tundishes. Fluid flow parameters and residence time distribution have been predicted in a shallow tundish without any flow control device and the effect of dams and weirs on the flow characteristics have been studied.

\section{Formulation}

Figure 6 shows the shape and dimensions of the tundish used for modeling of melt flow. It should be noted that the cross section of the tundish reduces significantly in width as well as in depth near the outlet, where the molten metal is delivered to a moving substrate. The effects of flow control devices such as dans and weirs on the melt flow have also been modeled. Figure 7 shows two 

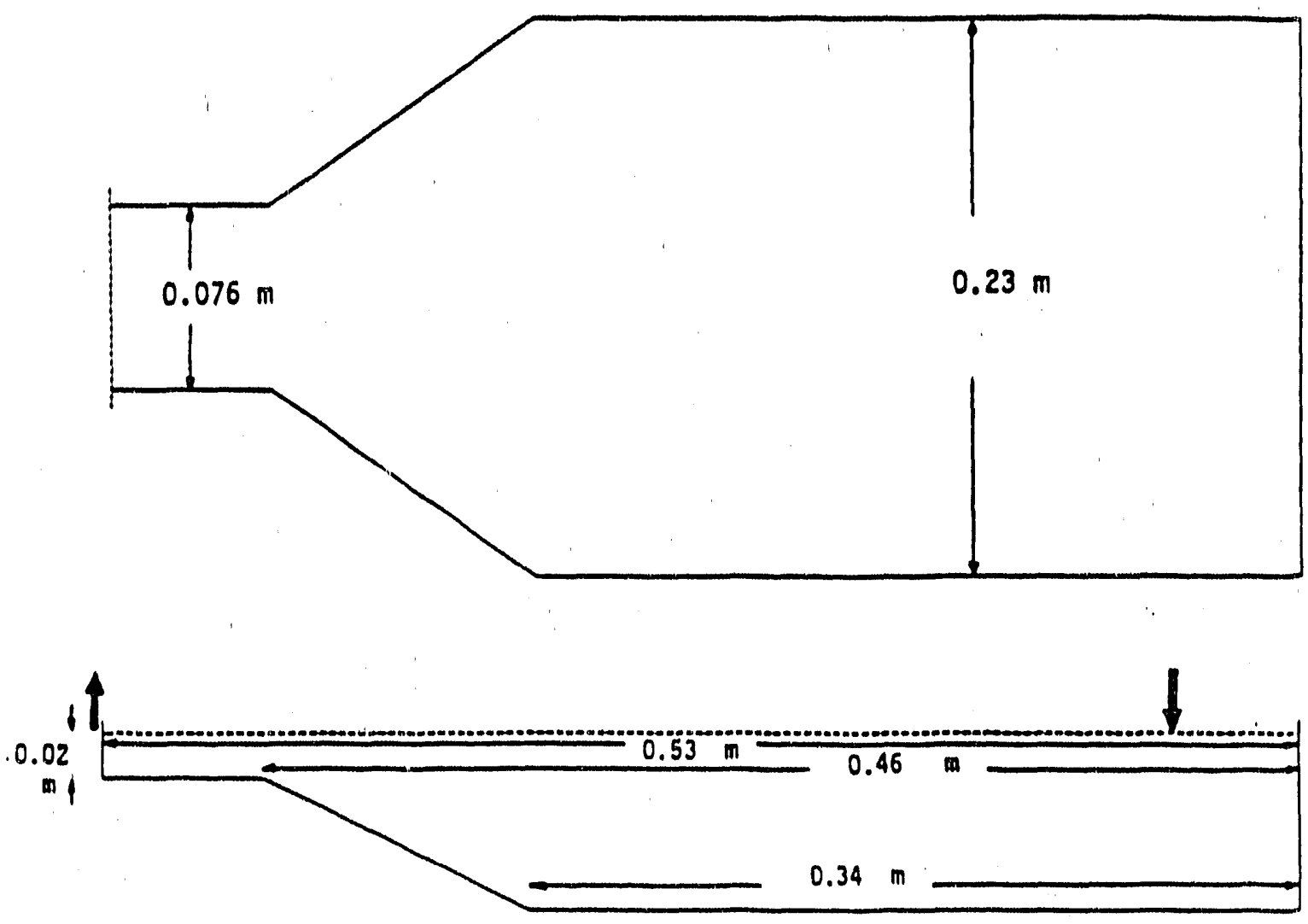

Figure 6 - Shape and dimensions of the tundish
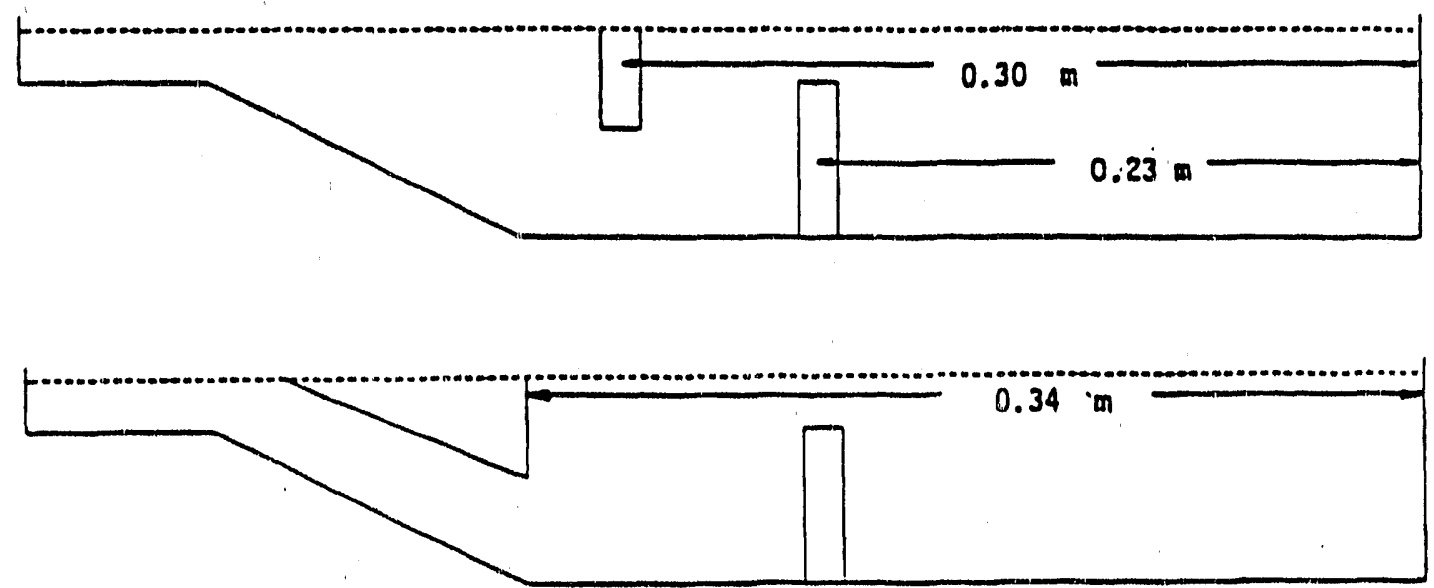

Figure 7 - Two dam and weir configurations. 
configurations of dams and welrs employed in this study. The dams and weirs run the entire width of the tundish. The bottom of the weir in the second configuration has the same inclination as the bottom of the tundish below the weir. The angle of the slope at the tundish bottom is important for obtaining the optimum flow characterlstics. The important parameters used in this study are given in Table $v$.

\section{Table V. Important Parameters used in computation}

Total Length

Total width

Depth near inlet

Depth near outlet

Bottoll inclination near the outlet

Volumetric throughput

Inlet velocity

speed of moving substrate
$0.53 \mathrm{~m}(1.740 \mathrm{ft})$

$0.23 \mathrm{~m}(.755 \mathrm{ft})$

$0.076 \mathrm{~m}(.249 \mathrm{ft})$

$0.02 \mathrm{~m}(.066 \mathrm{ft})$

$5.7 \times 10^{-5} \mathrm{~m}^{3} / \mathrm{s}\left(2.01 \times 10^{-3} \mathrm{ft}^{3} / \mathrm{s}\right)$

$0.14 \mathrm{~m} / \mathrm{s}(1.459 \mathrm{ft} / \mathrm{s})$

$2.50 \mathrm{~m} / \mathrm{s}(8.20 \mathrm{ft} / \mathrm{s})$

\section{Mathematical Model}

The model involves solution of the three dimensional turbulent Navier-stokes equation. Hence, the governing equations representing the model are the equation of continuity, momentum balance equations and the turbulent model equations. The turbulence has been modeled by the so-called $K$ - $E$ two equation model of Launder and spalding (1). The equations and the numerical solution procedure of the model are previously described $(2,3)$ and are not repeated here.

A symmetrical half of the tundish was considered for the computations. The domain was divided into a nonuniform grid of 29 in the length, 10 in the width and 10 in the depth. The inclined 
bottom and walls near the outlet were modeled by partially or completely blocking the finite difference celis outside the flow regions. Details of this treatment are also available in the previous publication. (2)

\section{Boundary Conditions}

Close to solid walls, Including any dam or weir, the varlation in flow properties are much steeper than within the bulk fluid, and levels of turbulence Reynolds number are sufficiently low for molecular viscosity to influence the production, dissipation and diffusion of $K$ and $\epsilon$, and local anisotropy no Ionger prevalis. Consequently, the momentum (three velooity components) and scalar ( $K$ and $E$ ) transport properties are modeled using wall functions (1). Also, no slip boundary conditions were imposed at the solid walls.

At the free surface, which was considered flat, and at the symmetry planes the normal velocity components and the normal gradients of all other variables (momentum and scalar transport properties) were used as zero. At the jet entry, the velocity perpendicular to the free surface was calculated from the volumetric flow rate and the area of nozzle and is given in Table V. This simulates submerged jet with no air entrainment. At the outlet, a vertical velocity of $2.5 \mathrm{~m} / \mathrm{s}(8.2 \mathrm{ft} / \mathrm{s})$ was imposed in the entire width of $7.6 \mathrm{~cm} .(.25 \mathrm{ft})$. 


\section{Tracer Diapersion}

The steady-state velocity and turbulence flelds were used in solving the time dependent mass transport equation to predict the tracer dispersion. Again, the equation is given in the previous publication (2) and is not repeated here. The boundary conditions required for the solution of tracer transport equation have to express the physical constraints that all the bounding surfaces are impervious to the tracer. Mathematically, this corresponds to zero flux at all the bounding surfaces.

\section{Results and Discussion}

The predicted flow fleld in the tundish without any rlow control device is shown in Figures 8,9 and 10 . Figure 8 shows flow at different elevations in the transverse horizontal planes. Figure $8(a)$ is near the free surface while Figure $8(d)$ is flow in a horizontal plane near the bottom. Figure 9 shows flow in longitudinal vertical planes. Figure 9 (a) is near the plane of symmetry in the middle of the tundish. Figures $9(b),(c)$ and (d) are flow in other vertical planes away from the symmetry plane towards the wall. Figure 10 shows flow in transverse vertical planes perpendicular to the length of the tundish at different downstream locations. Figure 10 (a) shows flow near the inlet stream while Figure $10(d)$ represents flow in the region where the tundish cross section is converging and finally flow in Figure 


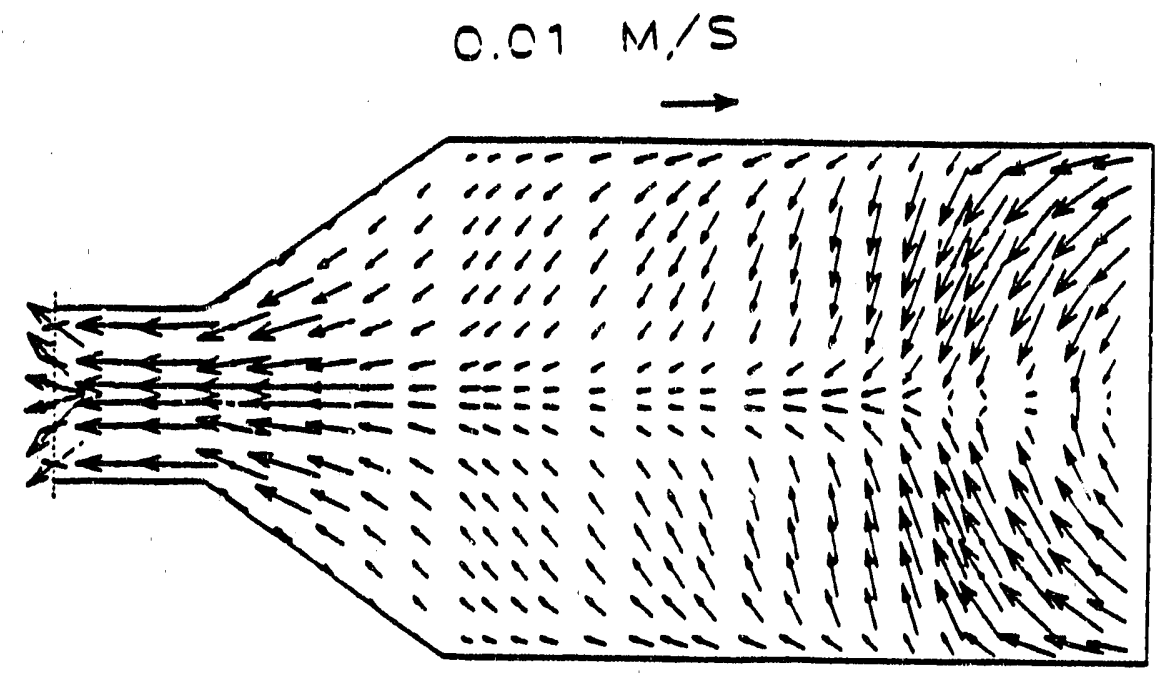

(a)

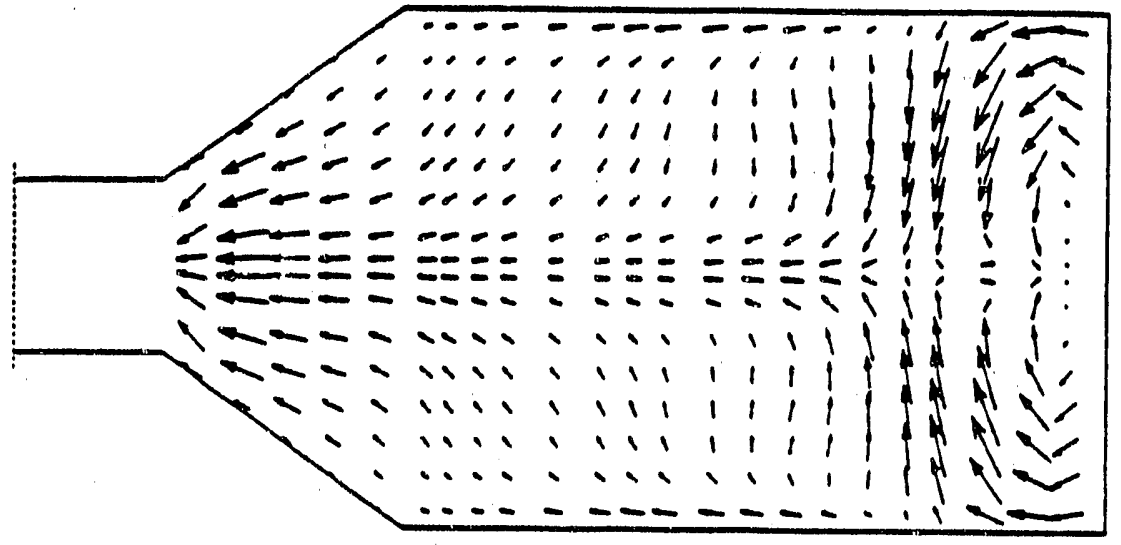

(b)

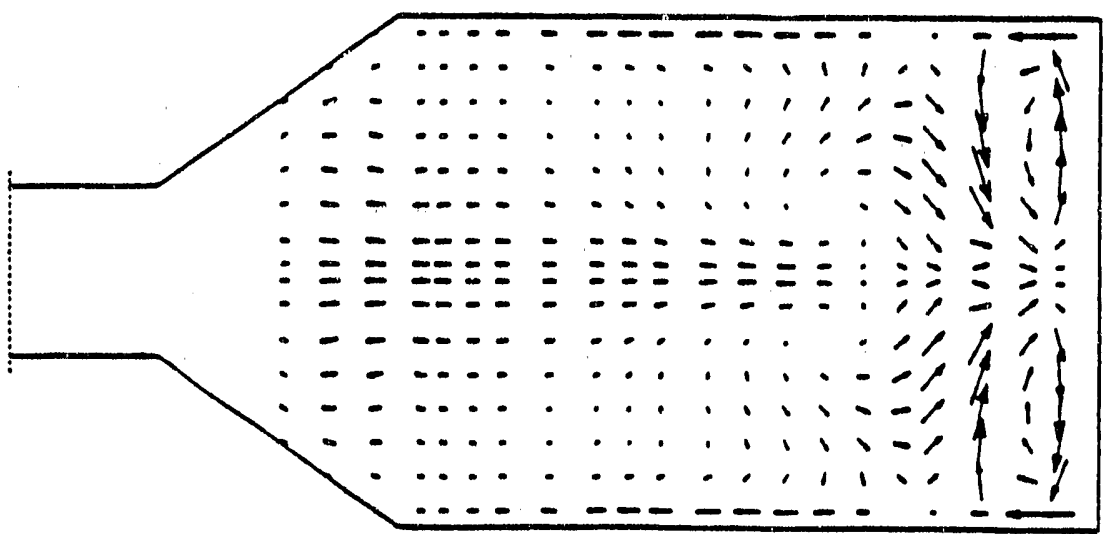

(c)

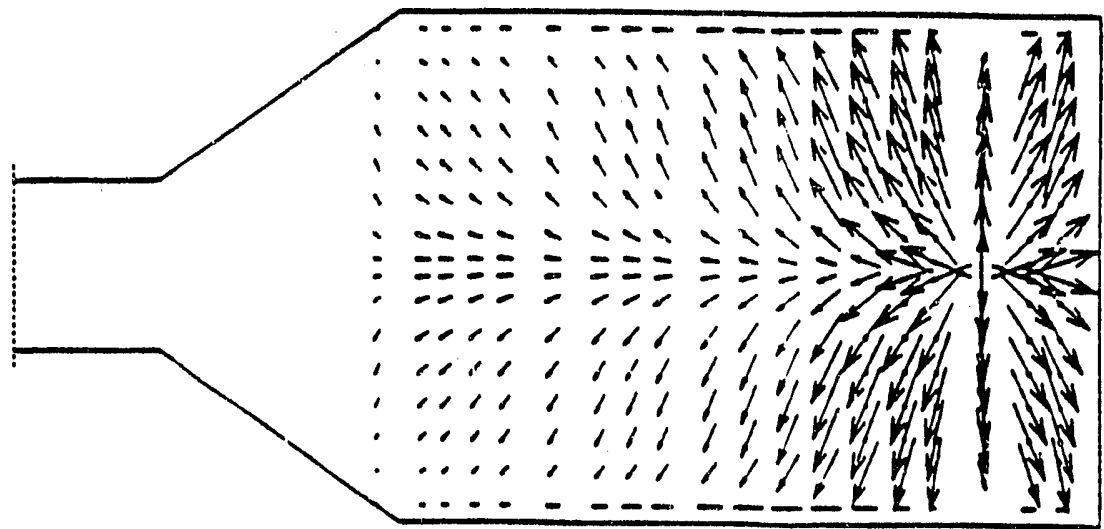

(d)

Figure 8 - Flow in transverse horizontal planes at different elevations with no physical flow control device. 

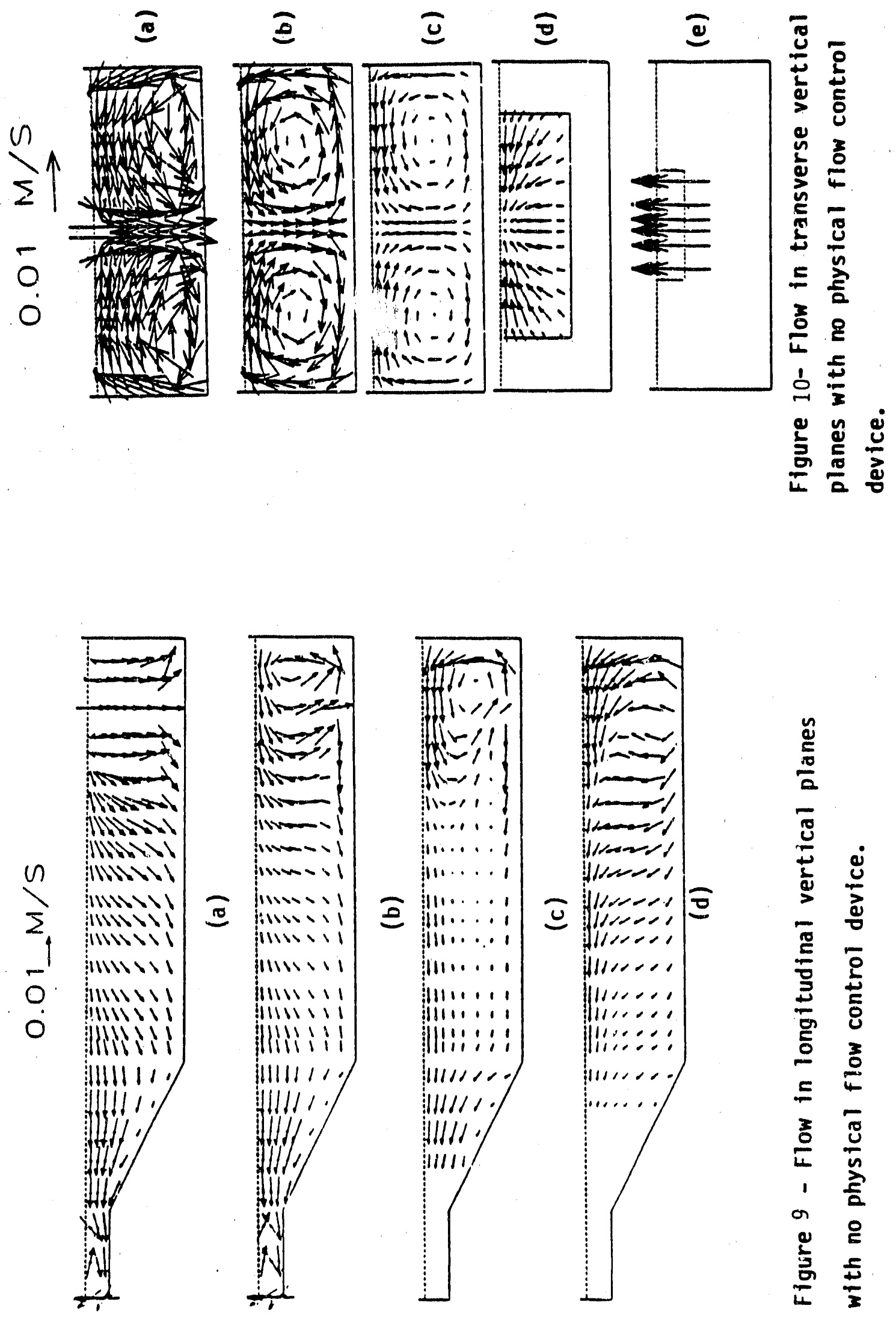
10 (e) is near the outlet and a strong vertical velocity is predicted.

The incoming metal stream goes down to the bottom where it spreads radially, as seen in Figure $8(d)$, and then starts ascending near the walls. Flow in transverse vertical planes near the stream (Figure $10(a)$ ) shows a strong recirculation, a downward flow in the middle of the tundish, and an upward flow near the walls. This recirculating flow is evident even in other downstream planes of uniform cross section. On the other hand, Figure 8 shows a fairly uniform velocity field towards the outlet in all planes. Flow in this uniform cross section could be considered as a spiral moving down-stream on either side of the symmetry plane. F'low in the converging region (see Figures $8(a),(b)$ and $10(d)$ ) is directed towards the symmetry plane and free surface. Finally at the end of the tundish, a small channel of uniform cross section results in a smooth delivery of fluid to the substrate. Since the liquid is being dragged up by the substrate at a very high speed, a recirculation is evident near the end in Figures 9 (a) and (b). In general, this design provides a very uniform flow through the tundish without any significant dead space. The converging region of reducing cross section and the shallow portion of uniform cross section at the end ensure the desired flow characteristics for the production of good quality strip. 


\section{Dam and Weir (Configuration 1)}

The use of a dam and a weir to modify the flow in such tundishes was studied. Figures 11,12 , and 13 show flow in the transverse horizontal, longitudinal vertical and transverse vertical planes, similar to previous figures. The dam and the weir were able to redirect the flow and created a small secondary recirculation on the downstream side as can be see in Figure 12 . They were also successful in breaking the strong spiraling flow as shown in Figure 13(c). Flow in the converging and the outlet regions was comparable with or without the flow control devices.

\section{Dam and Inclined Weir (Configuration 2)}

The melt flow with a dam and an inclined weir parallel to the tundish bottom is shown in Figures 14, 15, and 16. The only significant difference in flow between this and the previous configuration is in the converging region of the tundish. Because the area of cross section has been reduced by the inclined weir, the velocities are larger. These vectors are also directed towards the symmetry plane and the free surface, and they have a relatively larger vertical component.

Figure 17 shows the computed iso-kinetic energy of turbulence plots in the three cases discussed above. Figures $17(\mathrm{a}),(\mathrm{b})$ and (c) represent turbulence in planes shown in Figures 9(a), 12 (a) and 15(a) i.e. in the middle vertical in planes in which the entering inlet stream lies. Relatively higher regions of turbulence can be seen in the region of the incoming stream and close to the outlet. 


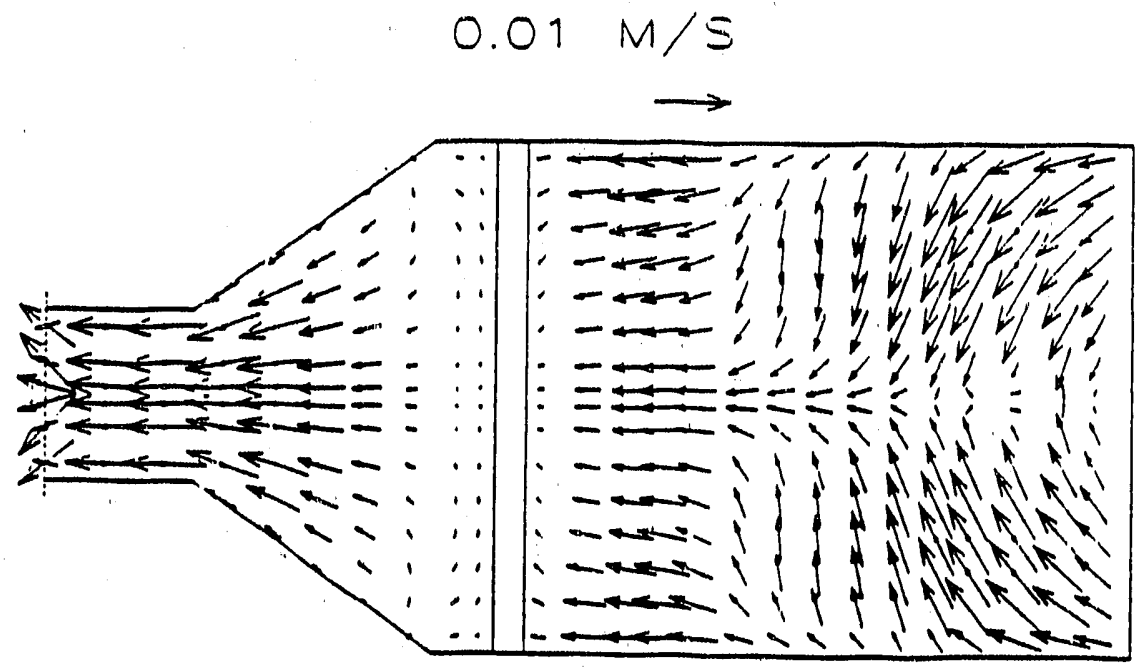

(a)

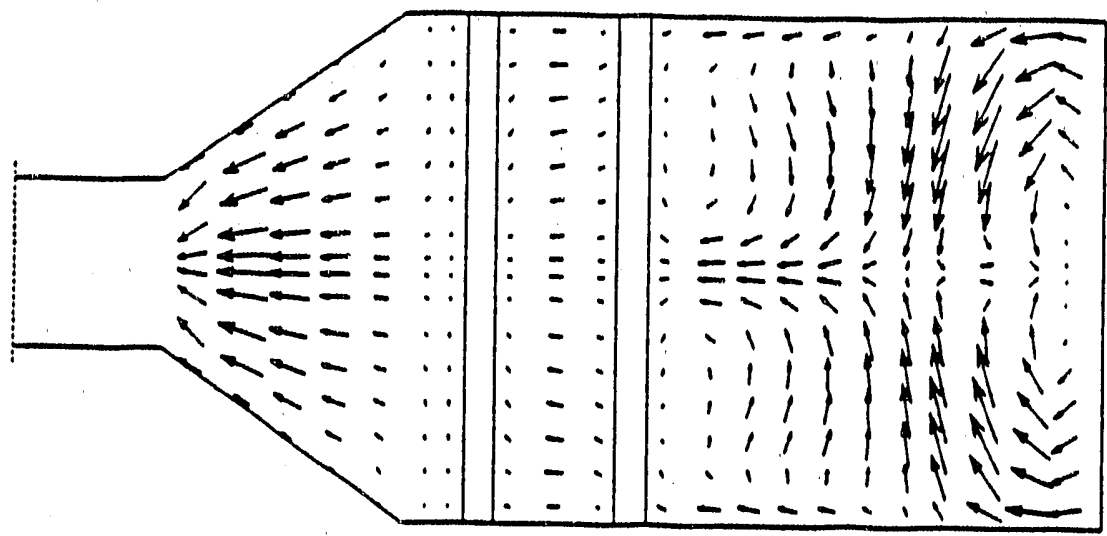

(b)

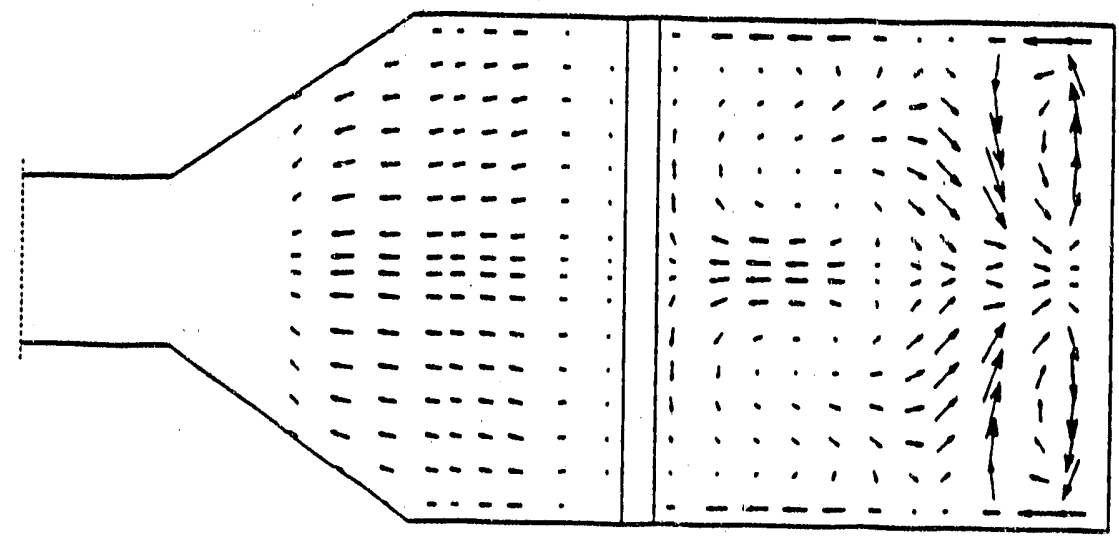

(c)

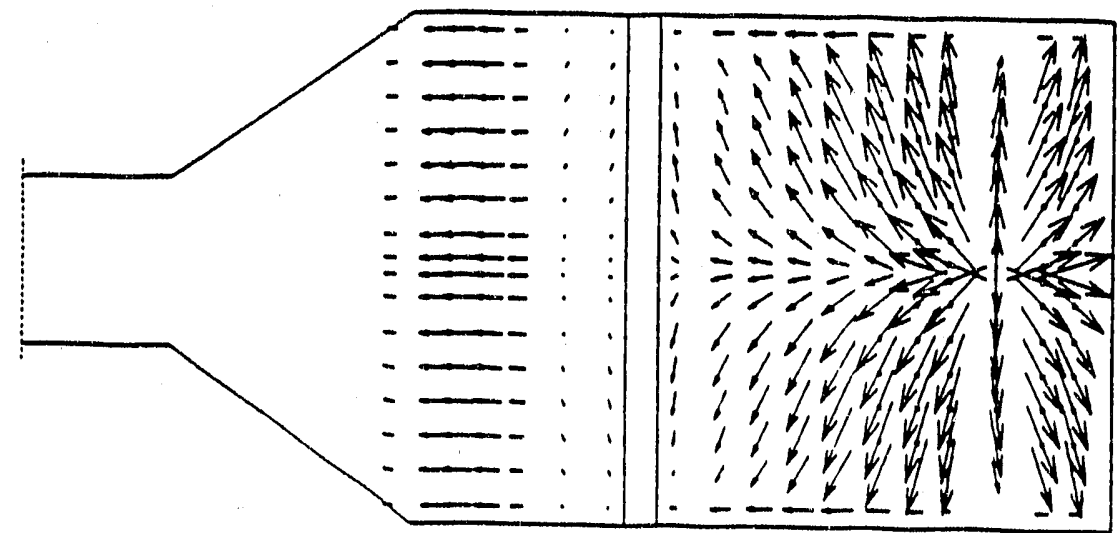

(d).

Figure 11 - Flow in transverse horizontal planes at different elevations with a dam and a weir. 

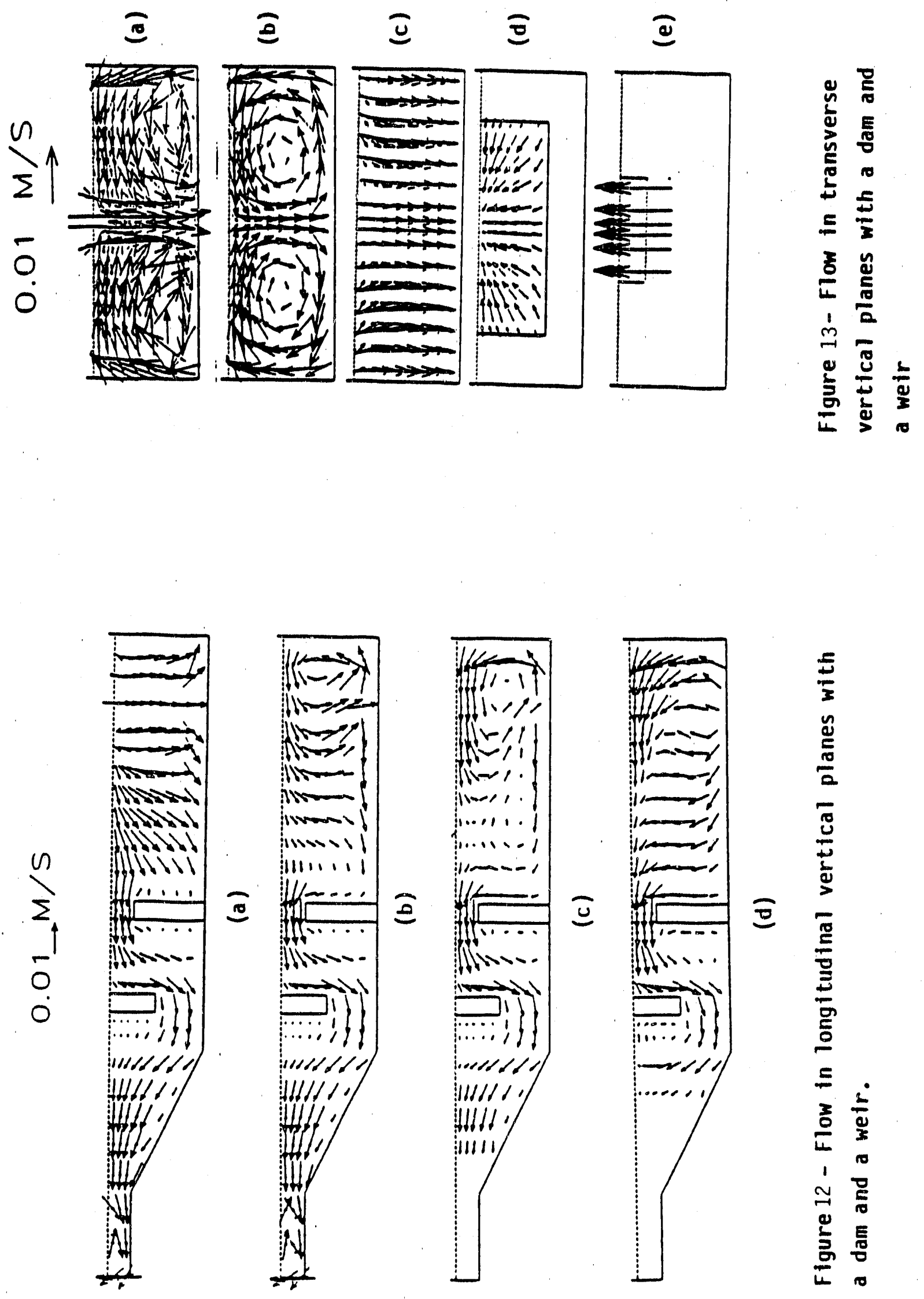


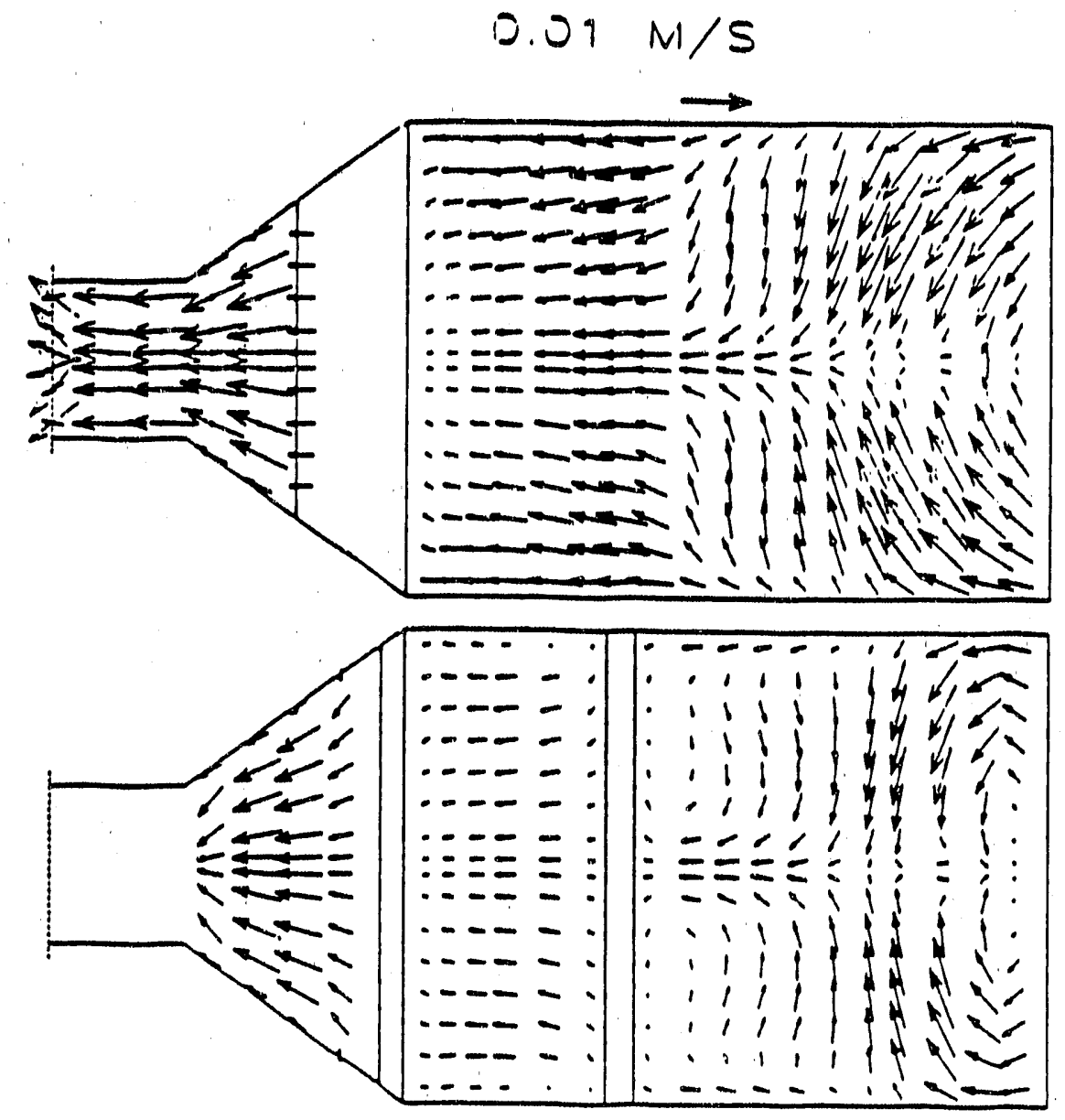

(a)

(b)

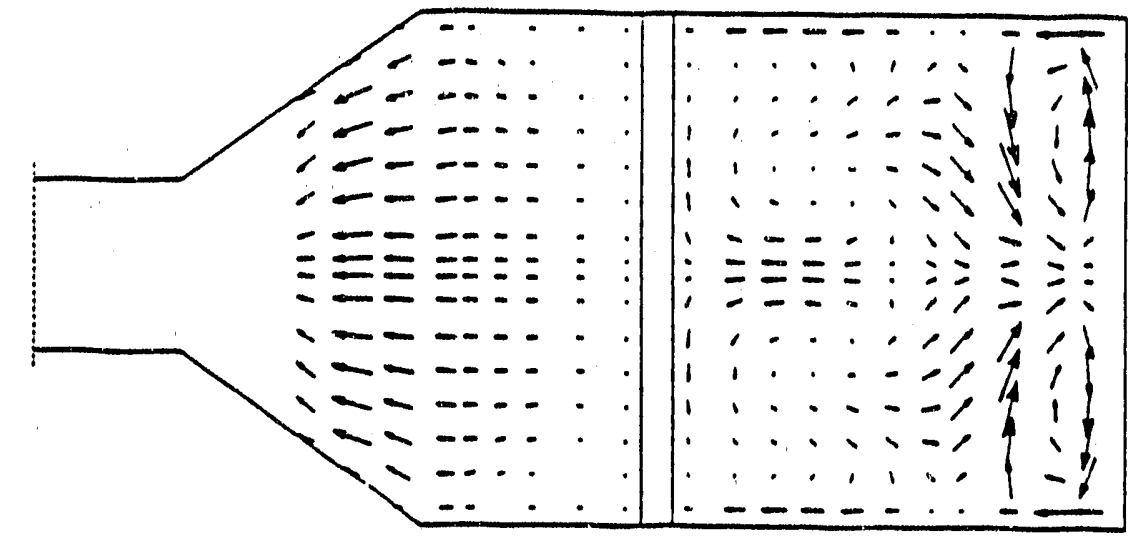

(c)

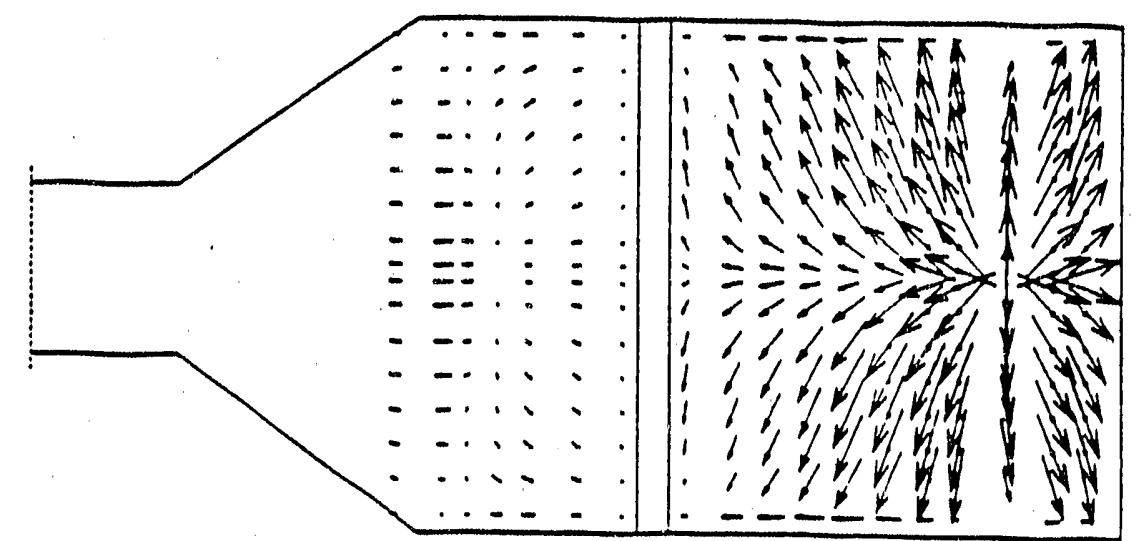

(d)

Figure 14 - Flow in transverse horizontal planes at different elevations with a dam and an inclined weir. 

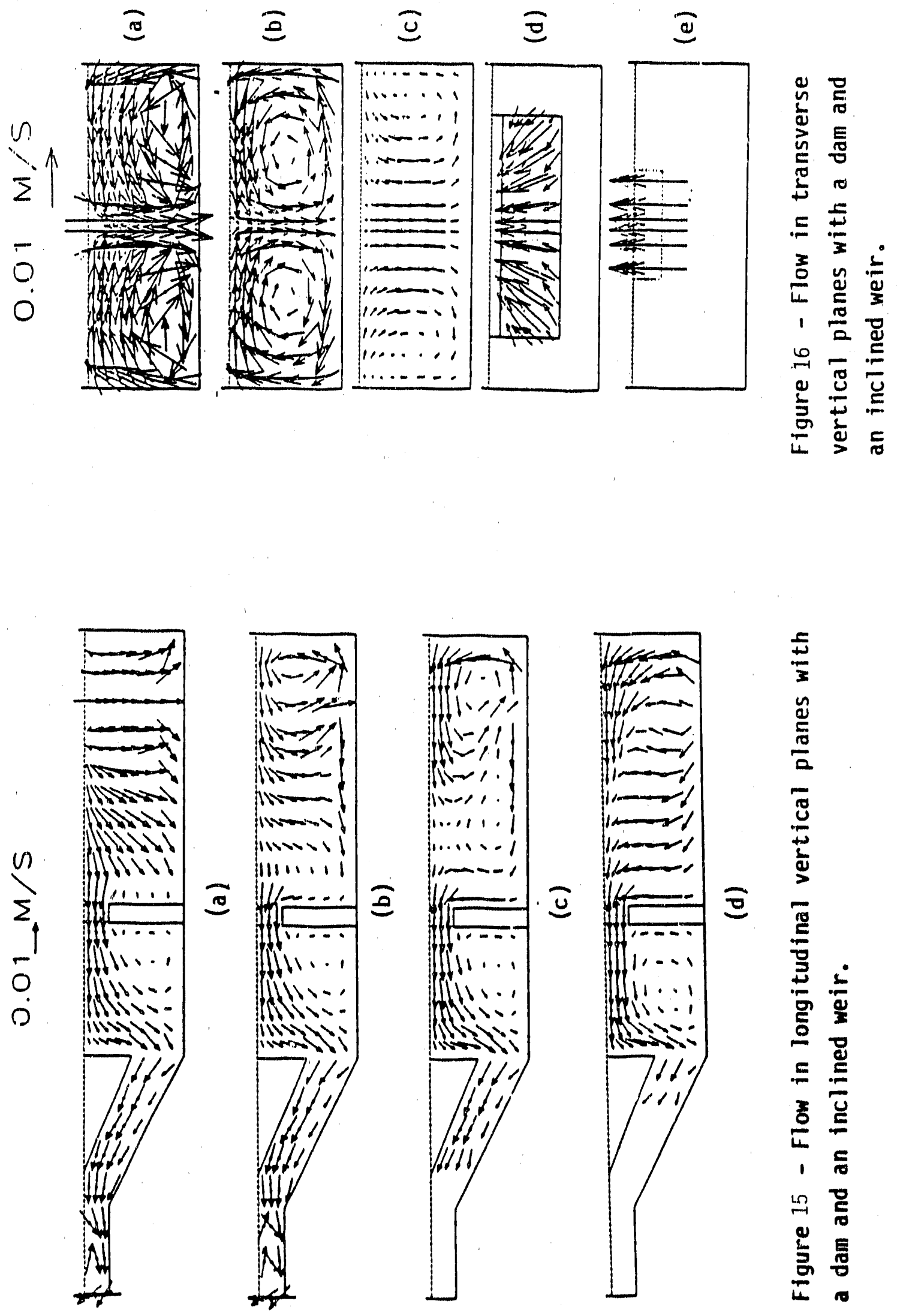

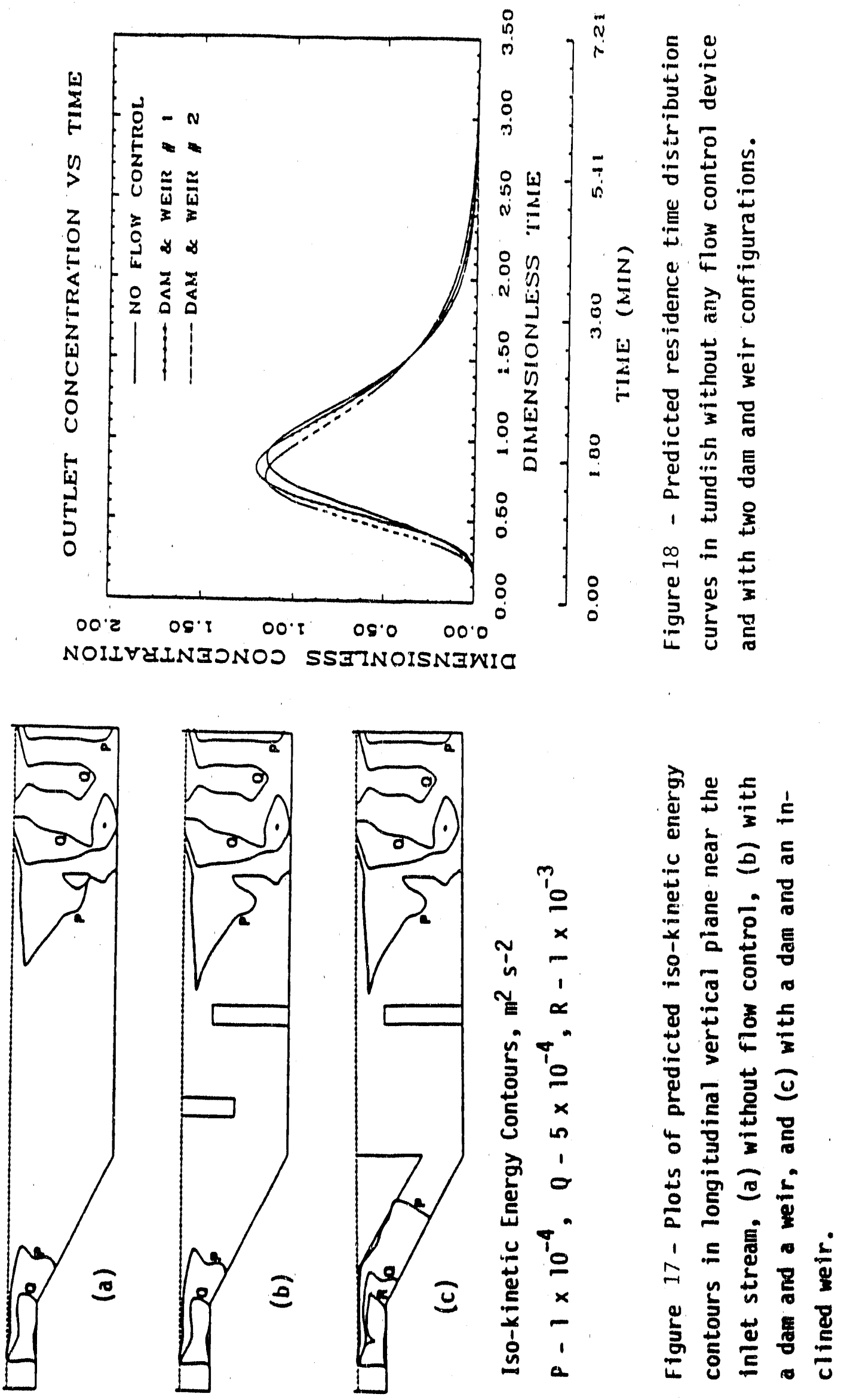
Near the inlet the recirculatory flow of high velocity contributes to this turbulence. Higher velocities in the converging region and near the outlet are responsible for higher levels of turbulence in those regions. Most of the other regions have very low levels of: turbulence (less than $0.0001 \mathrm{~m}^{2} / \mathrm{s}^{2}$ ). Upon comparing the three cases studied, it can be seen that the turbulence levels without flow control or with a dam and a welr (configuration 1) are nearly the same. With the inclined weir (configuration 2), the turbulence level is slightly higher near the outlet. This is due to the reduced cross section area in the converging region. The higher turbulence is dissipated to the metal being delivered to the substrate and could be detrimental to the uniformity of strip thickness.

\section{Tracer Dispersion and Mixing}

Figure 18 shows the predicted Residence Time Distribution (RTD) in the tundish with no flow control and with the two dam and weir configurations. It can be seen that the use of dam and weir has made very little change to the residence time of the melt. In fact, their use has slightly reduced the average residence time of melt in the tundish. of the two dam and weir configurations studied, the inclined weir results in the least average residence time and therefore should be the least desirable configuration.

The tundish design selected in this study provides very good fluid flow without any dam and weir due to the large length to depth ratio. However, in industrial practice, a dam in such 
shallow tundishes plays an important role in containing the inttlal surge of the molten metal at the start of the pouring from the ladle. A simple weir is helpful in preventing flow of any slag to the substrate.

\section{Conolusions}

A general-purpose mathematical model has been used for predicting the velocity and turbulence field in shallow tundishes with large length to depth ratios, typlaally employed for strip casting. It was found that such tundishes, if designed carefulily, provide very good melt flow characteristios needed for thin strip production. The use of a dam and a weir is not helpful in further. improving the flow characteristics but in industrial practice they may be needed to contain the initial surge of molten metal. at the start of metal pouring and to prevent slag being transferred to the substrate melt pool region.

\section{$\underline{\text { References }}$}

1. B. E. Launder, and D. B. Spalding, Computer Methods in Applied Mechanics and Engineering, 1974, Vol. 3, p 269.

2. Y. He and Y. Sahai, Metal1. Trans. B, 1987, Vol. 18B, pp 81-92.

3. Y. Saha1, Mathematical Modeling of Materials Processing Operations, TMS-AIME Publication, 1987, p. 431. 


\subsection{HEAT TRANBFER AND SOLIDIFICATION MODEL}

A simple mathematival model has been developed to prealat the thiokness of solidifled strip as a function of the substrate speed, the depth of molten metal in contact with the roll, the superheat of metal and the physical properties of molten metal. The model is based on the balance of heat loss from the molten metal during freezing and the heat removed by cooling water. Radiation heat losses were ignored.

The substrate roll speed and the depth of molten metal in contact with the substrate determines the solidification time. However, the molten metal depth at the 'Ilp' increases as the substrate speed goes up, due to the metal being dragged up with the moving roll. The extent of this increase of metal depth has been calculated in the following analysis by a force balance.

\section{Force Balance During Fluid Flow}

Consider the roll is moving at a speed, $V$. As shown in Figure 19, molten metal is dragged up to height, $H$, and the affected distance from the roll is $\mathrm{w}$. 


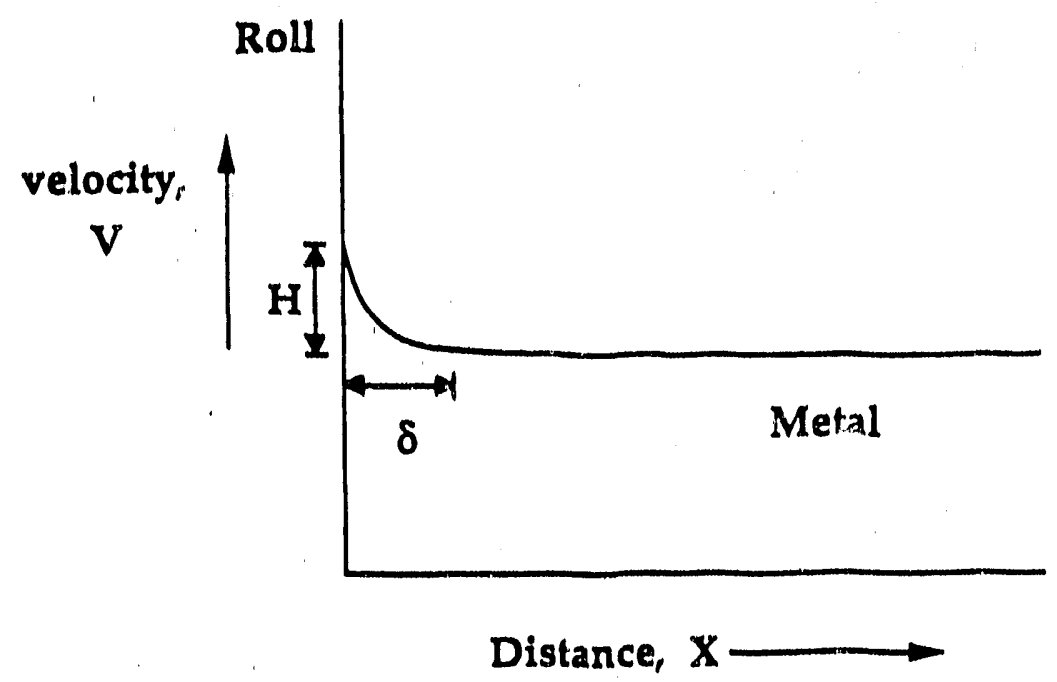

Figure 19: Schematic representation of molten metal meniscus on rotating wheel.

Force acting on this ilquid in upward direction, $F_{m}$

$$
\begin{aligned}
& F_{\mu}=H \cdot W \cdot \mu \cdot \frac{d V}{d x} \\
& \left.F_{\mu}=H \cdot W \cdot \mu \cdot \frac{(V-o)}{\varepsilon}\right)
\end{aligned}
$$

Where $\mu$ is the viscosity of molten metal, and $w$ is the width of the strip.

The force will be balanced by the weight of the metal.

$$
F_{g}=\frac{H \delta W}{2} \cdot \rho \cdot g
$$

where $\rho$ is the density of metal and $g$ is acceleration due to gravity. Equating equations (1) and (2), we get 


$$
\delta^{2}=\frac{2 \mu V}{p \cdot g}
$$

since the arfected region is very small it can be assumed that

$$
\delta=H
$$

So that

$$
H=\frac{2 \mu V}{\rho \cdot \lambda}
$$

Equation (5) can be used to calculate the increase of metal depth at the 'lip' at any roll speed. Values obtained by equation (5) were added to the depth of Iiquid at stationary roll and used in the determination of the solidification time.

\section{Heat Transfer Analysis}

The analysis of heat transfer, when metal comes in contact with a chill metallic surface of a roll, is very complicated. However, In the present analysis a simple heat transfer model is developed. Since molten steel does not normally 'wet' the roll surface, a thermal contact resistance exists at the solidified metal-roll interface. This resistance results in a large temperature drop at the interface. The thermal conduativity of the metal being cast also contributes to the overall resistance to heat flow and results in a thermal gradient within the solidifying metal. However, the major resistance to heat flow is offered by the mold-metal interface. The model is based on the following assumptions: 
1. The interface thermal resistance predominates over the thermal resistance offered by the metal.

2. Temperature in the water-cooled copper mold is constant, $\mathrm{T}_{0}$.

3. Metal freezes as a plane at $x$ where the temperature is at the freezing point of metal, $\mathrm{T}_{M}$.

4. Temperature profile within the solidifying metal layer is a linear function with distance.

5. Temperature losses from free surface are negligible.

As shown in Figure 20, solidified metal temperature at the interfaces is $T_{S}$, which is higher than the roll temperature, $T_{O}$, due to the interface resistance.

Heat transfer due to conduction in the solidified layer.

$$
q=K \frac{T_{M}-T_{S}}{M}
$$

where $\mathrm{K}$ is the thermal conductivity of the metal and $M$ is the thickness of the solidified layer.

Heat transfer at the metal-substrate interface

$$
q=h\left(T_{S}-T_{0}\right)
$$

where $h$ is the heat transfer coefficient. 


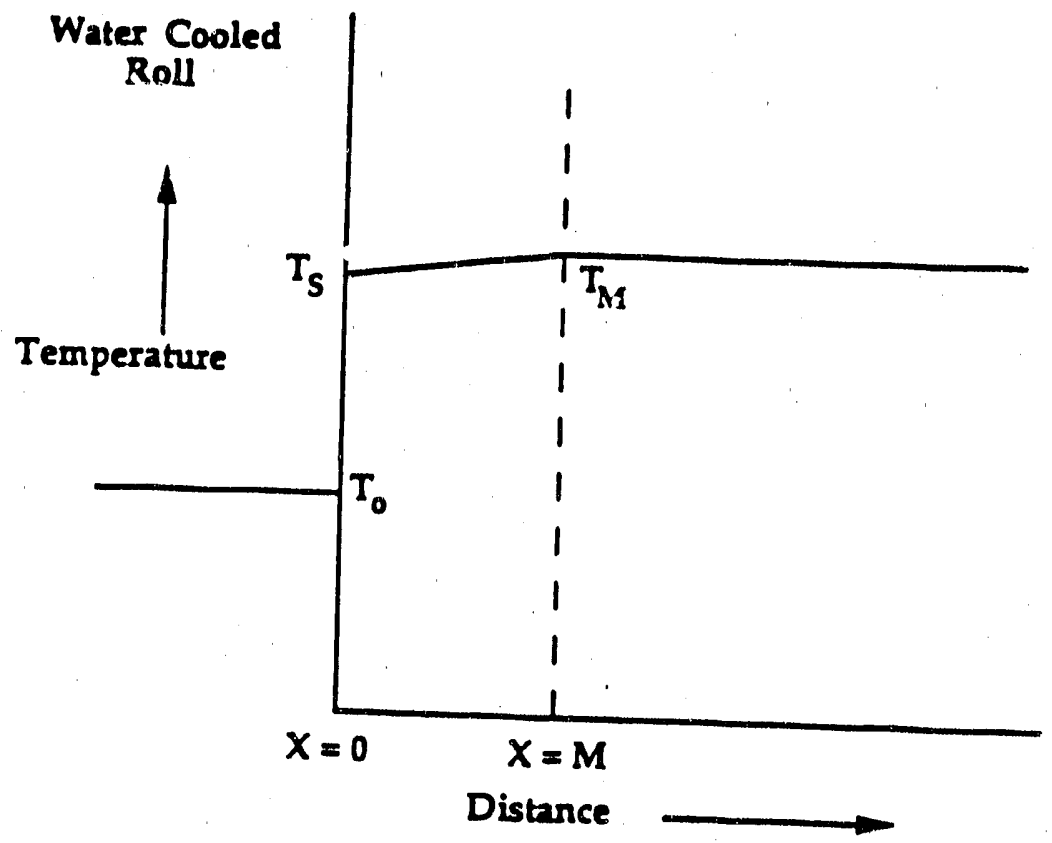

Figure 20: Temperature profile in solidifying metal. 
Overall heat loss due to the freezing of metal [combining equations (6)

and (7) j

$$
q=\frac{T_{M}-T_{o}}{\frac{1}{h}+\frac{M}{k}}
$$

Total heat evolved due to latent and superheat is given by

$$
q=\rho H_{f} \frac{d M}{d t}
$$

where: $t$ is time and $H_{f}$ is effective latent heat

$$
\mathrm{H}_{\mathrm{f}}=\mathrm{H}_{\mathrm{f}}^{\prime}+\mathrm{C}_{\mathrm{p}}, \mathrm{I} \Delta \mathrm{T}_{\mathrm{S}}
$$

$$
\begin{aligned}
& \mathrm{H}_{\mathrm{f}}{ }^{\prime} \text { is the latent heat of fusion, } \\
& \mathrm{C}_{\mathrm{p}, \mathrm{l}} \text { is the heat capacity of molten metal, } \\
& \Delta \mathrm{T}_{\mathrm{S}} \text { is the superheat. }
\end{aligned}
$$

Densities of liquid and solid metal at the melting temperature are assumed to be equal in deriving equation (9).

Equating equations ( 8$)$ and $(5 ;$, we get

$$
\rho H_{f} \frac{d M}{d t}=\frac{T_{M}-T}{\frac{l}{h}+\frac{M}{k}}
$$

Upon integrating with $M=0$ at time $t=0$, and $M=M$ at $t=t$, we obtain

$$
M+\frac{M^{2} h}{2 k}=\frac{h\left(T_{M}-T_{o}\right) t}{\rho H_{f}}
$$


Equation (12) can be used to determine the thickness of solidified layer, $M$ at any time, $t$.

The following data were used in calculating the strip thickness as a function of wheel speed, depth of metal in contact with roll, and superheat.

$\begin{array}{lll}\text { Heat transfer coeff. } & -10,000 \mathrm{~W} / \mathrm{m}^{2} \mathrm{k} & \left(1761 \mathrm{BTU} / \mathrm{Hr} . \mathrm{Ft}^{2} . \mathrm{F}\right) \\ \text { Heat of fusion } & -174500 \mathrm{~J} / \mathrm{kg} & (75 \mathrm{BTU} / \mathrm{lb}) \\ \text { Heat capacity } & -725 \mathrm{~J} / \mathrm{kg} \cdot \mathrm{k} & (.173 \mathrm{BTU} / \mathrm{lb} \mathrm{F}) \\ \text { Thermal conductivity } & -30 \mathrm{~W} / \mathrm{m} \cdot \mathrm{k} & (17 \mathrm{BTU} / \mathrm{Hr} . \mathrm{Ft}) \\ \text { Freezing Temperature } & -1490^{\circ} \mathrm{C} & \left(2714^{\circ} \mathrm{F}\right) \\ \text { Superheat } & -25-50^{\circ} \mathrm{C} & \left(45-90^{\circ} \mathrm{F}\right) \\ \text { Density } & -7860 \mathrm{~kg} / \mathrm{m}^{3} & \left(491 \mathrm{lb} / \mathrm{Ft}^{2}\right) \\ \text { Viscosity } & -6.3 \times 10^{-3} \mathrm{~kg} / \mathrm{m} . \mathrm{s} & \left(4.2 \times 10^{-3} \mathrm{lb} / \mathrm{ft} \cdot \mathrm{S}\right) \\ \text { Depth of metal } & -2.54-7.62 \mathrm{~cm} & (.083-.2 .5 \mathrm{ft}) \\ \text { Roll speed (linear) } & -0.5-4.0 \mathrm{~m} / \mathrm{sec} & (1.6-13 \mathrm{ft} / \mathrm{S})\end{array}$

The predicted results are shown in Figures 21 and 22 . The results are in excellent agreement with the experimentally obtained thickness of the steel strip. 


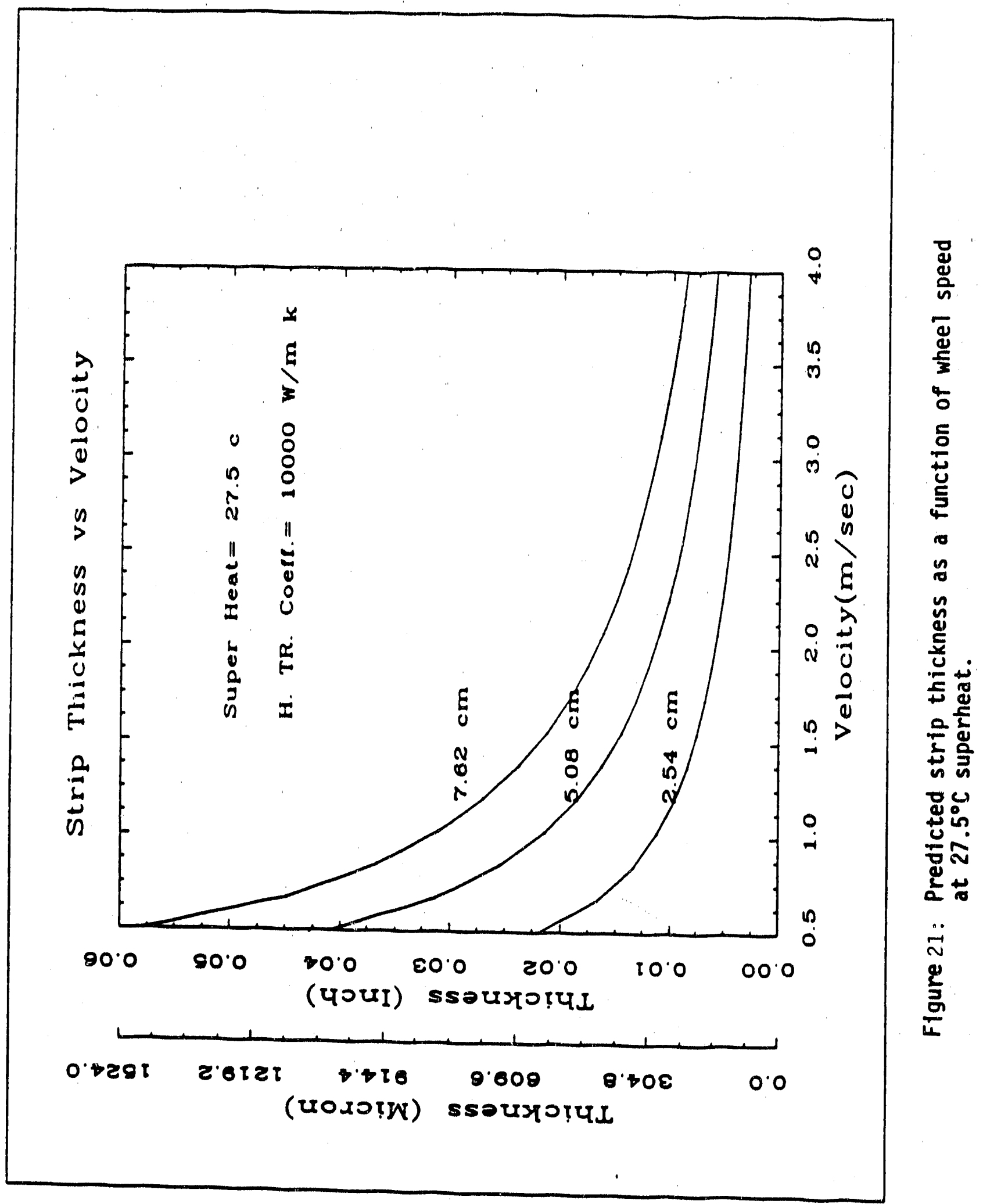




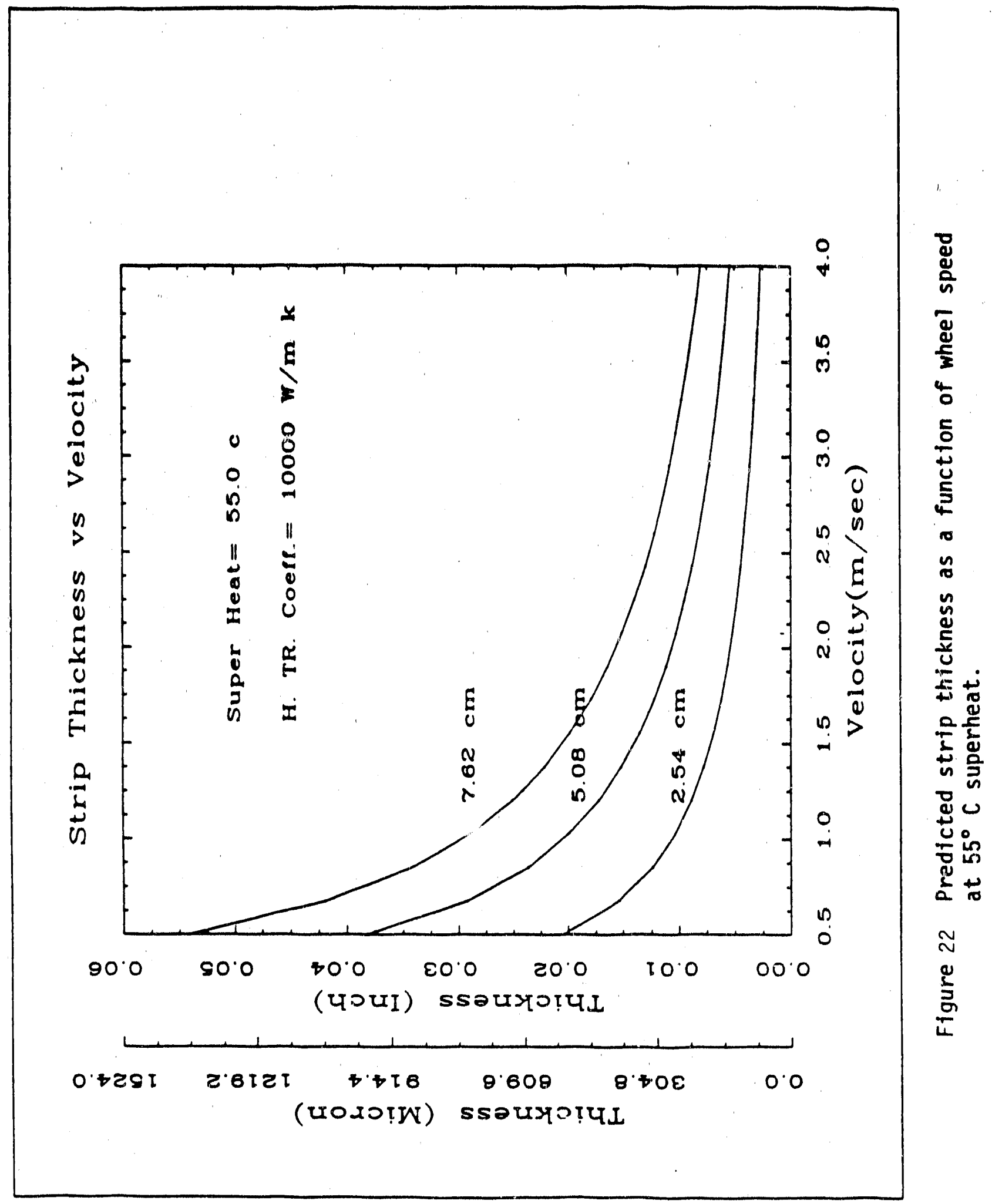




\subsection{Task 2.0 substrate Effects}

\section{summary and Conclusions}

The substrate study was undertaken in order to give guidance for the material selection and preparation for subsequent open Channel and Planar Flow casting trials. Additionally, it was hoped some understanding would result of the fundamental factors governing the melt/substrate interaction, and an ability to specify more exactly the substrate requirements. The task was successful in both endeavors. The conclusions can be summarized as follows: Copper substrates with a moderately smooth (80 grit abrasive paper, micro in. rms.) are the best choice for further development. Chemical compatibility between the melt and substrate does not appear to play as large a role as previously suspected. The major consideration is the ability to transfer heat from the strip interface to the cooling water with a stable, somewhat elevated outer surface temperature. For all substrates with the exception of stainless steel, a relatively thick oxide layer develops quickly during casting which consists of oxidized elements from the melt. In the case of the stainless steel substrate, this oxide, while still present, is much thinner and maybe more representative of an oxidized layer of the substrate rather than precipitate from the melt.

\section{Experimental plan}

In order to insure that the substrate trials accurately reflected the conditions during a normal cast, all tests were conducted as full scale (500 $\mathrm{jb}, 3 \mathrm{in}$. wide) casts on the small 
wheel caster. Other test parameters such as nozzle material, gaps, etc. were fixed at those values which, at that time, represented the best practice and had consistently produced successful casts. Table $V$ shows the fixed parameters for the substrate trials. It should be noted that the iron/copper substrate was tested early, before the fixed conditions were established. This was done to avoid dismounting the $\mathrm{Fe} / \mathrm{Cu}$ wheel, which was left on the caster from the previous work. Dismounting and remounting might have resulted in a large asymmetry, which would have been impossible to remove by the normal practice of machining in place, as the Fe layer was only a few mils thick.

TABLE VI

SUBSTRATE TRIAL CASTING PARAMETERS

WHEEL

SPEED

NOZZLE

GAP BETWEEN

NOZZLE AND

WHEEL

WATER FLOW

MELT

MISC.
14 in. diam. material and thickness varied:

Copper: 0.7 in. thick

Steel: 0.15 to 0.5

304 Stainless: 0.065 to $0.23 \mathrm{in}$. thick

Iron/Copper: .7 in. thick

$800 \mathrm{fpm}$ initial, slowed to 400 when possible

Vision, 3/8" weir gap, $60^{\circ}$ BTDC, CO gas bottom shielding, Argon shrouding

. 010 in. Set after preheat $\sim 005$ in. open loop adjustment at start of cast

55 GPM

Low carbon, low manganese, si killed $2960^{\circ}$ transfer temp. in ladle

Air knife stripper, no dresser 


\section{selection of Candidate Materials:}

As stated, the goal of this task was to determine the best avallable substrate for subsequent process development. Therefore, materials and conditions chosen for the survey were Ilmited to those which could be reasonably obtained and maintained for the large wheel caster. For materials, this limited the choices to single material rims, or possibly coated materials. Coating by means of spray deposition or plating on the $7 \mathrm{ft}$. diameter wheel, while not impossible, would be expensive and less desirable because of uncertainty as to how often resurfacing would be required to maintain the finish, and the difficulty of applying an even coating to the substrate.

All previous experience of this research program in casting steel strip had been using copper substrates. Some reports indicate that carbon steel substrates work best for casting carbon and stainless steel strip. It was decided that copper, low carbon steel and 304 stainless substrates would be included in the survey. In addition, one 1 ine of reasoning predicts that a chemically compatible substrate such as iron, which would promote wetting of the substrate by the melt and hence good spreading and adhesion, should be combined with an underlying high conductivity material such as copper, which would allow for rapid removal of heat. As a fourth candidate then, iron plated copper was selected. A 0.7 in. thick, 14 in. diameter copper wheel previously electroplated with .002 to $.003 \mathrm{in.}$ of iron was used. 


\section{Selection of substrate conditions:}

Varlous arguments have been advanced which advocate very smooth, slightly rough, grooved, or crosshatched casting surfaces. our previous casting experience inoluded various degrees of roughness from sandpaper, steel brushes, and widely spaced shallow grooves, but no systematic investigation had been undertaken. Surface conditioning was limited to sanding and grooving in the direction of rotation).

The primary effect of roughness was increasing the tendency for the strip to adhere to the wheel with rougher surfaces. In some cases, such as our previous large wheel trials on a copper wheel, additional adhesion is desired to allow for full solidification of the strip before exiting the wheel. In other cases, such as some previous work performed with steel substrates, adhesion can become catastrophic, i.e. pieces of strip are carried $360^{\circ}$ around the wheel with devastating results on the process. In some cases welding of the strip to the substrate occurs. Therefore, the range of roughnesses used for a given substrate was chosen according to the observed behivior after an initial trial with a smooth finish. Actual rms roughness values as determined by a portable profilometer, ranged from 10 to 1120 micro in..

It is well known that contaminants such as water or grease on the substrate have deleterious effects on the process. Accordingly, care was taken to clean the substrate prior to casting. Initially, a steel brush dressing wheel was to be used to 
remove the oxide formed on the substrate during casting. This was abandoned due to damage frequently suffered by the brushes from material carried past the stripper bar. Therefore, oxide was allowed to accumulate during the run.

\section{Results}

A total of twenty trials were successfully completed for the survey. Table VII lists the heat numbers and conditions. Also included in the Table is a calculated rim surface temperature. This was computed by scaling the rim measured surface temperature from Heat D88029 as explained in the "ANALYSIS" section below. A detaileci description of the casts is included in another section of the report. There were four $\mathrm{Fe} / \mathrm{Cu}, \mathrm{six} \mathrm{Cu}$, seven 1.C. steel, and three stainless trials. A brief summary of the results for each substrate follow.

\section{Iron/Copper:}

All attempts to use this substrate were totally unsuccessful. Initial adhesion of the melt to the wheel never developed. The melt gave the appearance of 'skating' on the substrate. only short lengths of strip were cast before freeze-up or leakage occurred.

\section{Copper:}

This was the most satisfactory substrate tested. Adhesion ranged from insufficient, for smooth substrates (rms < 25 micro in.), to immediate catastrophic sticking for very rough substrate with a fairly wide transition range in between. Several complete 


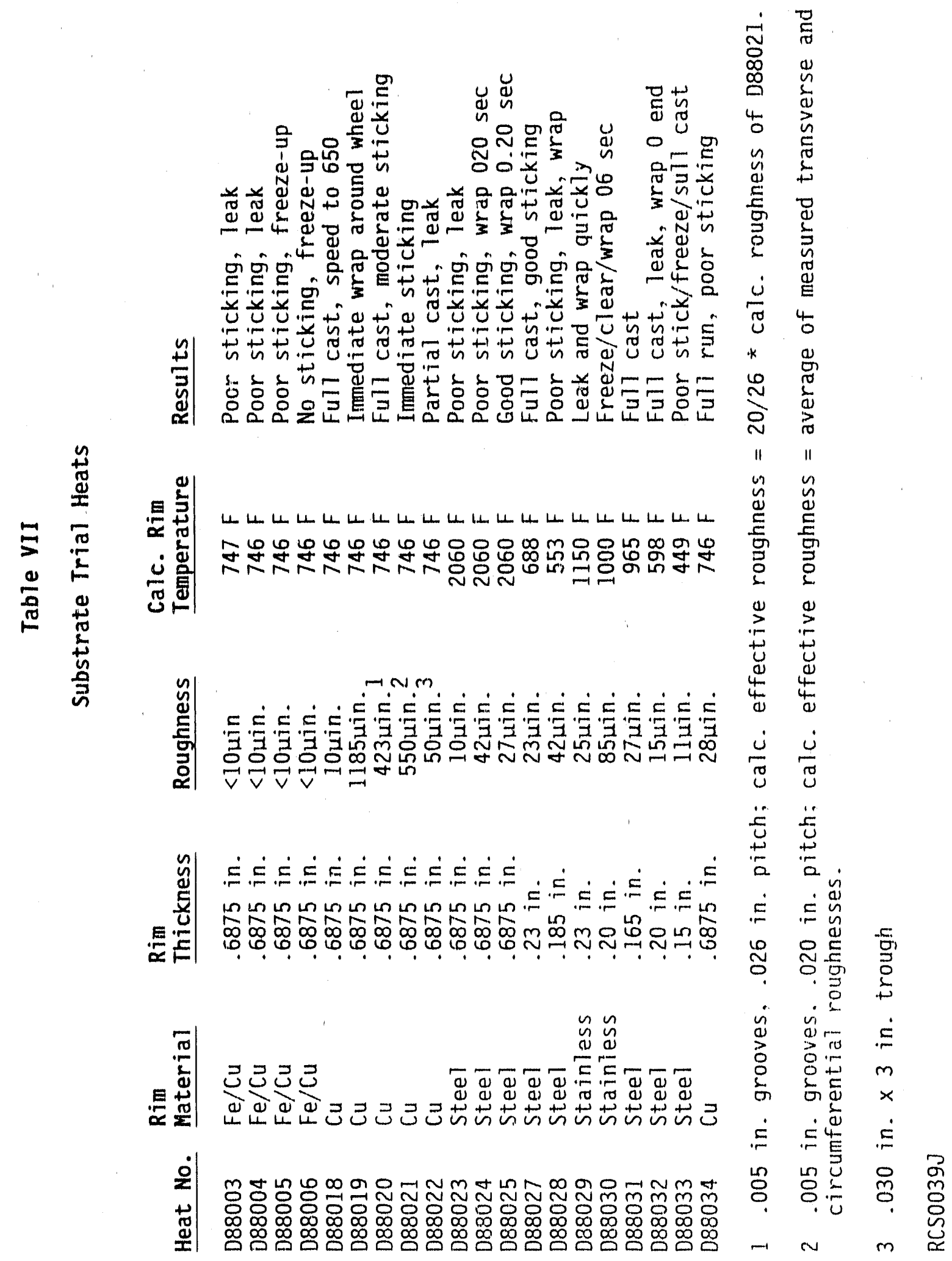


casts were made with large quantities of relatively good strip, .015 to .022 in. thlok produded. Grooveg resulted in enhanced adheston, .005 in. grooves, .020 in. spacing resulted in catastrophta adhesion, while .005 grooves, .026 in. spaaing resulted in a complete cast.

one additional doncept was tried whereby casting was accomplished in a $.030 \mathrm{in.} \mathrm{trough} \mathrm{machined} \mathrm{into} \mathrm{the} \mathrm{substrate.} \mathrm{The}$ hope was that additional cooling and some mechanical looking of the edges might occur which would result in better adhesion and complete filling of the channel and hence $.030 \mathrm{in}$. strip would be formed. This did not work and breakout from the baok ilp halted the cast after one minute.

\section{Low Carbon steel:}

All initial trials, using a thick (0.7 in.) rim, ended with catastrophic adhesion very soon after the start of cast. A very smooth finish resulted in initial 'skating' behavior, followed by sudden and complete adhesion. All trials were aborted after less than 25 lbs. of cast material.

In order to reduce the terminal outer temperature of the steel casting surface, a new wheel design was implemented with a cooling channel machined into a strong back rim and a substrate rim formed by a welded band on the outside of this rim. This allowed for very thin substrates while maintaining adequate structural integrity. The thinner $(0.23 \mathrm{in}$.) substrate cast. for 164 seconds before 
freezing off as the speed was lowered. An even thinner substrate (0.185 in.) resulted in very poor adhesion, with fallure due to a breakout under the nozzle.

\section{stainless steel:}

The results for stainless were similar to those for carbon steel. A rlm thickness of $0.20 \mathrm{in}$. resulted in rapid onset of catastrophic adhesion, while a $0.165 \mathrm{ln}$. substrate ran for 124 seconds. Unlike the other substrates tested, there was, in general, less build up of the heavy oxide coating. Also, in all oases, the strip produced on a stainless substrate was pitted. The pits appeared to be formed by gas being ejected through the unsolidified strip, as indicated by the raised rim around the holes, many of which were completely through the strip.

For trials D88029, D8830, and D88031 an infrared pyrometer located near the 6:00 position on the wheel (nearly $270^{\circ}$ after the casting position) yielded a continuous reading of the substrate surface temperature during the casts. All records indicate a very rauld initial rise followed by a more gradual increase. In the first two trials with the thicker substrate, the increase continued up to $1150^{\circ} \mathrm{F}$, at which point catastrophic adhesion occurred. For trial 31, the increase slowed and peaked at around $750^{\circ} \mathrm{F}$ for the remainder of the cast.

The absolute value of these temperatures is somewhat in doubt as the pyrometer is of the 'single color' type, whereby an estimate of surface emissivity must be set and fixed prior to casting. Any 
changes in the surface, such as roughening or oxidation which occur during the run, could alter the emissivity. For these tests, the emissivity of the blackened substrate after a cast was estimated by heating a stainless steel sheathed thermocouple with a torch, then adjusting the emissivity on the pyrometer until the two measurements agreed. The thermocouple sheath had a similar black appearance after heating as the substrate.

\section{Ars: is of Black oxide:}

After casting trial D88015 on a copper wheel, the black film was machined off the casting surface and collected for analysis. After sieving through a 200 mesh screen, the particles consisted of the black film and copper shavings from the machining operation. $x$-ray diffraction and electron microprobe analyses confirmed the presence of $\mathrm{Fe}, \mathrm{Mn}, \mathrm{Si}$, and $\mathrm{Cu}$. The $\mathrm{X}$-ray results showed the $\mathrm{Mn}$ and $\mathrm{Si}$ and some of the $\mathrm{Fe}$ to be in the form of iron manganese silicate ( $\mathrm{Fe}, \mathrm{Mn}){ }_{2} \mathrm{SiO}_{4}$ known as manganoan.

After trial D88030 on a stainless wheel, the thin oxide layer was machined off and analyzed. Only very qualitative energy dispersive $x$-ray analysis was possible for the small amount of sample. Fe was the major element, with Si, Cr, Ni, Mo, P, S also present. No chemical analysis was possible. 


\section{Analysis}

There appear to be two primary factors determining the adhesion of steel strip to the substrate: substrate surface temperature and roughness. In the case of copper, very smooth substratis (10 micro in.) demonstrated poor adhesion initially, but eventually settled into conditions allowing a continuous cast. Rough surfaces, especially grooved ones, result in very rapid adhesion and catastrophic adhesion. steel and stainless steel substrates behaved similarly, as long as the substrate thickness was reduced to bring the terminal outer skin temperature down below some critical level (estimated to be between $750^{\circ} \mathrm{F}$ and $1150^{\circ} \mathrm{F}$ for stainless). The iron plated copper substrate demonstrated very poor adhesion, possibly due to the extremely smooth finish after plating.

Subsequent trials on the large wheel caster using a rough copper substrate resulted in generally poor adhesion. This includes a trial using the .005 in. grooves on a .020 in. spacing, a condition which resulted in immediate catastrophic adhesion on the small wheel. A subsequent large wheel trial was performed with a greatly reduced cooling water flow (180 gpm vs. $1500 \mathrm{gpm}$ ) which resulted in improved adhesion. These results suggest again that terminal substrate surface temperature plays an important role in determining strip adhesion. The large wheel results are confounded with substantial changes made in nozzle design and cast position, and hence are not conclusive. 
Figure 23 shows the results schematically by plotting adhesion as a function of surface roughness and surface lemperature. The surface temperature was calculated by scaling the measured value of $1350^{\circ} \mathrm{F}$ from Heat $\mathrm{D} 88029$ by the parameter:

$$
f=d(\operatorname{sqr}(\alpha t))
$$

where:

$$
\begin{aligned}
& f=\text { scaling factor for substrate } \\
& \quad \text { surface temperature } \\
& d=\text { thickness of rim } \\
& a=\text { thermal diffusivity } \\
& t=\text { time for } 1 \text { revolution }
\end{aligned}
$$

This parameter is used frequently in transient thermal analysis. It is only a crude approximation, but does allow a rationalization of the data. Data from the large wheel casts (not part of the substrate study) have been added. Excessively rough or hot substrates resilt in catastrophic adhesion; too smooth or too cool, on the other hand, leads to inadequate adresion. A broad band exists wherein successful casts are possible for a number of different substrates. This analysis is of course very qualitative, as to be expected from an engineering survey.

\section{Best Candidate:}

Copper appears to offer the broadest range of acceptable casting conditions with thicknesses which allow substrates to be readily formed for use in our casting wheels. Its high conductivity allows for considerable 'reserve' cooling capacity in 
Figure 23

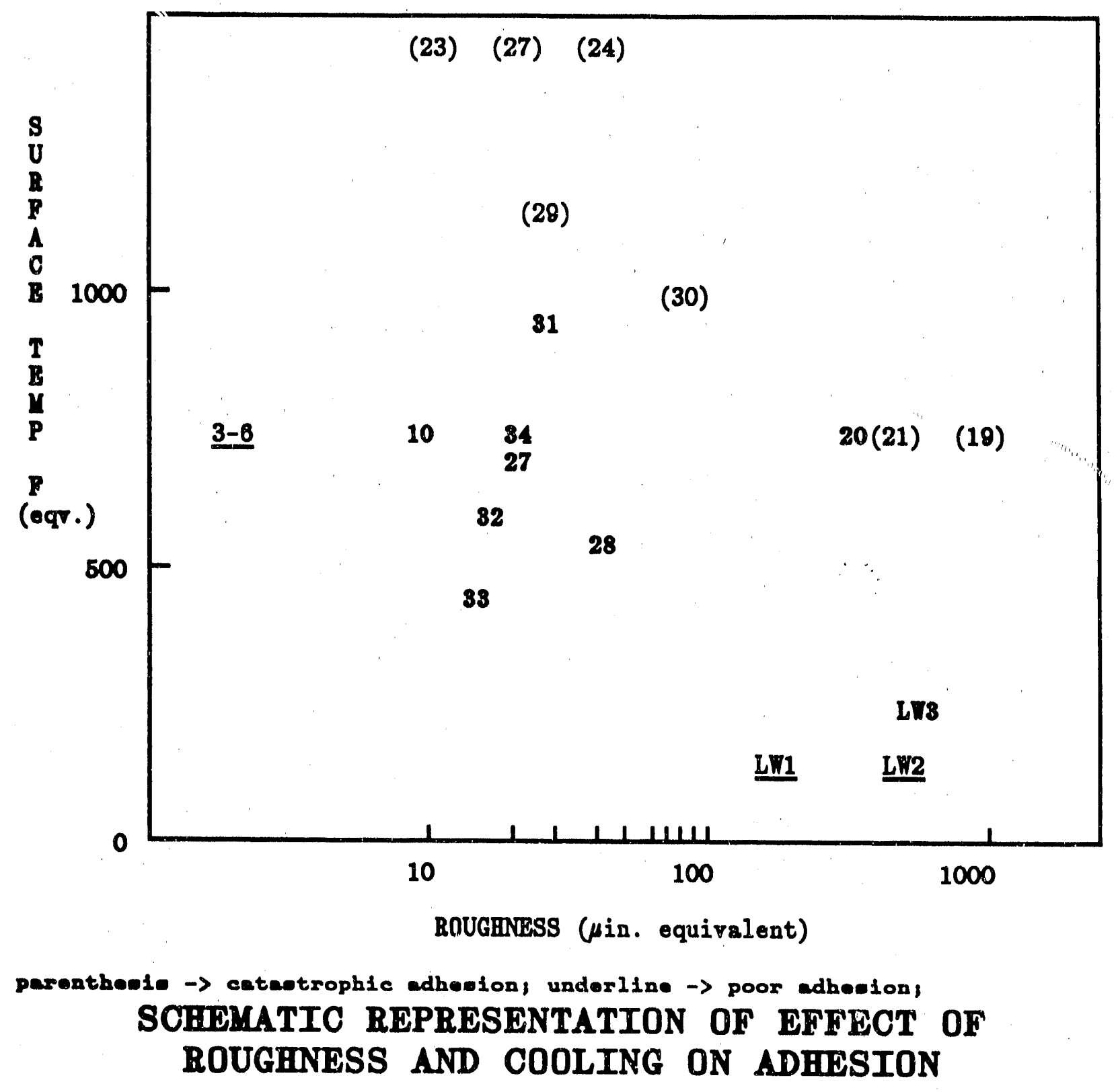


the event that the casting process advances to higher casting rates than presently possible. Furthermore, no detrimental interaction with the melt has been observed.

\section{Furtl.or Work:}

The casting process has been greatly advanced since this study was undertaken. Some effects, such as leakage and freezeups, which were originally attributed to the substrate, have been eliminated or reduced by careful selection of nozzle refractorles and precise gap adjustments. Further development of the copper substrate should be undertaken. In particular, the effect of surface roughness and temperature on the surface finish, thickness, and metallurgical properties of the cast strip must be determined. 


\subsection{Task 3.1 Melt Overflow Casting Experiments}

The small wheel caster which was constructed as part of the earlier Thin Strid casising program under the contract DE-AC07-83ID12443 and reported in Document 87-9D4-STRIP-R4 was used in the task. A brief description will be provided here.

The caster has a casting substrate of 16 in. diameter, approximately 6 in. wide and about 0.7 thick for copper wheels. Casting rims of OFHC copper, mild steel and stainless steel were fabricated and all of these substrates plus others were used during the casting program.' In the case of the copper substrates, a second concentric rim on the inside of the primary substrate rim provides a 0.125 in. cylindrical cooling channel through which water is supplied from a $1.5 \mathrm{in.} \mathrm{house} \mathrm{water} 1$ ine at a rate of about $60 \mathrm{gal} . / \mathrm{min}$. The cooling water exits directly to a drain. The cooling water system is fully enclosed and therefore slightly pressurized in the vicinity of the casting substrate surface. A photograph of the small wheel caster in the set up position for melt overflow casting is shown in Figure 24. The casting nozzle in position near the casting substrate is shown in Figure 25 .

The wheel surface speed is variable from $p 5$ to $1300 \mathrm{ft} . / \mathrm{min}$. Figure 26 also shows the stripper bar and wheel arsser. At the start of the casting the wheel is moved by an air cylinder horizontally towards the pouring box and then raised by a second air cylinder into the casting position. originally, the gap between the wheel and nozzle was adjusted during the cast with an 


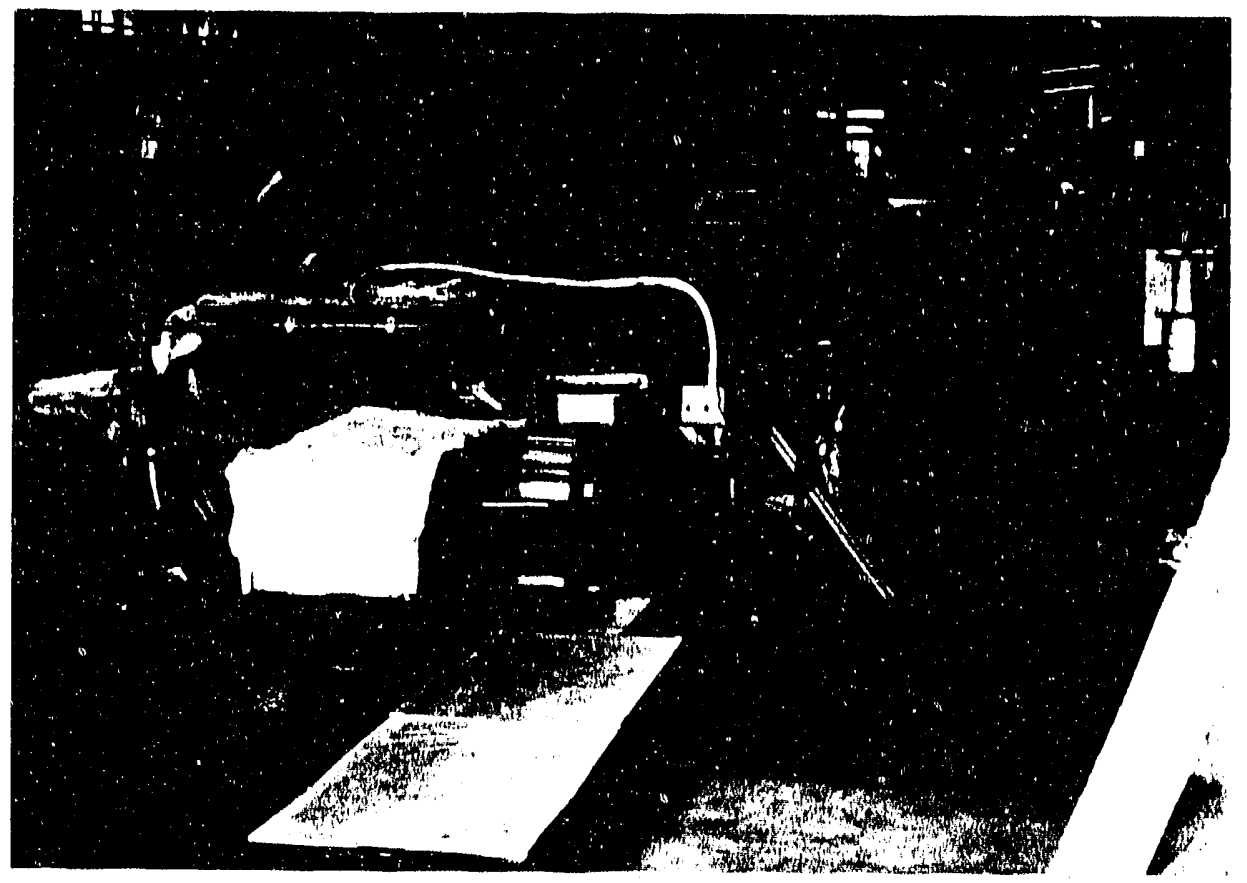

Figure 24: 'Photograph of the Sma11 Wheel Caster

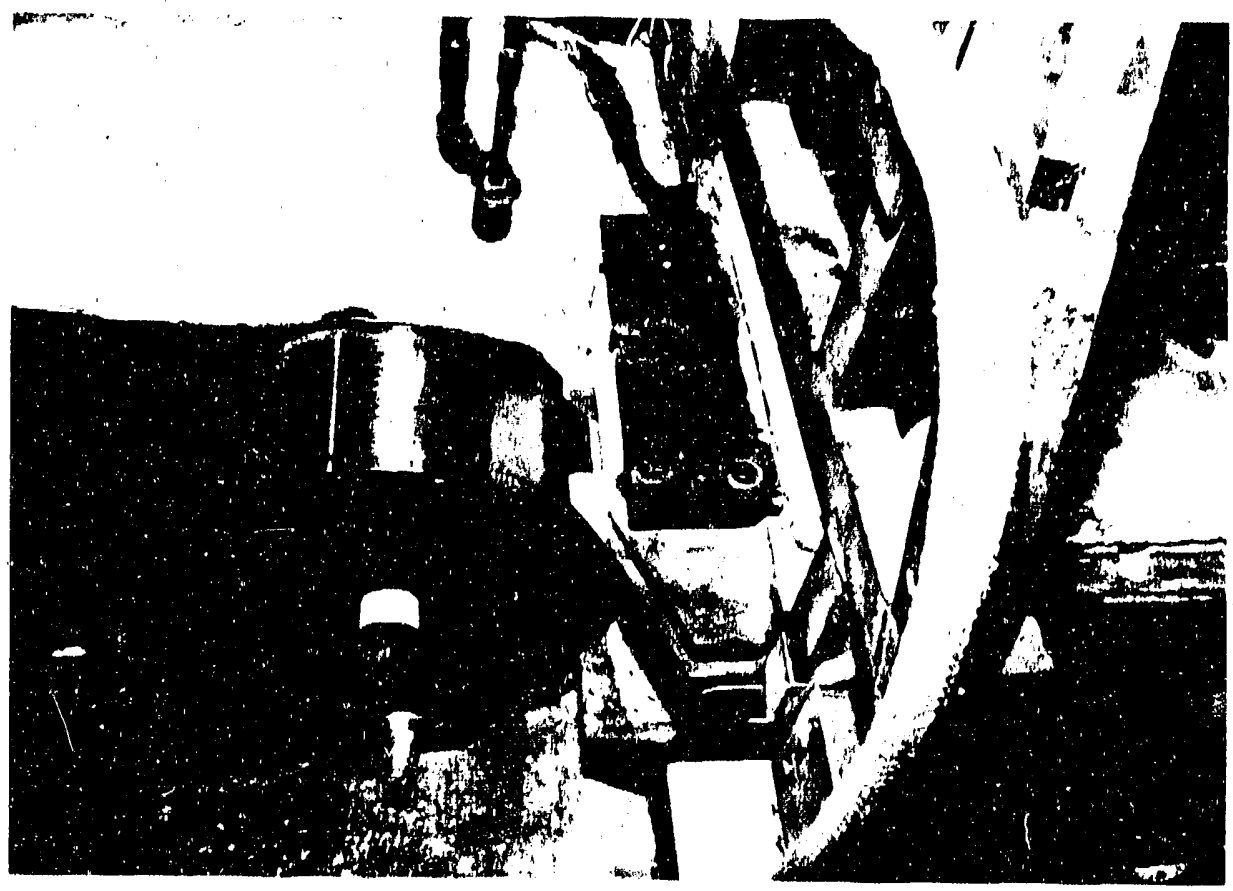

Figure 25: Photograph of Casting Nozzle in Position near Casting Substrate on Small wheel Caster 
air activated ratchet in $0.002 \mathrm{in}$. increments. This method was later improved as described elsewhere in this report. The pouring box incorporates an overflow spout on the side to permit the melt level to be maintained constant during the casts. Preheat burners, which ace applied to both the pouring box and the nozzle, are retracted automatically just prior to casting so that the desired temperatures are obtained at the start of cast. The ladle is supported separately and the tundish nozzle is inserted through the pouring box lid to allow for submerged pouring. All controls for the caster, with the exception of preheater movement and stopper rod control, are routed to an operator's console at a control station. A photograph of the control station is shown in Figure 27 .

\section{steelmaking and Liquid Metal Handing Procedures}

The general procedures and details of the melting furnace and ladle design are described in Report 87-9D4-STRIP-R4. In this report only those items that have been modified will be described.

A second 500 1b. furnace was activated on the same platform as the first furnace. The furnace has identical melting characteristics and refractory linings and the two were used interchangeably during the casting program. Several different refractory linings were tried during this casting program. The best lining was a zircon type and up to fifteen heats per lining were achieved during the campaigns. 


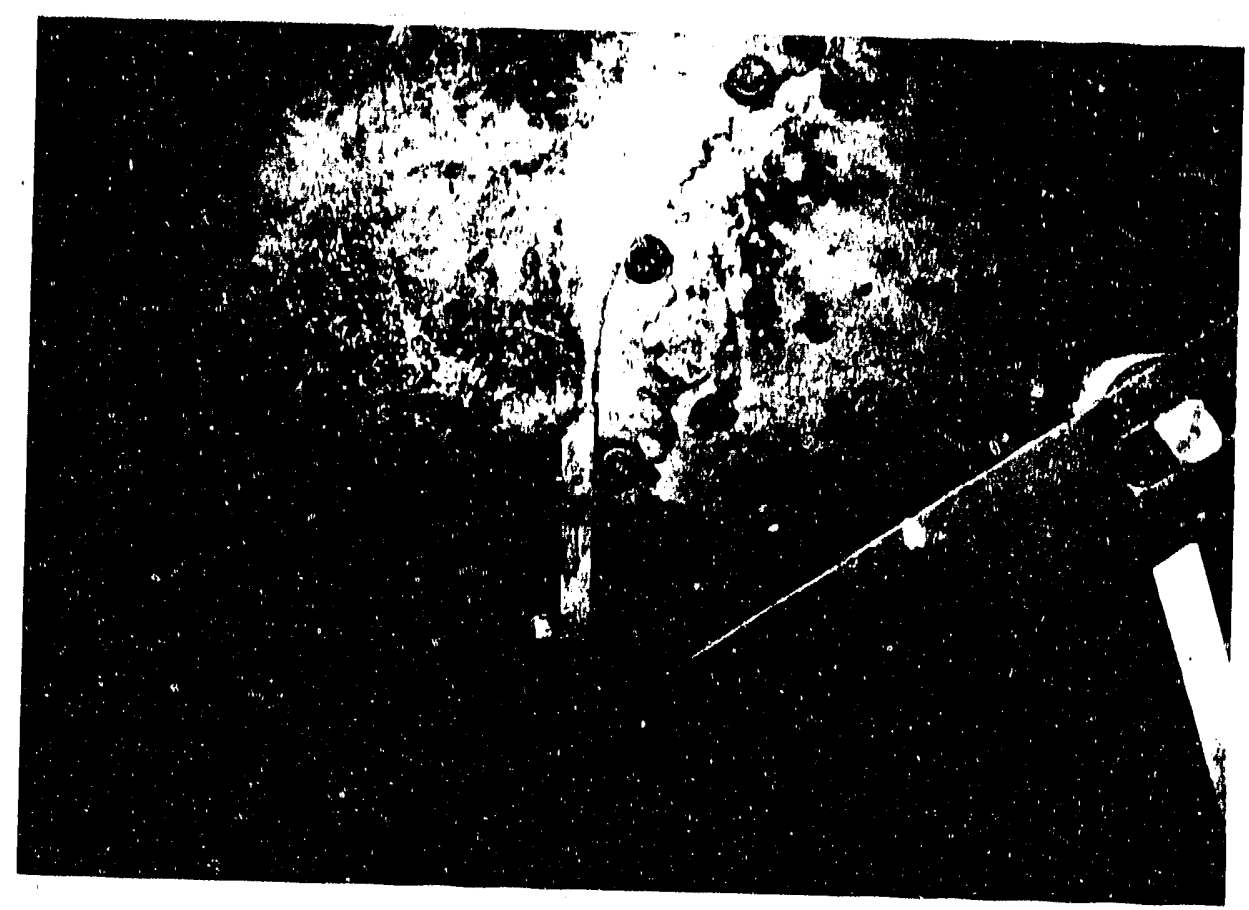
Figure 26: Photograph at Stripper Bar on Wheel of Smal1
Wheel Caster

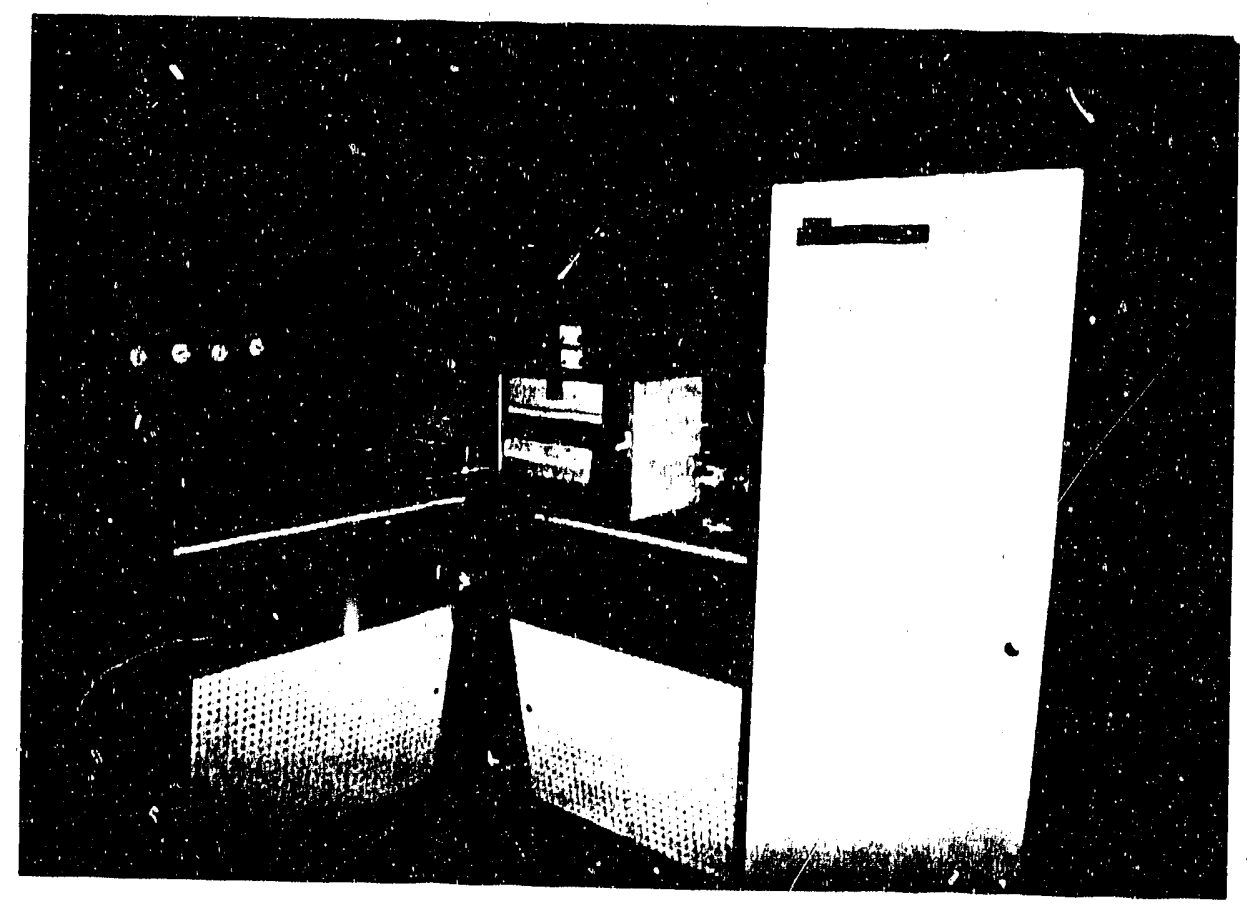

Figure 27: Photograph at Control Station of Smal1 Wheel Caster 
steelmaking and slag practices were modified only slightly during this phase as most of the practices for achieving chemistry and temperature control for silicon killed steel were well established in the earlier program. A photograph of one of the furnaces in tapping position is shown in' Figure 28.

The basic pouring box design is displayed in Figure 29. Most of the box was lined with $\mathrm{K}-\mathrm{Brj}$ ok with some higher quality silica brick in high wear areas. The flow control dam was ohanged to a high alumina refractory to improve wear resistance. Mortartily procedures were improved and by the end of the casting program the pouring boxes were often reusable for two or three casts.

A video camera was positioned to view directly down onto the melt pool to record the pool and the strip formation during the cast. Another cainera was positioned to record the overall view of the strip forming, exiting the wheel and being collected by strip catchers.

\section{Melt Overflow Experimental plan}

sixty-one melt overflow casts were made on the small wheel caster in this phase of the casting program. The task was divided into three parts as shown below: 


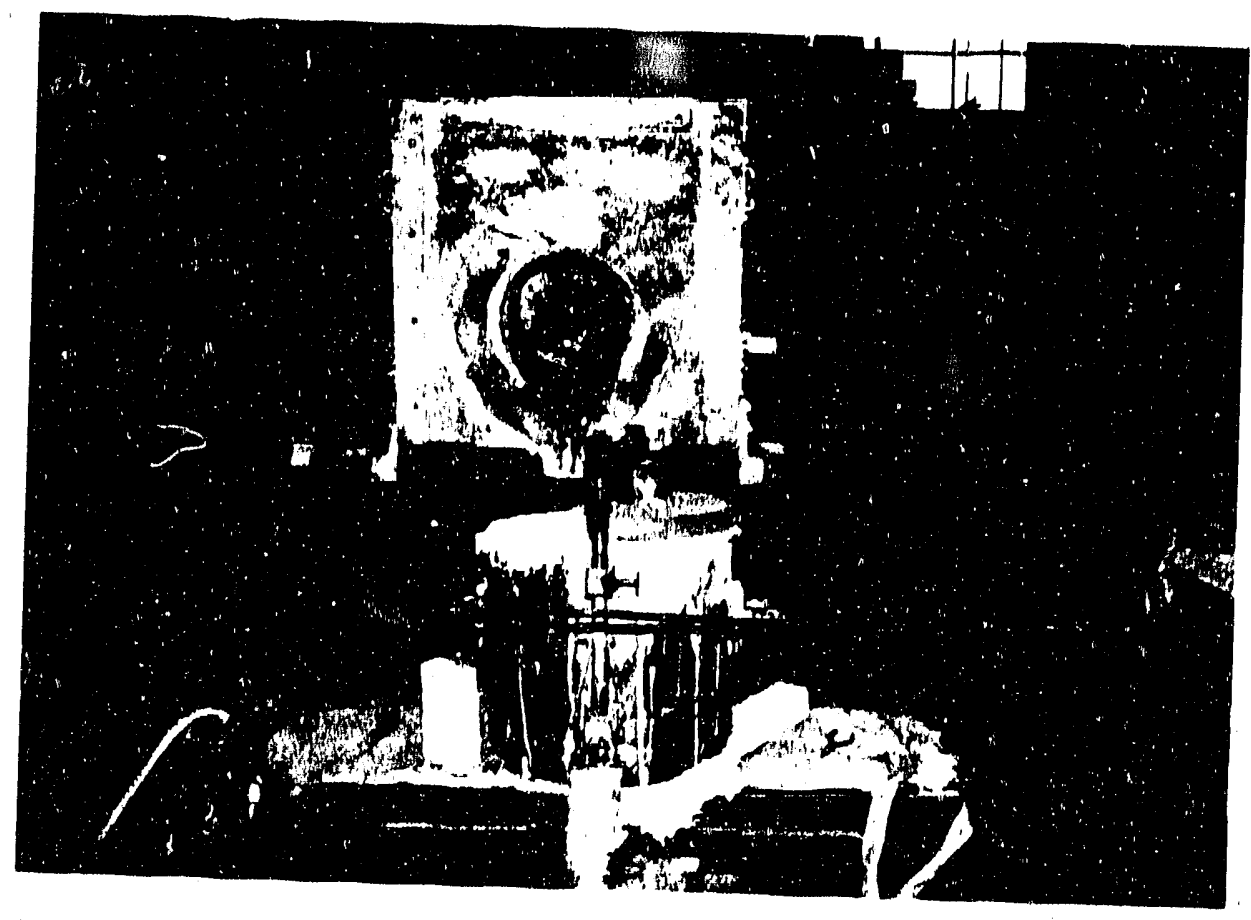

Figure 28; Photograph of Furnace and Ladle in Tapping Position 


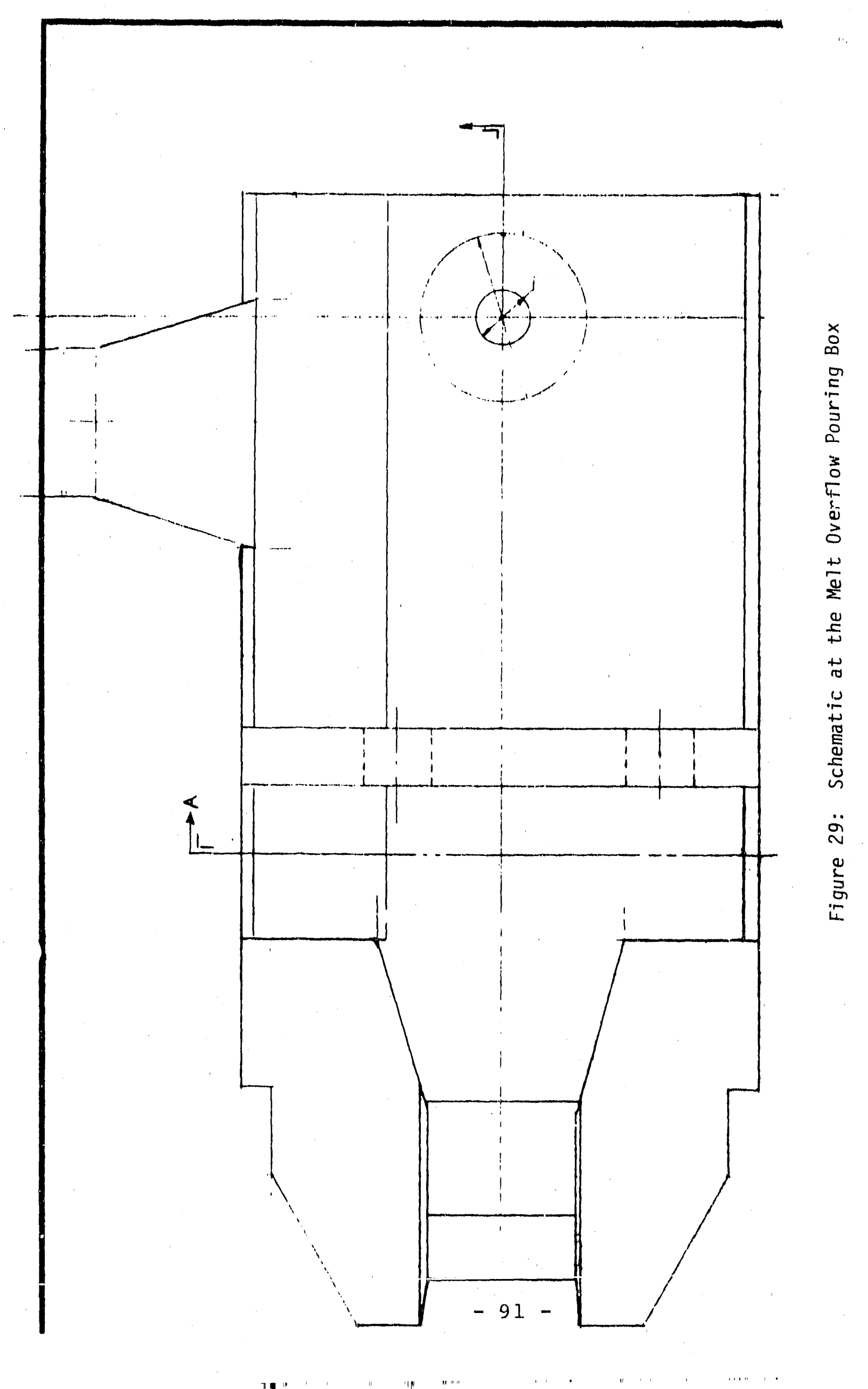


part of Task No. of Casts

1. Set up 11

2. Substrate

3. Improvement
20

30

\section{Purpose}

Establish the technology for the casting variables that remalned relatively unchanged during the program.

Test the effects of various casting substrates and substrate preparation.

Vary casting parameters to improve strip quality and thickness.

A summary of all of the casting trials is included in Appendix III whlch includes a definition of the casting terms.

\section{set Up Trials}

The basic casting non-variables were established in this part of the casting program and the results are summarized below. The copper wheel was used as the substrate for all of these trials.

Top shrouding of melt pool - Argon, nitrogen and no shrouding were tried in the vicinity of the melt pool. As the shrouding technique was not very sophisticated, little difference was seen in the scale blanket or top surface quality of the resulting strip. Argon was used in all of the substrate and improvement trials.

Bottom purging gas - Ignited carbon monoxide, argon and no gas were tried as the purge gas below the melt pool, intended to prevent air aspiration below the solidifying strip. Generaliy, little 
difference was found in the strip bottom quality during the trials. Carbon monoxide was selected as the bottom purge gas for subsequent trials.

Casting nozzle refractory - Alumina graphite, Na 33, and fused silia were tried as nozzle refractories during the set up trials. Fused silica was found superior to the others in integrity with silicon killed steel and was used at the start of the substrate trials. This refractory was subsequently changed and improved during the improvement trials.

Casting nozzle position - During the set-up trials, two casting positions were tried $-45^{\circ}$ and $60^{\circ}$ BTDC relative to the bottom $11 \mathrm{p}$ of the nozzle. The position $60^{\circ}$ BTDC was found to give more consistent control of the process and strip exiting the wheel. This casting position was used during all subsequent trials.

Preheating practices - Most of these practices for both the ladle and pouring box were already established during the Phase II casting program. A preheater was added for the front of the casting nozzle and assisted in all high and low head casting nozzle experiments during the improvement trials. It was necessary to check the flame of the preheaters periodically to avold generating a too oxidizing flame which often caused premature refractory deterioration.

Operating practices - Critical operating practices during ladle transfer, casting, abort, and strip withdrawing were established 
during the set up trials although many of these parameters were modified during the improvement trials.

Fater cooling - A method was developed to introduce hot water cooling to the wheel at the start of those trials in which the dew point exceeded the temperature of the cooling water. This prevented condensation of moisture onto the wheel prior to casting.

\section{substrate Trials are described in Task 2.0.}

\section{Improvement Trials}

During the improvement trial phase of this research, numerous changes were made to the casting process. Several different nozzle refractories were tried including fused silica, vision brick (zirconia + alumina + silica) and isostatically pressed zirconia. Improvements were made to gap control between the casting nozzle and wheel and also the stability of the casting system during preheat and casting. Computer data collection was improved and general casting procedures adjusted. Experiments were conducted on defining relationships between casting speed, melt pool depth, and strip thickness. Some improvements were made to substrate preparation and conditioning during the cast. steel temperature was increased and better controlled during the wst.

Several important problems were identified during the set up and substrate trizls that had to be attacked during the improvement trials. The most salient of these and the pertinent sclutions are described below. 
1. Freeze ups at the nozzle/wheel interface, particularly at start of the cast: This problem was multi-faceted and several changes were required to minimize the problem. As described earlier, a method was developed to add hot cooling water to the wheel at the start of cast. This eliminated condensation on the substrate when the humidity was high. Another contribution to freezing appeared to be the substrate surface preparation. A consistent practice was developed to finish the copper wheel with 80 grit sand paper just prior to casting. The combination of these changes eliminated the freeze ups at the start of cast.

Freeze-up during casts of high head nozzles: During the cast, freeze ups were experienced with high head nozzles made from Vision brick. These refractories have a fairly high thermal conductivity and low heat capacity (high thermal diffusivity) compared to other high quality refractories such as fused silica, zirconia, and alumina. It appears that the refractory will heat up fairly quickly but does not retain heat. As the cast proceeds, the refractory passes its heat to the cold copper whee? and the junction at the wheel/steel/nozzle becomes colder until after about 25 seconds, a dam of frozen metal forms which rapidly grows across the nozzle until the full freeze up occurs.

Improvements to the flow of steel to create a turbulent flow pattern in the melt pool at the wheel also appears to reduce 
the potential for freeze ups both at the start of cast and later into the cast.

2. Poor level control of the melt pool contributing to poor steel quality: This problem was a critical contributor to mediocre strip top surface quality and sometimes strip edge curling. The problem was reduced by improving operating procedures for metal pouring and by making design changes to the pouring box so that the overflow port was properly fositioned to control the melt level at a constant position. A monitor was positioned next to the ladle operator so that he could continuously view the melt pool level and throttle the flow to maintain the desired pool depth.

3. Leakage under the wings of the refractory casting nozzle. This problem was especially prevalent when using fused silica nozzles. It appeared to be related to the use of low thermal conductivity, high thermal capacity (low thermal diffusivity) refractories and to inadequate control of the nozzle to wheel gap. The riost important changes that decreased these problems were related to the gap control. New pouring boxes were constructed from thicker steel plate and reinforcement of the nozzle was improved; this reduced the movement of the box refractory and nozzle during preheat and casting. The structure supporting the ladle and pouring box was structurally reinforced to inhibit movement during preheating and casting. Gap control techniques were developed that automatically measured the gap between the nozzle and wheel during casting 
and signaled the operator to adjust the position of the wheel to maintain a constant gap. The refractory nozzle was changed to isostatically pressed zirconia which is non-wetting for steels and thus was less susceptible to steel leakage under the nozzle wings.

4. Temperature loss in the steel during casting leading to freeze up in the nozzle: Time and budget did not allow implementation of a method of heating the steel in the pouring box during casting. Therefore, it was necessary to improve the preheaters to minimize temperature loss from the steel during casting. The steel transfer temperature in the ladle was also gradually increased from $2930^{\circ}$ to $2980^{\circ} \mathrm{F}$ during the improvement trials, as the caster was made more stable and the gap control procedures implemented. All of these procedures led to longer casts $w_{+}$th better quality strip. The temperature variation during casting for four heats is plotted in Figure 30 .

5. Strip top surface holes, ripples, and coarse texture: Significant improvements in strip top surface quality were made during the improvement trials. A comparison of the strip from the set up trials and the improvement trials is shown in Figure 31. This was achieved by implementing many of the technologies described above that abetted the overall control of the prociss and the gap between the nozzle and wheel. Modifications to the liquid flow in the pouring box and in the melt pool had a major impact. Problems still exist with accumulated scum in the melt pool, which is incorporated into the stip on the top surface. 
Figure 30

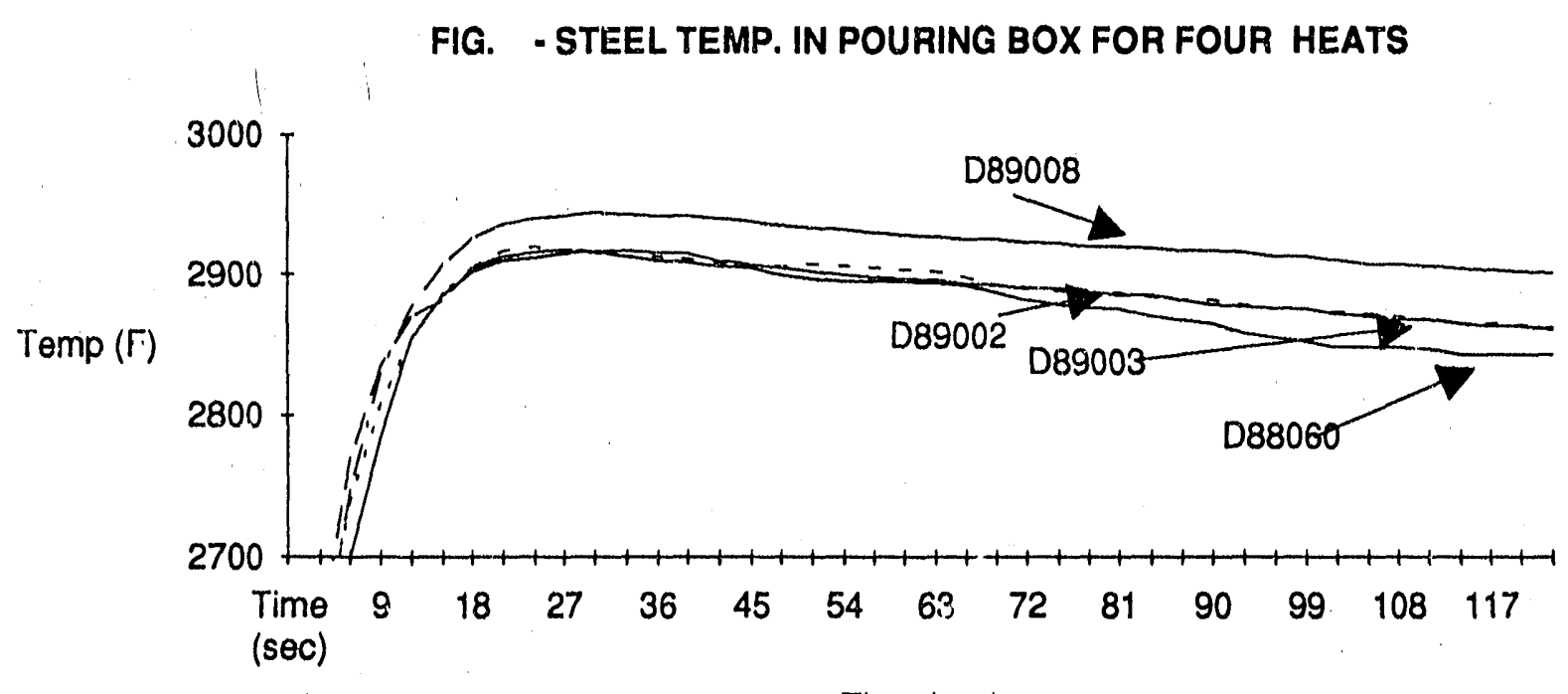

Time (sec) 
Improved inert gas shrouding in the vicinity of the melt pool should alleviate this problem.

6. Noticeable deterioration of the strip quality during the cast: This problem was related to the formation of the black, oxide film on the casting wheel during the cast as described in the substrate trials. The solution was to use abrasive flapper dressing wheels (shown in Figure 32) to continuously restore the substrate surface to near original conditions while casting. The dressing wheels rotated counter to the rotation of the casting wheel and were brought to position by an air cylinder at the start of cast.

7. The cast strip often had ripply and torn edges: The gap control improvement played a role in improving edge quality. Also, the correct design of the vertical taper in the nozzle was essential for improved edges; too great a taper was very deleterious.

\section{"Go/No Goll Decision Trials}

Between December 14, 1988 and January 9, 1989, five consecutive trial heats were cast to meet the criteria that had been established to continue the project into the next phase. The criteria that had been agreed to by Armco and the D.O.E. were as follows: 


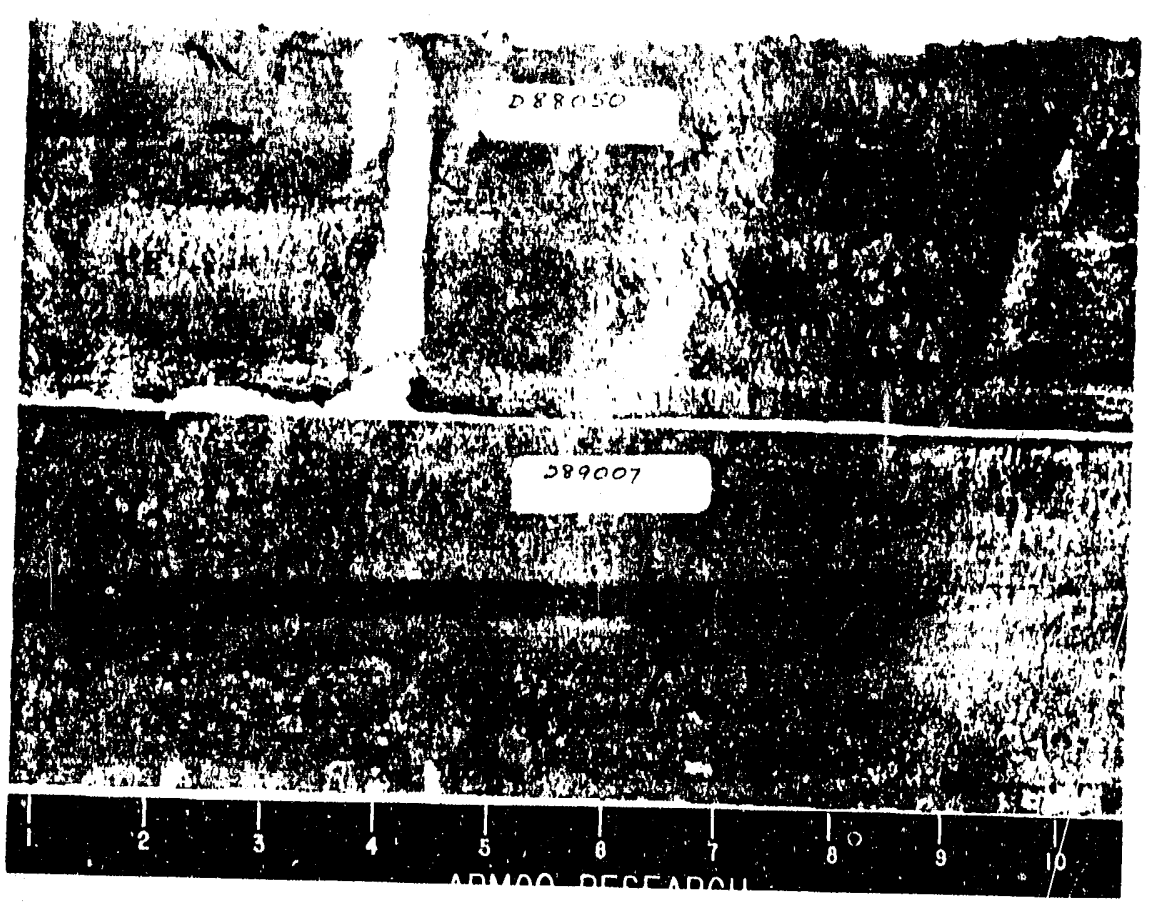

Figure 31: Photograph of Cast Strip at Start of Program (above) and after Improvement Trials (below)

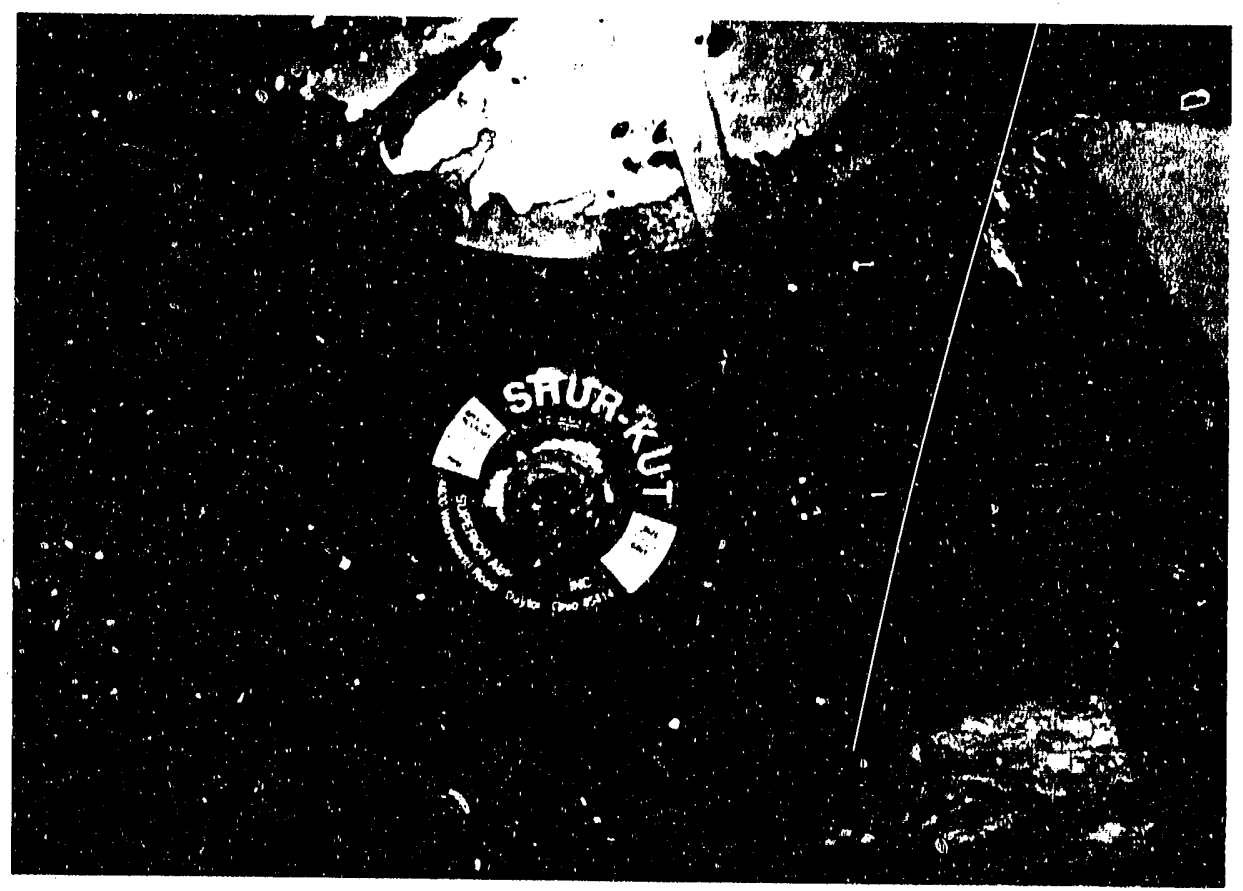

Figure 32: Photograph of Dressing Wheel in Position on Small Wheel Caster 


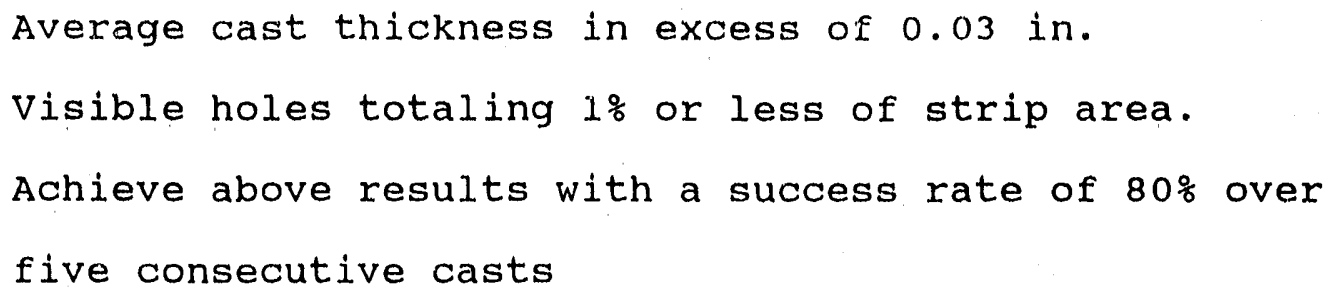

A summary of the results of the five casts is shown in Table VIII. It was difficult on all of these trials to cast more than 200 lbs. Of the 450 lb. heats before the temperature of the steel in the pouring box became too low and freeze-up occurred in the nozzle. A commercial caster using this technology will almost surely need a method of maintaining the steel at a fairly constant temperature in the pouring box.

The strip quality produced on these five trials was in general, quite excellent. Virtually no holes could be found in any of the strip produced in these trials and the strip was generally free of transverse or longitudinal cracks. Some tearing at the edges was experienced. This was probably due to setting too steep a vertical taper in the casting nozzle.

Much of the strip was a bit less than the desired .030" thickness although subsequent trials produced strip in the .033-.035" thickness range. In order to produce thicker strip, it is necessary to elther reduce the wheel speed or increase the contact length of the melt pool with the casting substrate. Speed reduction below 100 FPM was unsteady because the motor drive and DC controller produced unstable rotation. It was not possible to modify these controls within the time and budget of the project. 
Increasing the contact length of the melt pool with the wheel was impossible because the required zirconia nozzle refractories were unavailable. Therefore, it was necessary to use nozzles that restricted the maximum head in the melt pool to $1.25 \mathrm{in.}$. This was not sufficient to consistently produce .030 in. thick strip at the high wheel speeds imposed by limits of the controller.

\section{Description of the strip}

The strip produced during the go/no go decision trials and subsequent trials were evaluated in a fairly cursory manner because the funding for extensive product evaluation was to be part of the next phase. Nevertheless, a limited study was made of some of the strip.

\section{TABLE VIII}

\section{TRIALS FOR "GO/NO GO" Criteria}

\begin{tabular}{lcccccc} 
Heat No. & Date & $\begin{array}{c}\text { Length } \\
\text { of Run } \\
\text { (Sec.) }\end{array}$ & $\begin{array}{c}\text { Amount } \\
\text { of Strip } \\
\text { (ft.) }\end{array}$ & $\begin{array}{c}\text { Thickness } \\
\text { (in.) }\end{array}$ & Head \\
\cline { 1 - 3 } D88059 & $12 / 14 / 88$ & 200 & & 480 & $.021-.028$ & 1.25 \\
D88060 & $12 / 16 / 88$ & 252 & 554 & $.022-.028$ & 1.25 \\
D89001 & $1 / 4 / 89$ & 165 & 289 & $.023-.035$ & 1.25 \\
D89002 & $1 / 5 / 89$ & 120 & 250 & $.021-.025$ & 1.25 \\
D89003 & $1 / 9 / 89$ & 228 & 570 & $.020-.021$ & 1.25 \\
D89006 & $1 / 20 / 89$ & 29 & 75 & $.033-.035$ & 2.75
\end{tabular}

A typical piece of strip is shown in the photograph in Figure 33. Directly off the caster, the strip had an oxide layer on both sides that had a directional build-up. The edges showed a degree of curling that become more pronounced at higher heads in the melt pool. After casting, the strip was flattened (but not rolled) in a 
set of rolls and the scale was removed by a bead blaster. The appearance of the top and bottom sides of this strip is shown in the photographs in Figure 34. Both sides displayed very attractive surfaces, free of transverse and longitudinal cracking. The bottom surface was extremely flat and smooth while the top surface was also quite smooth, generally free of the puckered and ripply appearance of strip cast earlier in the program.

A small amount of strip was cold rolled $30 \%$ and this strip is shown in Figure 35. The strip rolled easily and no internal cracking was revealed as tears did not develop. A few pieces of the cold rolled strip was tested by the cup test and photographs of these test pleces are provided in Figure 36. The test values were very good for silicon killed steel of this chemistry and gauge in comparison to commercially available silicon steels.

\subsection{Task 3.2 Planar Flow Casting}

\section{Large Wheel Modifications}

PROBLEMS: At the conclusion of the previous series of trials on the large wheel caster, several problems had been were noted in the wheel operation, which is shown in Fig. 37. The leakage of cooling water past the face seals had steadily increased to the point where there was doubt about the ability to maintain a dry substrate surface; Large amounts of rust were being generated in the water; Permatex sealant was oozing between the copper shims and the steel supporting wheels. A schematic of the casting wheel system is displayed in Fig. 38 . 


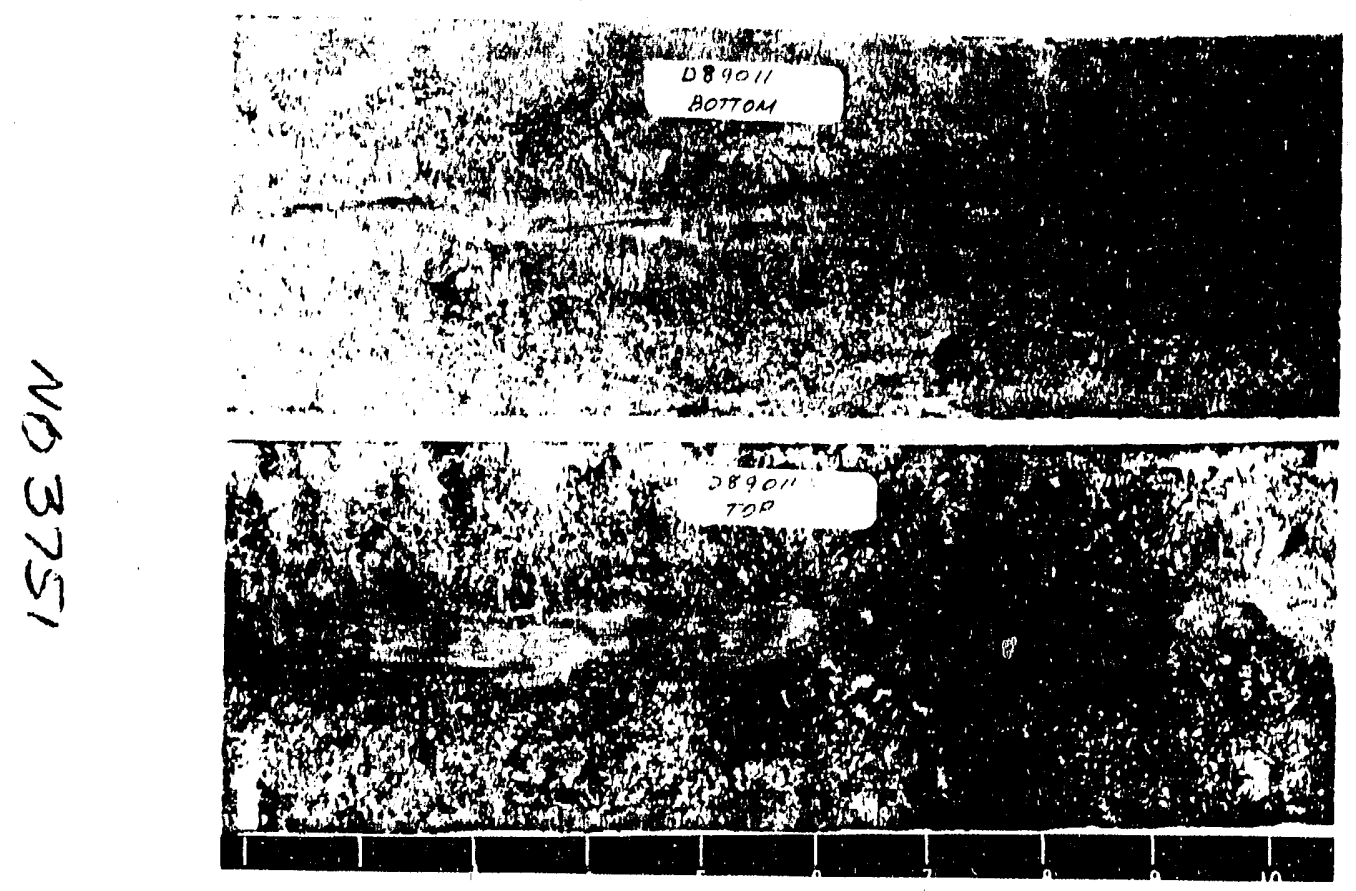

Figure 33: Photograph of Cast Strip Top and Bottom from Satisfactory

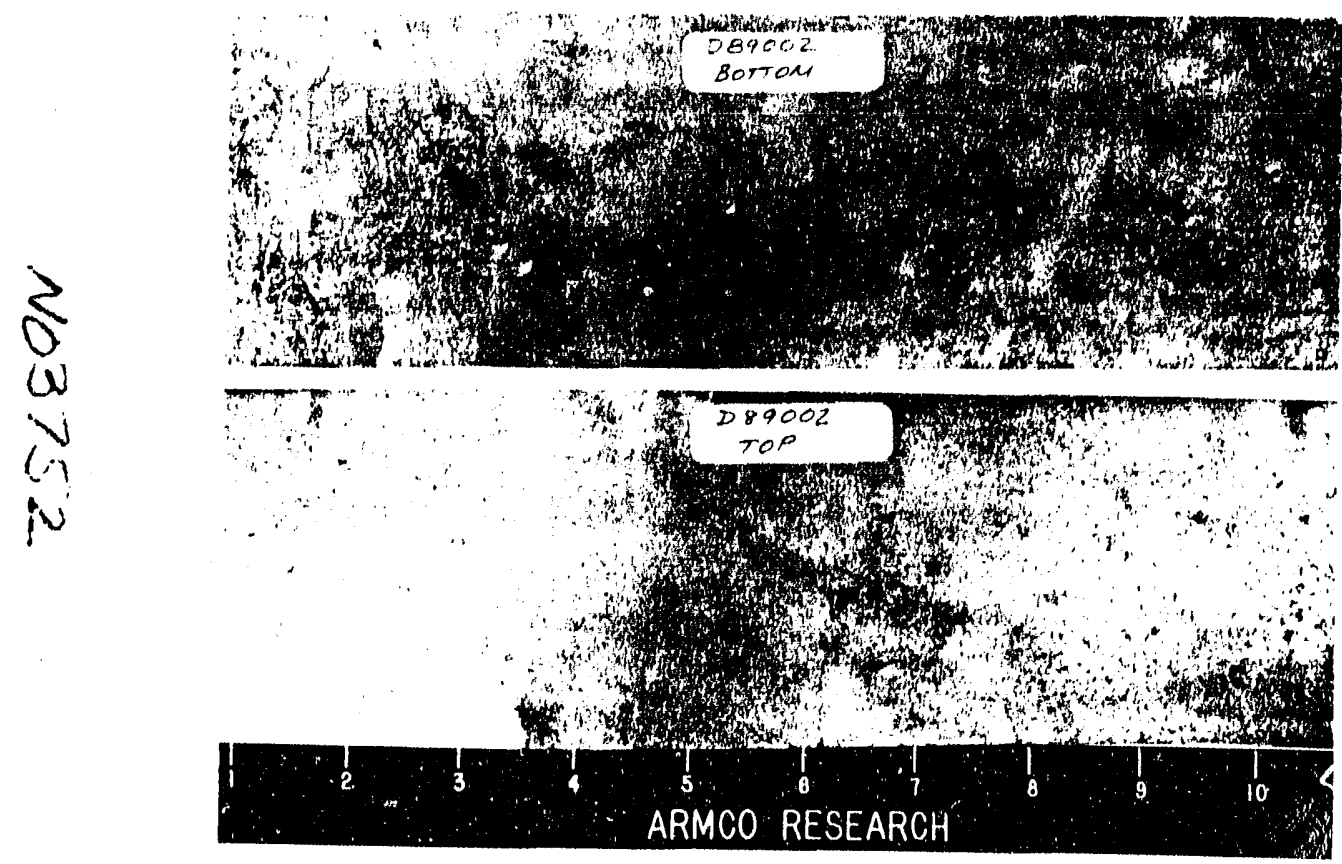

Figure 34: Photograph of Bead Blasted Cast Strip Top and Bottom from go/no go Trial Heat 


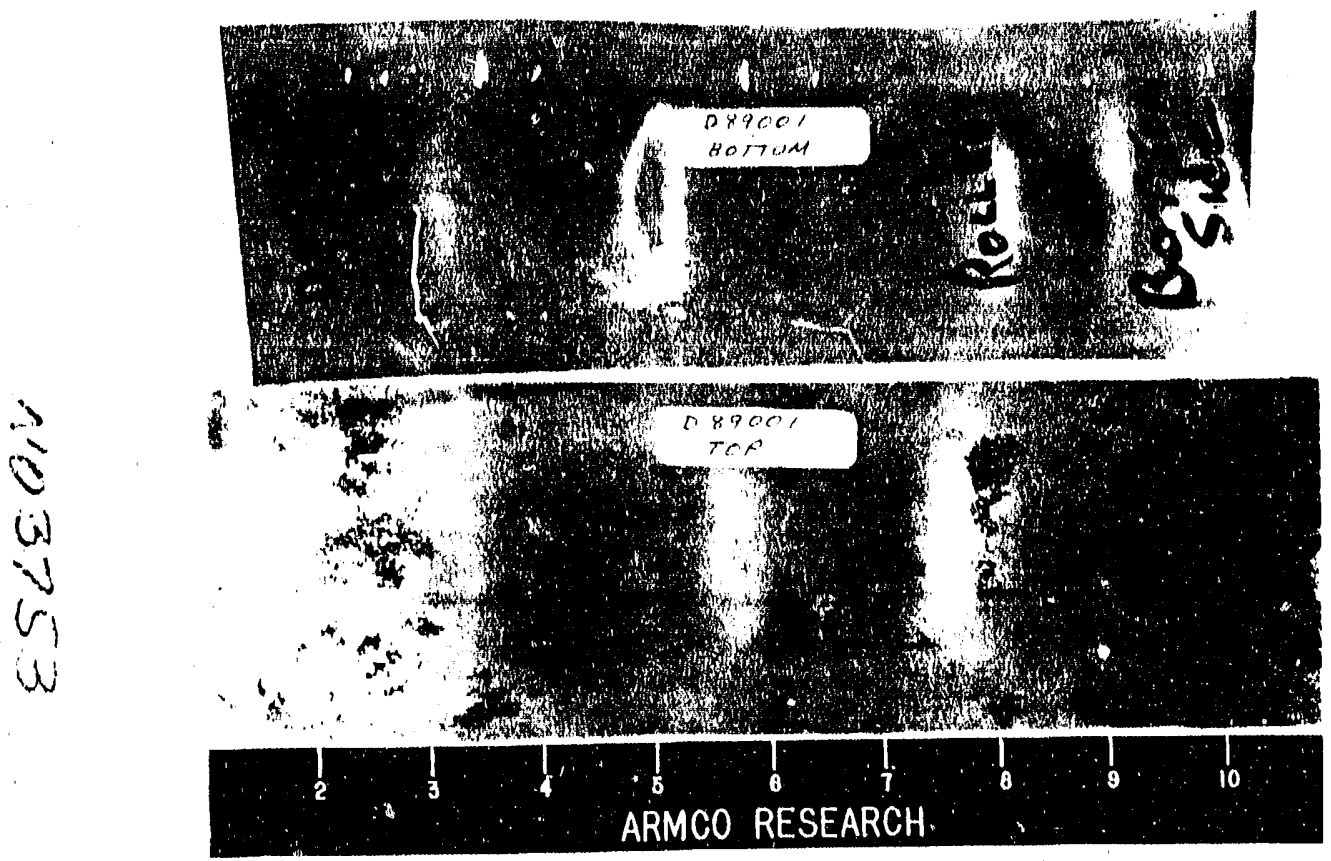

Figure 35: Photograph of Rolled Strip (35\%) from go/no go Decision Trial Heat

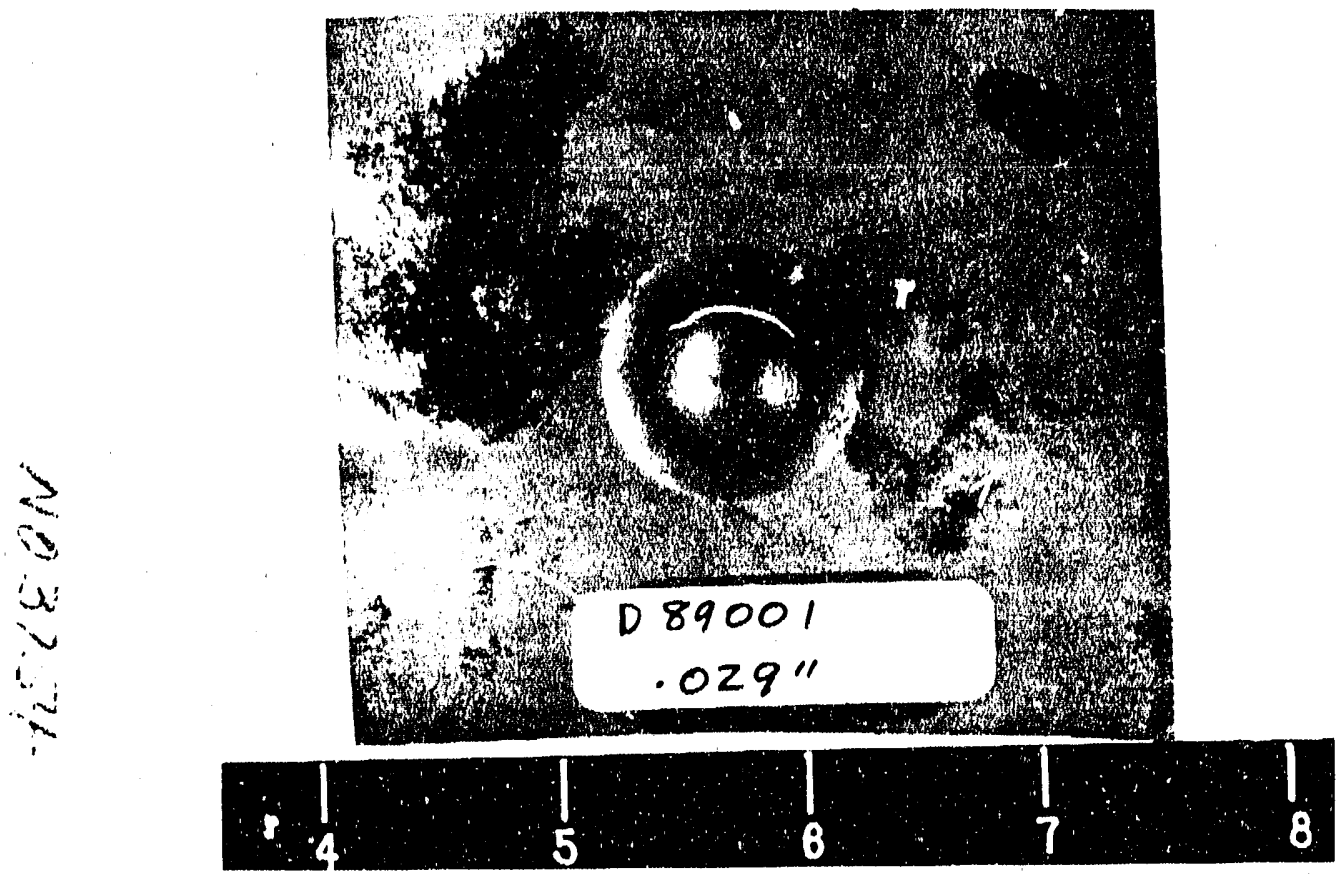

Figure 36: Photograph of Successful Cup Test from go/no go Trial Heat 


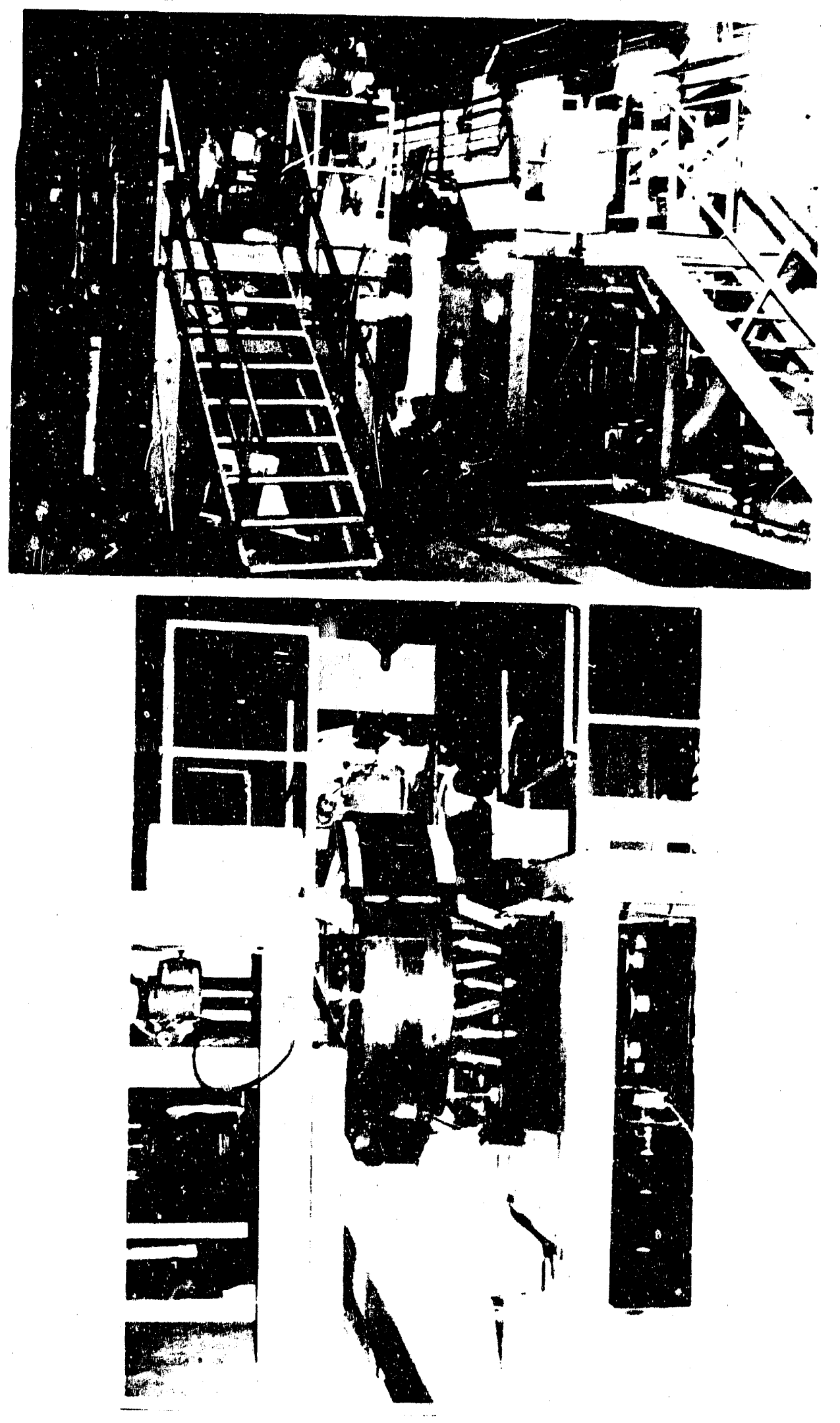

Figure 37 - Cork platiorms cocated on each side of casting wheel. 

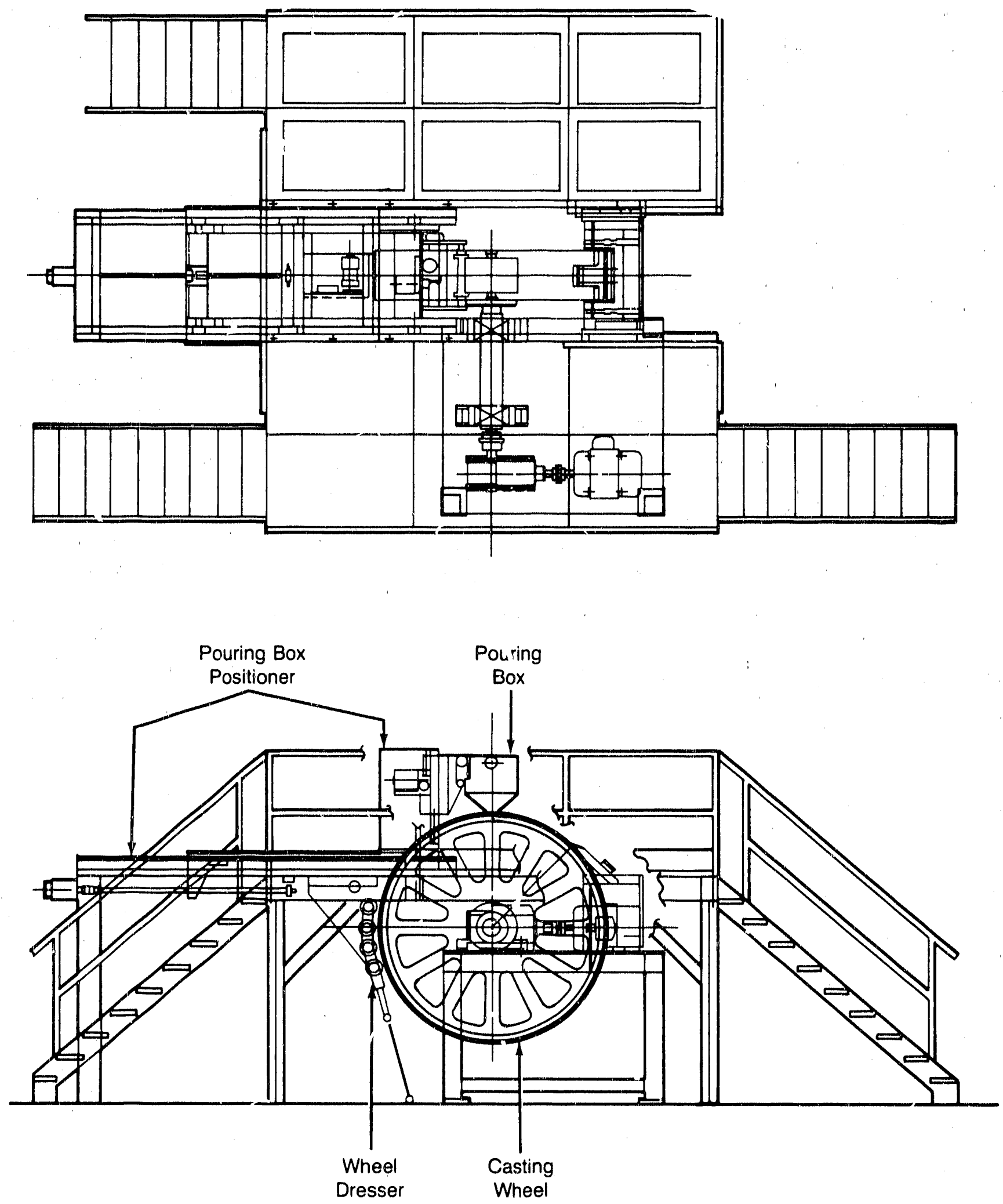

Figure 38

Schematic of casting wheel system, pouring box system and working platforms. 
The leakage problem was attributed to several factors:

- Poor o-ring groove design allowing o-ring to slip out of its groove and weaken the seal.

- The joint between halves of seal rings sealed poorly resulting in major 'squirting' leaks.

- Teakage between seal grooves at the joints resulted in poor control over the seal activation pressure.

- Excessive run-out between the stationary inner wheel and the outer wheel, requiring large movement of the seals to follow the running face.

- Contact between running face and seal ring resulted in smearing of metal in places which locked the seals.

- Machined steel running face susceptible to rust and wear.

- Inadequate drainage from the low pressure gap between the second and third seals, gap too narrow to allow adequate accumulation of pressure.

- Handling of leakage inadequate, no sump.

Other areas needing improvement were the carriage control mechanism and the water temperature sensing. The carriage control was separated into $x$-axis, with no computer control or sensing, and $y$-axis which was totally under computer control. This limited the movements between preheat and cast to simple $x$-axis motion. Also, 
the wheel growth compensation could only be in the $y$-axis and not perpendicular to the surface as might be desired. The combination of the Type $J$ thermocouples and the MMAC interface resulted in poor resolution of the water temperature $\left(+-.75^{\circ} \mathrm{C}\right)$.

solutrons: Replacement one-piece saal rings were designed and ordered. The new rings included a land between the first and second seals to prevent contact with the running face near a seal groove. An accumulating groove was added between the second and third grooves for equalization of the drain pressure. Additional drain ports were added and the manifold blocks were completely redesigned to provide larger feedthroughs for air pressure and water. True o-ring grooves were machined into the slots.

The steel wheel and outer support ring were nickel plated after the running faces were remachined. The mating surface to the inner hub was remachined to be true to the shaft $\left(90^{\circ}\right)$. o-rings were added to seal between the copper wheel and the steel wheels. The input manifold to the third cooling shoe was removed (aeactivating this cooling zone) and the aluminum shroud originally attached to the stationary wheel was attached to the rotating outer support wheel. A large sump was thus formed, into which two auxiliary pumps were placed. The suction manifolding was improved and the squeegee (last line of defense) was improved and made activated by an air cylinder.

The Type J thermocouples were replaced with RTDs with 4-20 ma transmitters, which improved resolution to $.1^{\circ} \mathrm{C}$. The carriage 
control was switched to one two axis controller interfaced to the computer. The control software was modified to allow multi axis movement. The water flow valves were switched to automatic control so that flow rate could be specified directly. Numerous other small improvements were implemented.

\section{As8EMBLY: There were problems with vendor delivery and} accuracy which resulted in several months delay. After assembly, leakage problems occurred because the seal to running face gap was too large and the anti-rotation pins in the seals were inadequately engaged. The wheel was reassembled starting with a careful alignment of the rotating wheel to the shaft at the machine vendor's location to minimize runout. The seals themselves were machined to reduce the amount of gap at the segment joints. Finally, improved anti-rotation pins were inserted.

After reassembly, the seal to running face gap was too narrow. Contact between the two members resulted in damage to the seal and running face plating. The wheel was disassembled and a gasket removed to increase the overall gap. Also, a solid shim was inserted on the shaft to fix the position of the stationary wheel.

After the third assembly, the wheel was declared operational. Operation during all the PFC trials was good. The only water problem currently observed is a very slight seepage between the copper and steel members at the high water flow conditions. This is probably due to a flattened spot on the o-ring and should not 
degrade further. It is not a large problem and does not inhibit casting.

Other changes made to the large wheel during tue PFC trials include the addition of the abrasive flapper brushes for surface dressing and a modification to the carriage assembly to allow operation further from top-dead-certer of the wheel. A four bumper gap sensor and associated indica or box were also added. Finally, the control software was modified to improve the operator interface to the carriage position system.

PLANAR FLOW CABTING (PFC) EXPERIMENTS: The purpose of this subtask was to establish the suitability of planar flow casting as a candidate for further developmental work in the second phase of this program. The approach was to use insights gained in the water modeling (Task 1.1) and substrate studies (Task 2.0) to select PFC parameters most likely to produce strip in the desired thickness range of .030 to $.040 \mathrm{in}$. The results of the first two attempts were discouraging. These yielded a 'pile of chips' similar to those produced by previous PFC heats. A third attempt, using a modified technique which is called Planar Drag Casting, successfully produced continuous strip .035 to $.040 \mathrm{in}$. thick, 3 in. wide, without holes and fair surface quality. As the name implies, this modified technique combines some aspects of the PFC and the melt drag (or overflow) processes. 
In summary, continued development of the pure PFC approach as had been practiced does not appear to offer hope of near term success. However, a combination of the planar flow and open channel casting technique does look very promising.

Trial \# D88043: The parameters for the initial trial was taken from water modeling and substrate trials, with the exception that the casting angle on the wheel was $25^{\circ}$ rather than $45^{\circ}$ because the large angle would have required major modifications to the pouring box and carriage. Another point concerns the substrate condition. As lack of adhesion had been a major problem for the previous PFC trials, a roughness of around $80 \mu \mathrm{in}$. was desired, greater than the $50 \mathrm{\mu}$ in. routinely used on the small wheel open channel cast, in order to increase sticking. In fact, due to the presence of grooves remaining on the substrate after the final PFC of the previous program, the measured roughness was in the range of 112 to $125 \mu$ in. Table IX gives the casting parameters for all three PFC trials.

The cast produced a pile of .040 to .050 in. chips. The strip broke as it came around the wheel to the position where it became subject to tension due to gravity. It clearly had very little strength and was thought to be partially molten. The video close-up record of the flow from the casting nozzle from two angles showed the flow exiting the nozzle was not ideal. Either the edges were folded over, or pinched and roped at the edge. This of course would lead to poor strip formation. 

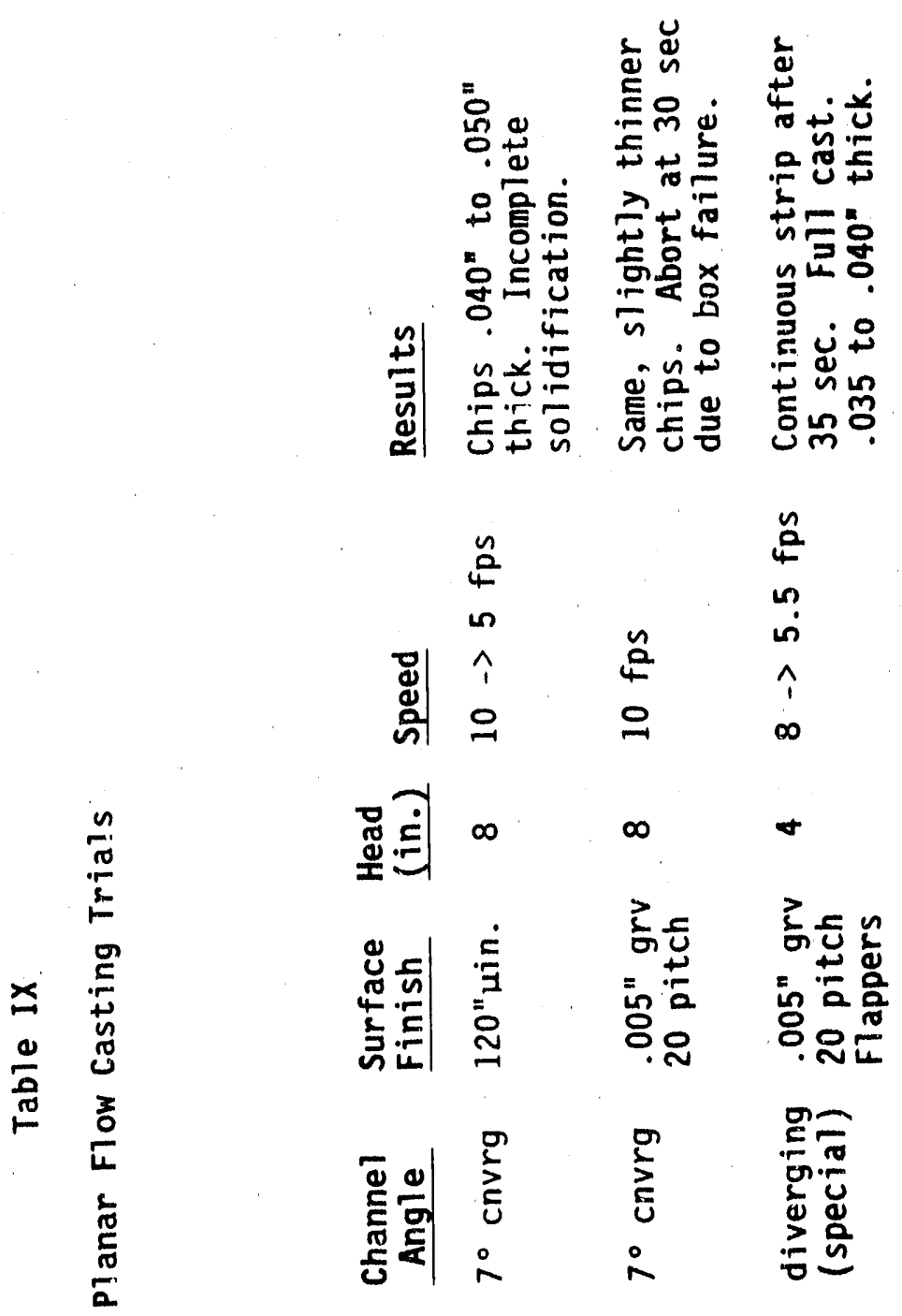

4

물 년

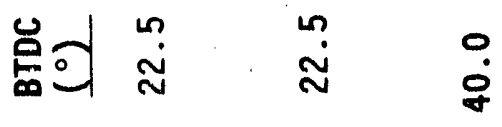

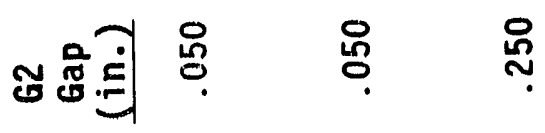

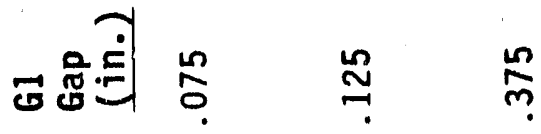

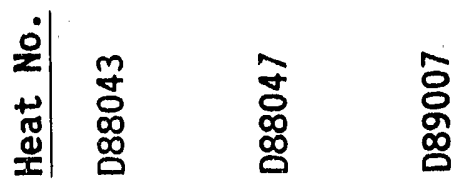


Trial D88047: The second trial followed the direction of the first trial; the substrate was significantly roughened using .005 in. grooves on a 20 pitch, and the primary nozzle was opened to increase the ratio of $\mathrm{Gl}$ to $\mathrm{G} 2$. The pouring box metal head height, initially $8 \mathrm{in}$. for the previous heat, was intended to be lowared during the cast if no continuous strip was produced, in order to decrease the cast thickness.

The results were very similar to the first trial. The flow was perhaps a bit better, but still rather unstable. No continuous strip was produced, only chips. Unfortunately, before any adjustments in wheel speed or head could be made, a leak developed between the nozzle and the pouring box, resulting in an abort after 30 seconds.

Trial D89007: At this point, it was decided to make a major change in casting parameters. A new pouring box was constructed and modifications to the carriage made to allow casting near $45^{\circ}$ BTDC of the large wheel. The new box included changes in the nozzle to incorporate some of the melt overflow process.

Further analysis of the substrate study results suggested that the poor adhesion observed on the second PFC trial, as compared to the catastrophic adhesion during small wheel casts with the same surface conditions, could have been caused by overcooling; this lowered the terminal outer rim temperature to a point where adhesion was inadequate. Accordingly, the cooling flow for all three active cooling zones was reduced to $60 \mathrm{gpm}$. This represented 
a factor of 10 reduction for zones 1 and 2 , and a fotor of 5 for zone 4. The primary factor determining heat transfer to the water at the inside rim surface is the water velocity. The average velocity is determined by the volumetric flow rate divided by the area of cross section. Each cooling shoe has approximately 400 $1 / 8$ in. orifice nozzles which roughly equal the $1 / 8$ in. by 14 in. diameter of the small wheel cooling channel in total crossectional area. Thus, maintaining the same water flow through each cooling shoe as through the small wheel caster (1.e., $60 \mathrm{gpm}$ ), should result in a similar heat transfer at the inner rim and thus similar outer rim temperatures would result for equal rim thickness.

As a final major change, an abrasive flapper dressing wheel was added to the large wheel in order to remove the black oxide formed during the cast. 80 grit paper was used as with the small wheel caster. This undoubtedly improved the heat transfer as had been observed on the small wheel trials.

The results were most encouraging. Initially, strip was pulled from the pool and broke periodically under gravity as it came around TDC. After about 35 seconds, as the speed was reduced from 8 to $7 \mathrm{fps}$, the strip started to hold together so that it could be hooked and dragged away. Strip was produced continuously for about 2 minutes, until the ladle was emptied. Strip thickness was between .035 and $.040 \mathrm{in}$. as measured by the point micrometers. The surface was heavily oxidized. This was to be expected, as the thick strip retained heat for a relutively long time after casting. The surface was also somewhat lumpy. It was observed on the nozzle 
close-up video that a certain amount of turbulence was created on the top of the pool due to filling and refilling as the melt level was adjusted by the operator. Also, large floating masses were observed on the pool. These were probably oxides formed either from contact with the air or evolved from the melt. These masses at times had an adverse effect on the flow. overall, however, the flow from the nozzle was very even and quiet, the best ever observed on a large wheel cast.

ANALYSIS OF DATA: Fig. 39 and 40 show plots of some of the recorded parameters for trial D88043 and D89007 respectively. Note the similarity in the overall cast times and wheel speeds, but the drastic difference in the amount of temperature rise in the cooling water and in the amount of wheel expansion measured by the gap sensor. This is due to the severe reduction in cooling water flow from nearly $1500 \mathrm{gpm}$ to $180 \mathrm{gpm}$, which caused the water to heat more and the average temperature of the wheel to increase.

For trial D88043, the flow through shoe \#1 was $600 \mathrm{gpm}$, with a change in water temperature of .86 F. This computes to about $258000 \mathrm{BTU} / \mathrm{hr}$ of heat extraction. The corresponding figures of shoes \#2 and \#4 (\#3 being inactive) yield 436000 and $41000 \mathrm{BTU} / \mathrm{hr}$ respectively. Thus, the overall heat extraction rate was 735000 $\mathrm{BTU} / \mathrm{hr}$ or roughly $102 \mathrm{BTU} / 1 \mathrm{~b}$ when averaged over the $200 \mathrm{sec}$ cast of $400 \mathrm{lb}$ of metal. This is close to the $110 \mathrm{BTU} / \mathrm{lb}$ heat of fusion for steel. 


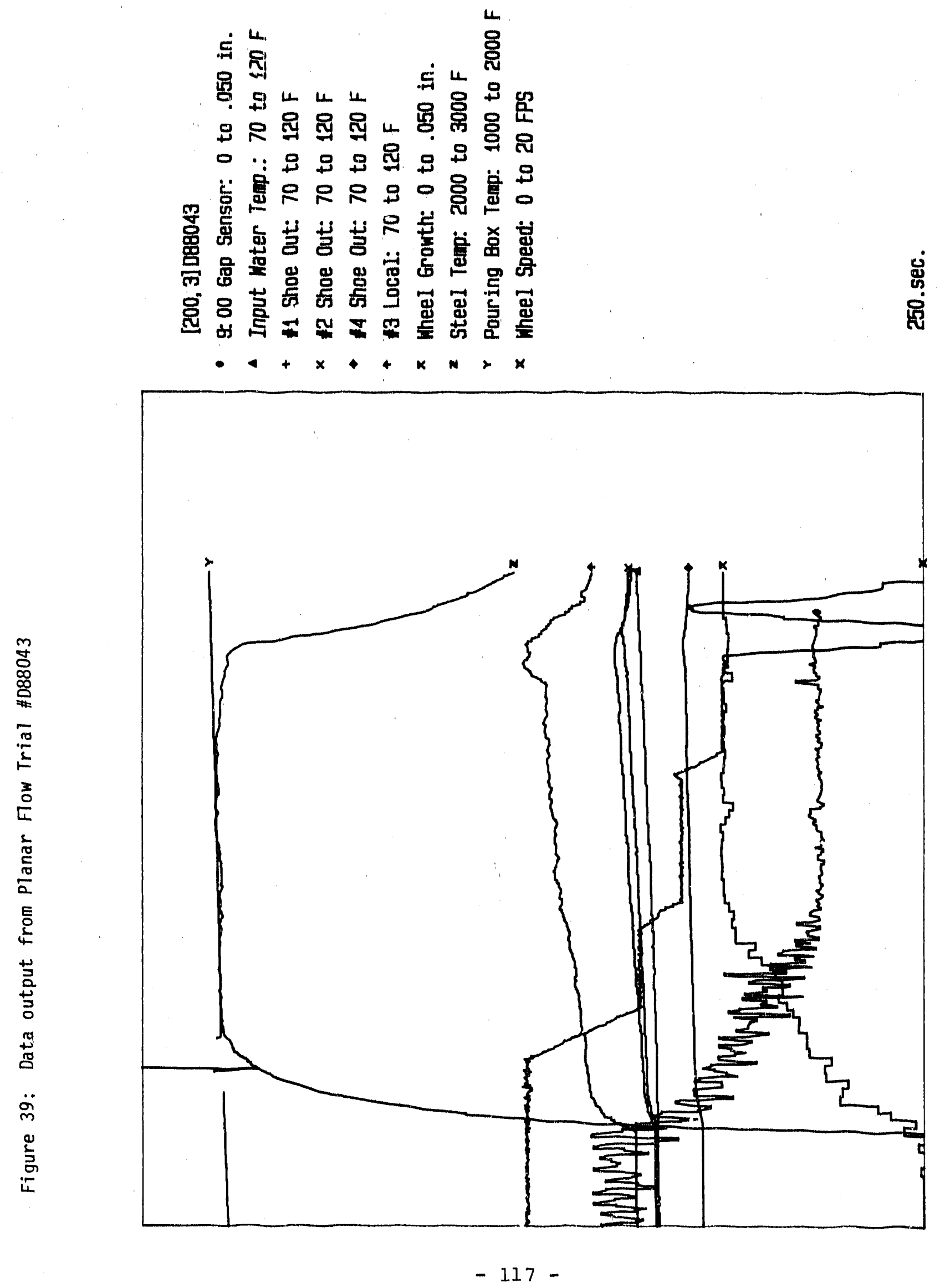




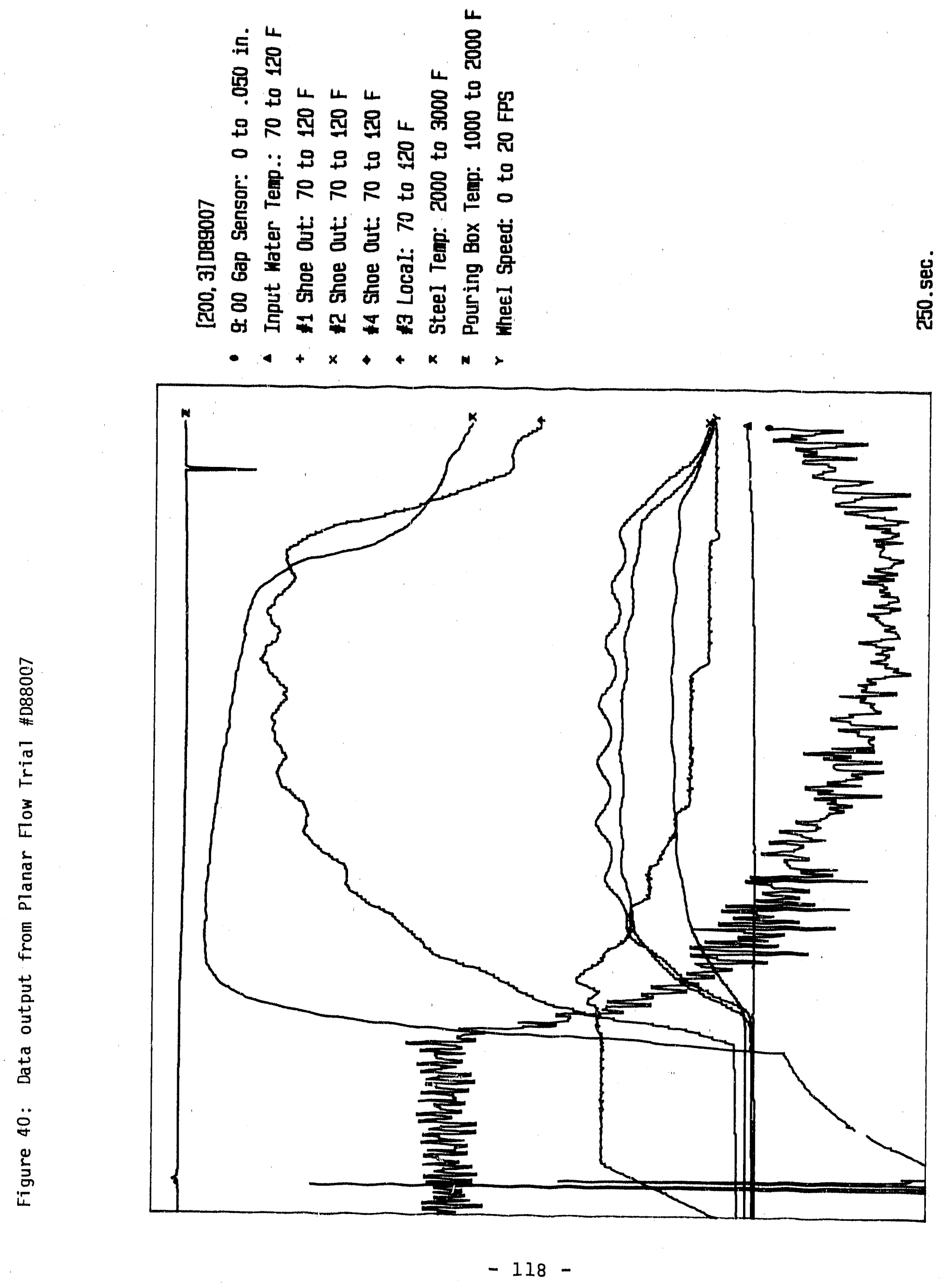


For Trial D89008, these calculations yield heat flows of 256000, 297000, and $159000 \mathrm{BTU} / \mathrm{hr}$ for shoes \#1, \#2, and \#4 with the overall transfer equal to $702000 \mathrm{BTU} / \mathrm{hr}$, slightly less than for D88043. This implies that it is the reduction in strip thickness for the planar-drag process and not an increase in heat transfer coefficient which contributed to the improved results of trial D89007.

It should be noted that the RTD measurement of the output water temperature for shoe \#4 was apparently offset. A baseline determined from the before and after portions of the cast data was used to calculate the effective input temperature. Also, the oscillations in the water temperatures during D89007 were caused by unstable flow control which resulted because the controllers were tuned at the original high flow rates.

CONCLUSIONs: Stable, complete solidification is more difficult to achieve with planar flow casting as compared to the non-pressure driven processes such as open channel casting. This is to be expected, due to the problems of matching fluid flow with substrate speed. Any mismatch promotes wave formation (instability). For the open channel processes, the mismatch occurs in the melt pool where there is no free surface upon which to form a wave. The major advantage of the modified process used for the final large wheel trial is that the free surface parallel to the fluid motion is eliminated. Productivity for PFC processes is likely to be higher than for open channel processes of similar 
geometries due to the increase in heat transfer under a pressurized pool, and the ability to force added material through the nozzle using the head pressure.

\section{Referenoes:}

(1) U.S. Dept. of Energy on Contract DE-AC07-83ID-12443 Topical Report: Strip Casting Literature Survey.

(2) S. C. Huang and H. C. Fiedler, Effects of wheel surface Finish and Wheel speed on the Topography of Amorphous Ribbons.

(3) Ed Murthy and Mollard, Met Soc AIME (1981) pp 127-135, Continucus

Casting of Small Cross Sections. 
APPENDIX I

Critical Review of Single-Wheel Casting Technologies

\author{
A. A. Freilich \\ Now Matorials \\ Armco Research Center \\ Middletoim, Ohto
}




\section{CONTENTS}

\section{Page}

I. Introd t un .................. 123

II. Literature Review............... 125

III. Patents Review................... 143

IV. Summary and Conclusions............ 194

\section{ATTACHAENTS}

A. Summary of recent Allegheny patents on strip casting (by R. C. Sussman)

B. Literature and patents search requests 


\section{INTRODUCTION}

It is known, to people sktlled in the art of strip casting via napld Solidification Technology (RST), that this fleld can be divided into two areas: foil ("thin") and "thick" strip casting, where foil means strip to a thickness of about $0.010 "(0.25 \mathrm{~cm})$ and "thick" means above about $0.010 "(0.25 \mathrm{~cm})$. This division, even though it is arbitrary, has some justification in the fact that some processes work better than others for different strip thicknesses. For example, Planar Flow Casting (PFC) seems to give better results for thin strip/foil, while melt-drag process, or its modifications, seems to favor thicker strip.

Since the objective of this project is to develop a method of producing thick strip, this review will primarily focus on patents and literature pertaining to it. Information obtained in the research and development of the foil casting, mostly amorphous, can be pertinent to the thick strip ribbon. Since much of this information can be found in the literature review done in the Phase II of this project(1), it is omitted here.

It also appears that the information obtained on low melting metals and alloys has very little bearing on the casting process/technology in RST of low carbon steels. Therefore, this review is limited to the high melting/casting temperature metals and alloys such as various "thick" steels and superalloys cast on a single wheel. Also omitted is the review of the enormous number of patents on the melting/casting of nonferrous metals and alloys, such as tin, 
aluminum and their alloys, amorphous alloys, brazing alloys, etc. These would not be pertinent to this project.

Special attention was given to the Allegheny Steel's patents for strip casting, although they pertain mainly to stainless steel casting. Attached is a special survey of their patents by R. C. Sussman (Attachment A) which is an integral part of this review.

For the computer search of the literature and patents, the following criteria were applied. The search was limited to strip casting of steels and superalloys. Also, the only language searched was English as very little work is reported in any other language. The time range was from 1968 to 1988 and covered U.S., Western Europe and Japan. Applicable key words were applied. For details, see Attachment B.

The review was written from viewpoint of highlighting the experience, data, equipment or technology which could benefit the research of single-roll casting (RST) of low carbon steel strip. Literature pertaining to that was found to be extremely limited. Patents are abundant but there is often no way of knowing whether claims were supported by experimental evidence or have any practical value. As with any literature and/or patent search, this represents what is available at this time. 


\section{LITERATURE REVIEW}

The computer search confirmed just what was known before, namely, that there is little literature pertaining to casting high temperature materials such as steels or superalloys. There were, however, three papers $(2,3,4)$ that seemed directly related to our project. These are reviewed in detatl.

The most pertinent paper(2), by $k$. Schwahe et al., describes the experimental work of an Austrian company Voest Alpine, in Linz, on casting low carbon steel strip on a single wheel. This is the only paper dealing with single-roll direct casting of low carbon steel strip and it is reviewed in detail since it has a lot of information bearing on the goal that we are trying to achieve $(0.030$ to 0.125 " thick strip) (0.76 to $3.18 \mathrm{~mm})$.

The authors start with a discussion of the three processes leading to a strip production: conventional thin slab casting, advanced thin slab casting and direct strip casting. After analyzing the three, they come to the conclusion that the direct strip casting is the preferred way to go.

They start with theoretical investigations based on water model studies. They choose a single roll melt overflow process and conclude that it is possible to cast strip of thickness in the range from 0.016 " to $0.048^{\prime \prime}(0.4-1.2 \mathrm{~mm}$ ) (see Fig. 1). Further part of the work describes the actual experiments with a trial caster (Fig. 2), characterized as follows: 
CALCULATED SOLIDIFIED SHELL THICKNESS DEPENDING ON POOL HEIGHT

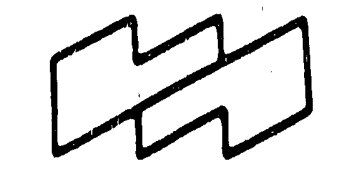

VOEST-ALPNE CC-TECHNOLOY

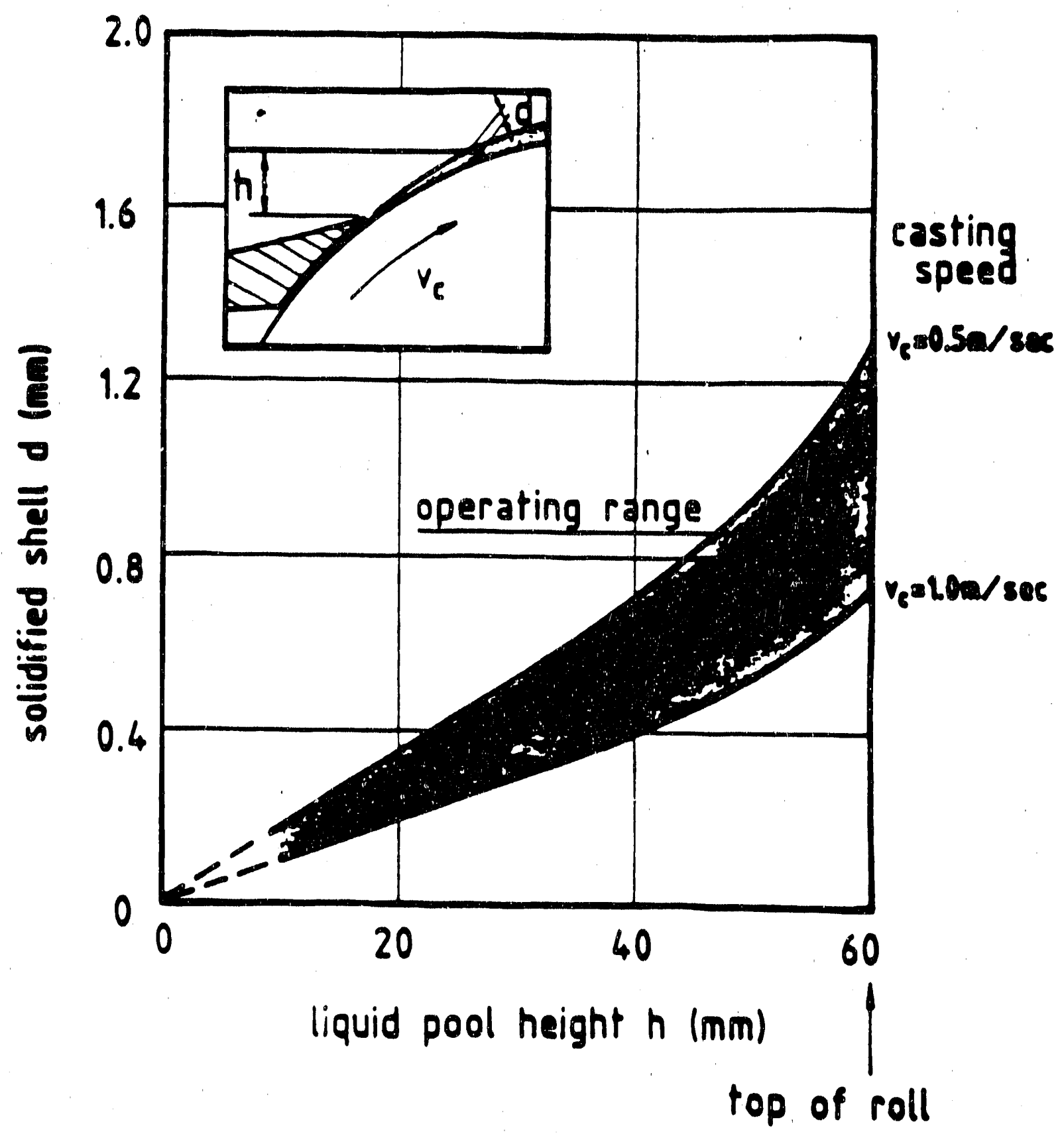

FIG. I. 


\begin{tabular}{|c|c|c|}
\hline Ladle content & $5.00 t$ & \\
\hline Tundish content & $0.45 t$ & \\
\hline \multicolumn{3}{|l|}{ Casting roll } \\
\hline material - & steel & \\
\hline diameter - & $680 \mathrm{~mm}$ & 271 \\
\hline barrel length & $1000 \mathrm{~mm}$ & $39.4^{\prime \prime}$ \\
\hline Casting speed max. & $1.5 \mathrm{~m} / \mathrm{s}$ & $5 \mathrm{ft} . / \mathrm{sec}$ \\
\hline Strip thickness & $0.5-1.0 \mathrm{~mm}$ & $.020-.040^{\prime \prime}$ \\
\hline width & $250 \mathrm{~mm}$ & $10^{\prime \prime}$ (at present) \\
\hline
\end{tabular}

The caster could be operated also in twin roll mode.

On this caster, low carbon steel strip $10^{\prime \prime} \times .020^{\prime \prime}=.040^{\prime \prime}(250 \times .5 .1 \mathrm{~mm})$ was cast and they achteved "steady state" condttions. Two types of nozzles were used: slot nozzle and "through nozzle". A steel wheel was used and proved to be a good substrate. They cast steel with less than $0.05 \%$. After pickling the top surface, the strip showed irregularities of a solidified free surface. The bottom face was flat, but had small voids caused most likely by air entrapment. This last effect depends on the gap. Authors conclude al so that to obtain good quality top surface, a second chill surface is needed. The microstructure of the as cast strip was described as "poor", but after an anneal of 5 min. at $920^{\circ} \mathrm{C}$ had a microstructure similar to conventionally hot rolled strip!

The second important paper(3) by J. D. Nauman and D. B. Love of Allegheny Steels describes their work and experience in direct strip casting (DSC) of 304 stainless steel. 
Table 1. Strip casting processus under development in Japan(9)

\begin{tabular}{|c|c|c|}
\hline No. & Process & $\begin{array}{c}\text { Casting speed and roll } \\
\text { dimensions }\end{array}$ \\
\hline 1 & $\begin{array}{l}\text { Vertical twin } \\
\text { roller process }\end{array}$ & $\begin{array}{l}V C=3-12 \\
D=400 \sim 550, \quad W=500, \\
T=0.12 \sim 0.5\end{array}$ \\
\hline 2 & $\begin{array}{l}\text { Vertical twin } \\
\text { roller process }\end{array}$ & $\begin{array}{l}V C=0.1-0.8 \\
D=500, W=200, T=1-10\end{array}$ \\
\hline 3 & $\begin{array}{l}\text { Vertical twin } \\
\text { roller process }\end{array}$ & $\begin{array}{l}V_{C}=0.01-0.1 \\
D=300,620, W=350, \\
T=6-60\end{array}$ \\
\hline 4 & $\begin{array}{l}\text { Inclined twin } \\
\text { roller process }\end{array}$ & $\begin{array}{l}V_{C}=0.1-0.2 \\
D=186, \quad W=200, T=1-2\end{array}$ \\
\hline 5 & $\begin{array}{l}\text { Inclined twin } \\
\text { roller process }\end{array}$ & $\begin{array}{l}V C=0,1-0.2 \\
D=150, \quad W=260, \quad T=1 \sim 2\end{array}$ \\
\hline 6 & $\begin{array}{l}\text { Modified melt } \\
\text { drag process }\end{array}$ & $\begin{array}{l}V_{c}=0.25-0.5 \\
D_{m}=1020, D_{S}=200, \\
W=600, T=1.5 \sim 2\end{array}$ \\
\hline
\end{tabular}

Vc: casting speed $(\mathrm{m} / \mathrm{s})$

D: roll diameter $(\mathrm{mm})$

W: roll width (mm)

$T$ : thickness of cast strip (mm)

Subscripts $m$ and $s$ : $m a$ in and sub rollers respectively. 

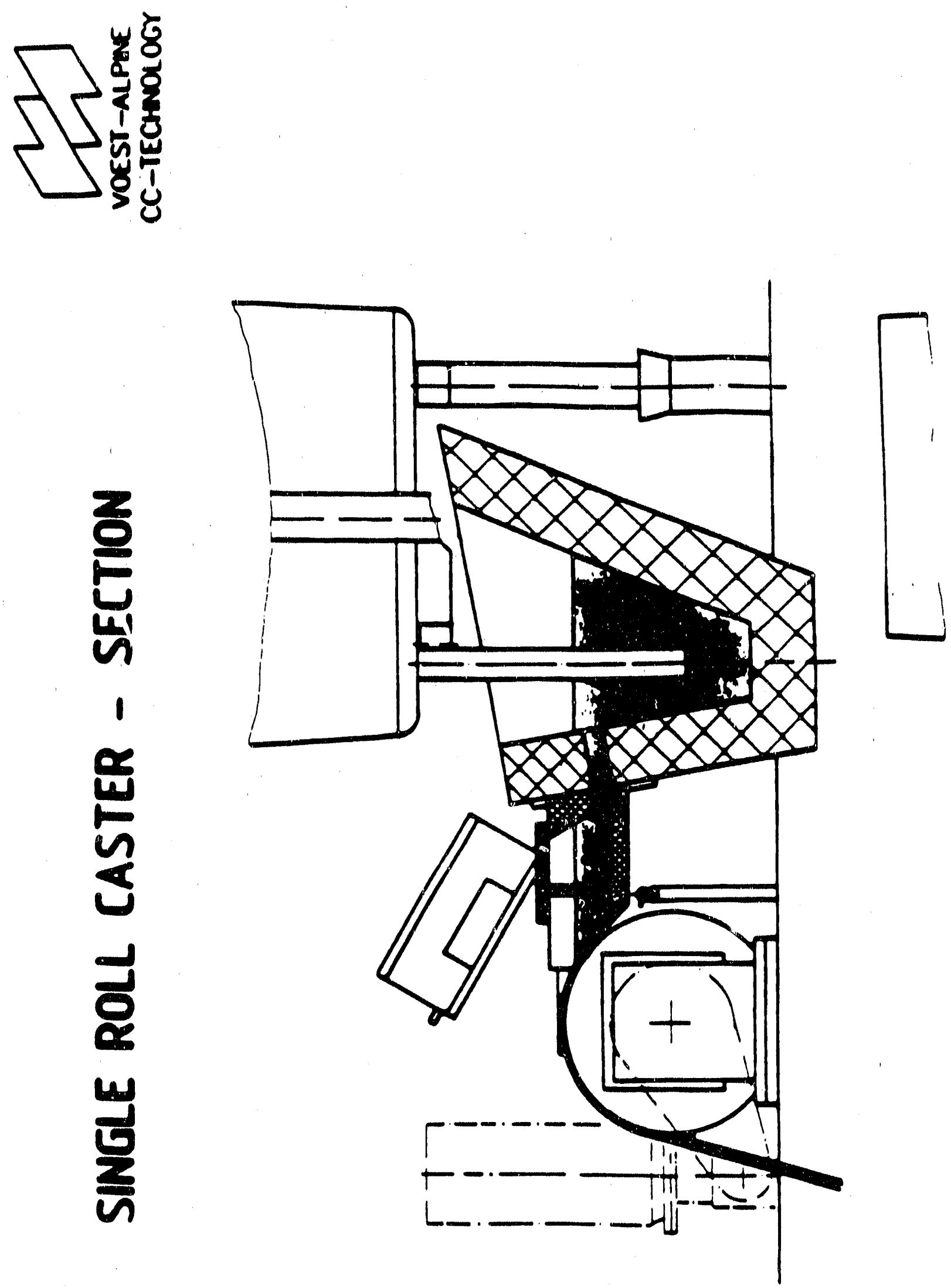

i 
The paper describes brtefly the DSC process (single roll) of stainless steel strip (Fig. 3) and the analyses of the properties of the cast strip (strength and ductflity) and microstructure. Further, the authors look at the effect of the alloy chemistry on the shape and qualtty of surface of the strip. They come to the conclusion that $\mathrm{Cr}$ and $\mathrm{Ni}$ does not effect the width, shape, edges or thickness of the strtp. However, at the higher levels $u f \mathrm{Cr}$ and $\mathrm{NI}$ the top surface becomes rougher. Higher speed (12 m/sec above standard) seemed to increase slightly the porosity and the number of volds.

Also variations in alloy composition resulted in variations in microstructures and subsequently in the properties of the strip. Width of the strip was approximately equal to the width of the casting nozzle. The changes in the width of the casting tundish had no effect on the shape of edges, thickness or surface of the strip.

The speed of the substrate noticeably affected the edges which had less curl with higher speed. Width was not affected and thickness varied as expected $($ see Fig. 4).

The speed of the wheel had also a profound effect on the microstructure via change of the cooling time and contact time with the liquid material. There was a change in dendritic growth pattern at the top of the strip which resulted from the change in cooling conditions at different roll speeds. Increased speed of the substrate was beneficial for surface smoothness and mechanical properties of the strip.

The length of the pool primarily affected the thickness of the strip. As the length of the pool was increased, the thickness of the solidified strip also increased. 


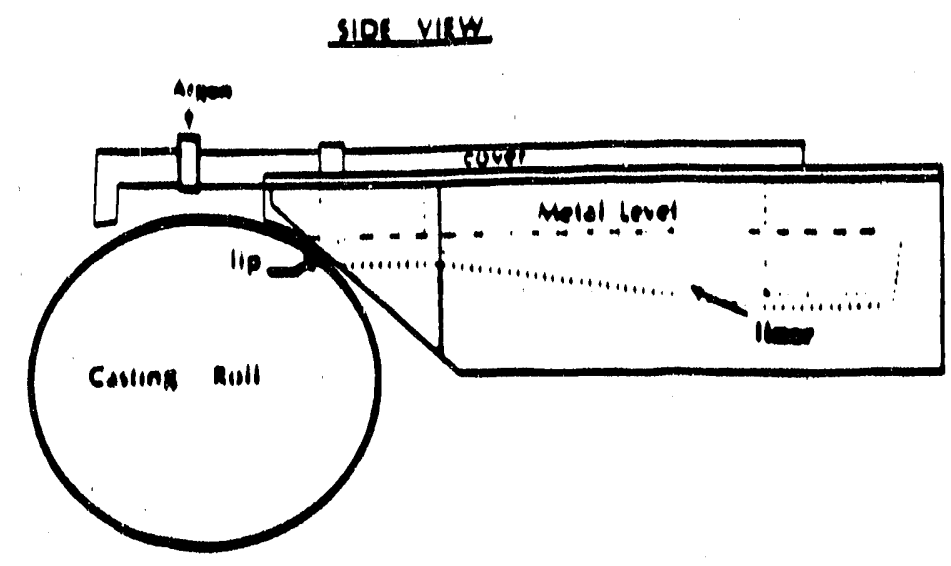

Figure 3. Side Viow of singlo-roll caster tundish and roll.

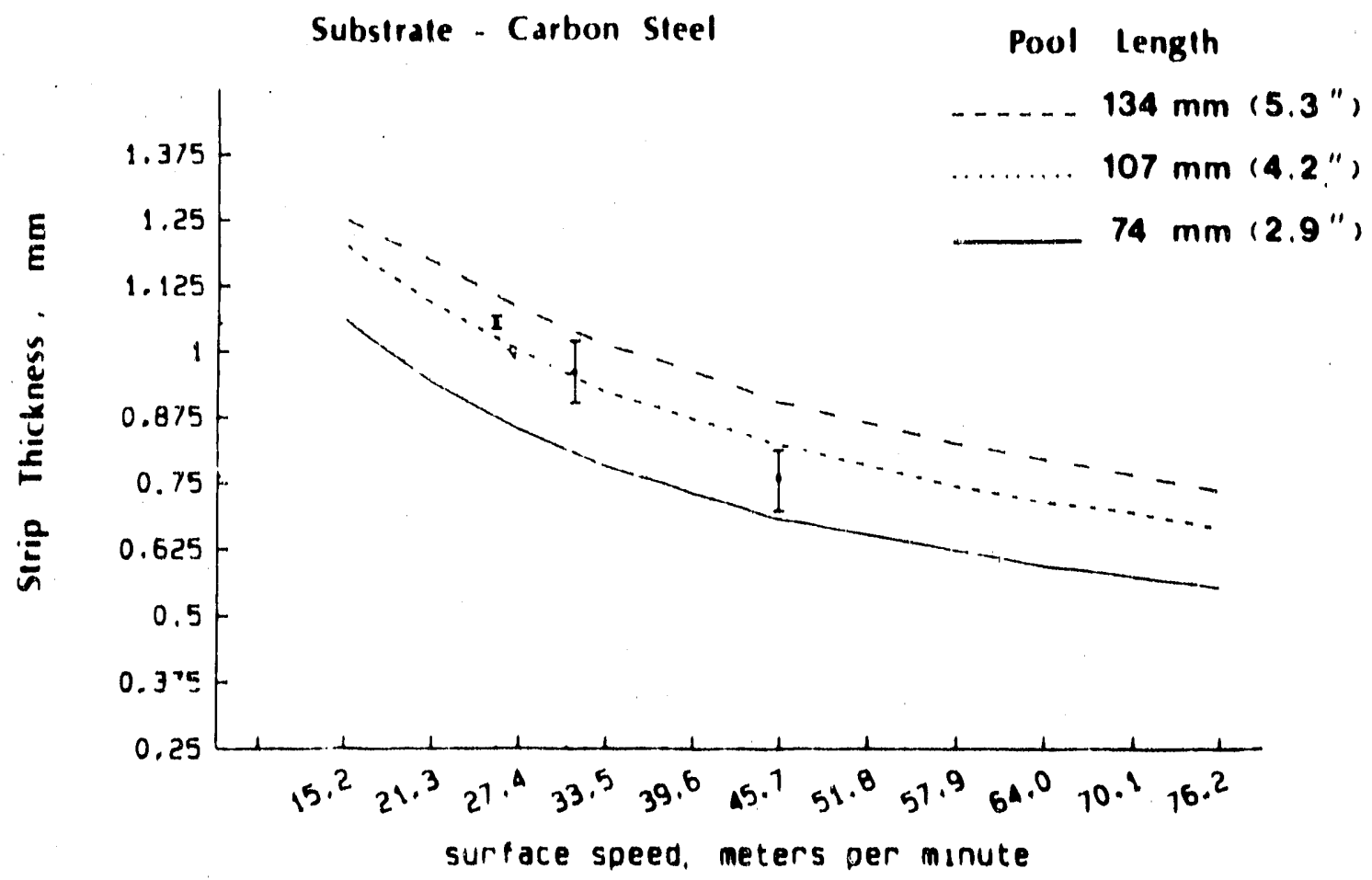

Figure 4. Type 304 sirip thickness vs. surlace speed for vailous lengins ot ine molten poul. 
Dtameter of the casting wheel did not have any significant effect. Three substrate compositions evaluated were carbon steel, stainless steel and copper. Casting on stainless steel and copper resulted in coarser structures although for different reasons. The stainless steel did not have suffictent heat conductivity. In the case of copper, the bottom surface solidifled very quickly and lost contact with the substrate. The authors don't discuss the results of casting on the carbon steel substrate.

Some superheat from the standard casting temperature did not affect significantly the properties of the strip (304SS).

Finally, the third important paper is by R.S. Carbonara and R.A. Glelchner(4) from Battelle Development Corp. In Columbus, Ohio. This paper deals with single roll direct strip casting in general terms. It discusses the effect of casting variables on the strip, as well as the limitations of the process.

The authors claim that because of thermal resistance at the molten metal/casting wheel interface (heat barrier) there is a theoretical limitation to maximum strip thickness in the single roller process. They claim that the limit for low carbon steel is $-1.27 \mathrm{~mm}(0.050$ in.). Also, a relatively larger solidification range (undercooling) has produced thicker and smoother strip.

As a consequence of the high casting speed, the DSC depends critically on the control of the process parameters "on the fly", in order to reduce losses if an unacceptable strip is produced. Molten metal must be controlled reliably and automatically. This can be achieved by using an interactive microprocessor based feedback system to regulate molten metal flow from melter to the wheel. 
According to the authors, the wheel substrate is one of the most important factors in the DSC process and the quality of the product depends on $i t$. The main substrate-related parameters that have to be considered are: matertal, speed, surface preraiation and maintenance (during casting), and surface temperature. Due to the unlque propertles of each new material, substrate modifications are required for each material cast. This goes as well for any scale-up of laboratory operations to a commercial size.

The chotce of substrate material is based primarily on the empirical observations of which matertals cast better on which substrates. However, the considerations of mechanical strength and toughness, heat transfer characteristics, and resistance to thermal fatigue cracking also play an important role.

For a commercial operation, a means of continuous on-1ine strip thickness control is very important, so that the substrate speed can be adjusted during the casting run.

Preparation of the subsirate surface should be done by dry sanding or polishing followed by a distilled water or ethyl alcohol rinse. The maintenance of this surface during casting is a problem. Care has to be taken so that foreign particles such as debris gases, oll, water, etc. are not deposited onto the substrate. Substrate surface temperature is important but can not be measured precisely. It's a problem in the present day technology of DSC.

The above three papers were the most directly connected with the low carbon steel strip casting. The following is a review of other papers. Since they 
do not contain as much information pertinent to our project they are discussed in less detail.

S.M. Pimputkar et al. (5) uses a model (Fig. 5) to compare single roll and double roll processes for casting of low carbon steel strip. The paper, based on his model, is very general and theoretical. It compares, through the model, the fluid flow, dynamic and thermal phenomena in DSC. Strip thickness was chosen as the primary parameter to be investigated. Theoretically, the strip thick:uss will depend essentially on the wheel-nozzle gap, the pressure of 1 lquid and the speed of the wheel, as the graph (Fig. 6) shows.

The above mentioned substrate-related parameters affect th: thickness the most; the other parameters - much less. The authors come to the conclusion that ribbon up to $.050^{\prime \prime}(1.27 \mathrm{~mm})$ can be cast on the single roll (SR).

According to authors somewhat different parameters affect double-roll (DR) casting process. These are: puddle height, wheel speed, liquid metal temperature and substrate material, in that order (as far as thickness of the strip goes).

The authors conclude that their model shows that for single roll casting, strip thickness is sensitive to operating parameters, while the strip integrity is not. The opposite is true for the double roll process. The model also shows that the SR process is simpler than the DR process, has a larger operating window and will produce integral strip over a wider range of operating conditions. 


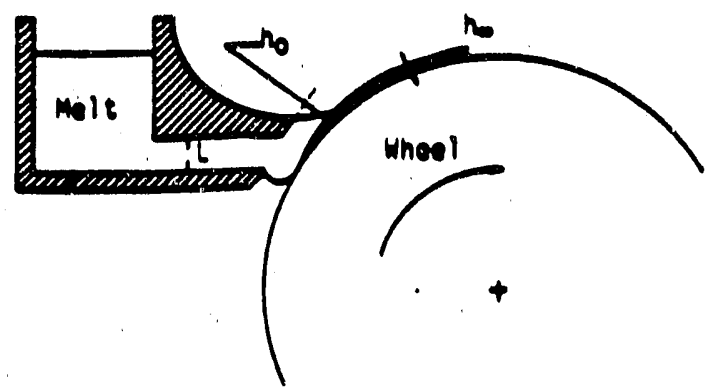

FIGURE -

Schemste of single-roller casting system

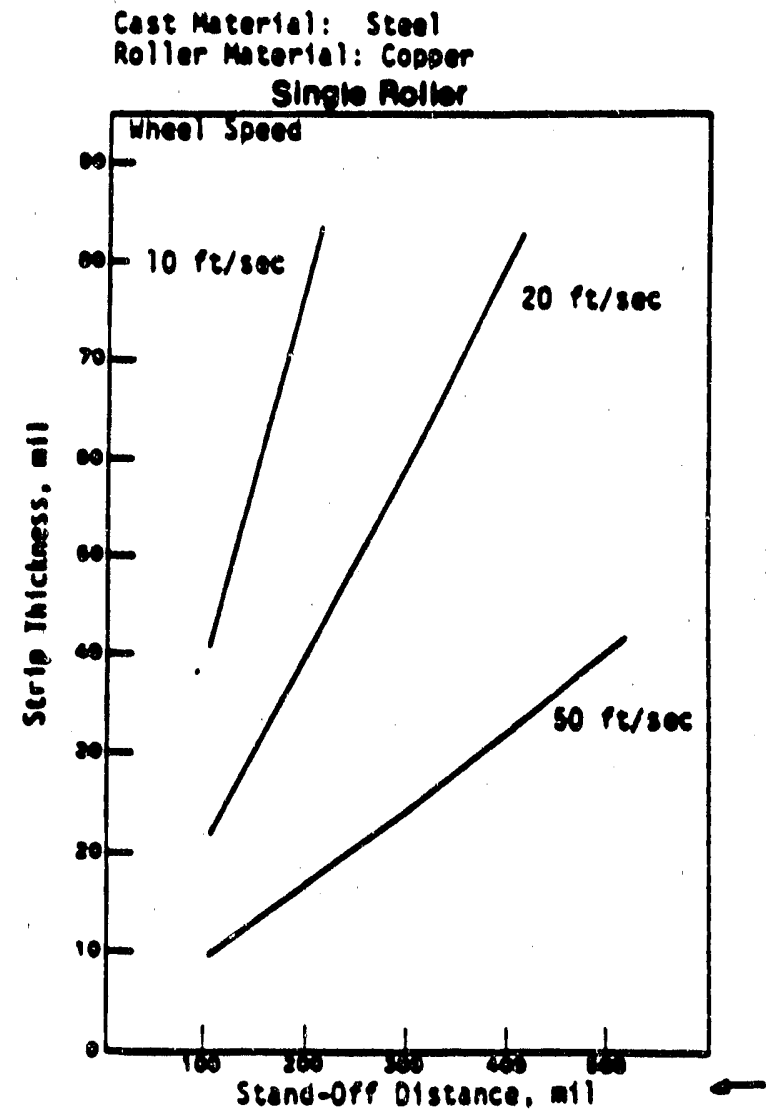

Whael-mogghe gap.

FIQURE 6

SR serip thickness as a function of stand-oft

distance for differene wheel speeds (senel case

on copper). $\left(\right.$ mil $\cdot 10^{-3}$ ineh. 
The following papers are reviews. They don't bring in much new information, but rather confirm the state of the art at present and shed mainly some light on what is being investigated in the field of direct strip casting.

The G.T. MacManus work(6) reviews the various processes which result in strip as the end product. It goes into some details of what is being done by industry in the field of thin slab casting, as well as, in strip casting.

Author describes work on the SMC and Hazelett processes for thin slab casting. Subsequently, he mentions Armco-Westinghouse work on the single roll casting of low carbon steel and Bethlehem work on the double roll casting. He mentions also Allegheny work on stainless steel strip casting on a single roll, and thick strip casting work at LTV. The latter involves a roll-belt arrangement and can produce allegedly .030 to 2 inch $(.76$ to $51 \mathrm{~mm}$ ) thick slabs. LTV feels that it is necessary to provide cooling and containment on both sides of the strip.

R. Steffen and $R$. Thielman( 7 ) review in detail the existing thin slab techniques and then go into the different strip casting techniques (Fig. 7 ). This report basically outlines the fundamentals of the present process development stage of thin slab and strip casting of steels.

Reviewing existing techniques of single roll casting the authors describe an interesting casting apparatus from Nippon Metal, where there is, in addition to the wheel, an auxiliary ceramir, roll to help keep the "thick" strip on the wheel (Fig. 8).

M. Cygier and $M$. Wolf $(8)$ review the history of strip and thin slab casting from Sir Henry Bessemer in 1856 to the present time. As far as the strip 

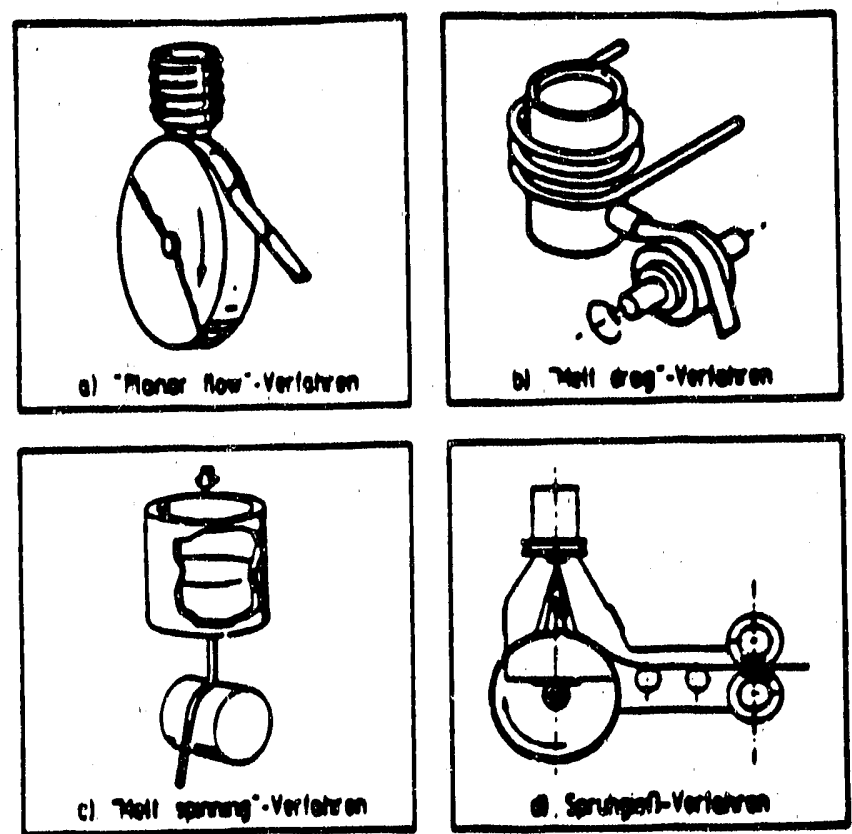

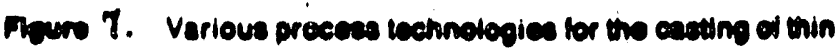
urrip in the singlo-roll mothody

a) Moll spinning proceces b) Moll drag preceas

c) Planar llow casting process d) sprey casting procens

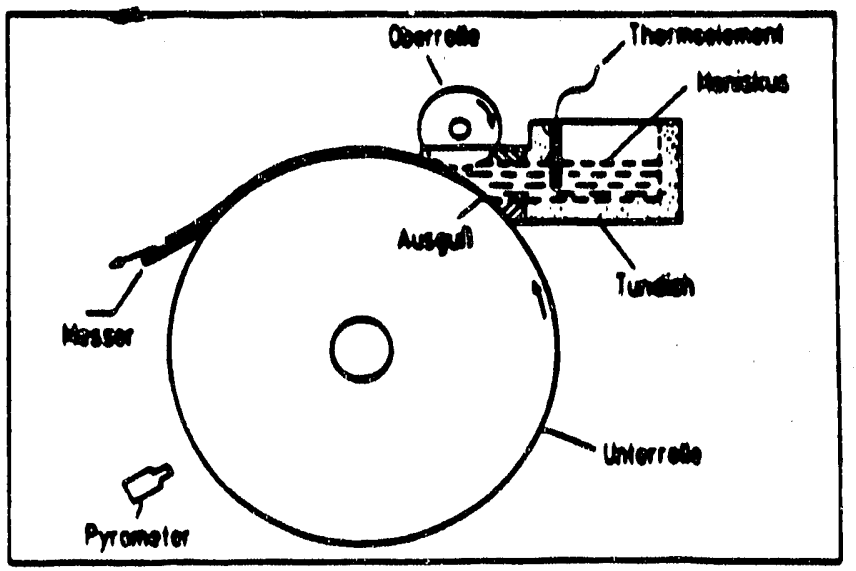

Prours 8 . Strip ceating prececes coveloped by Nipeen Meral (Bonom roll: 1020 dla.; top roll: $200 \mathrm{~mm}$ db.; $300 \mathrm{~mm} \times 2 \mathrm{~mm}$; $201030 \mathrm{~m} / \mathrm{min}$ )

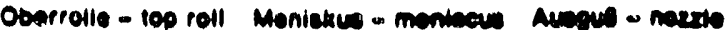

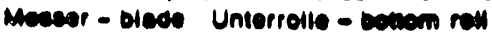


casting is concerned; the authors review a broad spectrum of existing techniques of casting (Fig. 9). For casting of thin folls, they mention a single wheel caster developed jointly by the University of Basel and Concast Standard (Fig. 10) (see also section with patent reviews). Twin-roll cast strip (by Kawasaki Steel, Nippon Steel and Nippon Kokkan) is also discussed. The rest of the paper is concerned with thin slab casting.

The paper by $F$. Ohnaka( 9 ) discusses the state of $R \& D$, in Rapid Solidification, in Japan. It describes in detalls the developments of various types of processing to produce powders, ribbons, wires and sheets thinner than $10 \mathrm{~mm}\left(0.4^{\prime \prime}\right)$. The promise of the processes and problems to be solved are also discussed. The author discusses alloys suitable for rapid solidification and comes to the conclusion that the amount of undercooling that the alloy can achieve is the most important characteristic of a "good alloy" for rapid quenching.

He discusses also successful casting of stainless steel strip by twin-roll process and powder atomization process. The paper mentions several double-roll strip casting techniques as shown in the Figs. 11,12 and 13 and single-roll strip casting in fig. 14 (For details see the patent review section). The table below gives some casting parameters and products dimensions. 


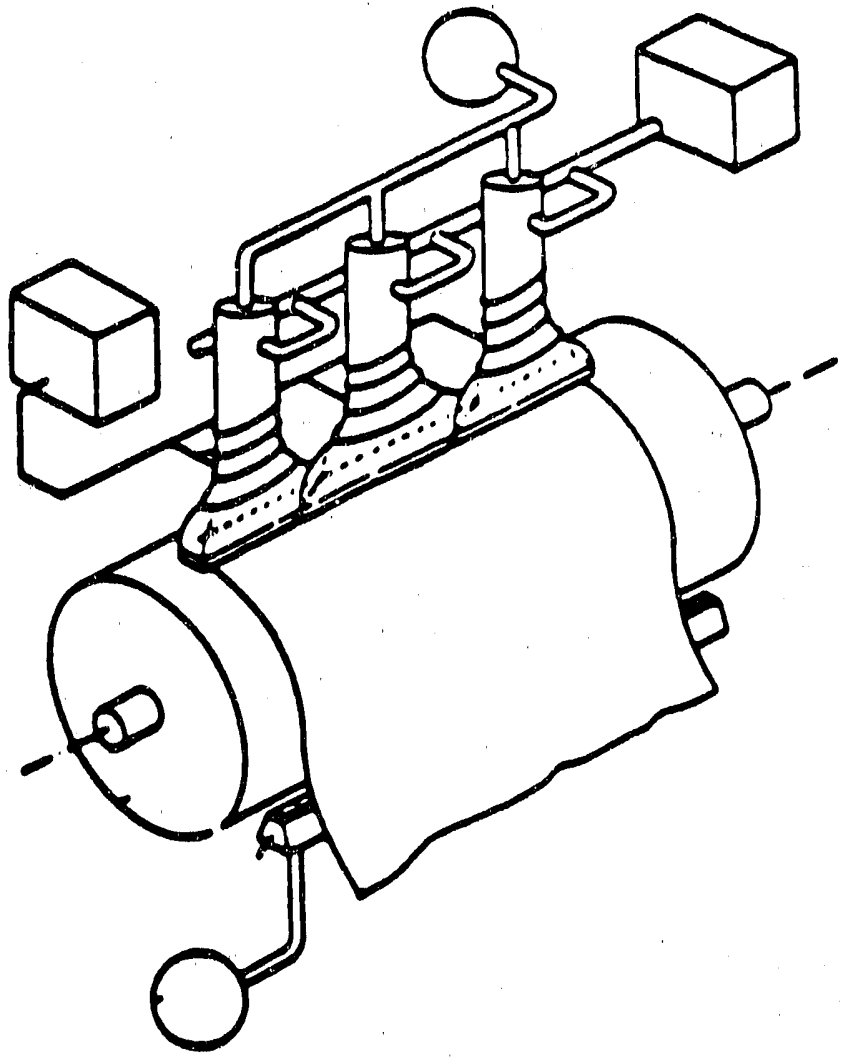

Fla. 9 - Onewhel casler designed by CONCABT Standard AO and ine University of Basle tor sirie casling of amor. phous motals.

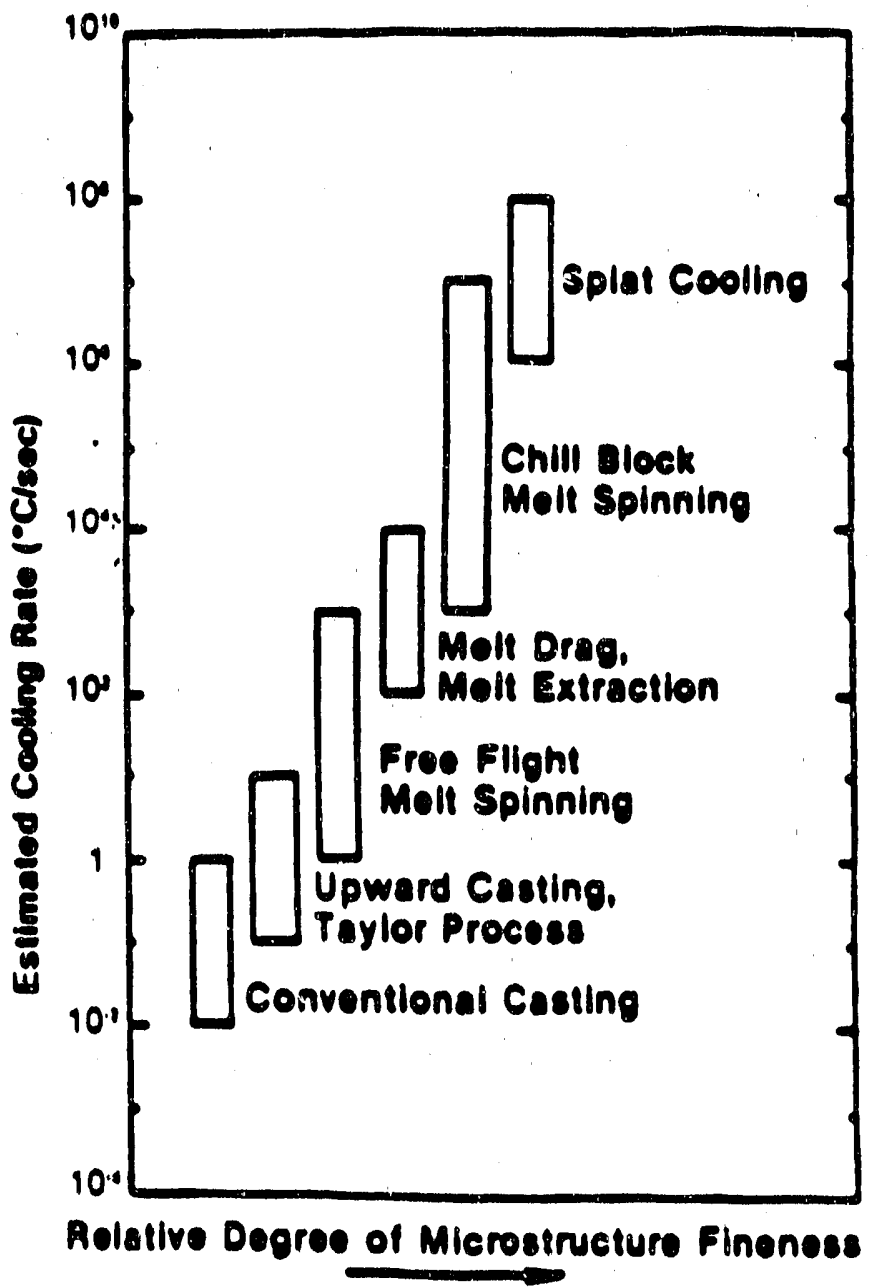

Flo. 10 - Cooling rates of various casting procesese and ineir elteci on mierosiructure finencas. 


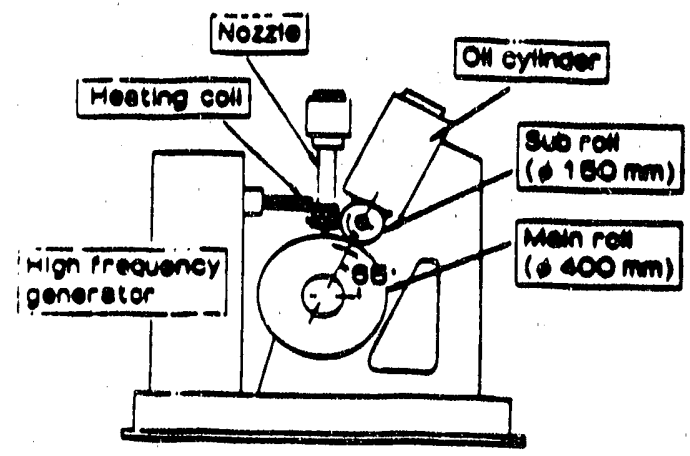

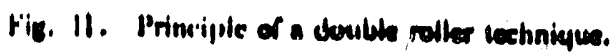

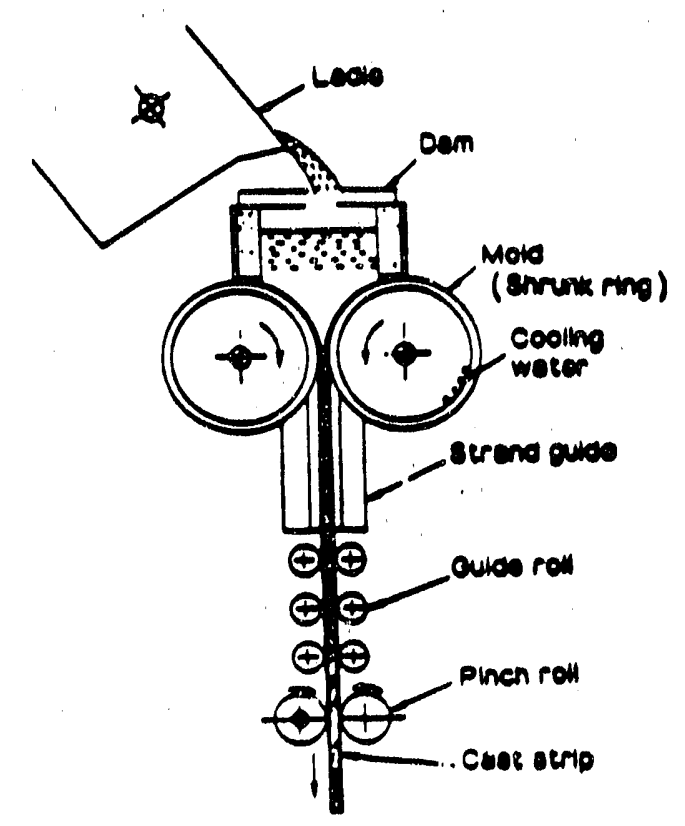

Fis. 12. An example of vertical iwin roller utrip cauing.

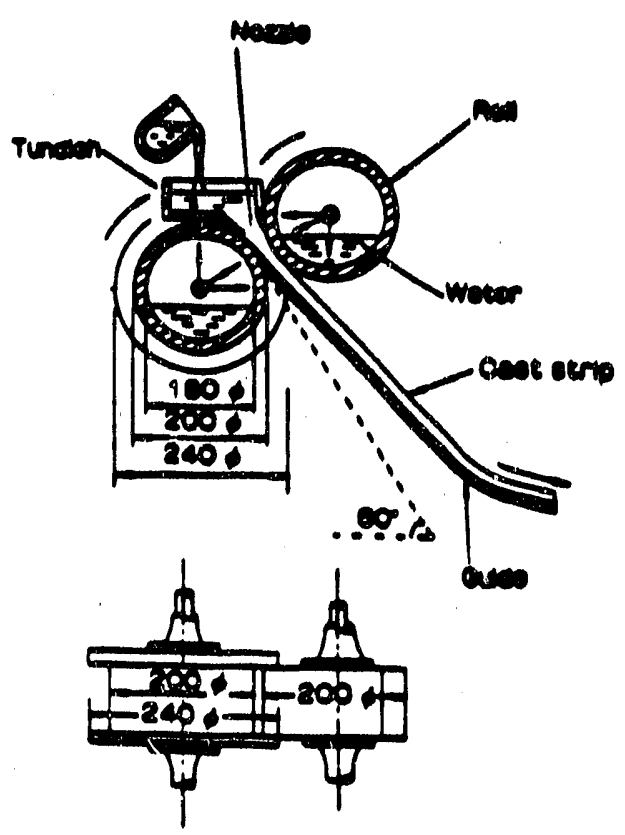

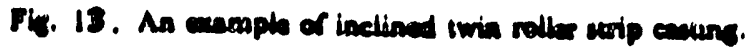




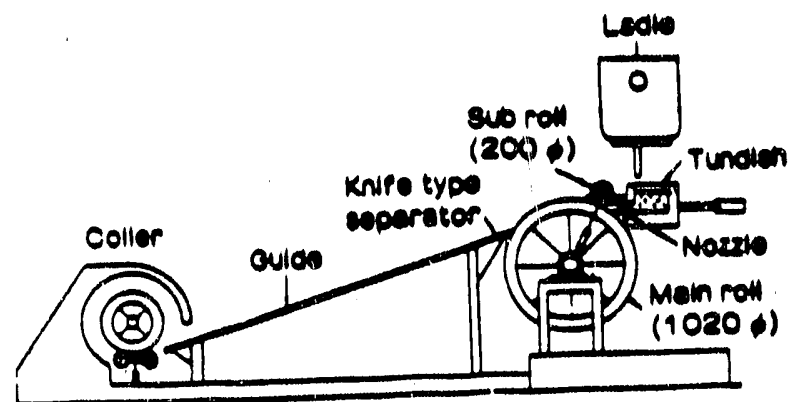

(a)

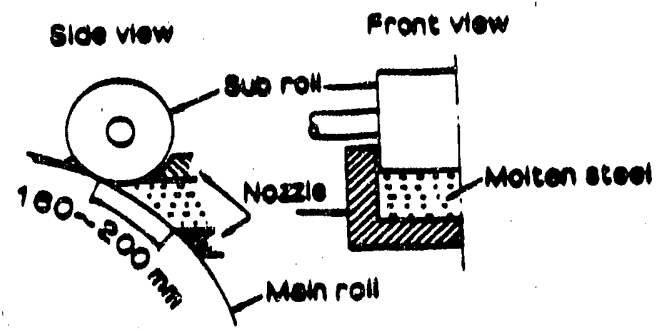

(b)

(a) Front view

(b) Structure near the nocale

Hig. 14. Modified malt dros urip casing. 


\section{References}

1. John C. Powe 11, "Strip Casting Literature Survey", Westinghouse, Pittsburgh, PA., Spring, 1987.

2. K. Schwaha et al. "Strip Casting of Low Carbon Steel at Voest Alpine", Steel Times, July $8 \%$.

3. J. D. Nauman and D. B. Love, "Controlling the Shape of Cast Stainless Steel Strip", 89 th Annual General Meeting of CIM-1987, International Symposium on Near-Net-Shape Casting of Strip, 1987 Toronto. Paper/presentation No. 222.

4. R. S. Carbonara and R. A. Gleichner, "Limitations of the Single Roller Direct Strip Casting Process", 89th Annual General Meeting of CIM-1987, Paper/presentation No. 221.

5. S. M. Pimputkar et al. "Comparison of the Single Roller and Double Roller Processes for Casting Low Carbon Steel", Rapidiy Quenched Metals, S. Steel, H. Warlimond (eds.), Elsevier, 1985.

6. G. T. MacManus "Steelmakers Pursue Thin Strip Casting", Iron Age, August 1987 Review.

7. Rolf Steffen and Rainer Thielmann "Developments for the Strip Casting of Steel", Stahl v. Eisen 106 (1986) Nr.11 Review.

8. M. Cygler and M. Wolf, "Continuous Strip and Thin Slab Casting of Steel an Overview", I \& SM, August 1986.

9. T. Ohnaka, "State of the Art of Research and Development in Rapid Solidification Technologies in Japan", Trans. Iron Steel Inst. Jan. 27 (1987) No. 12. 


\section{PATENTS REVIEH}

The patents revtewed below pertain to direct casting of thick crystalline strip, as different srom casting of thin (mainly amorphous) foll. Patents specifically aimed at direct casting of amorphous foll (very abundant) were as mentioned in the introduction omitted from this review. The cos suter search which was limited to the period 1968-1988 identified the following patents, which are going to be reviewed in chronological order.

It has to be said that direct strip casting on a drum has been known for a long time - since the last century. so, the bastc patents predate our search period and have even expired long time ago. All the patents reviewed are patents pertaining to various parts of the casting system or improvements to the casting process, but do not $r$ ally introduce any basic novelty to the direct strip casting.

The earliest patent entitled "Method of Direct Strip Casting on a Coated Drum", by W. M. Wojcik(1) that the search uncovered is from 1970. The method of direct casting of strip described in this patent is quite different from the ones that we intend to use, but the patent contains results from experiments. which can be pertinent to our work. It describes a method of melt drag casting, where the wheel is partially immersed in molten bath and the strip is drawn from it. The patent applies to casting of low carbon steel strip suitable for subsequent rolling, to a uniform thickness. The basic set-up is shown in Fig. 1 . 

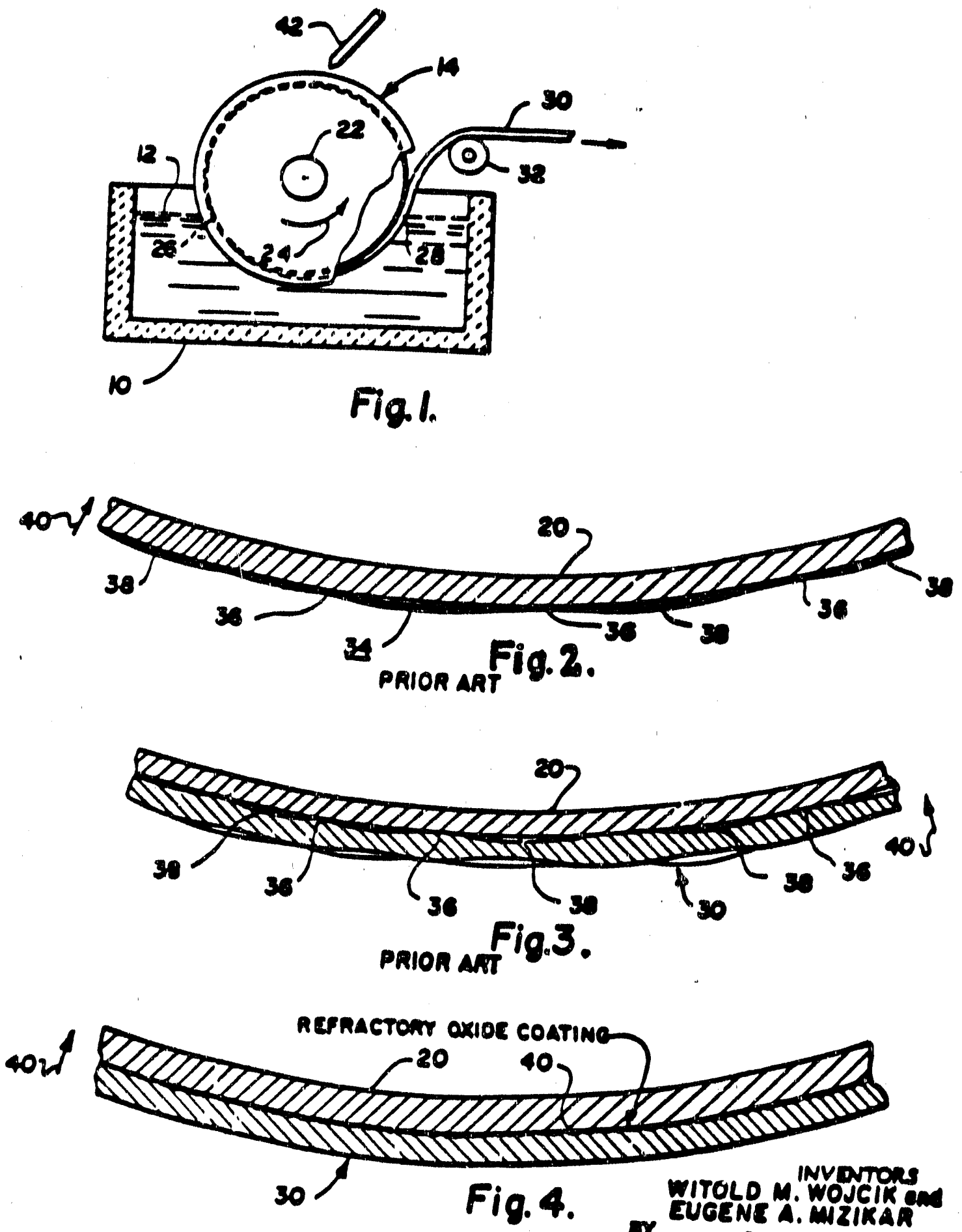
T.N. Stmanal 
The substrate was coated with refractory metal oxide prior to the immersion into the bath. Zircon mold wash, alumina, magnista, stlica suspenston or any combination of these can be used to coat the wheel. Up to $300^{\circ} \mathrm{F}$ whael temperature - aqueous solution can be used. Above $300^{\circ} \mathrm{F}$ - binder (zircon wash $\left(400^{\circ} \mathrm{F}\right)$, ammontum phosphate, aluminum phosphate $\left(900^{\circ} \mathrm{F}\right)$ ) has to be applied.

Data concerning the set-up:

Wheel - statnless steel, chlll temperature - $700^{\circ} \mathrm{F}$ Molten metal temperature - $2810^{\circ} \mathrm{F}, \mathrm{C}=0.10 \%$, strip thickness up to .250".

Refractory metal oxide - larger than 200 mesh but not greater than 100 mesh.

Cu wheel was also used but results were infertor to the stainiess steel wheel. A smooth $\mathrm{Cr}$ coated $\mathrm{Cu}$ also produced good strip.

In Fig. 2 and 3 the inventor shows prior art products and in Fig. 4 - strip obtained by this method.

No patents, that would pertain to our work, were found in the nineteen seventies. One has to remember that this was the time when the development of rapid solidification strip was concentrated primarily on the amorphous (thin) strip/foll. However, in the late seventies - early eighties, Allegheny Ludlum Steel started an active program to develop the strip casting of stainless steel. Several patents appeared as a result of this ongoing development. First five patents pertaining to the direct strip casting by Allegheny from 
the early eighties, were previously reviewed for Armco in the Attachment $A$ by R. C. Sussman.

Below is a brief suminary of other, later patents, found by the computer search.

1. Pat. $4,479,528$ - R. E. Maringer, Strip Casting Apparatus.

This invention, as the author states, is directed to an apparatus (Fig.

5) for rapidly casting thin metallic (preferably amorphous) strip material.

The apparatus is different from others by the virtue of having a nozzle with a curvilinear element in it (figs. 6 7). The patent shows different nozzles and orifices/slots/shapes (Figs. 8 to 13) for casting amorphous and crystalline matertals. An example, given in the patent, of the strip cast is as follows:

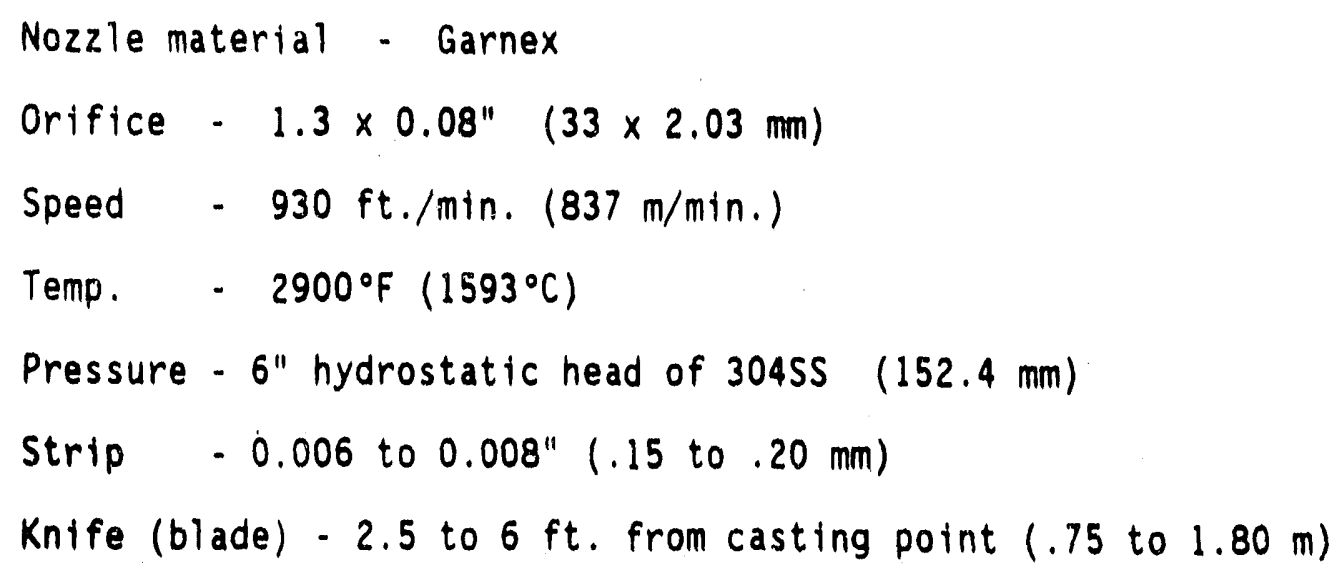


U.S. Patent Oct. 30, 1984 Sheet 1 of $4 \quad 4,479,528$

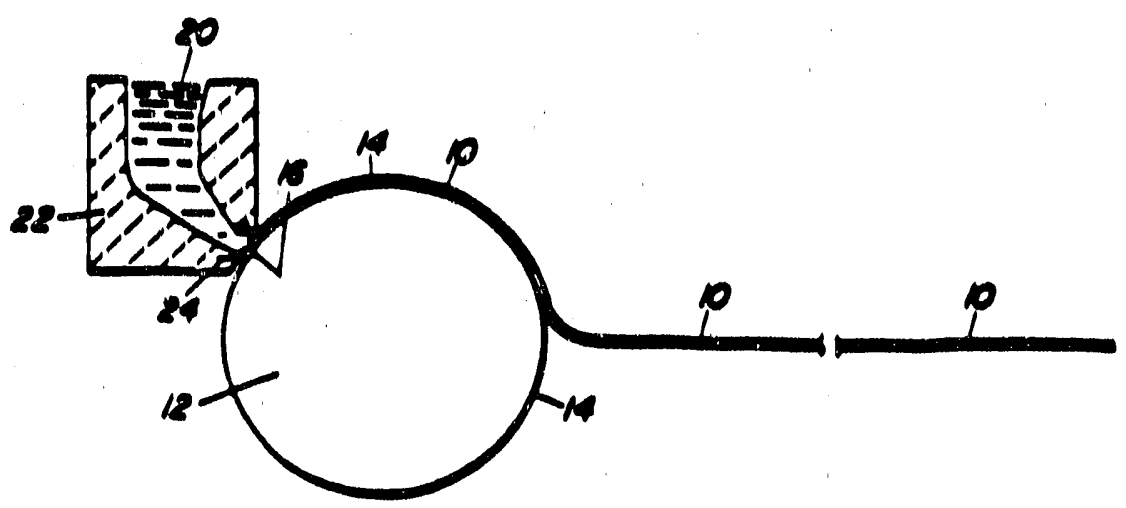

Fla.s

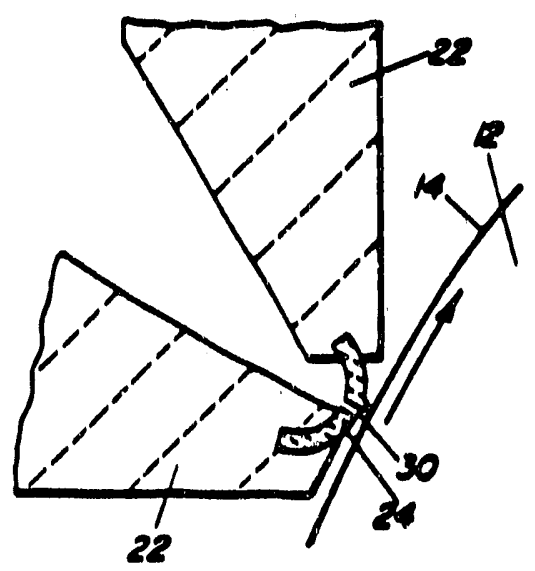

FIG. 6

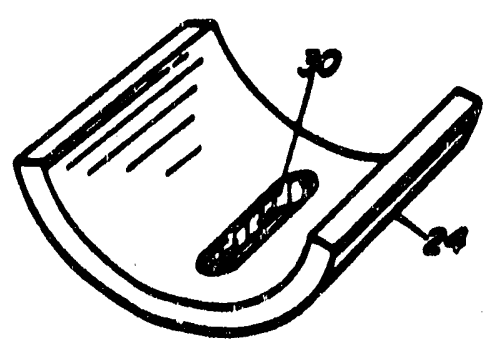

FIG.7

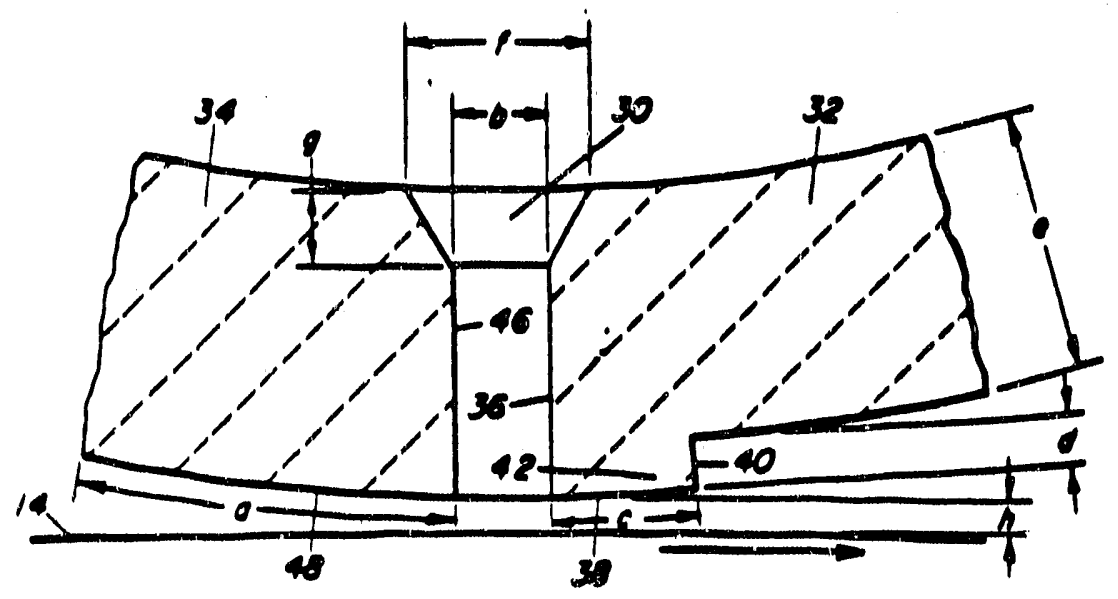

FIG.8 


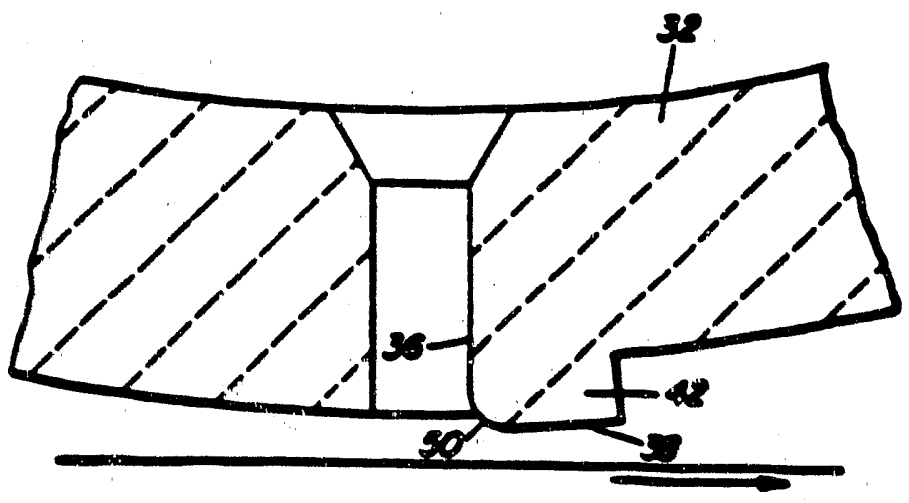

Fla.9

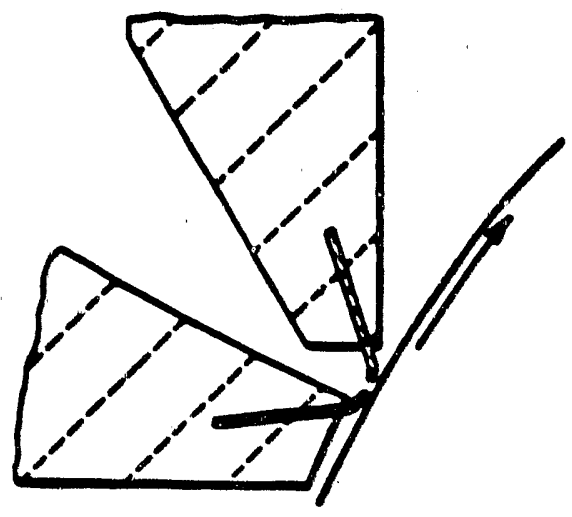

F1G.10 


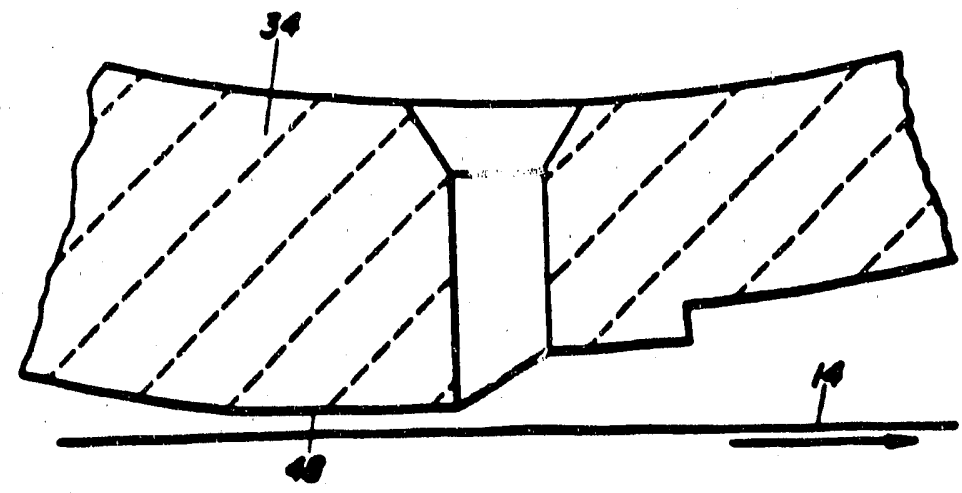

FIG.II

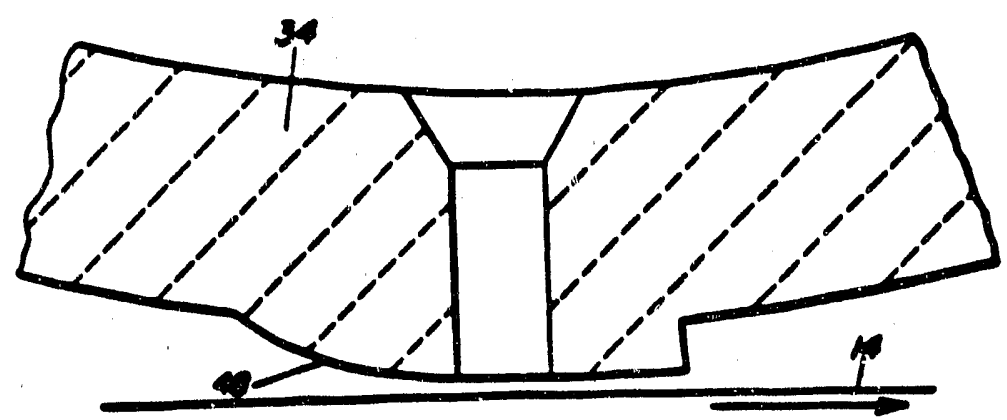

FIG.18 


\section{U.S. Patent Oct. 30, 1984 \\ Sheet 4 of 4 \\ $4,479,528$}

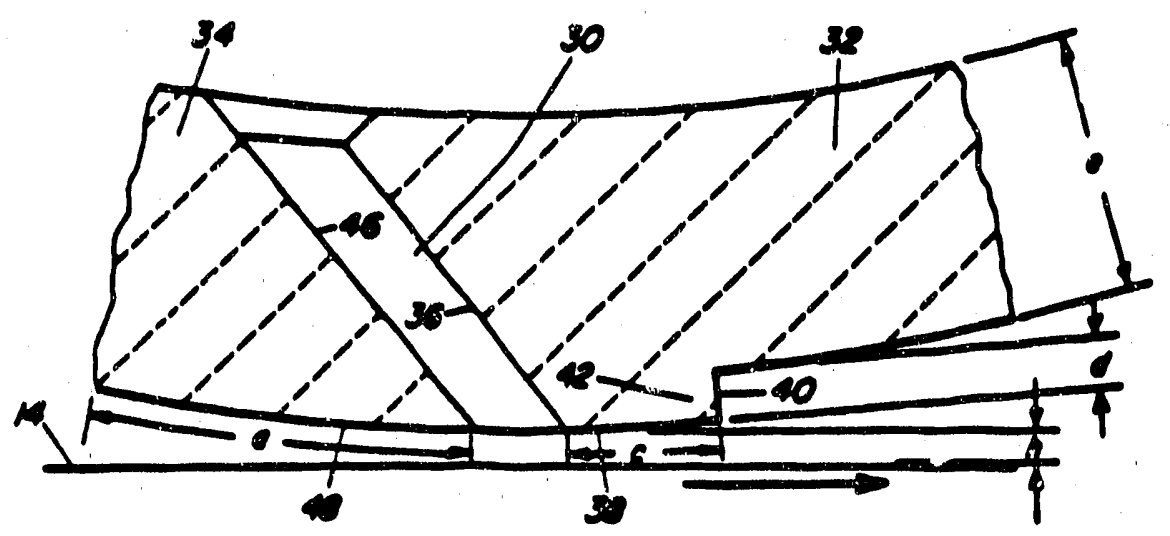

$F / G .13$ 
2. Pat. $4,488,590$ - N.Y. Toker, Apparatus for Strip Casting Having a Heated Orifice

The maintenance of slot dimensions, including prevention of freezing of molten metal, becomes more critical as the width and the thickness of the strip increases. Hot gases are delivered to certain tundish locations affecting tundish material. This patent describes a method where the goal of heating the orifice is achieved through gas heating and the tundish is protected from reactive gases.

Boron nitride plate is used to construct parts of the nozzle or tundish under molten metal attack. Also $\mathrm{SiN}, \mathrm{SiC}, \mathrm{BC}, \mathrm{SiO}_{2}, \mathrm{Al}_{2} \mathrm{O}_{0} 3, \mathrm{TrO}_{2}, \mathrm{Zr}$ sllicate (stab.), Quartz, graphite, $\mathrm{Al}_{2} \mathrm{O}_{3}$ - graphite, fire clay, clay-graphite, MgO, chrome magnesite and combinations of these materials can be used. Protective layer on the plates included: graphite bearing cements or other high resistance to flame materials.

Figures 14 through 18 show the details of the invention.

3. Pat. $\# 4,562,878$ - B. G. Lewis, Electromagnetic Shaping of Thin Semiconductor Ribbon Strip Cast Onto a Chill Block.

This patent invention applies to the thin ribbon (strip) which is being shaped electromagnetically on the wheel and slowly cooled.

Magnetic field is holding the metal in the form of a solid rod and keeping the end drop of the liquid. This allows a definite structure to form. Ideally, a single crystal material is formed by initially seeding the ribbon. 
FIG. 14

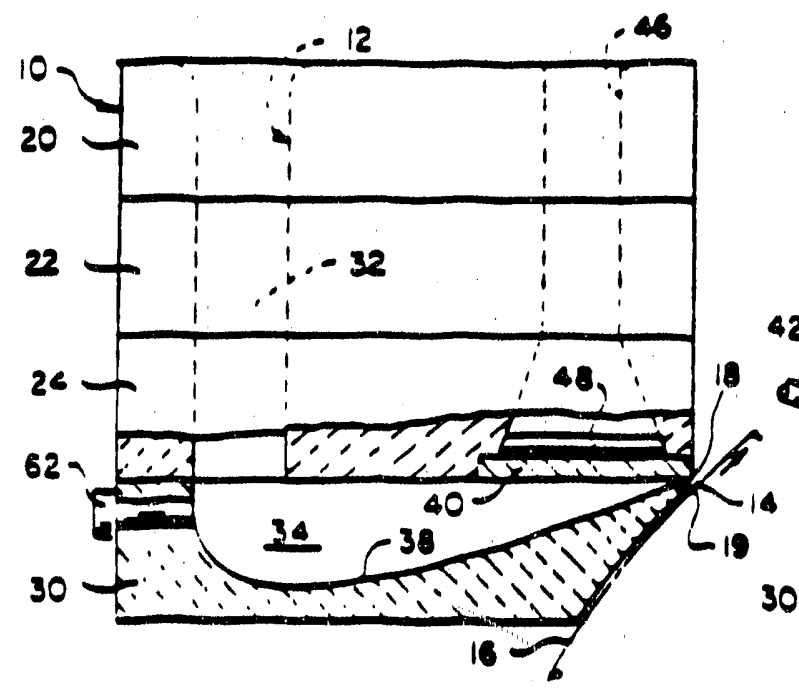

FIG. 16

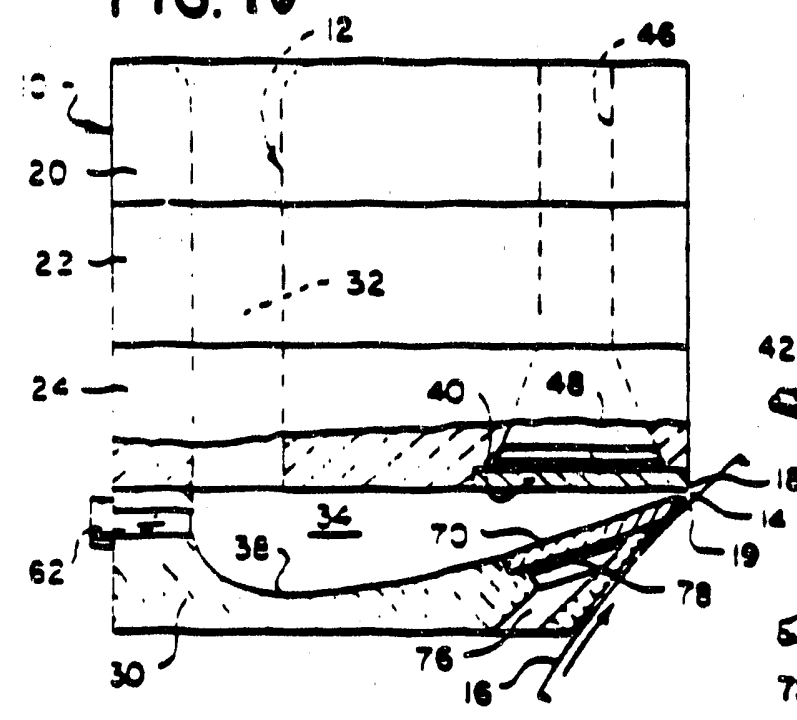

FIG. 15

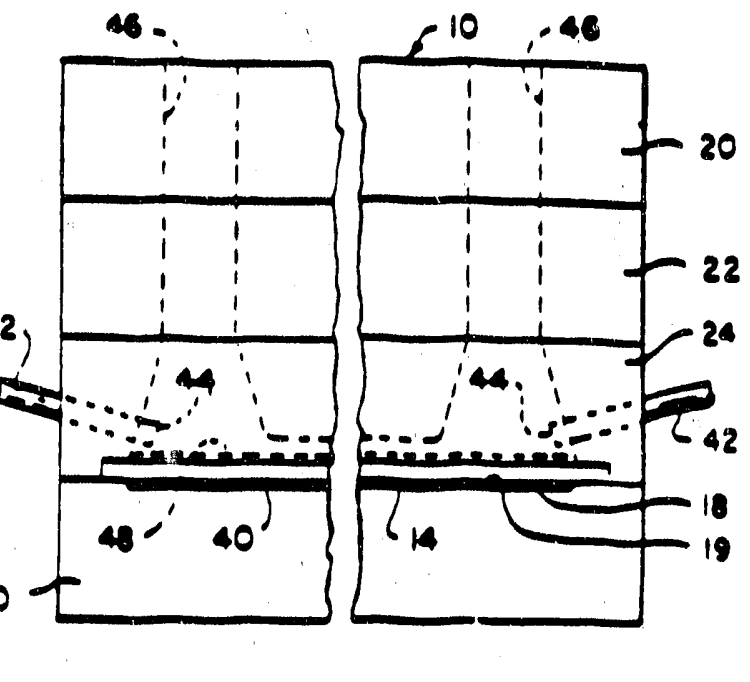

FIG. 17

40.
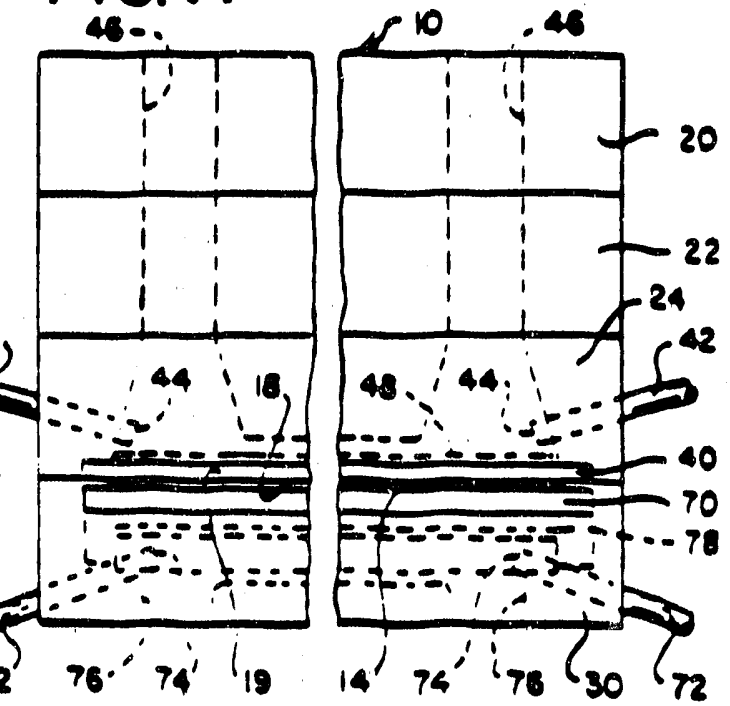

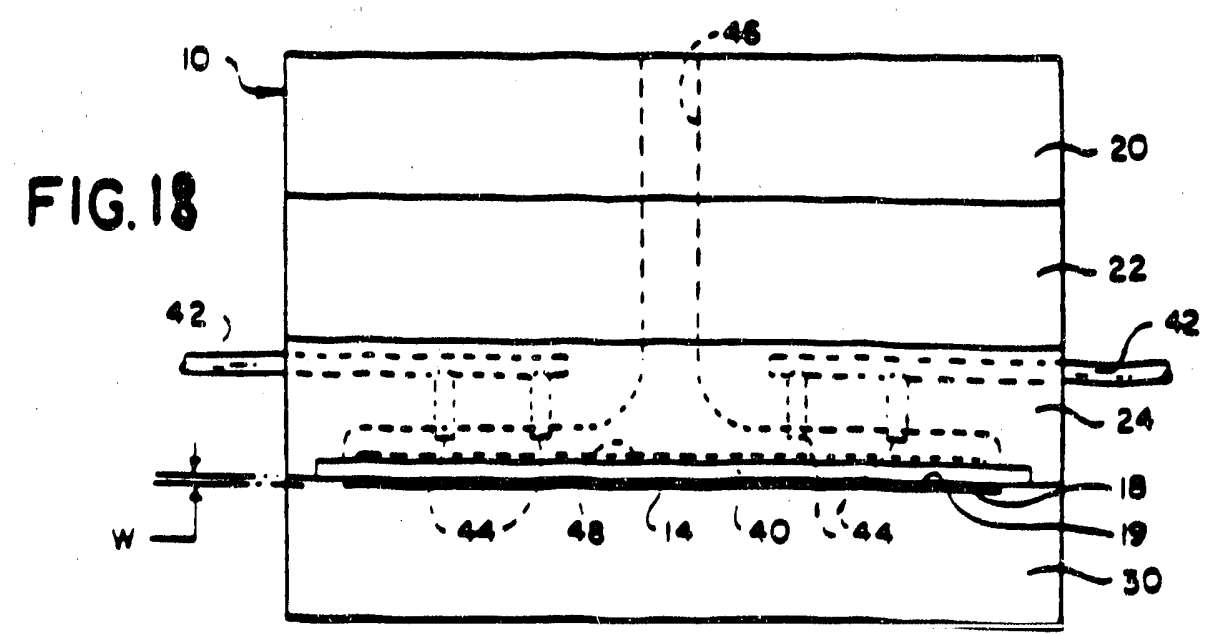


The ratio of frequency to power of the electromagnetic field determines how much energy goes into squeezing pressure (which squeezes molten material into strip) and how much into heat.

Again, Figs. 19 through 23 show the detalls of the set-up.

The invention claims that the magnetic field "forms" the ribbon on the wheel. But the impression from reading of the patent $1 \mathrm{~s}$, that the mechanism of ribbon formation is the same as in Planar. Flow Casting, except that to form a semiconductor ribbon much slower speeds (up to $20 \mathrm{~cm} / \mathrm{min}$. only) are used.

4. Pat. \#4,588,015 - H. H. Lieberman, Casting in an Exothermic Reducing Flame Atmosphere.

$\mathrm{CO}$ and $\mathrm{O}_{2}$ are brought upstream of casting wheel and ignited to create an exothermic reaction that provides a low density flame atmosphere near the puddle of molten metal. This results in less gas pockets entering the puddle and more contact area between the molten metal and the quench surface. Because of the reducing atmosphere and more uniform quenching, there is less oxidation, and the properties of the strip are improved. Figs. 24 through 29 show the details and the way the invention works; Figs. 30 and 31 compare the surface of strip made before the invention and with the invention; Figs. 32 and 33 show some theoretical and experimental results pertaining to the process parameters.

5. Pat. $\$ 4,600,048$ - T. Sato, Method for Continuous Casting of Metal Strip. In this invention jet casting is used and the casting surface is preheated by a laser beam just prior to entering the puddle. This high 
U.S. Patent Jan. 7, $1986 \quad$ Sheet 1 of $2 \quad 4,562,878$

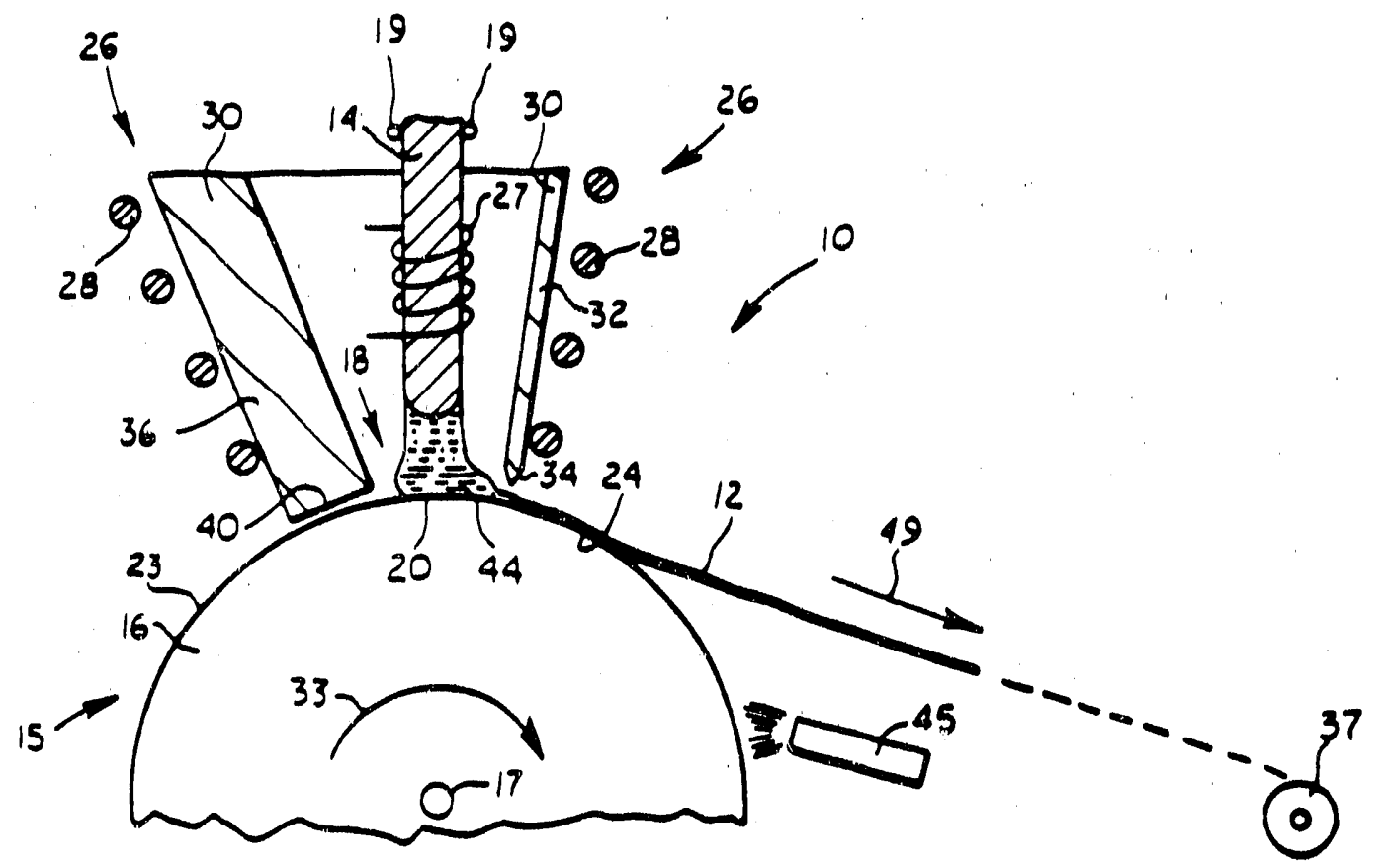

Fig- 19

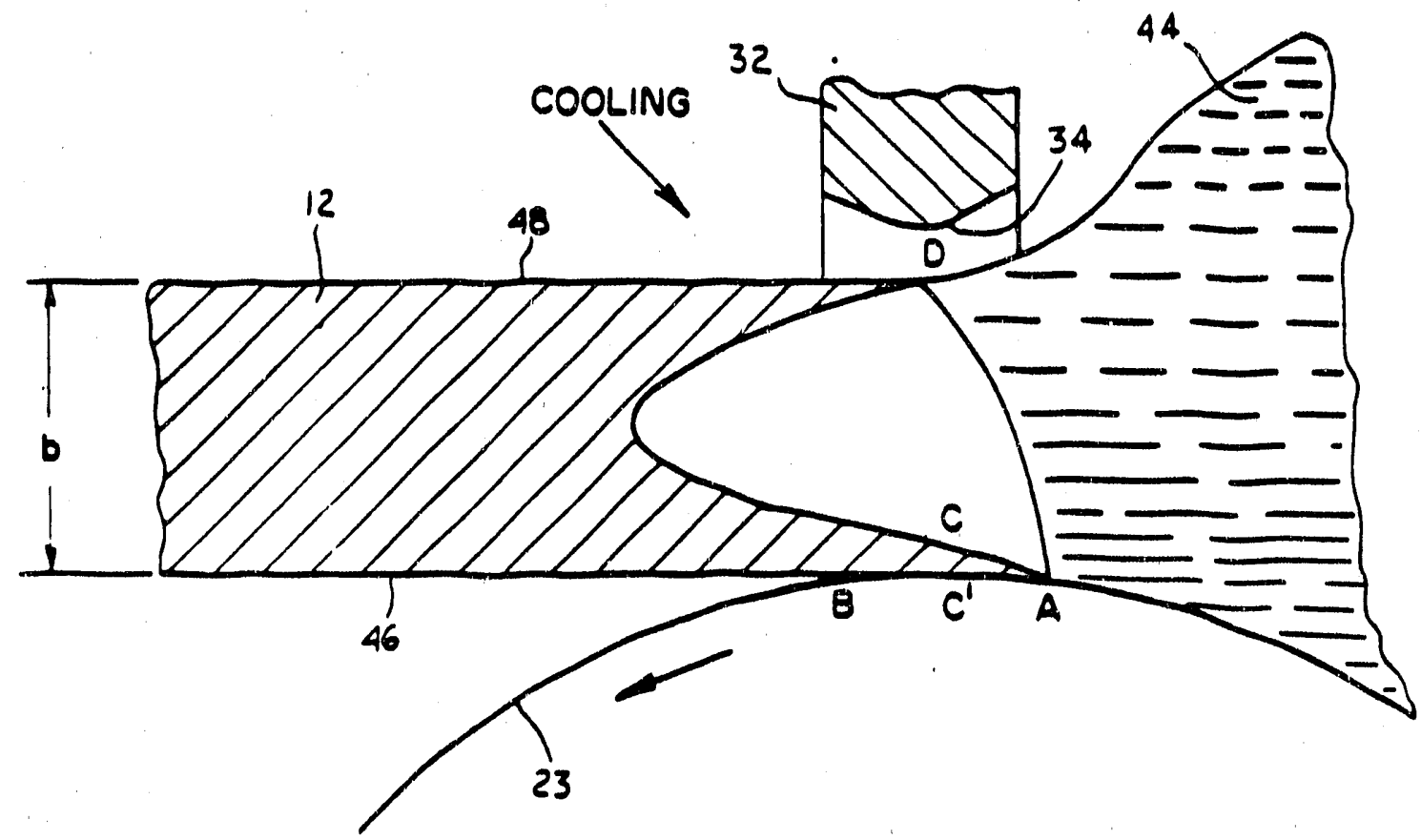

Fig-20 
U.S. Patent Jan. 7, $1986 \quad$ Sheet 2 of $2 \quad 4,562,878$

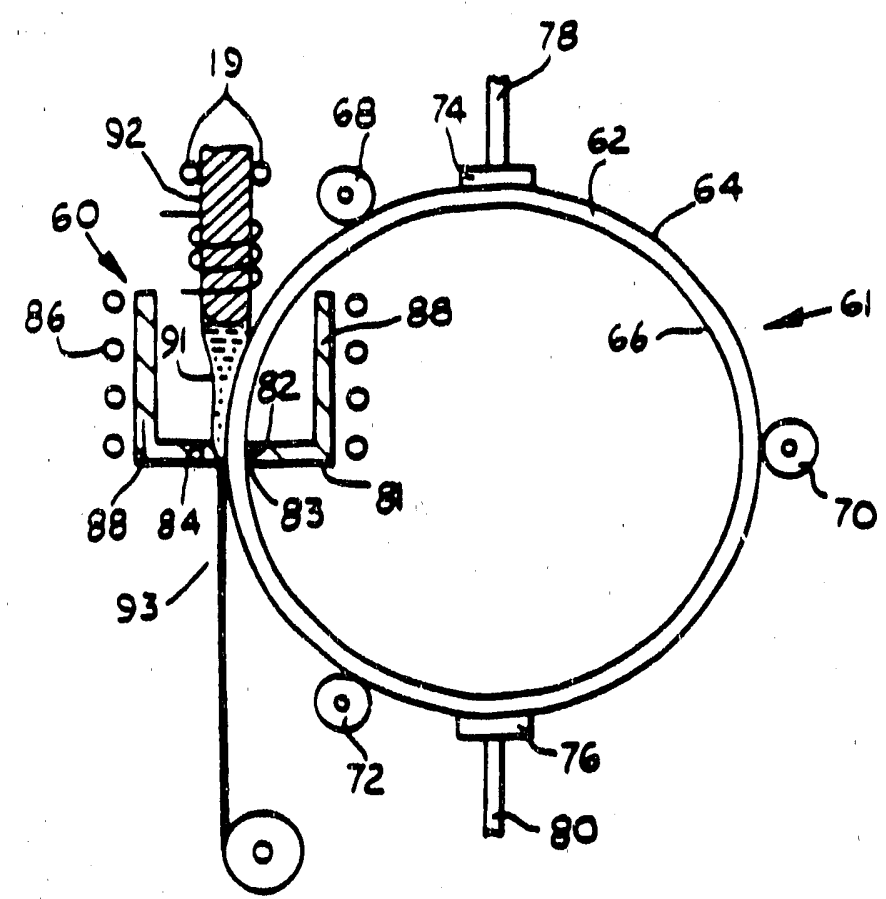

Fig-2I

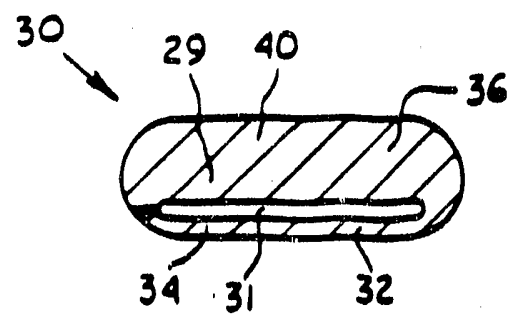

Fig-22

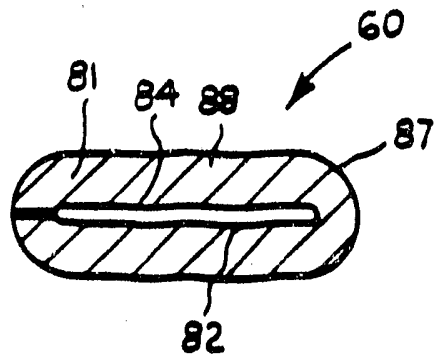

Fig-23 
U.S. Patent May 13,1986 Sheet 1 of $6 \quad 4,588,015$
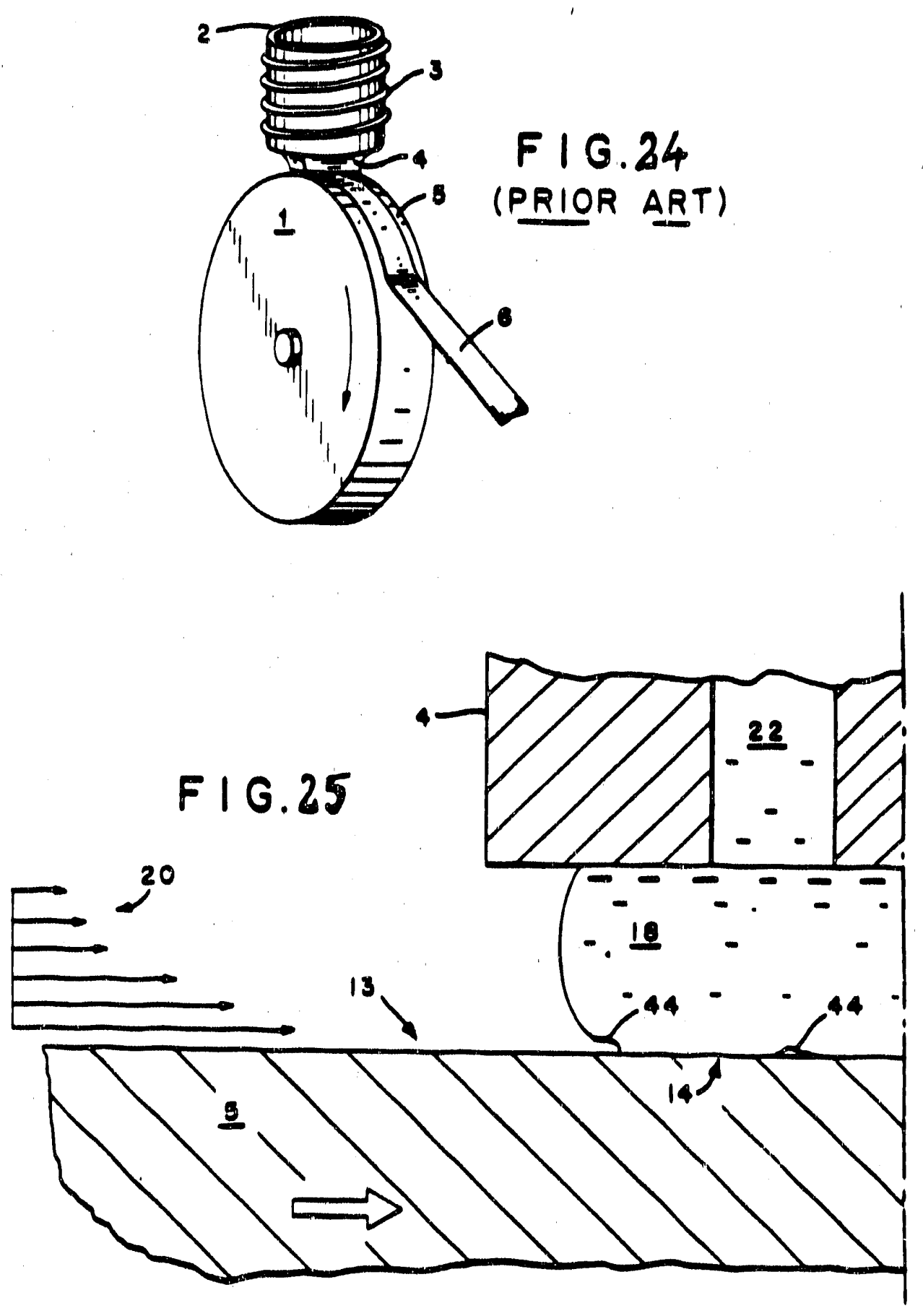


\section{U.S. Patent May 13,1986 Sheet 2 of $6 \quad 4,588,015$}
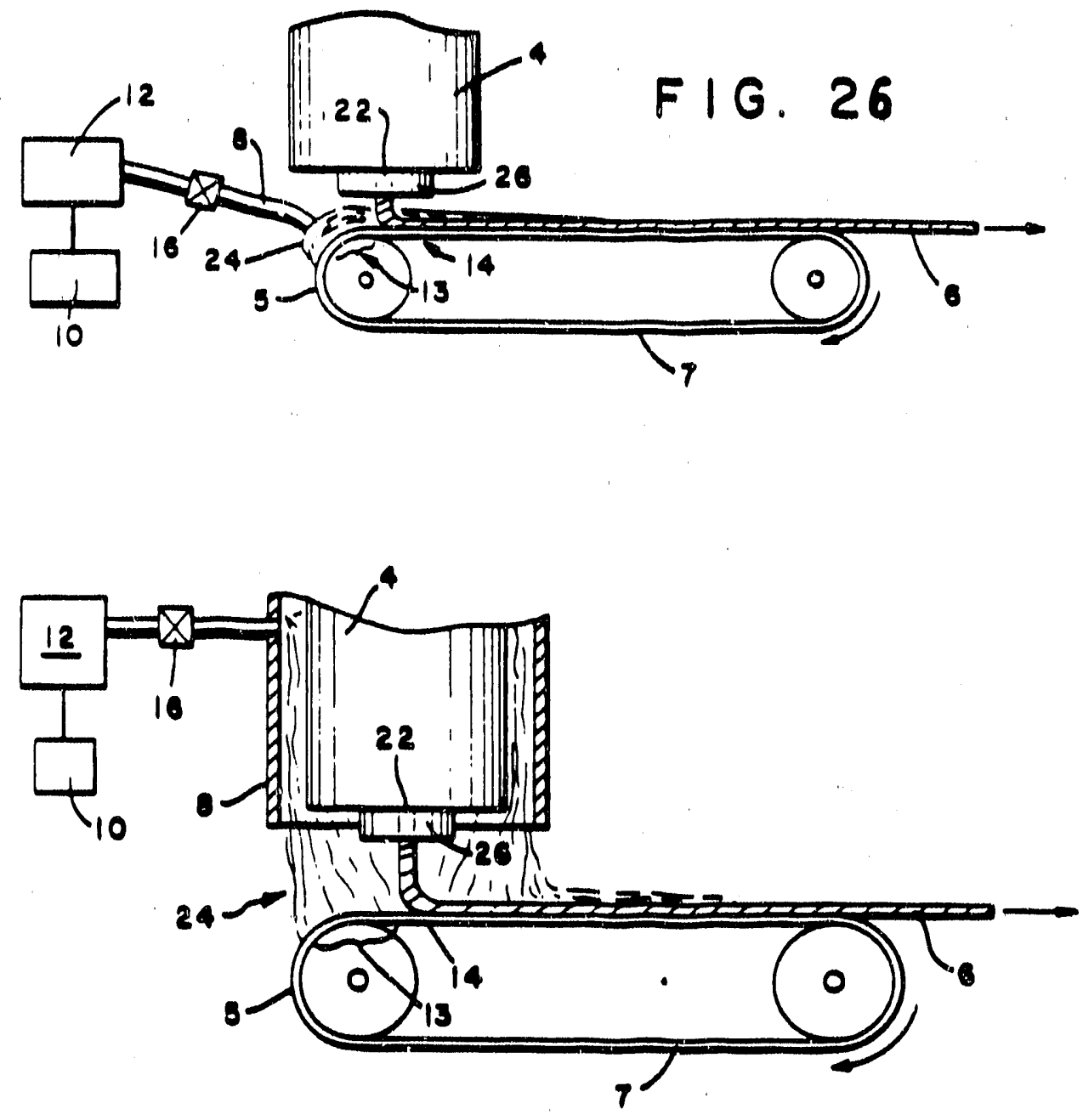

F | G.27 
U.S. Patent May 13,1986 Sheet 3 of $6 \quad 4,588,015$
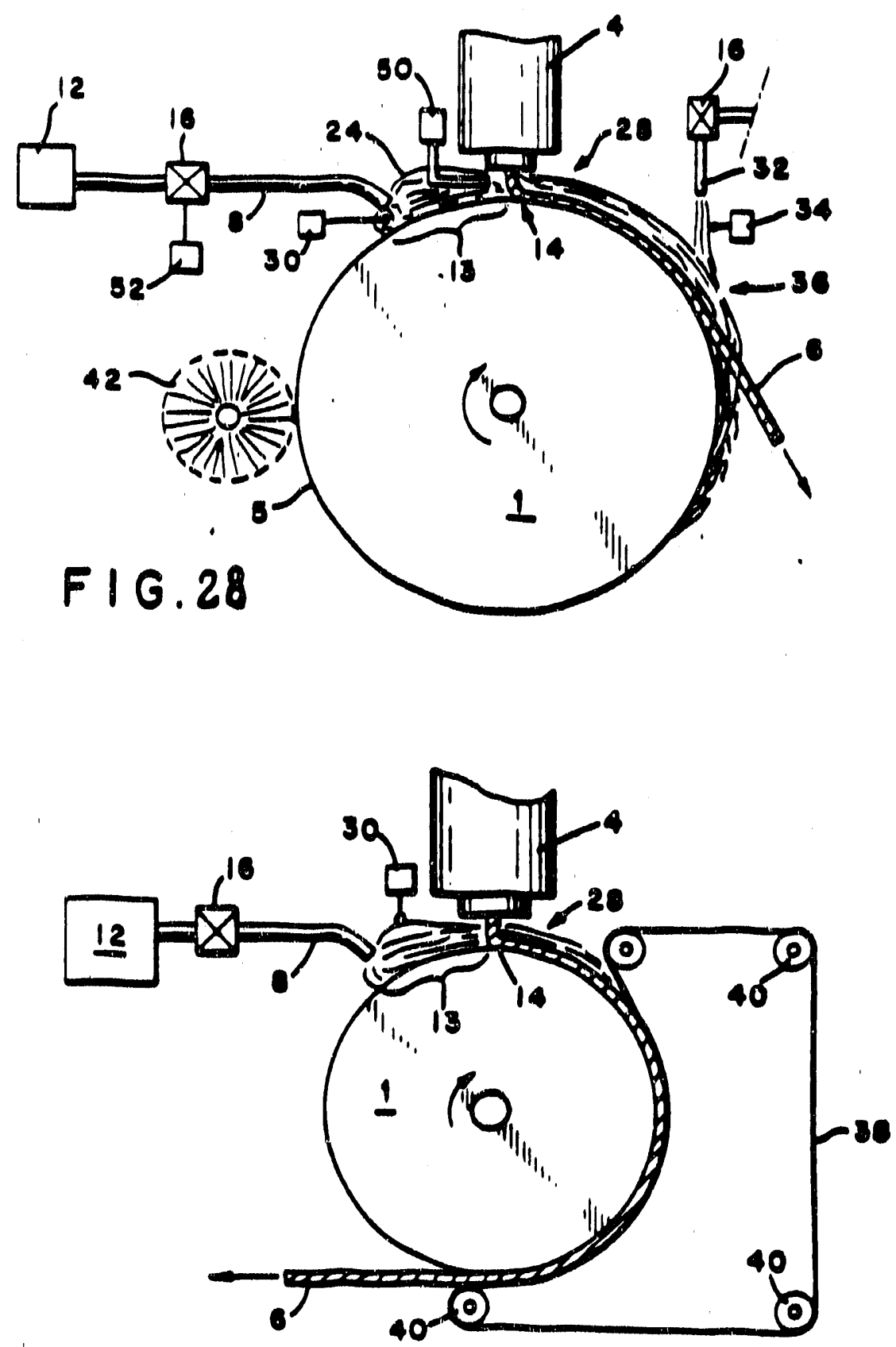

FIG.29 


\section{U.S. Patent May 13, 1986 Sheet 4 of $6 \quad 4,588,015$}
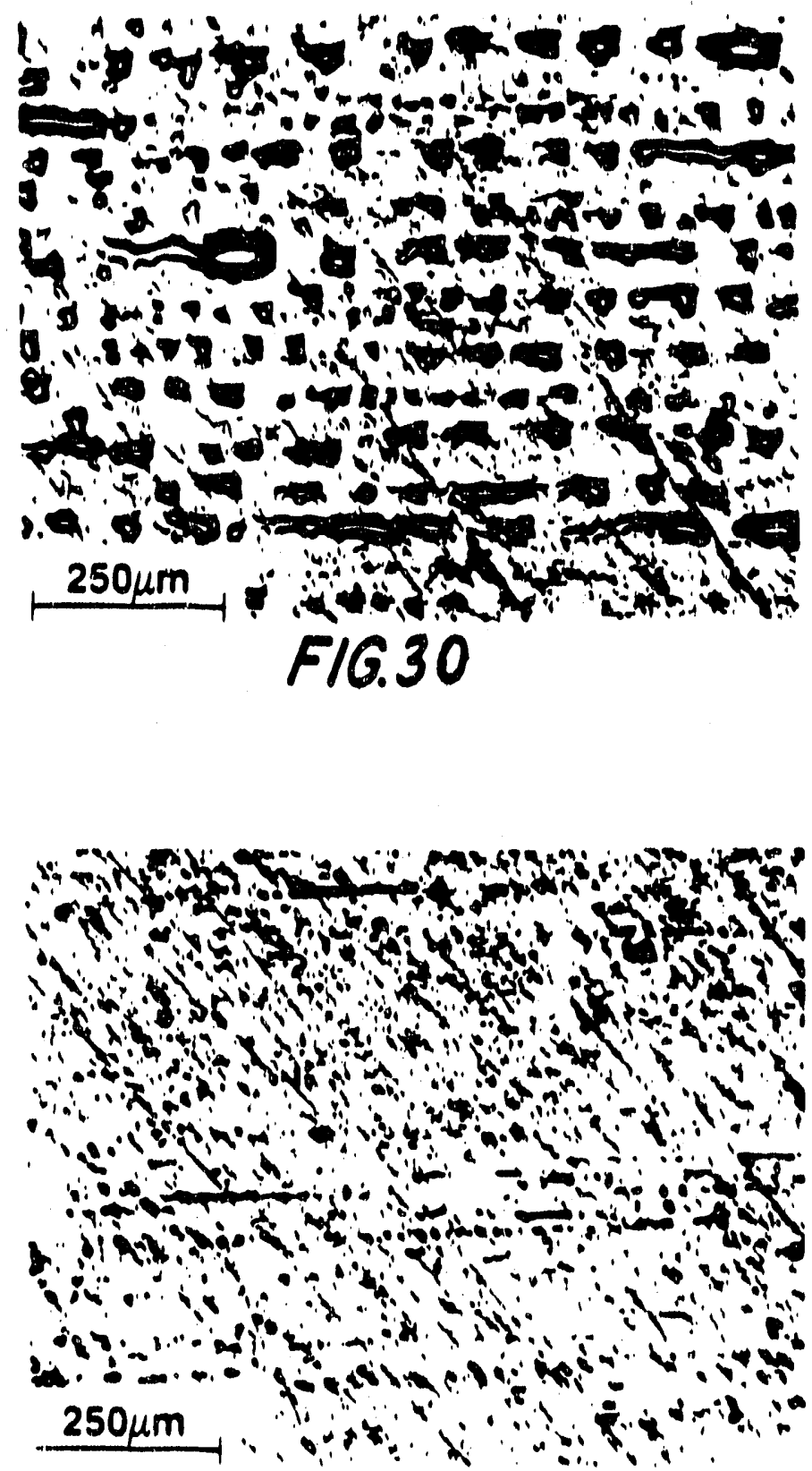

FIG.31 


\section{U.S. Patent May 13, 1986 Sheet 5 of $6 \quad 4,588,015$}

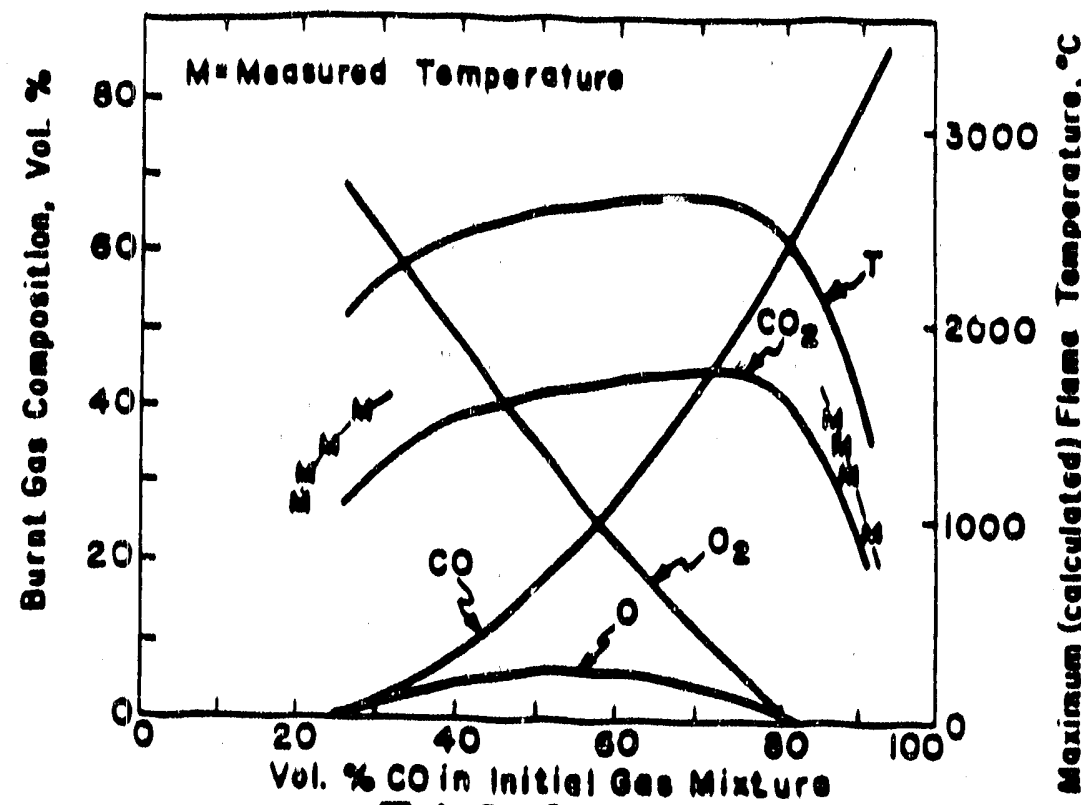

F | G. 32

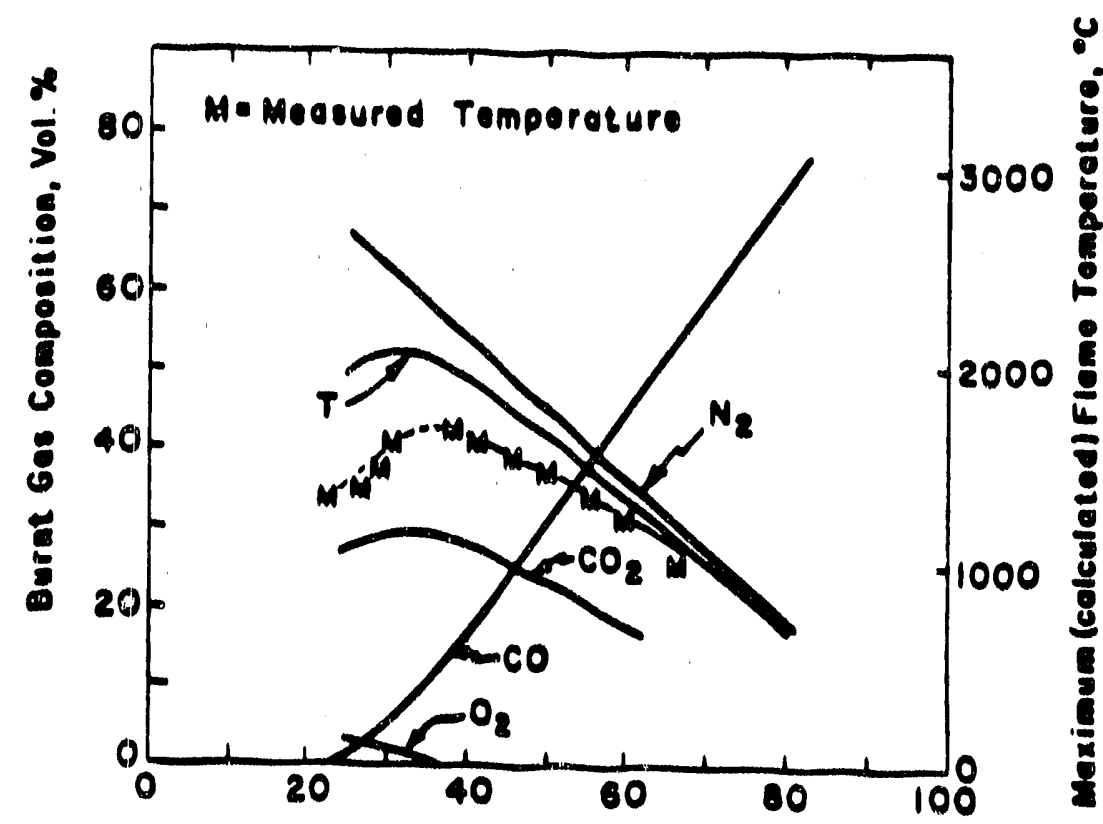

Vol. \%coin Initial oos Mixture

F IG.33 
density energy source heats up the surface of the wheel to a relatively high temperature. The authors clatm a better and more uniform strip is made by their process.

Detalls of the process are shown in the flgures 34-38. F1g. 34 shows the set-up; Fig. 35 the vartous orifice arrangements; and Figs. 36, 37 and 38 the various laser beam arrangements and distances from the casting point.

6. Pat. $\# 4,601,326$ - C. T. Tingler, Ribbon Casting Apparatiss with Magnetic Retainer and Resilitent Spacer.

In this invention a magnetic field is used to prevent early departure of ribbon from the belt. Resillent spacer (stainless steel, slim stock) is used to separate the belt (25) from the magnets $(30,32)$. Fig. 39 is the experimental set-up and Figs. 40 and 41 show the detatls of the resilient spacer (40).

7. Pat. $\# 4,646,812$ - R. E. Maringer, Flow Casting.

This invention relates to the method of casting polycrystalline metallic strips having thicknesses of $20-500 \mathrm{~m} / 1 \mathrm{~s},(.508-12.7 \mathrm{~mm})$ at high quench rates. The strip is quenched from buth sides; belt on the bottom side and a squeegee roll on the top. Fig. 46 shows the general view of the invention and Figs. 42 through 45 the details of the arrangement.

8. Pat. \#4,649,983 - V. Laxmanan et al., Chill Roll Casting of Metal Strip. In this invention a metalitic mesh hugger belt (4)(Figs. $47 \& 48$ ) is used to control the pressure on the wheel and strip. As a result, more 


\section{U.S. Patent JuL 15, 1986 Sheet 1 of $2 \quad 4,600,048$}

FIG. 34

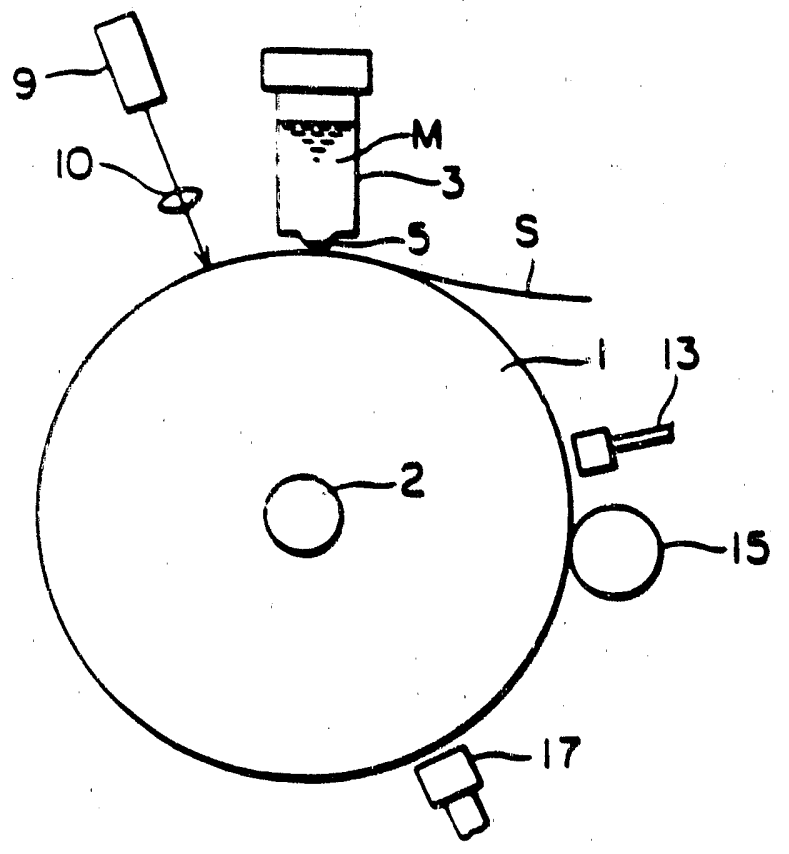

FIG. 35
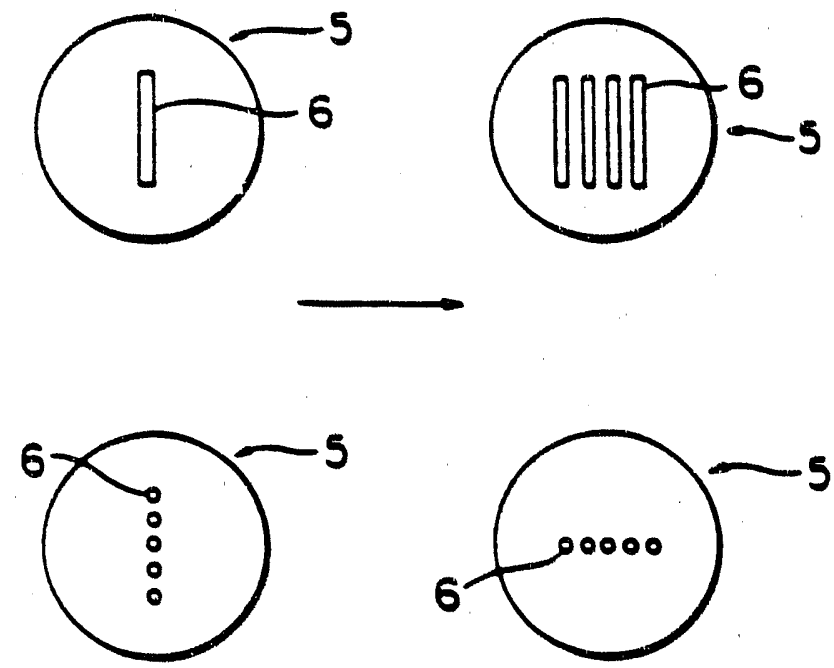
U.S. Patent JuL 15, 1986 Sheet 2 of $2 \quad 4,600,048$

FIG. 36

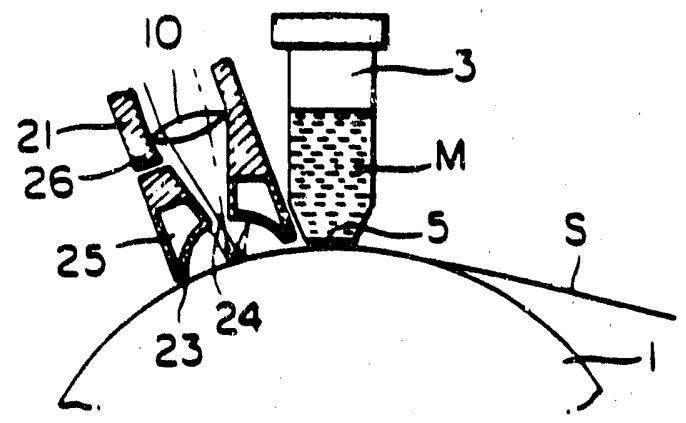

FIG. 37

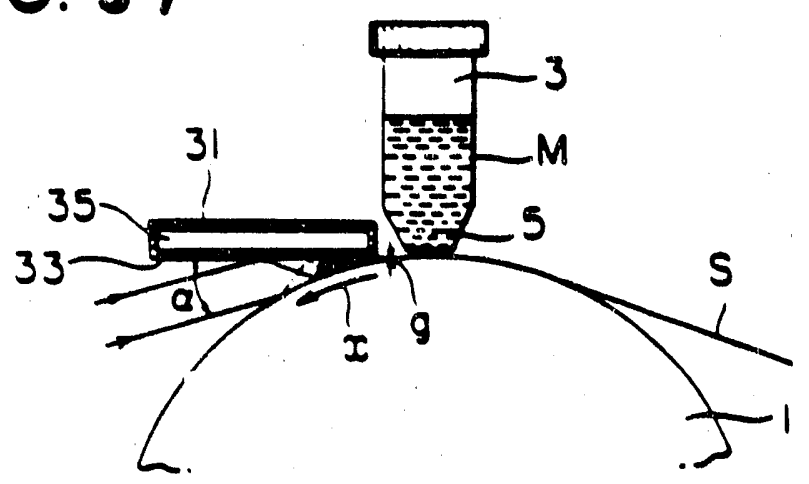

FIG. 38

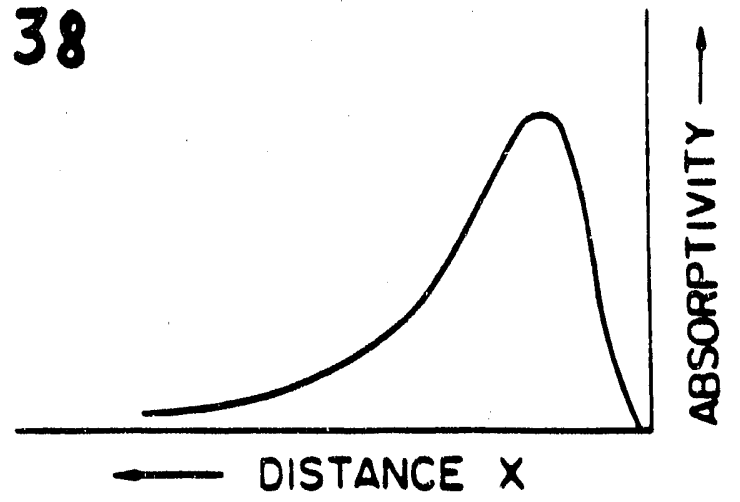


U.S. Patent

Jul. 22, 1986

$4,601,326$

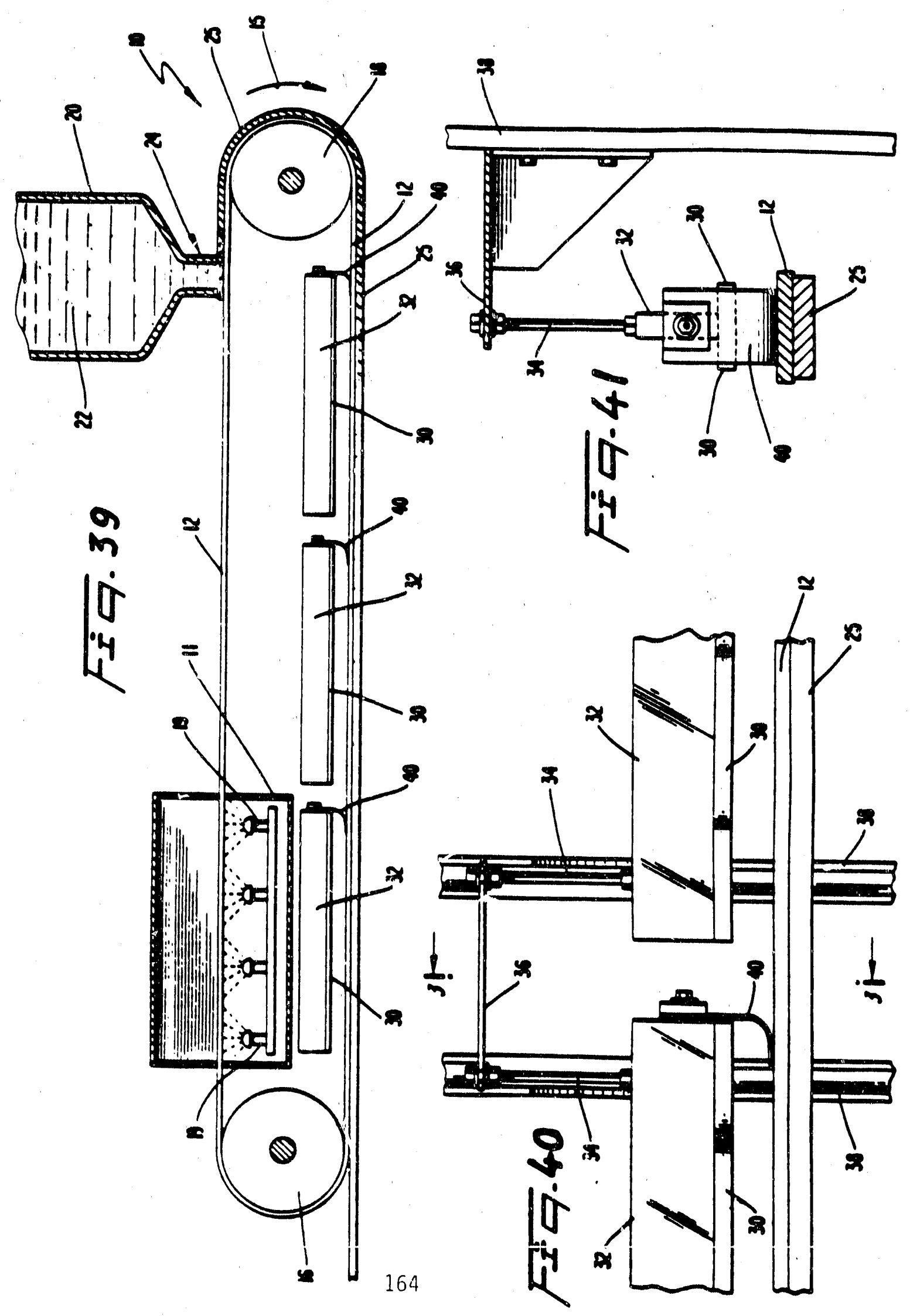




\section{U.S. Patent $\quad$ Mar. 3, $1987 \quad 4,646,812$}
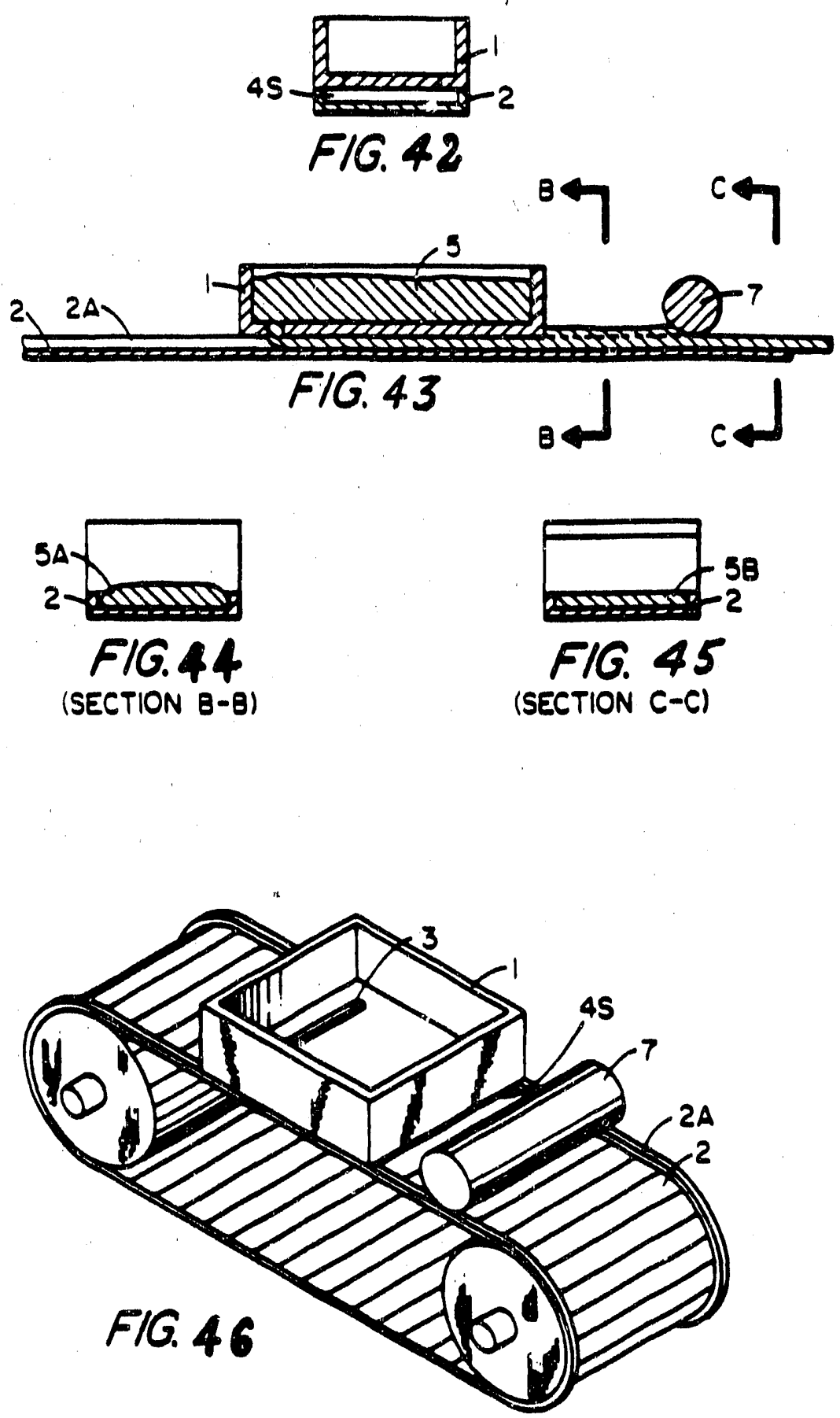
U.S. Patent Mar. 17, 1987 Sheet 1 of $15 \quad 4,649,983$
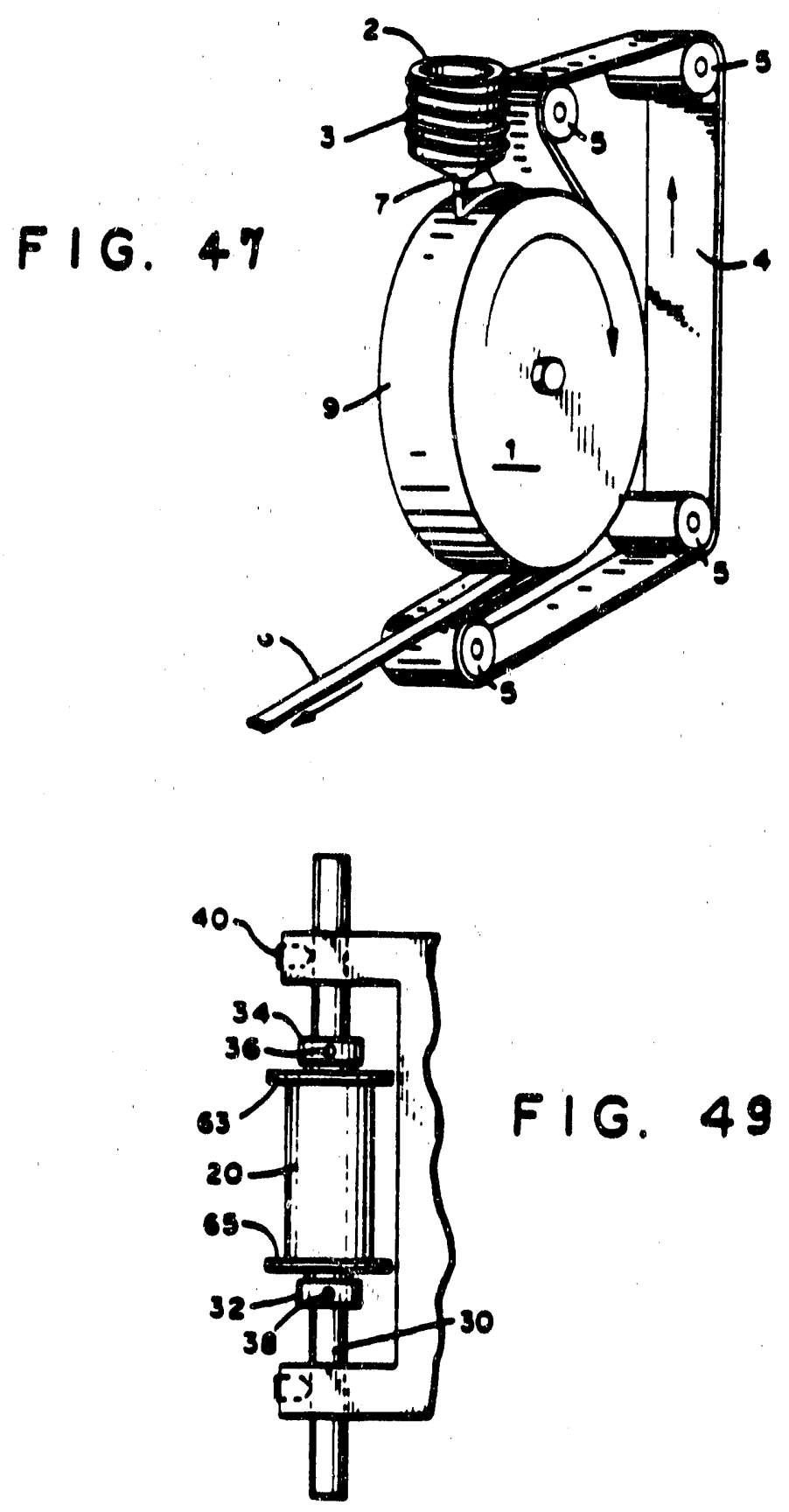


\section{U.S. Patent Mar. 17, 1987 Sheet 3 of $15 \quad 4,649,983$}

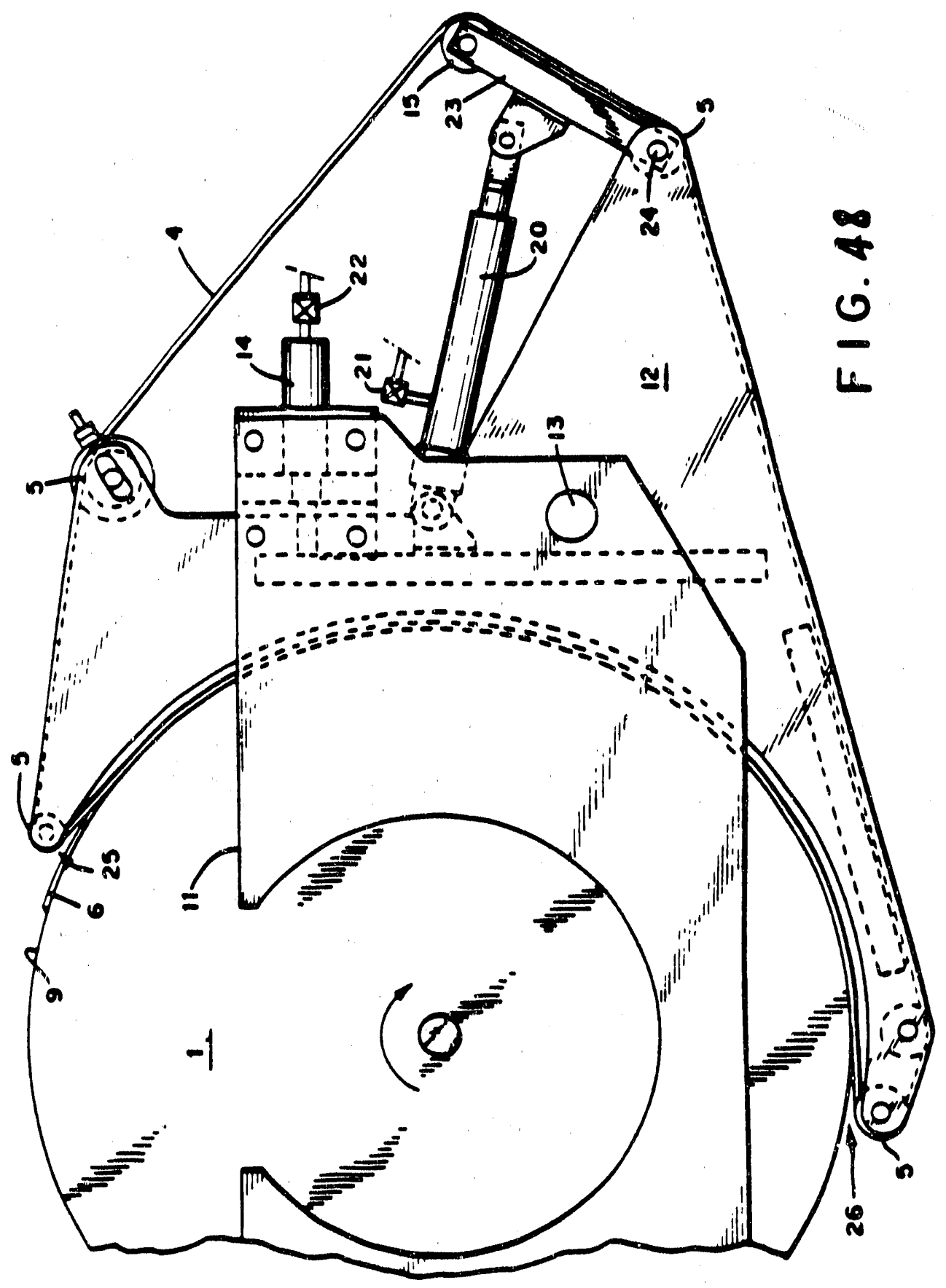


uniform strip dimensions and physical properties are obtained. Especially improved are the magnetic properties in a $\mathrm{Fe}-6.5 \% \mathrm{Si}$ alloy.

In case of the $\mathrm{Fe} \cdot 6.5 \%$ st alloy, the invention produces a columnar grain structure with<100> fiber structure (Fig. 51 \& 52). This proce:s includes pickling the ribbon in an acid bath and subsequent annealing in an oxygen 1 imited atmosphere, such as in a vacuum or a hydrogen atmosphere. The material has excellent isotropic ferromagnetic properties (B-H curve) (Fig. 53 a, b, c).

Enclosed figures show the set-up as it existed prior to this invention (Fig. 47), and of this invention (Fig. 48). Fig. 49 shows details of a belt roller; fig. 50 the optional arrangement for a casting belt.

9. Pat. $\$ 4,649,984$ - J. R. Bedel et a1., Method of and Apparatus for Casting Metal Strip Employing a Localized Conditioning Shoe.

The invention contains a description of a "shoe box", encompassing the nozzle, which controls, to a degree the atmosphere around the casting nozzle. They call it a "conditioning chamber"; it forms a low density atmosphere around nozzle which minimizes air pockets on the wheel. This results in a better strip and strip properties.

Figs. 54 and 55 show two possible embodiments of the invention (shown from two different sides - from the front and from the side of the casting wheel). Figs. 56 and 57 show specific details of the shoe box arrangements. 


\section{U.S. Patent Mar. 17, 1987 Sheet 2 of $15 \quad 4,649,983$}
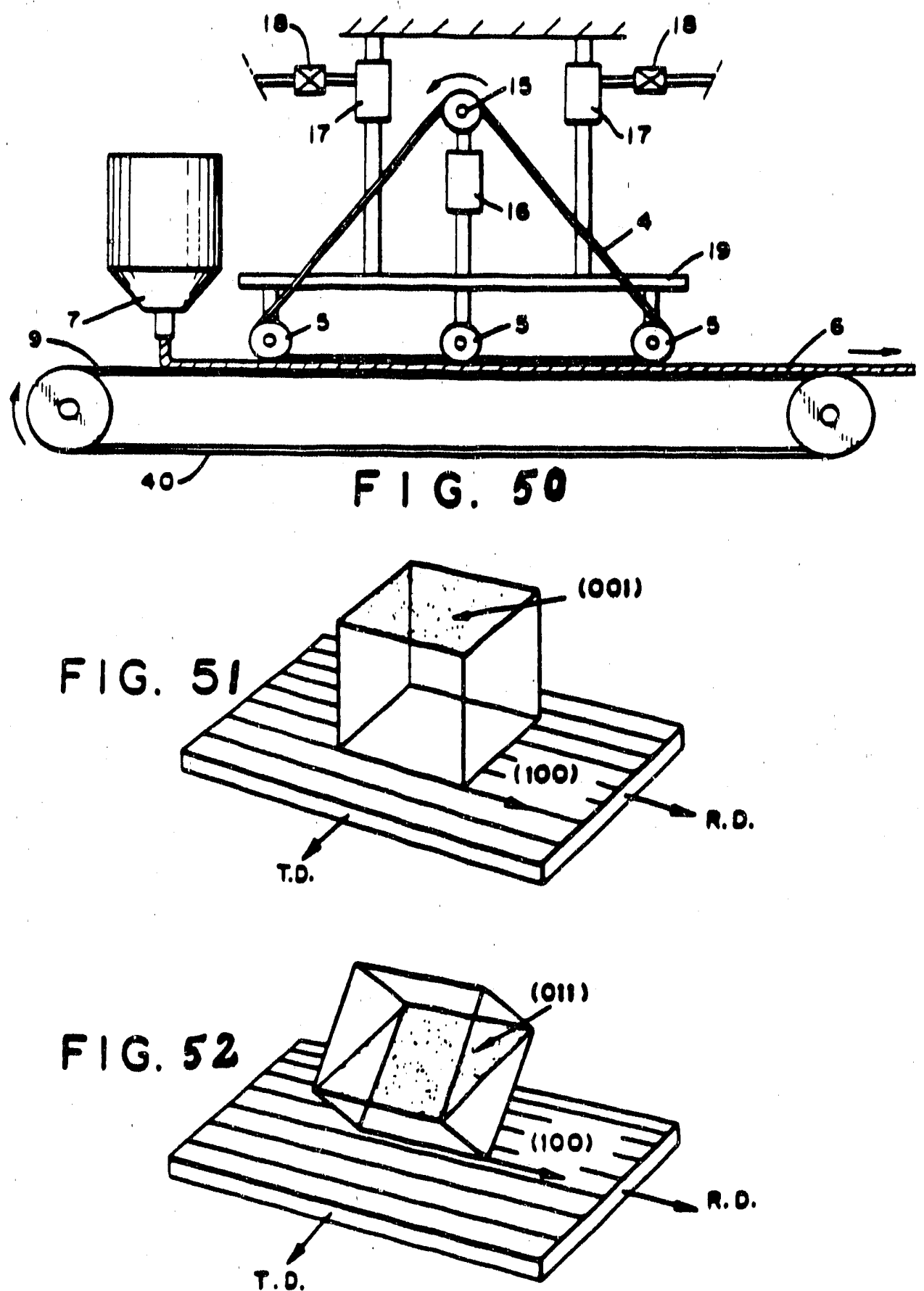

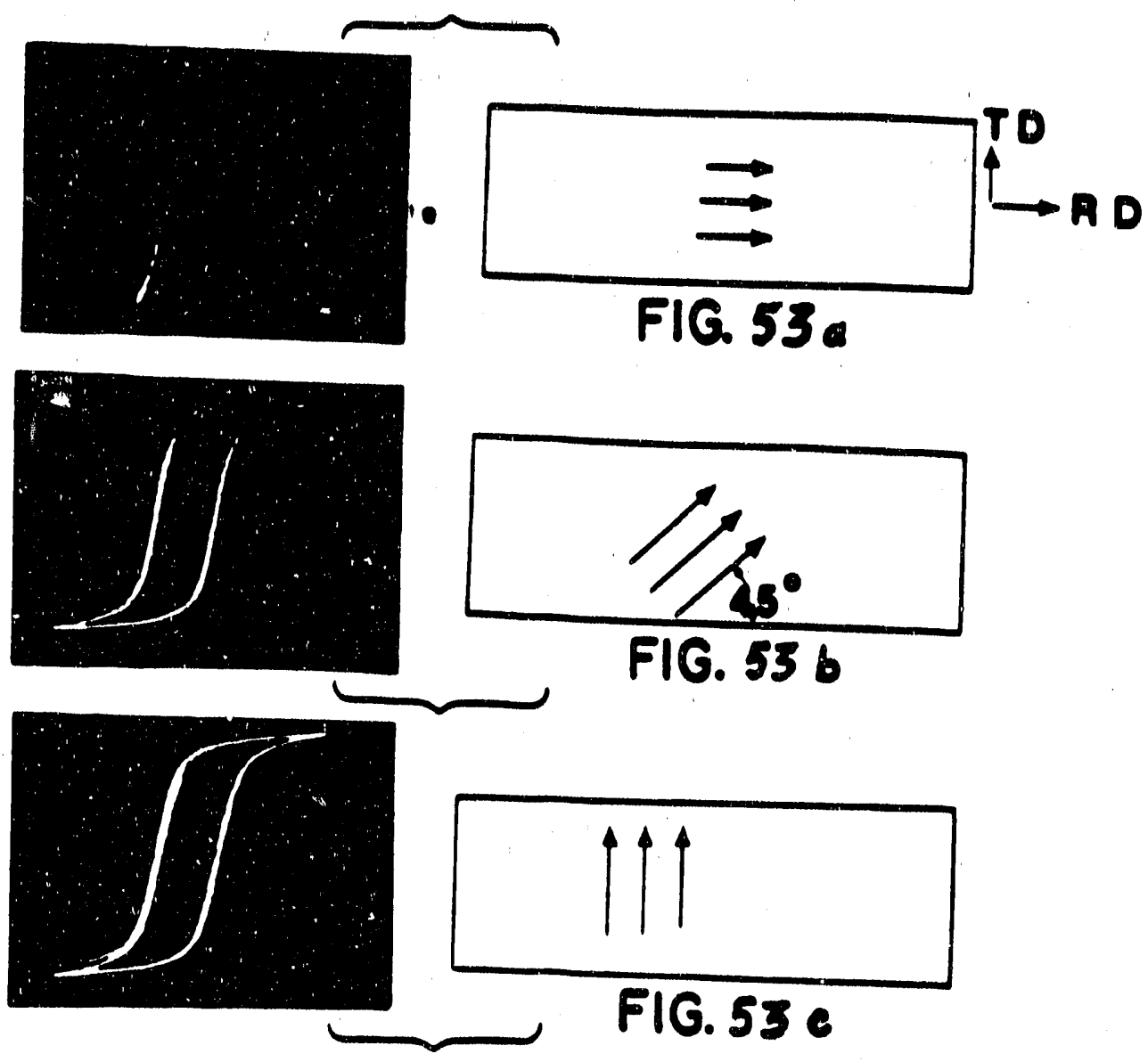


\section{U.S. Patent Mar. 17, 1987 Sheet 5 of $9 \quad 4,649,984$}

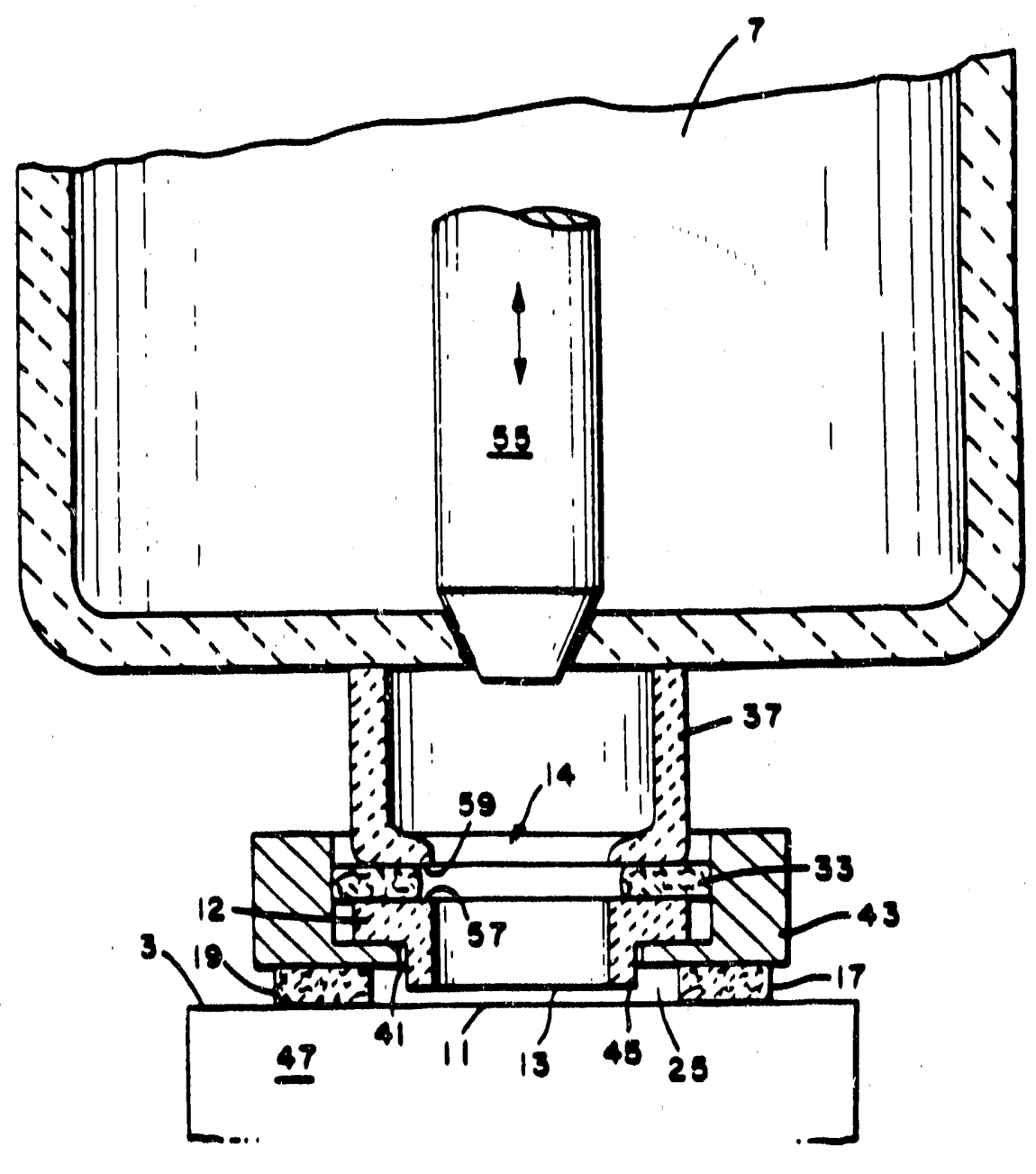

F IG. 54

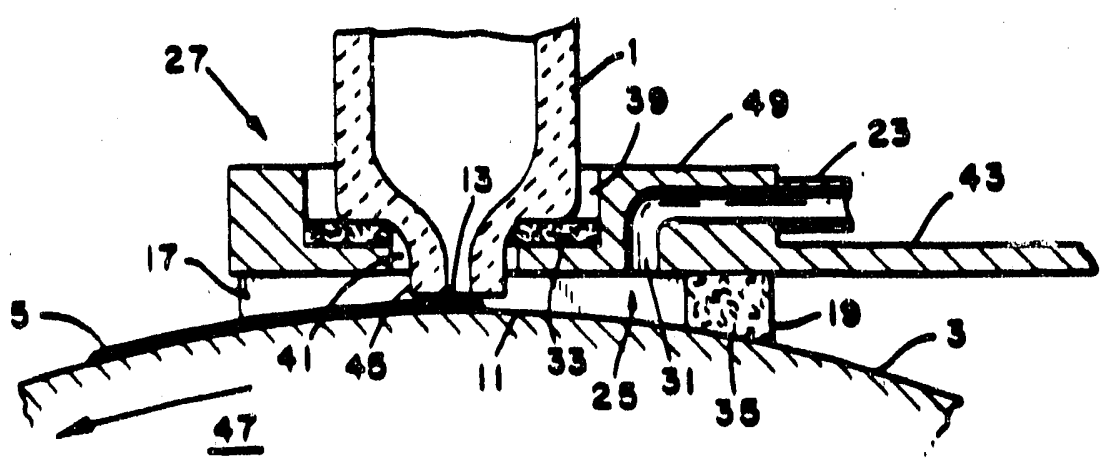

F!G. 55 
U.S. Patent Mar. 17, 1987 Sheet 4 of $9 \quad 4,649,984$

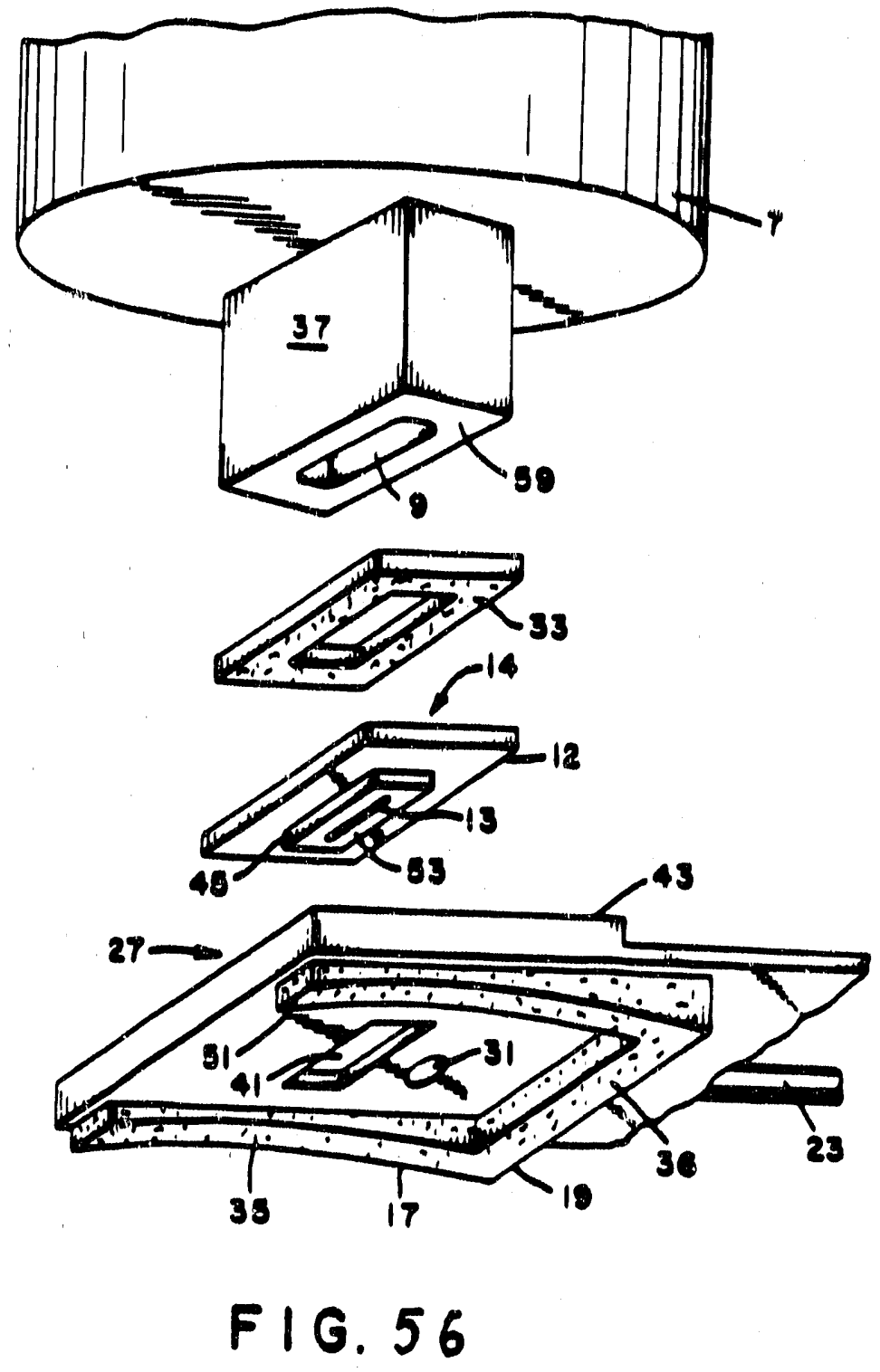




\section{U.S. Patent Mar. 17, 1987 Sheet 3 of $9 \quad 4,649,984$}
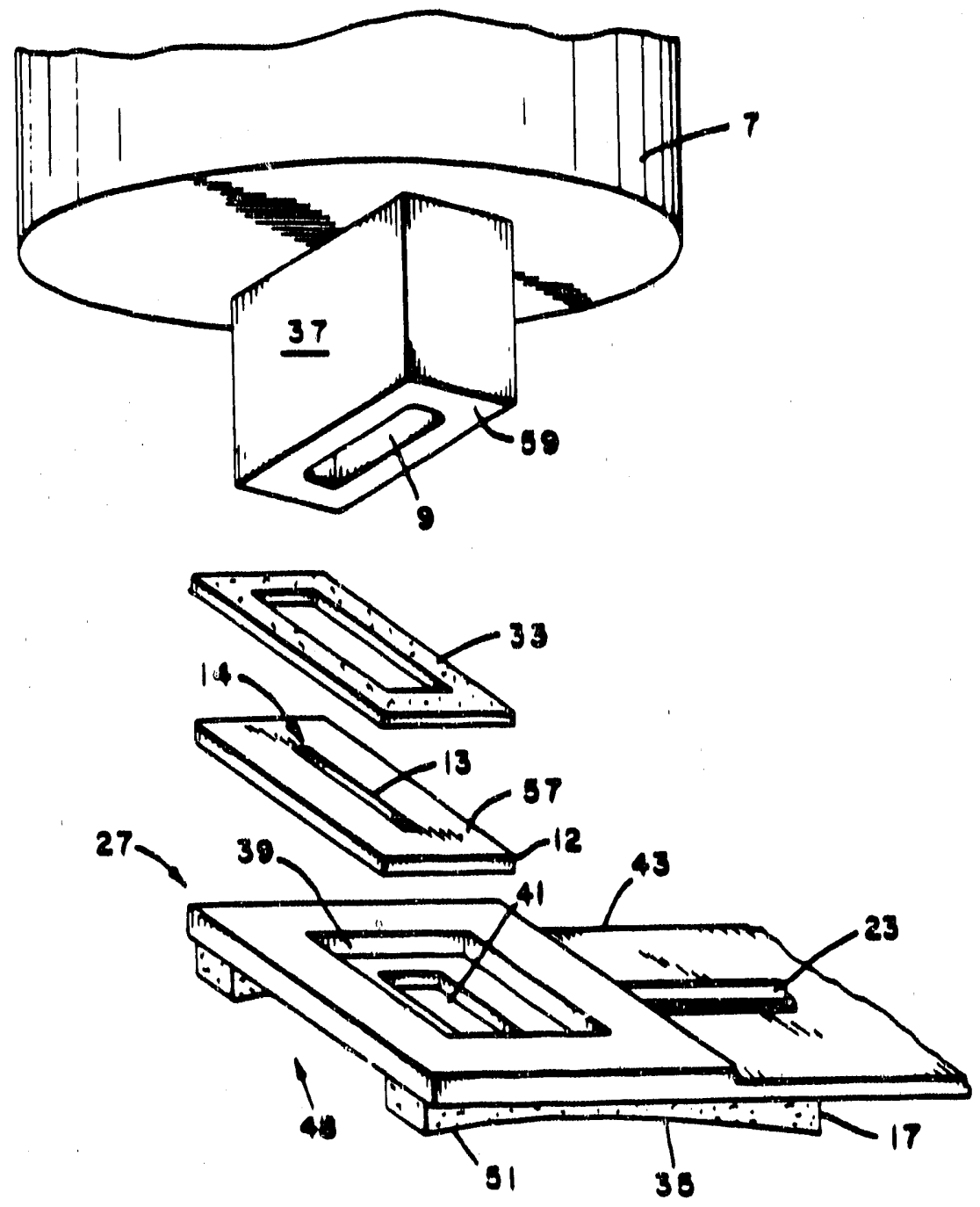

F IG. 57 
10. Pat. \#3,650,618 - W. Hetneman, Method for Producing Strip-11ke or Foll-11ke Products.

The object of this invention is to make unlimited width strip, with separate areas of different structures (e.g. amorphous and/or crystalline). This is achieved through a plurality of juxtaposed nozzles, for metals and oxides. Different areas of the substrate have different thermal conductivity charactertstics. Thts can be useful in casting simultaneously strlps with different properties. Fig. 58 shows the general view of the invention and Fig. 59 - side view. Fig. 60 shows posstble nozzles orifices arrangements and Fig. 61 - possible casting wheel configurations.

11. Pat. \#4,705,095 - T. A. Gaspar, Textured Substrate and Method for the Direct, Continuous Cisting of Metal Sheet Exhtbiting Improved Uniformity.

According to this invention "thick" strip can be cast with uniform thickness and properties with the use of a textured surface as a substrate. Preferably the texture is constructed utilizing conventional knurling techniques which produce a surface as shown in Figs. 62 and 63 . The inventors use standard melt-drag process for casting on the knurled surface of the wheel. They claim that their experiments show that it significantly affects thickness of the cast ribbon (Fig. 64). However, the knurling technique for increased heat conductivity is mentloned in the U.S. Patent 3,345,738 (1967) (not reviewed here), but not as a significant factor in increasing the quenched thickness of the strip. 
U.S. Patent Mar. 17, 1987 Sheet 1 of $6 \quad 4,650,618$

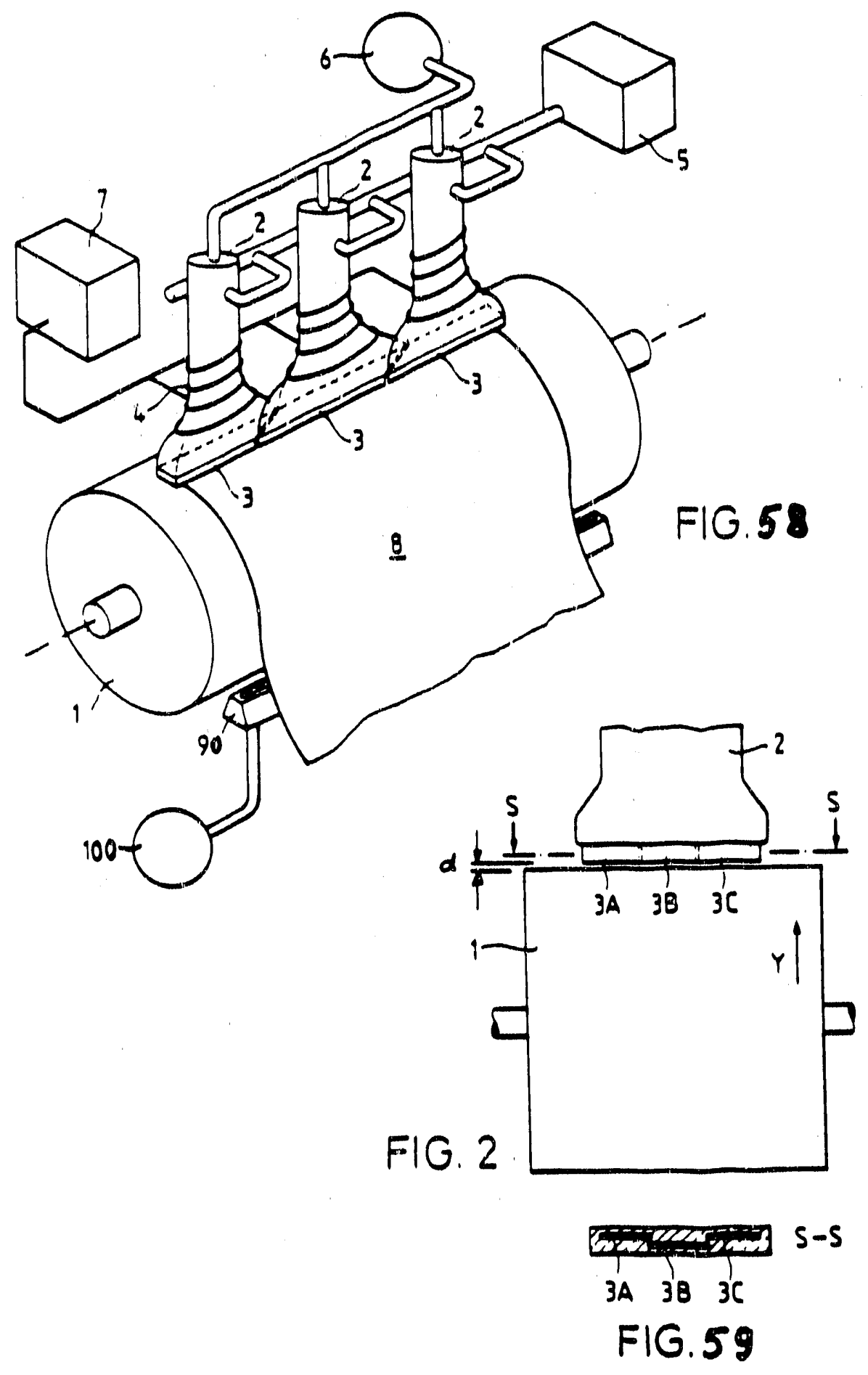




\section{U.S. Patent Mar. 17, 1987 Sheet $3 \propto f 6 \quad 4,650,618$}
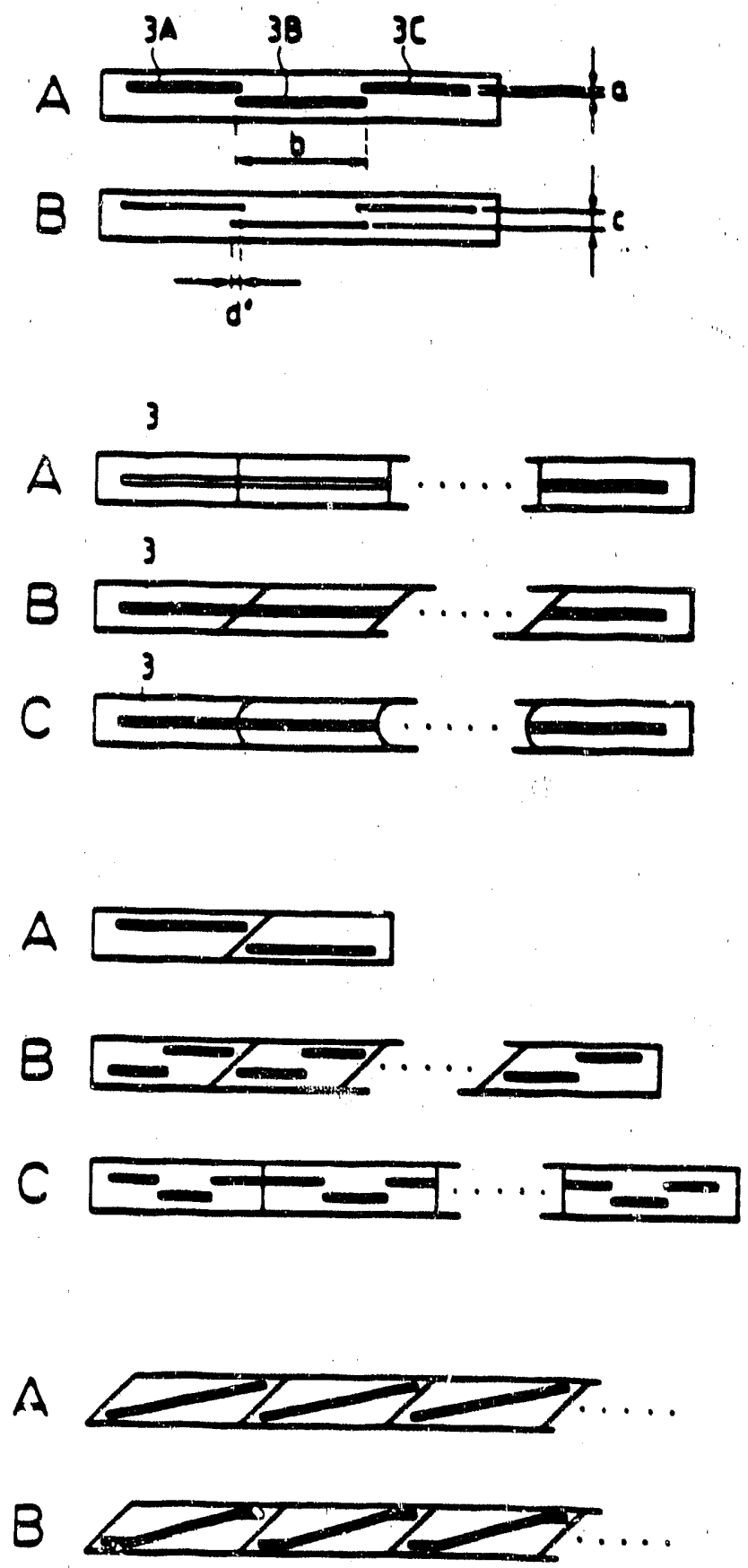

FIG. 60 


\section{U.S. Patent Mar. 17, 1987 Sheet 5 of $6 \quad 4,650,618$}
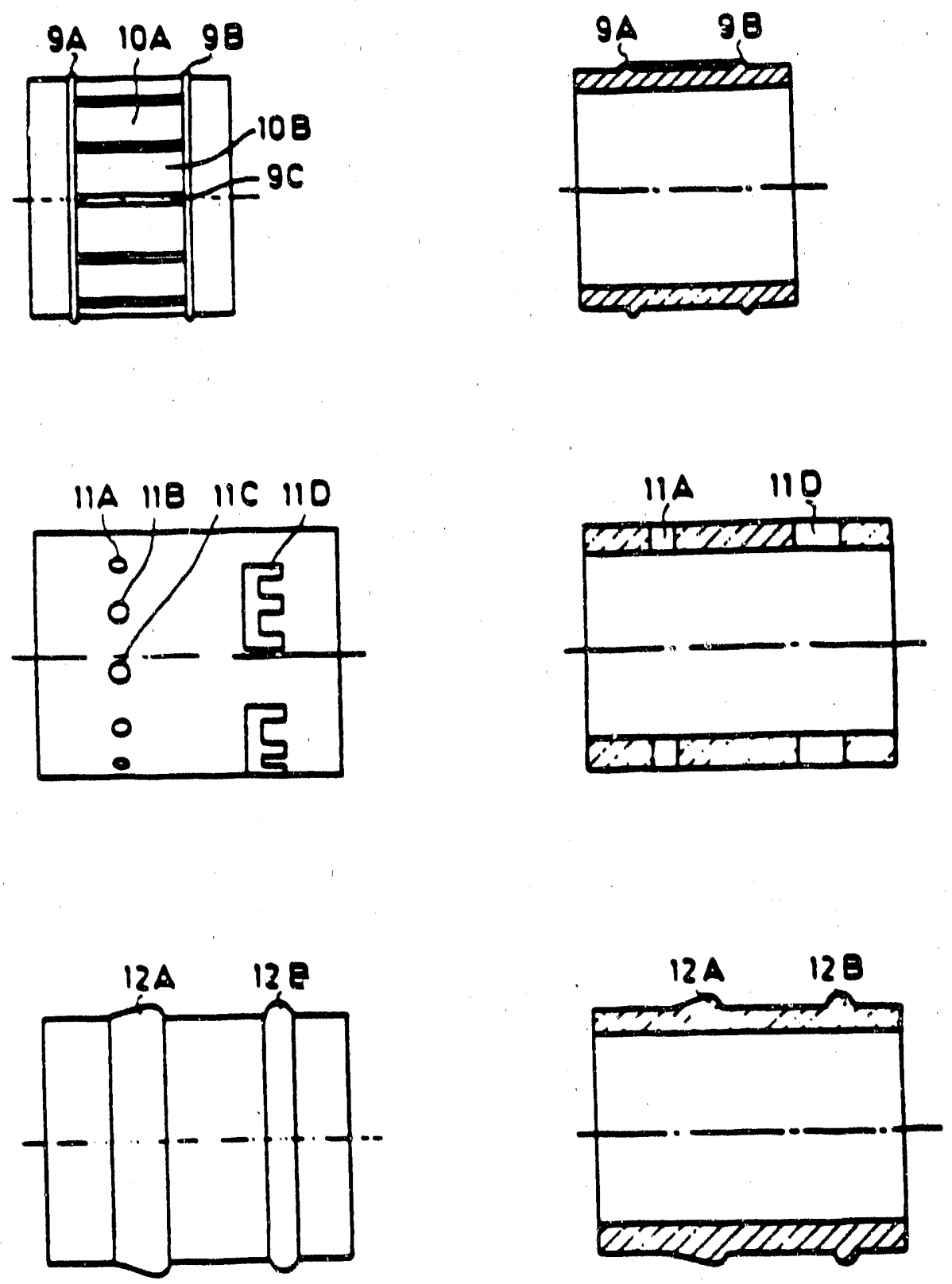

$F \mid G .61$ 
U.S. Patent Nov. 10, 1987 Sheet 2 of $4 \quad 4,705,095$
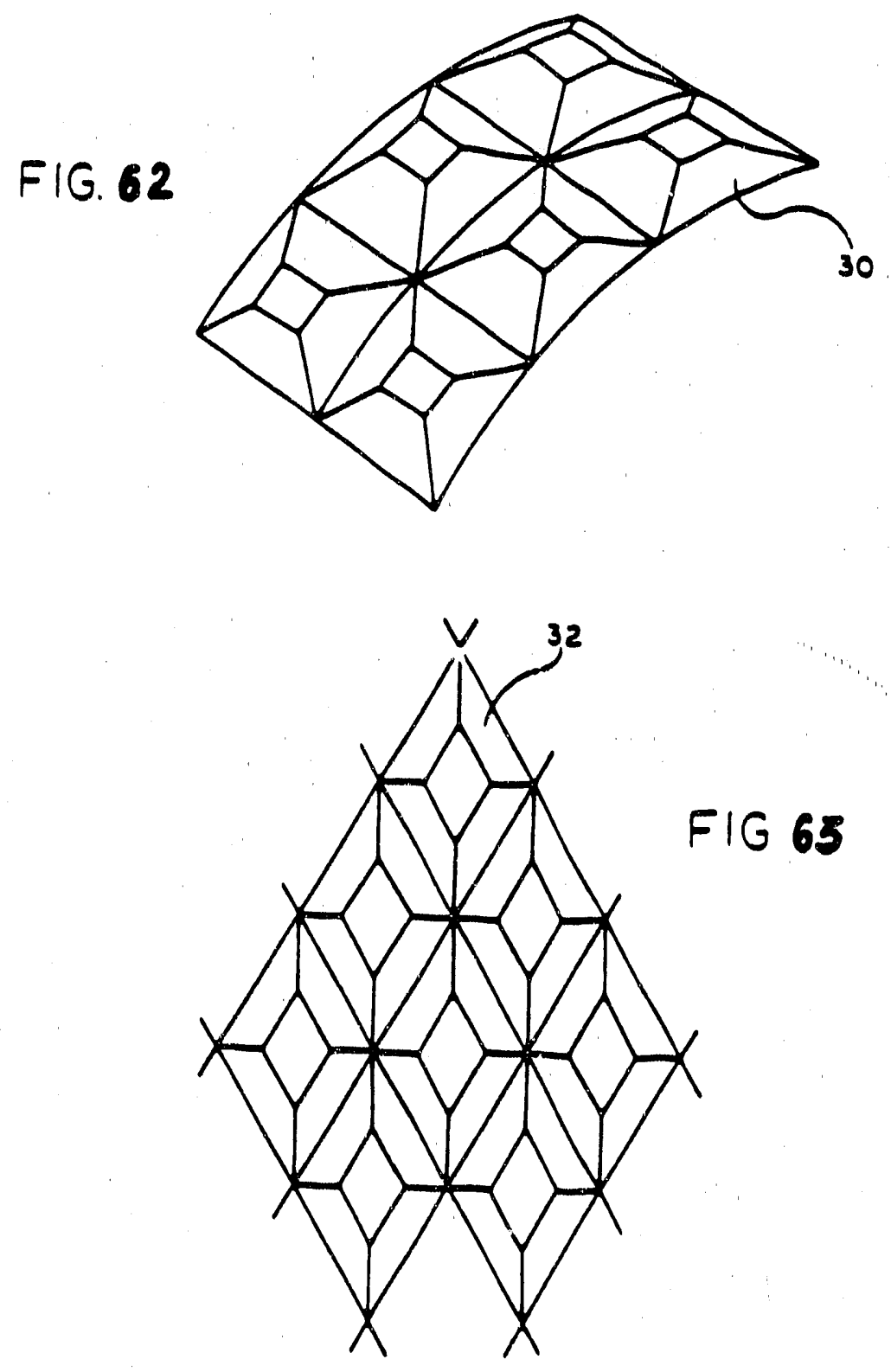


\section{U.S. Patent Nov. 10, 1987 Sheet 4 of $4 \quad 4,705,095$}

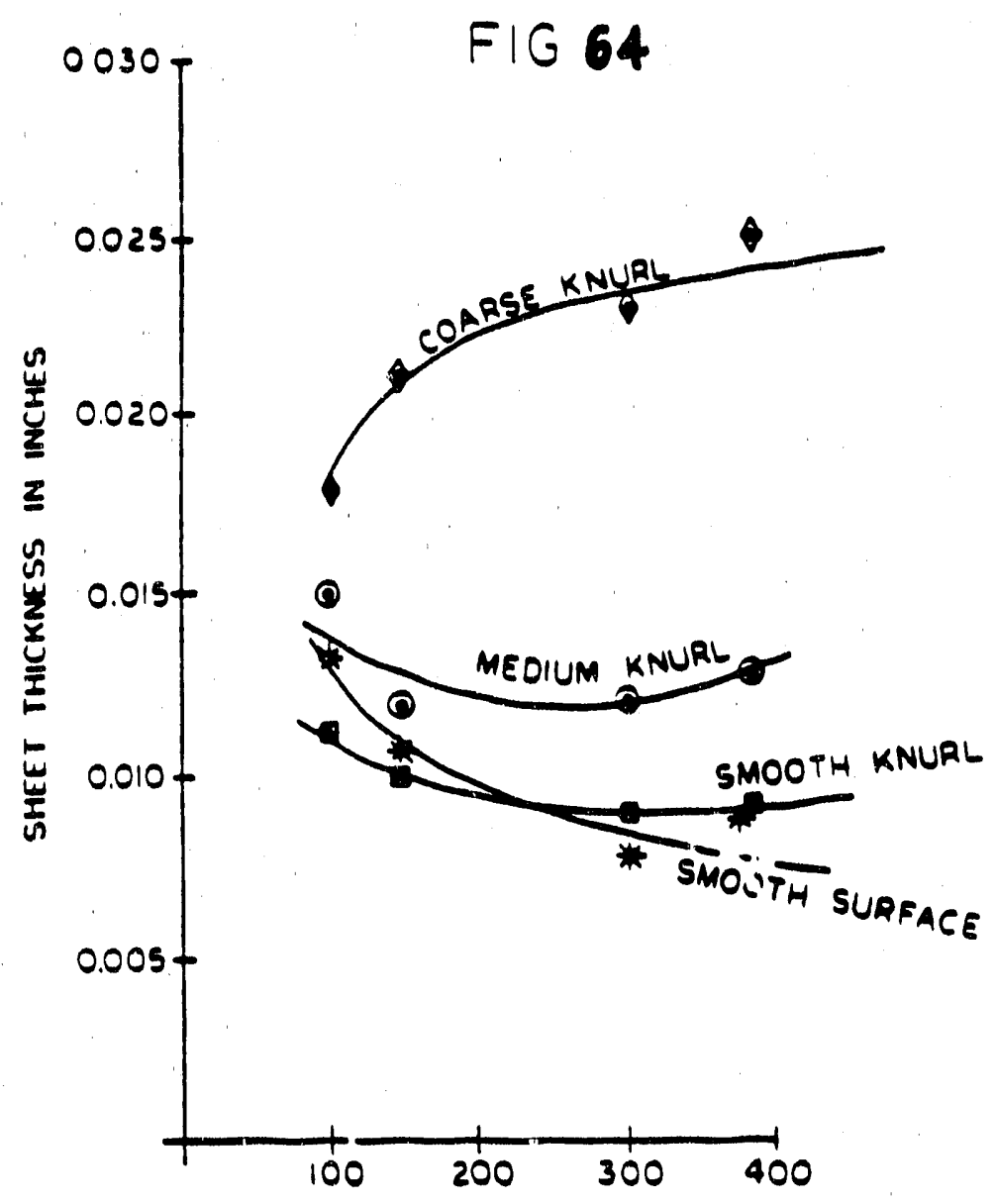

SUBSTAATE SURFACE VELOCITY IN CM/SEC

ALL KNURLED SURFACES DIAMOND

FINE KNURLS 33 PITCH

MEDIUM

21

COARSE

14

PITCH 
12. Pat. \#4,708,191 - F. R. Block et al., Apparatus' for Indicating the Level in Metallurgical Vessels by Electromagnetic Means.

Transmitting and receiving electromagnetic coils are embedded in the walls of the ladle/tundish. They transmit signals (voltages) which are proportional to the height of metal in the tundish. The general scheme of the set-up is shown in Fig. 65.

The drawback of this method is the fact that the transmitting and receiving coils have to be put into the walls which makes this method a complicated one and costly.

13. Pat. \#4,708,194 - W.R. Mohn, Method and Apparatus for Raptdly Solidifying Metal Employing a Metallic Conditioning Brush.

The improvement of this invention, which consists of a metal brush contacting the chill surface, removes contaminates, and friction welds a smooth, metallurgically clean and thermally conductive layer of the brush metal onto the chill surface. The brush matertal should be preferentially softer than the substrate. Fig. 66 shows the general view of the set-up with the invention; Fig. 67 shows the details of the brush arrangement and the action of the brush on the substrate surface.

14. Pat. \#4,709,743 - A. G. Law and M. T. Fleetwood - Casting Metal Strip.

This invention provides the control of and metering of the molten metal through the orifice by varying the width of the orifice. To achieve this the authors made the two of the orifice walls movable. They are in the form of plates - two are stationary and two are movable (Fig. 68). More 
U.S. Patent Nov. 24, 1987 Sheet 1 of $4 \quad 4,708,191$

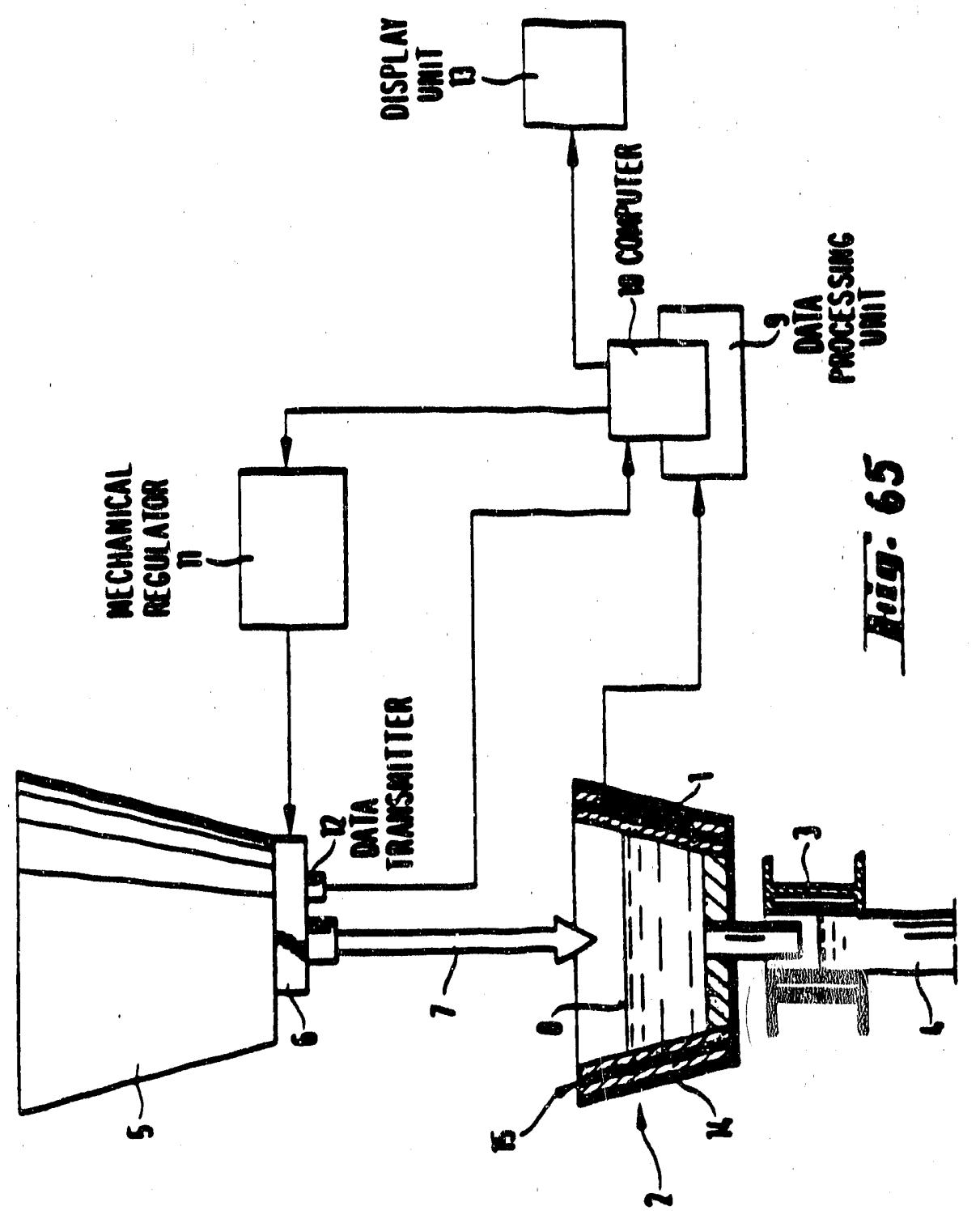


U.S. Patent Nov. 24, 1987 Sheet 1 of $3 \quad 4,708,194$

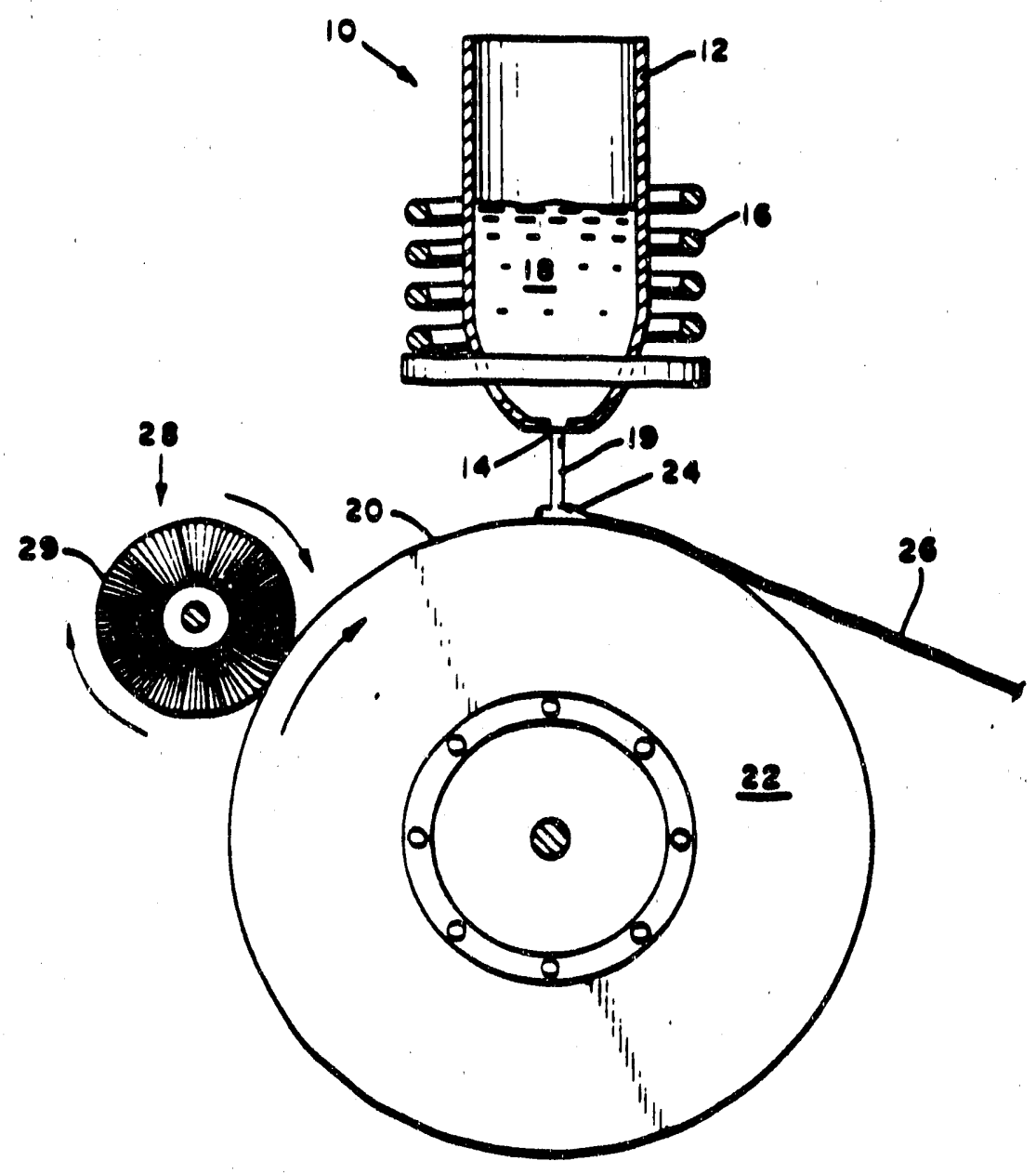

F I G. 66 


\section{U.S. Patent Nov. 24, 1987 Shoet $2 \propto 3 \quad 4,708,194$}

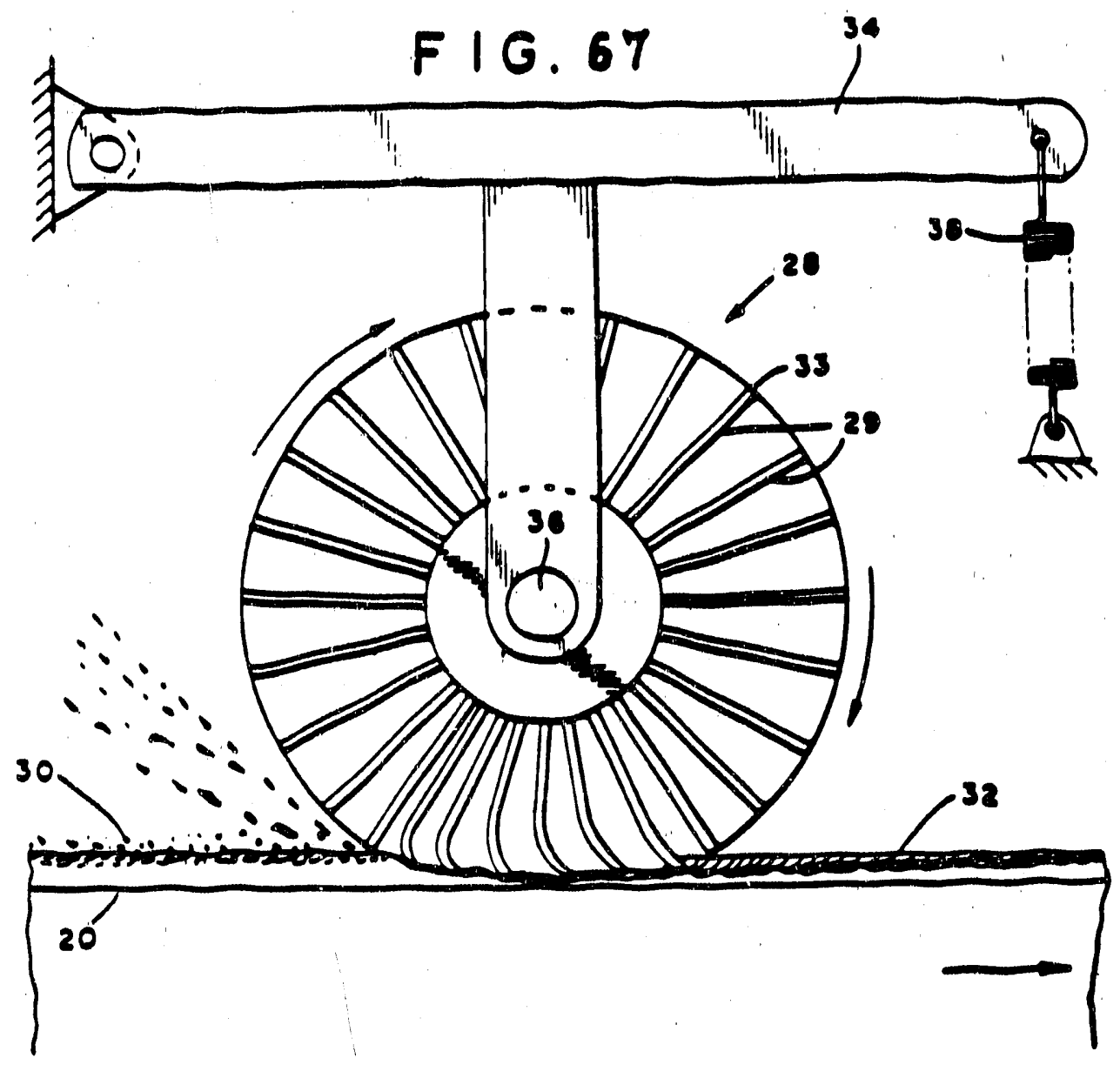


U.S. Patent Dec. 1, 1987 Sheet 2 of $4 \quad 4,709,743$

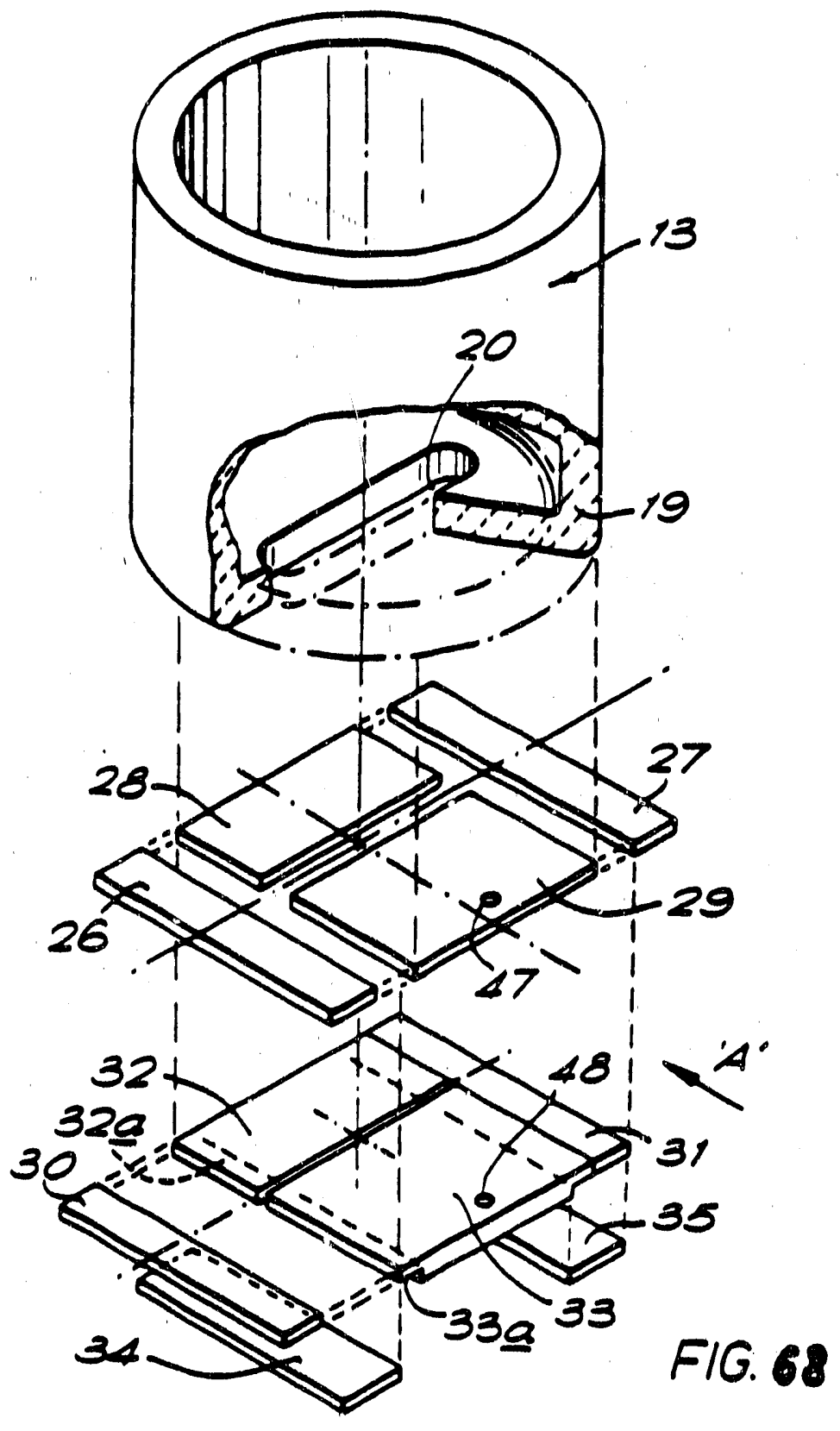


detalls of the arrangement is shown in figs. 69 and 70 . The general view of the set-up is shown in Fig. 71. The authors claim that the movable walls of the orifice, while enabling to control the orffice width, obviate also the effects of chllling and thermal stress while in use. They see several more advantages in manufacture and installation of the system.

15. European Pat. Applic. No. PCT/US86/02125 - E. S. Burtlett and R.E. Maringer - Direct Casting on Grooved Wheels.

In this application the inventors claim that grooved wheels allow them to obtain a qualitatively better strip (more uniform thickness) of aluminum, copper or low carbon steel. Fig. 72 shows the casting method used; Fig. 73 - wheel surfaces with different grooves and the strip $(a, b, c)$.

16. European Pat. Applic. No. PCT/US86/02134 - C. V. Vaught, Method of and Apparatus for Continuous Casting of Metal Strip.

The inventor claims beneficial effect of a low pressure air jet stream directed at the liquid metal at a point where the solid strip emerges. The casting method in the set-up is the melt-drag. Fig. 74 is an illustration of the casting method used, Figs. 75 and 76 show details of the invention. 
U.S. Patent Dec. 1, 1987 Sheet 3 of $4 \quad 4,709,743$

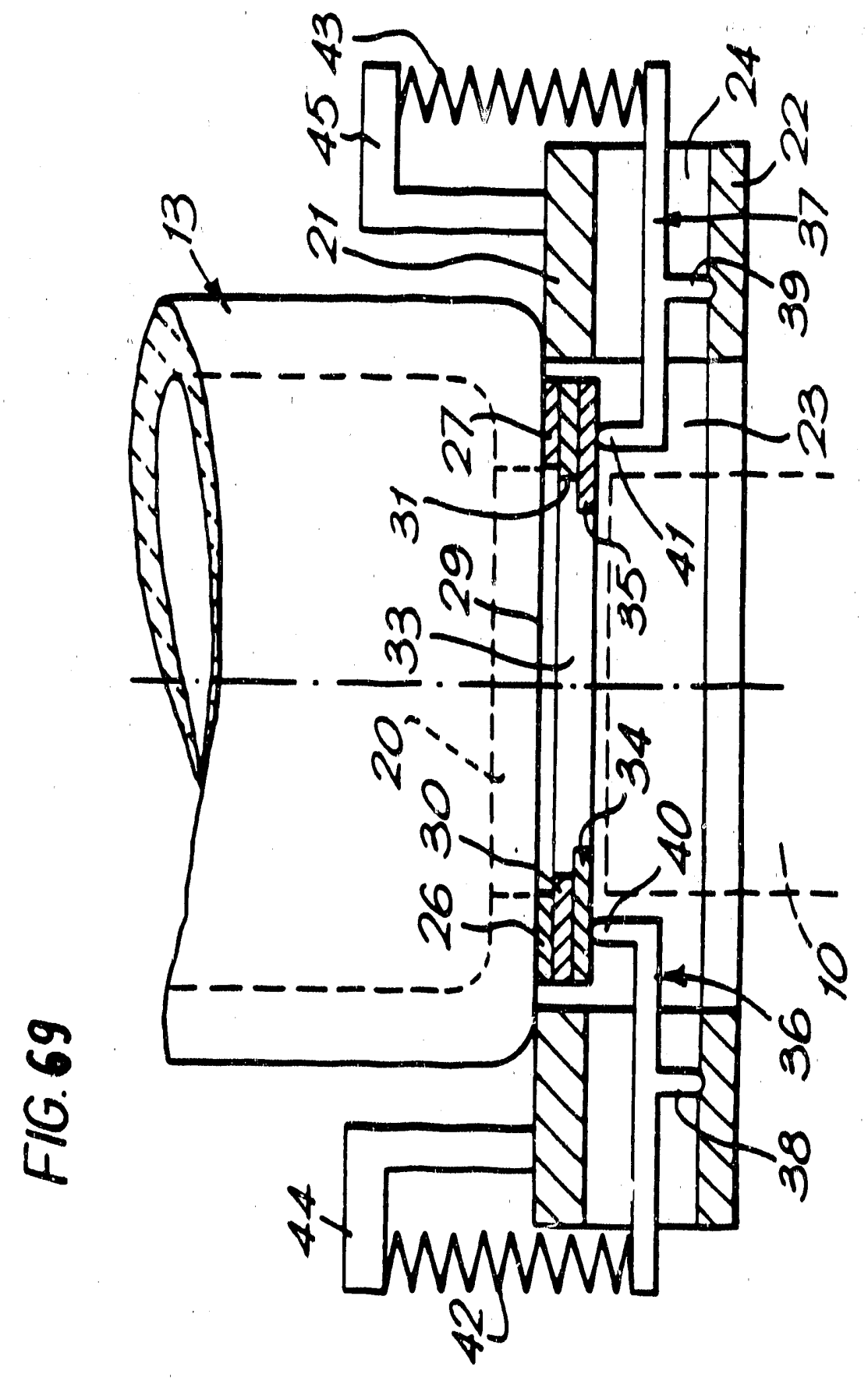


U.S. Patent Dec. 1, 1987 Sheet 4 of $4 \quad 4,709,743$

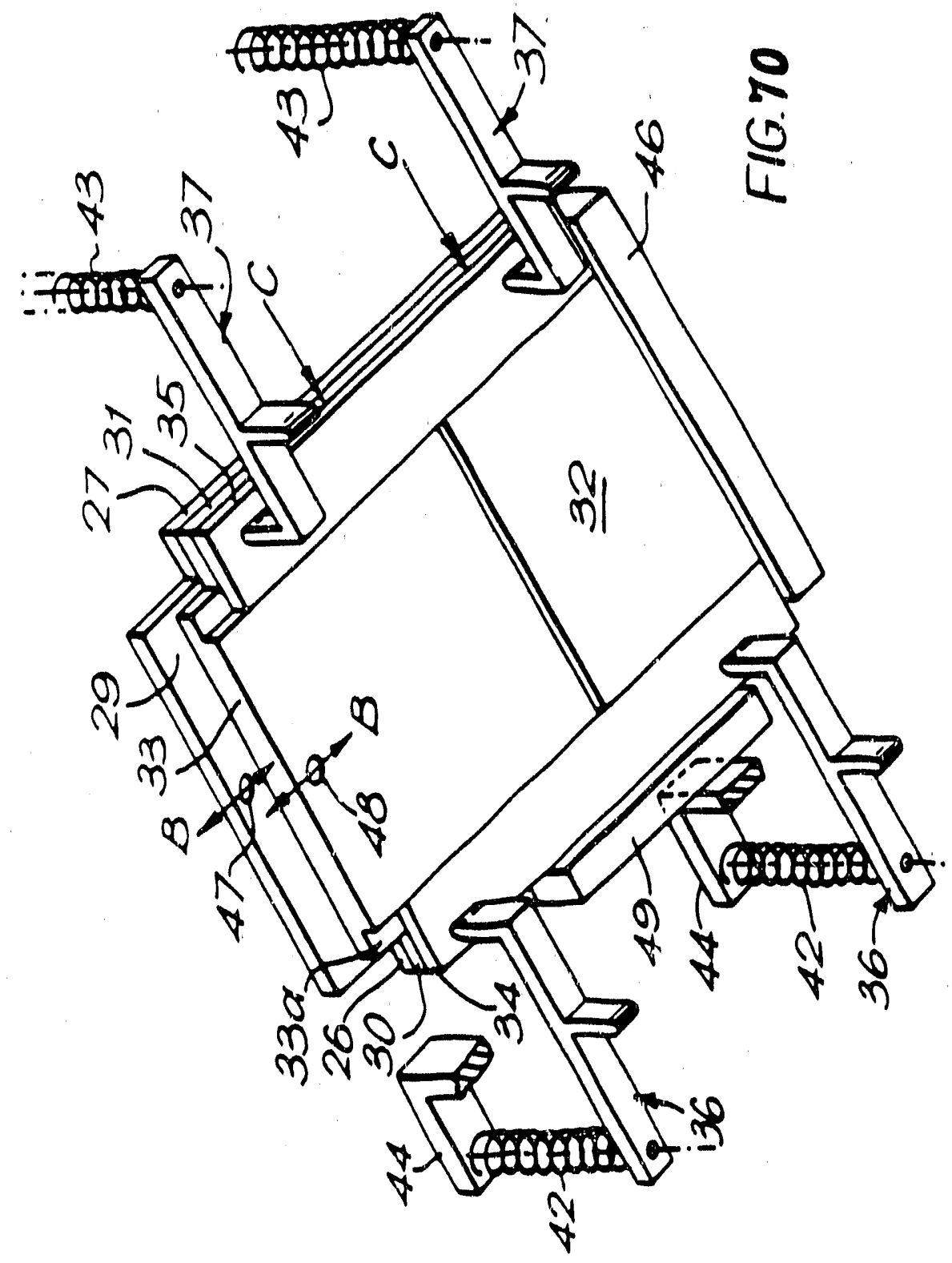


U.S. Patent Dec. 1, 1987 Sheet 1 of $4 \quad 4,709,743$

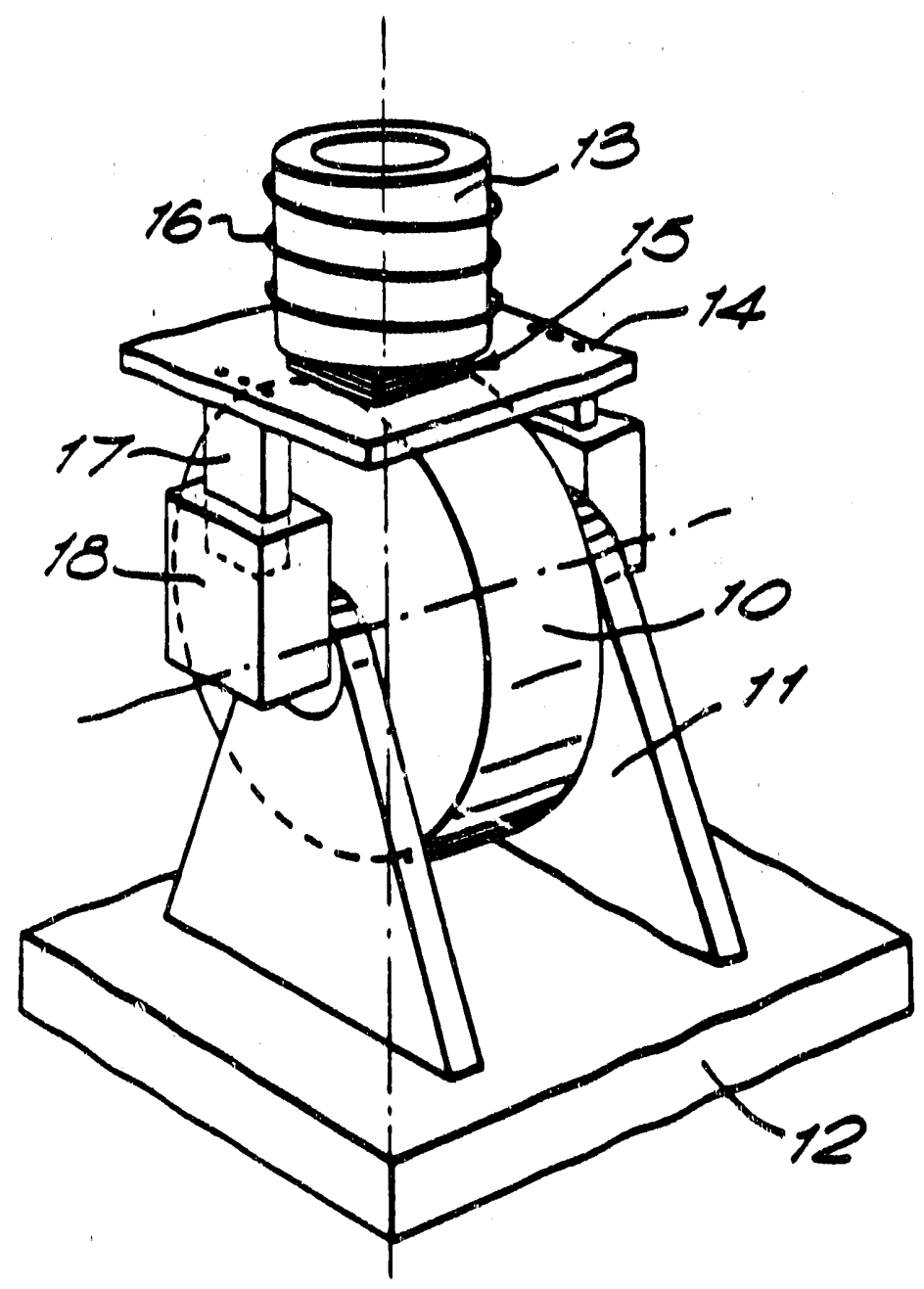

FIG.7I 
$1 / 2$

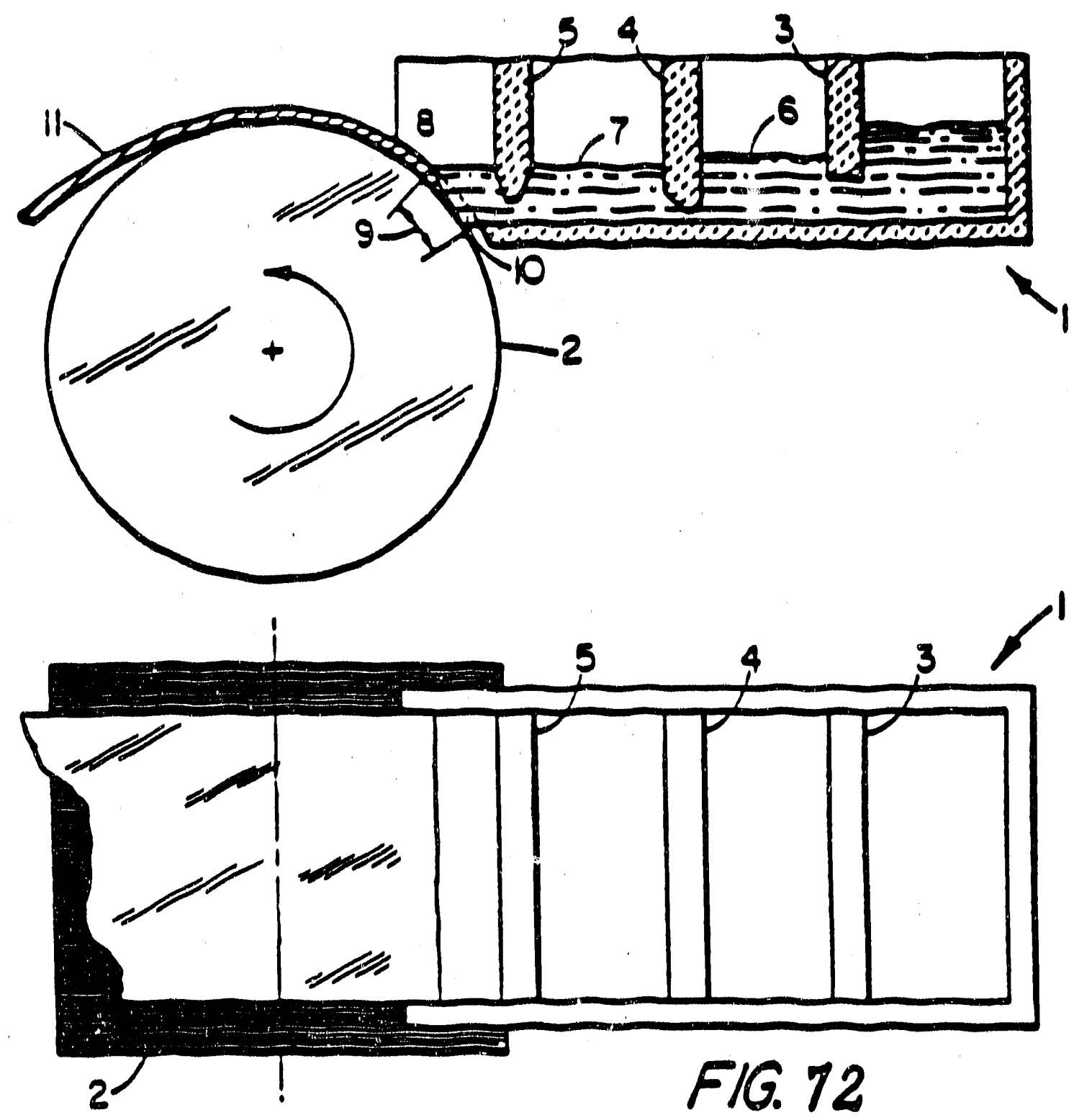



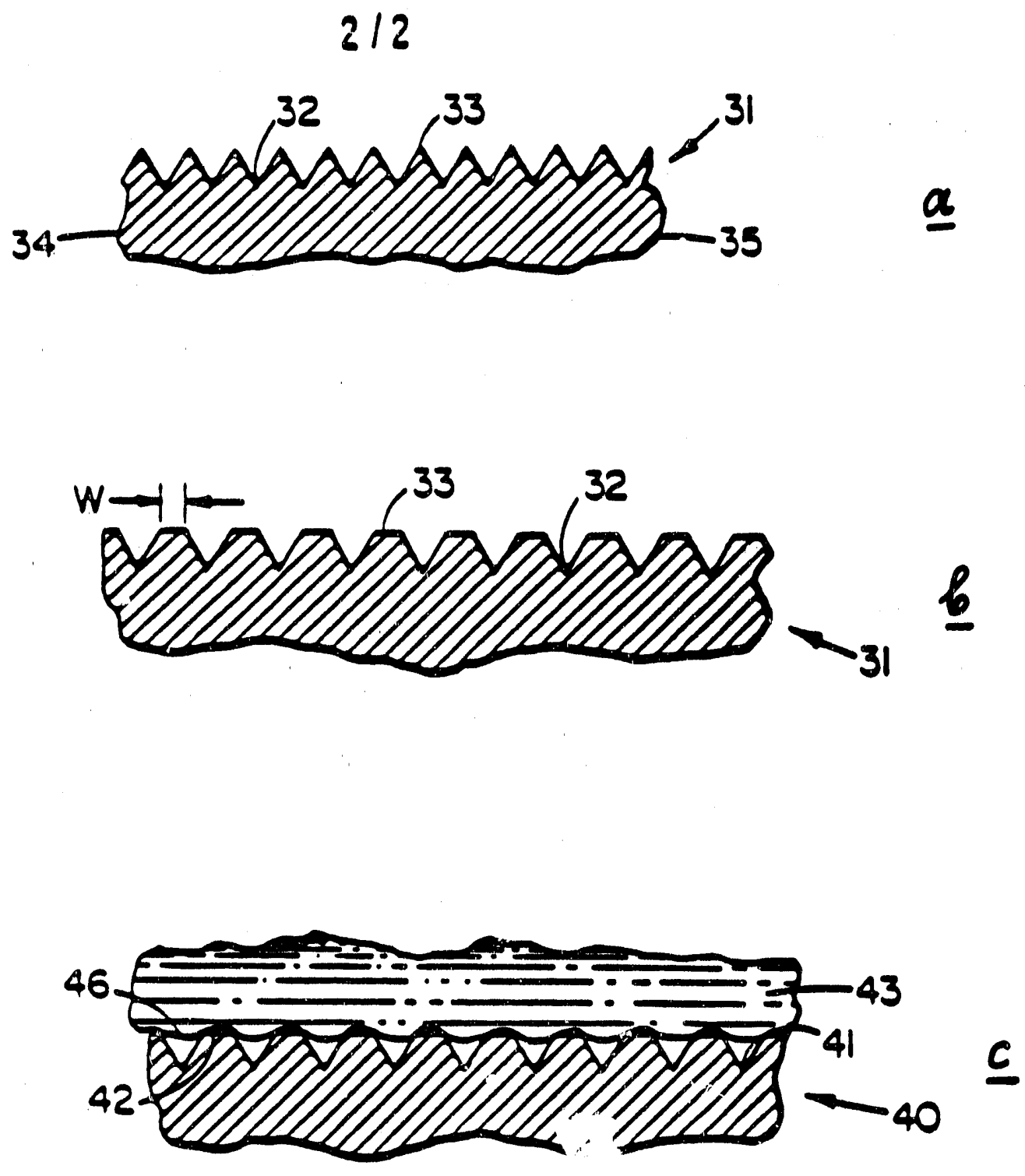

$F / G .73$ 

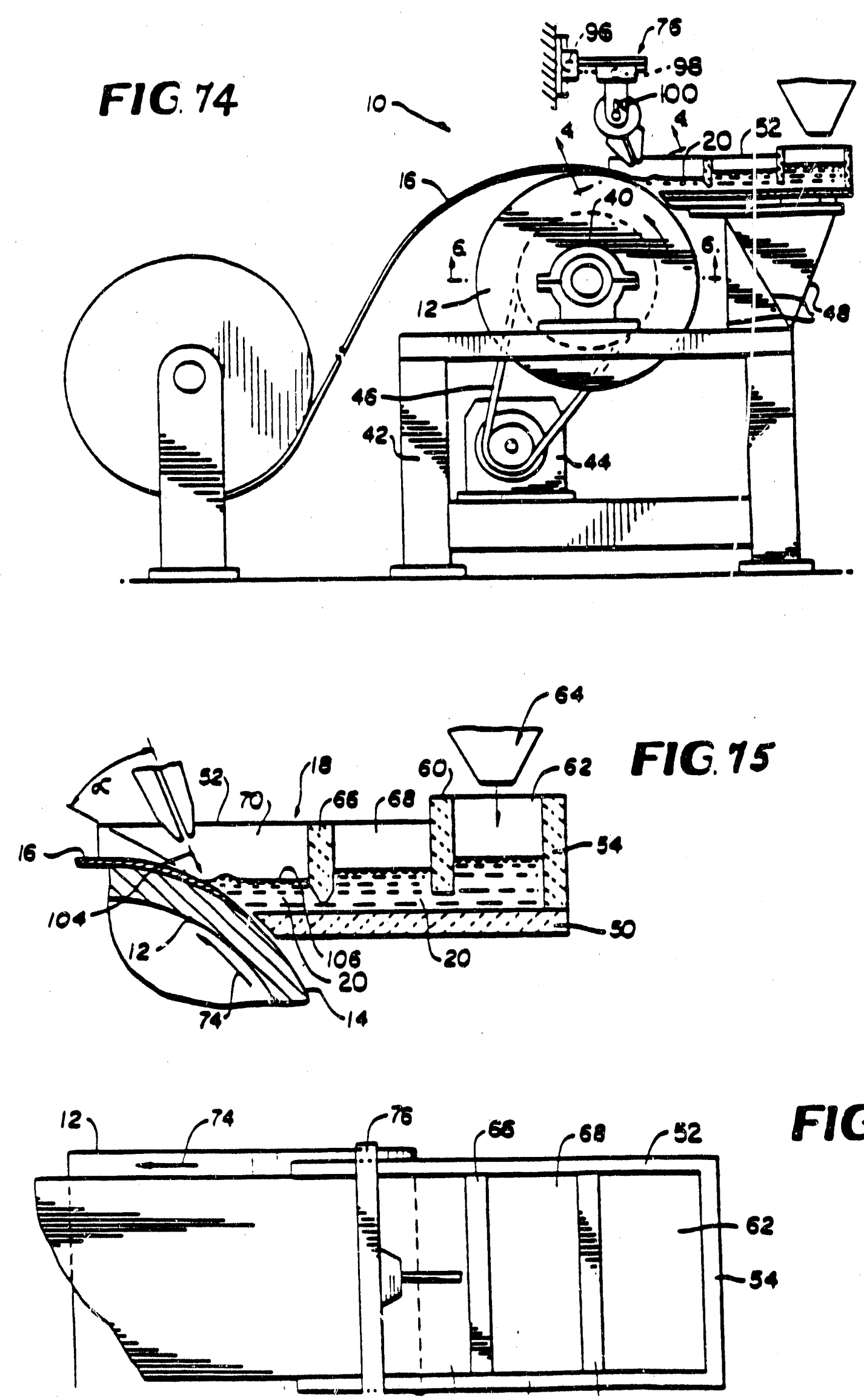

FIG. 76 


\section{LIST OF PATENTS REVIEWED}

1. Patent No. 3,540,517 - Witold M. Wojcik, E. A. Migikar, "Method of Direct Strip Casting on a Coated Orum" (Jones \& Laughlin Steel Corp.), 11/17/70.

2. Patent No. 4,479,528 - R. E. Maringer, "Strip Casting Apparatus" (Allegheny Ludlum Steel Corp.), 10/30/84.

3. Patent No. 4,488,590 - N.Y. Toker, "Apparatus for Strip Casting Having a Heated Orifice", (Allegheny Ludlum Steel Corp.), $12 / 10 / 84$.

4. Patent No. 4,562,878 - B.G. Lewis, "Electromagnetic Shaping of Thin SemiConductor Ribbon Strip Cast Onto a Chill Block" (01 in Corp., New Haven, Connecticut), 1/7/86.

5. Patent No. 4,588,015 - H.H. Liebermann, "Casting in an Exothermic Reducing Flame Atmosphere" (Allied Corp.), $5 / 13 / 86$.

6. Patent No. 4,600,048 - T. Sato et al., "Method for Continuous Casting of Metal Strip" (Kawasakt), 7/15/86.

7. Patent No. 4,601,326 - C.T. Tingler, "Ribbon Casting Apparatus with Magnetic Retainer and Resillent Spacer" (EPRI), $7 / 22 / 86$.

8. Patent No. 4,646,812 - R.E. Maringer, "Flow Casting" (Battelle Dev. Corp.), 3/3/87.

9. Patent No. 4,649,983 - V. Laxmanan, et al., "Chill Roll Casting of Metal Strip", (Ali ied Corp.), 3/17/87.

10. Patent No. 4,649,984 - J.R. Bede11, et al., "Method of and Apparatus for Casting Metal Strip Employing a Localized Conditioning Shoe" (Allied Corp.), 3/17/87.

11. Patent No. 4,650,618 - W. Heinemann, et al., "pethod for Producing Strip-like or Roll-like Products" (Concast Standard AG, Zurich), 3/17/87.

12. Patent No. 4,705,095 - T.A. Gaspar, "Textured Substrate and Method for the Direct, Continuous Casting of Metal Sheet Exhibiting Improved Uniformity". ("ibbon Technology Corp.), 11/10/87.

13. Patent No. 4,708,191 - F.R. Block, "Apparatus for Indicating the Level in Metallurgical Vessels by Electromagnetic Means" (Stopine Aktiengesell sciaft, Switzerland) $11 / 24 / 87$. 
14. Patent No. 4,708,194 - W.R. Mohn, "Method and Apparatus for Rapidly Solidffying Metal Employing a Metallic Conditioning Brush" (Allied Corp.), 11/24/87.

15. Patent No. 4,709,743 - A.G. Law et al., "Casting Metal Strip" (Inco Engineered Products and General Electric of Engiand), 12/1/87.

16. European Patent Application No. PCT/US86/02125

(Batelle Dev. Corp. of Columbus, Ohio)

"Direct Casting on Grooved Whee is"

by E.S. Bartlett and R.E. Maringer, 10/11/85.

17. European Patent Application No. PCT/US86/02134

(National Aluminum Corp. of Pittsburg, PA)

"Method of and Apparatus for Continuous Casting of Metal Strip"

by C.F. Vaught, $3 / 11 / 86$. 


\section{SUMMARY ANO CONCLUSIONS}

There is not much literature on the subject of SR direct strip casting. However, from the reviewed literature and patents, that there are two outstanding methods of strip casting with the SR process. One is Planar Flow Casting (PFC), the other is Melt-Drag (MD). There is no definitive answer as to which one is better. However, the impression from reading the literature and patents is that the PFC process is somewhat better suited for casting thin (below .010") strip, while the MD process gives better results when it comes to casting thick (above .010") strip. Although it is known that several companies have been working on the subject, they have not published details of their apparatus nor the effect of process parameters.

From the literature found there are only three papers that contain some pertinent information on the direct strip casting by SR process. Only one that describes actual experiments, on a pilot plant scale, with casting low carbon steel strip. From these papers, it seems that the main difficulty in casting low carbon steel is the ability to obtain commercially viable thicknesses of the strip. The limit seems to be .050" thick material primarily because it is difficult to solidify strip of a greater thickness with a single cooling surface.

The reviewed patents do not specify limits to the strip thickness. Since they speak in general terms, it is difficult to know whether the conclusions are experimentally determined or put in to protect the patent rights of the inventor. 
It seems that the following parameters are the most, important for OSC: a) substrate material and its surface condition, b) speed of the substrate, c) melt pool height (length) in the nozzle (for the MO process), d) melt chemistry.

Of the substrates tried, it seems that the best results were obtained with casting of steels on steels. Copper and its alloys comes in second for variety of reasons, even though it has much superior heat conductivity to steel.

The effect of substrate speed is reflected, obviously, in the thickness and in the microstructure (solidification speed!), which in turn affects the strip properties. Higher speeds result in smaller grains but in thinner strip.

In the MD process melt pool height (length) affects primarily the thickness of the ribbon, but melt chemistry can have a profound effect on the whole process via effect on the adhesion to the substrate and obvfously on the final properties of the strip.

The patents essentially shed light on the improvements in the basic methods of strip casting. They are mainly revolving around some improvements of the nozzle, or auxiliary devices, to more effectively control the casting process parameters.

In summary, there is a lot of information available, in general, about casting of metal strip by SR process. However, little information concerning direct casting of the low carbon steel strip is available in the literature. No experimental data was found about the maximum thickness of the low carbon steel that can be cast using a single roll process continuousiy and the 
resultant properties such strip would have. And there is no information on any heat treatment of the strip after casting. This type of information is indispensable for the development of any economic evaluation of the process. 


\title{
ATTACHMENT A
}

\section{SUMMARY OF RECENT ALLEGHENY PATENTS ON STRIP CASTING}

\author{
R. C. Sussman
}

This is a summary of five recent Allegheny Steel patents pertaining to strip casting. From the chronology of their patents, it is apparent that the effort began by casting amorphous strip and gradually shifted towards casting thicker, crystalline materials. It also appears that the present technology centers on casting through a tundish and special nozzle onto a single wheel with very critically controlled dimensions of tundish and pouring nozzle. One of the most recent patents pertains to the nozzle design itself $(\$ 4,475,583)$. The following patents are reviewed in chronological order of the filing date.

1. Patent No. 4,330,025 - Robert H. Johns, Nozzle in a Strip Casting Apparatus

This patent pertains to a design for a casting nozzle in which the casting slit fans out at the periphery. It is unclear whether this design was meant for amorphous casting of thin materials or thicker, crystalline materials. The objective of the improved nozzle is to insure uniform gage of the strip material across the transverse width of the strip including the edge portions, so as to remove the need for edge trimming. The main claim refers to a nozzle of the design shown below and has the following critical parameters. 
Preferred

$L<3 W$

$H<2 W$

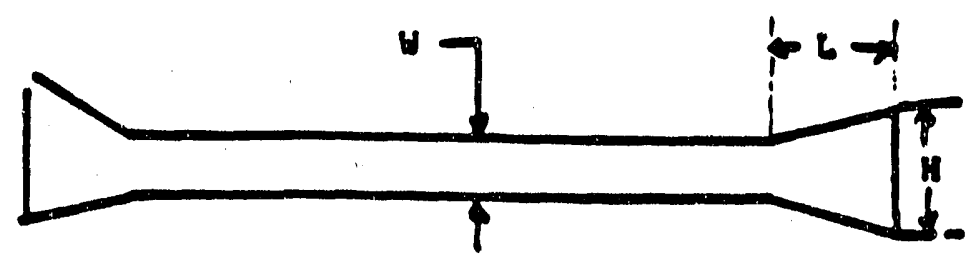

There is some mention of this nozzle design in more recent patents.

2. Patent No. 4,399,860 - Robert H. Johns, Apparatus for Strip Casting

This patent is very comprehensive in detalling specific dimensions for the tundish design of the caster with both broad ranges and preferred dimensions. Other details on the refractory, support brackets, and nozzle preheaters are specified. Figure 1 shows the configuration of the caster with most of its features, including:

1. A large head of metal for feeding to the nozzle 32 .

2. A non-wetting refractory top plate, 40, for controlling the flow of the metal onto the wheel.

3. A removable plug 62 for draining the tundish to stop the cast.

4. A system for preheating the casting nozzle top plate, using gas jets, 42, to fire onto the surface of the plate. The top plate is 
coated with a flame resistant heat conductive layer, such as graphite.

Critical dimensions specified in the patent.

\section{Preferred}

Orifice distance from wheel

Base cavity (Figs. 2-8)

Orifice opening

$h_{c}$, height base cavity of

central portion (Figs. 2-11)

Refractory in tundish - Kaolin boarcs, graphite, aluminum graphite, clay graphite, fire clay, quartz, BN, $\mathrm{SiN}, \mathrm{SiC}, \mathrm{BC}, \mathrm{SiOZ}_{2} \mathrm{Al}_{2} \mathrm{O}_{3}, \mathrm{ZrO}_{2}, \mathrm{MgO}$, chrome magnesia.

Orifice plate - BN, same as tundish refractory above.

3. Patent No. 4,484,614 - R. E. Maringer, Method of and Apparatus for Strip Casting

The patent contains only a few major disclosures that can't be found in the other patents. 
1. The patent discusses using a weight or pressure on the insert (top plate) of the orifice to maintain dimensional integrity.

2. The paterit disclose (Figure 3 ) using one insert plece above the other to be able to adjust the casting gap before and during a cast without moving the tundish, and change out the insert without rebuilding the tundish.

3. The critical casting nozzle dimensions, following the designation on Figure 4.

Dimension Designation

a nozzle gap

b length of front edge surface

C insert gap

d near wall gap
Preferred

Limitation

$0.010-0.080^{\prime \prime}$

$.00-.16$

$<.080^{\prime \prime}$

$<.020^{\prime \prime}$
More Preferred Limitation $.025-.035^{n}$ $.02-.06$ $.101-.020^{\prime \prime}$ $<.010^{\prime \prime}$

\section{Patent No. 4,485,839 - Brian L. Ward, Rapidly Cast Alloy Strip Having} Dissimilar Portions

This novel patent adds the additional wrinkle to the other patents $c$ i casting dissimilar. grades of steel or material on the same strip by positioning several tundishes parallel to each other and joining the strips by overlaying the metal. Another technique has tundishes consecutively positioned so that one material (Figure 5 ) can be overlayed on the others, such as chromium deposited on carbon steel. Most of the alloys tested and used as examples in this patent are amorphows metals of the $\mathrm{Fe}_{x} \mathrm{~B}_{y} \mathrm{x}_{z}$ type. 
5. Patent No. $11,475,583$ S. Leslte Ames Strip Casting Nozzle

This patent appears to be the most recent and authoritative description of their casting nozzle design. An almost identical patent was applied for in Europe. This patent mentions having experimented with casting brazing alloys, stainless steels; silicon steei, and some amorphous metals. The key features of the casting nozzle are shown in Figure 6 and detail a converging, diverging arrangement of a nozzle made of such materials as fiberized kaolin, $\mathrm{SiN}, \mathrm{SiO}_{2}$, graphite, clay graphite, $\mathrm{BN}$, alumina graphite, etc. The material for the casting wheel was $98 \% \mathrm{Cu}$ $2 \% \mathrm{Cr}, 2$ inches thick and $8 \mathrm{ft}$. in diameter. The dimensions of the casting nozzle, detailed in Figure 6, are reprinted in the patent as follows:

\section{Dimension Designation}

a bottom surface of first lip

b width of slot at maximum dive, gence

c bottom surface of second i ip

d standoff distance between second

$l$ ip and casting surface

e standoff distance between first

1 ip and casting surface

$f$ width of slot between parallel, facing surface

h depth of diverging area of slot depth of parallel area of slot
Preferred Limitation

at least .001"

$.020-.200^{\prime \prime}$

$.01-.16^{\prime \prime}$

$<.080^{\prime \prime}$

$<.080^{\prime \prime}$

$.010-.080^{\prime \prime}$

$.050-.200 "$

$.050-.200 "$
More

Preferred

Limitation

$.25-.50^{\prime \prime}$

$0.125^{\prime \prime}$

$.02-.06^{\prime \prime}$

$<.010^{\prime \prime}$

$<.010^{\prime \prime}$

$.025-.035^{\prime \prime}$

$.125^{\prime \prime}$

$.125^{\prime \prime}$ 
U.S. Patent Aug. 23, 1983 Sheet 1 of $3 \quad 4,399,860$

Fig.I.

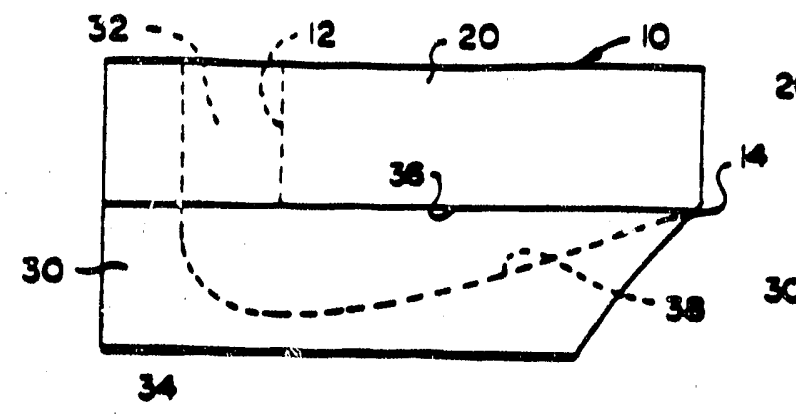

Fig. 3 .

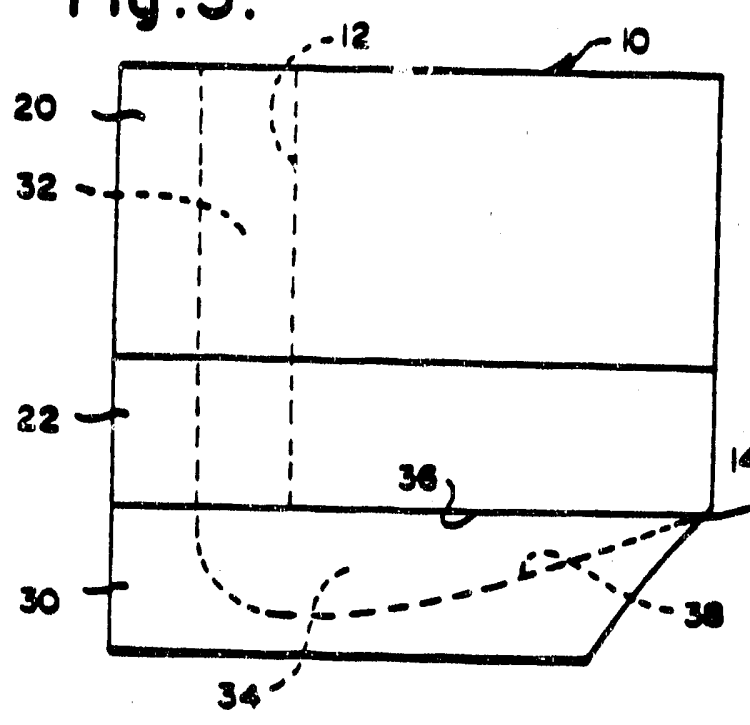

Fig. 5.

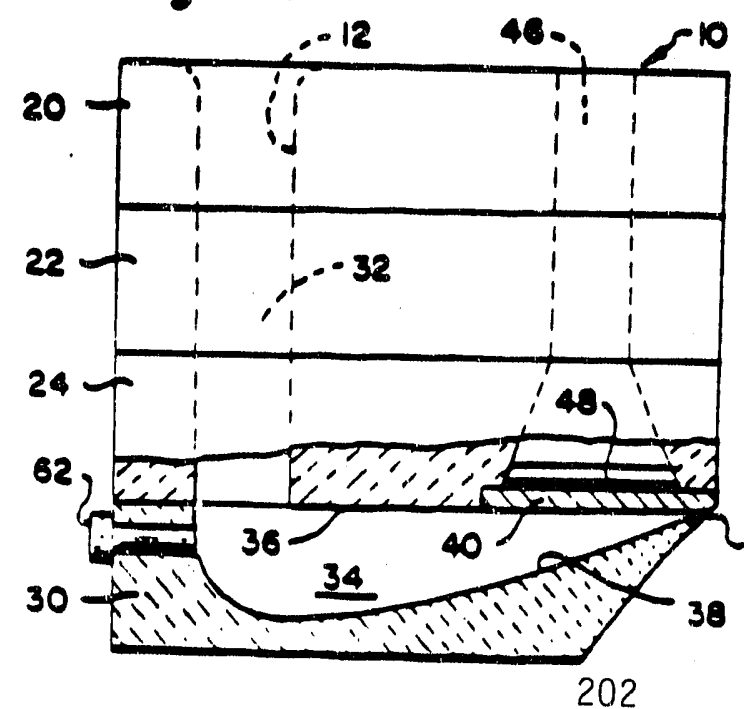

202
Fig.2.

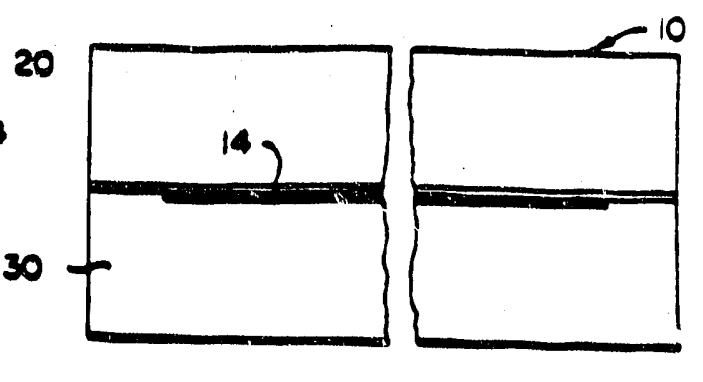

Fig. 4 .

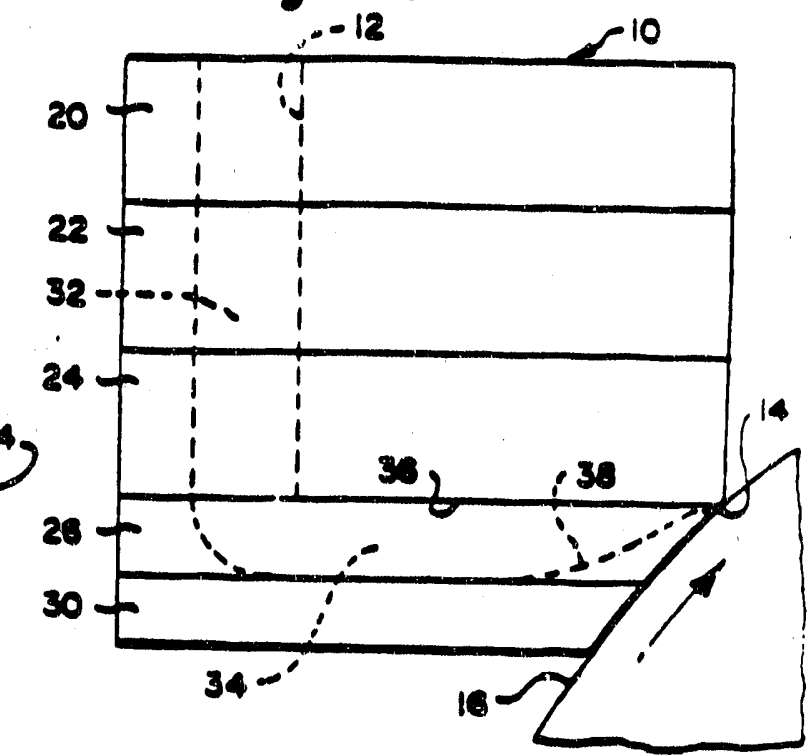

Fig.6.

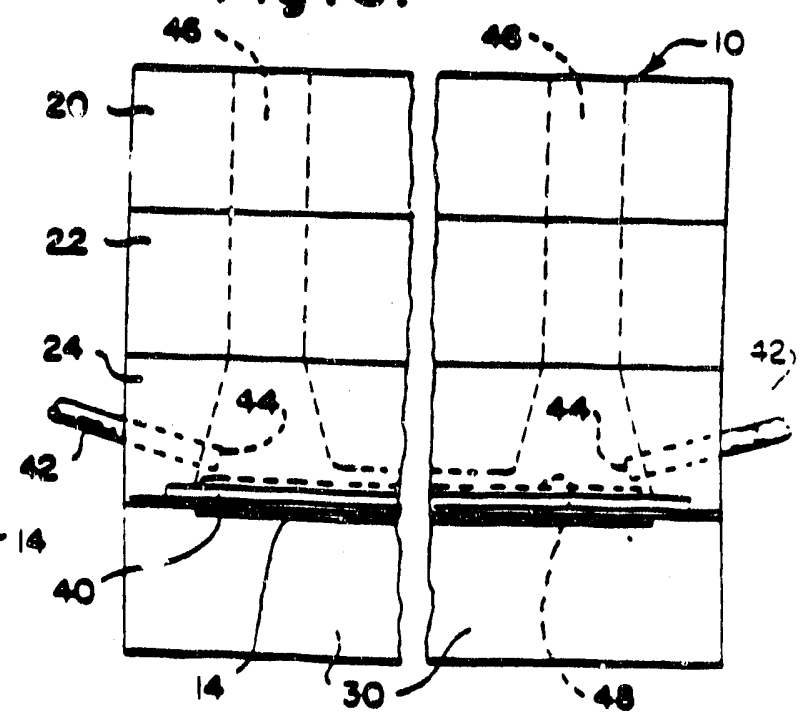


U.S. Patent Aug. 23, 1983 Sisee 2 of $3 \quad 4,399,860$
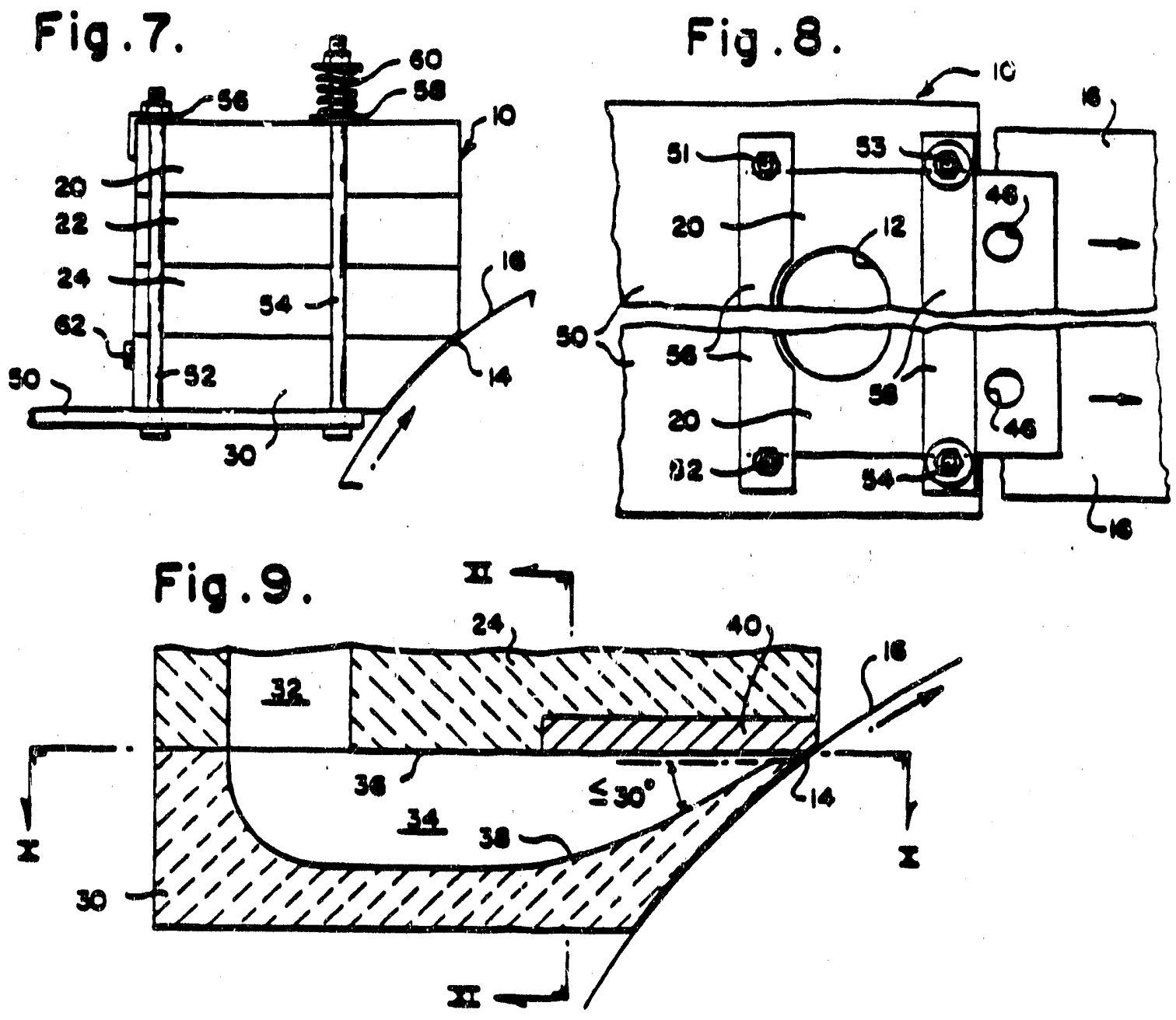

Fig. 10.

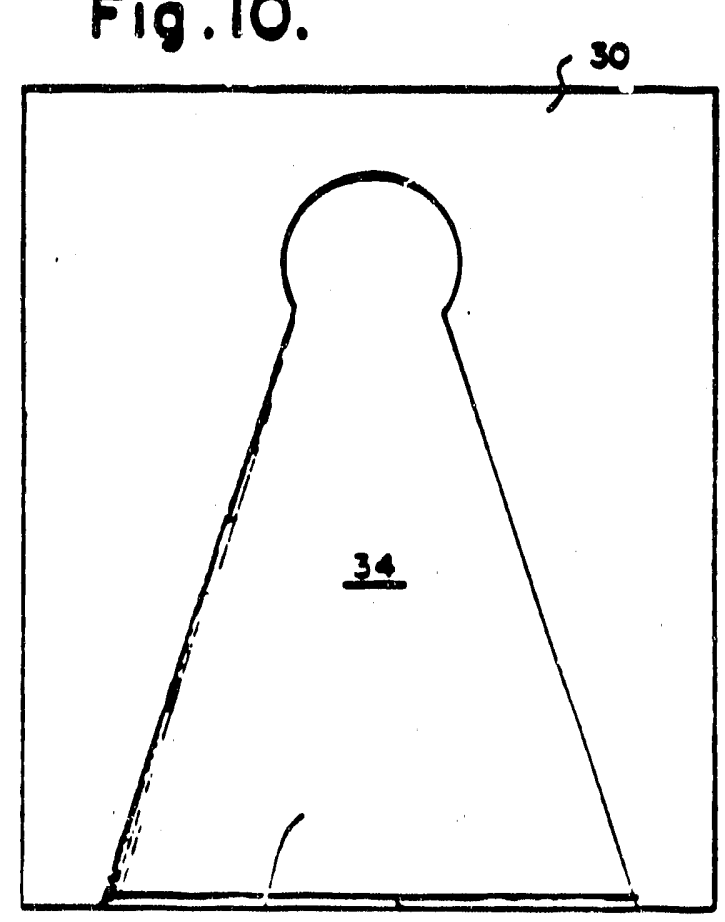

Fig. 11 .

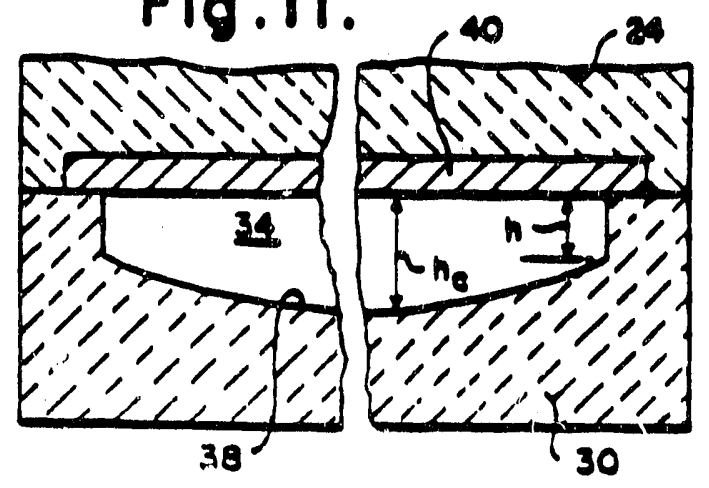

Fig. 12.

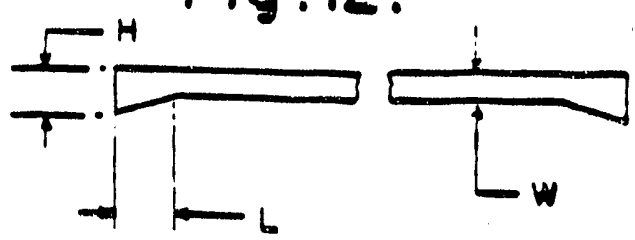




\section{Tochnical Information Conter}

\section{Search Request}

Requester Alfred Frellich

Mailing Address/Dept.
Date $1 / 18 / 88$

Phone 5199

Needed by

Of no use after

Statement of the request Please do d L Literature search on the singlemwheel casting

technology of steels, especially low carbon steel, limited to strip casting.

Description of search request: including keywords, synonyms, reforences, authors, date range to cover, language restrictions, areas to exclude, etc.

If this is a RUSH search please explain why. Lanquage - Englisti only: 1968-1988

Key Words: single-wheel casting of strip sheet Limit to:

double-wheel casting of stripe sheet

1) Steels

rapid solidification casting of strip, sheet

- low carbon

chill casting of strip, sheet

- staintess

chill-block casting of strip, sheet

chill-roll casting of strip, sheet

2) Superalloys

melt spinning of strip. sheet

Thoroughness of search, reason for request. e.g., a few good raferences, very thorough coverage, etc.

Very thorough coverage of low carbon steel strip castings.

Type and number of references interested in receiving, $\mathbf{0 . 9 .}$. include or exclude patents, no more than 20 references, include all dvailable, eic.

Exclude patents; exclude: tape, ribbon, foil, slab casting, plate

Armco Researnh \& Technology

Technical information Center

Door 225

Middletown, Ohio 450.43
Date received in TIC

Date result's sent

No. citations sent

No. offline prints

Time online

Searcher: 


\section{Kenwords for Computer Patent Search}

1. Single-wheel strip casting of steels/superalloys/low carbon steel

2. Double-roll casting (quenching) of steels/superalioys/low carbon steel

3. Rapid quenching of steels/superalloys/low carbon steel

4. Rapid solidification of steels/superalloys/low carbon steel

5. Rapid solidification processing of steels/superalloys/low carbon steel

6. Chill casting of steels/superalloys/low carbon steel

7. Chill-biock casting of steels/superalloys/law carbon steel

8. Chill-roll casting of steels/superalloys/low carbon steel

9. Melt-spinning of steels/superalloys/low carbon steel

10. Chill-block melt spinning of steels/superalloys/low carbon steel

Date range to cover: 1968-1988

Search: worldwide

Thorough coverage: U.S., Hestern Europe, Japan 
Attachment B 


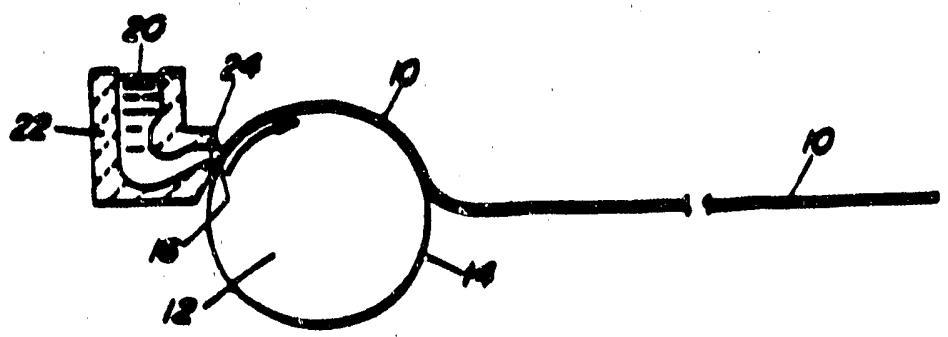

\section{Fla. 1}

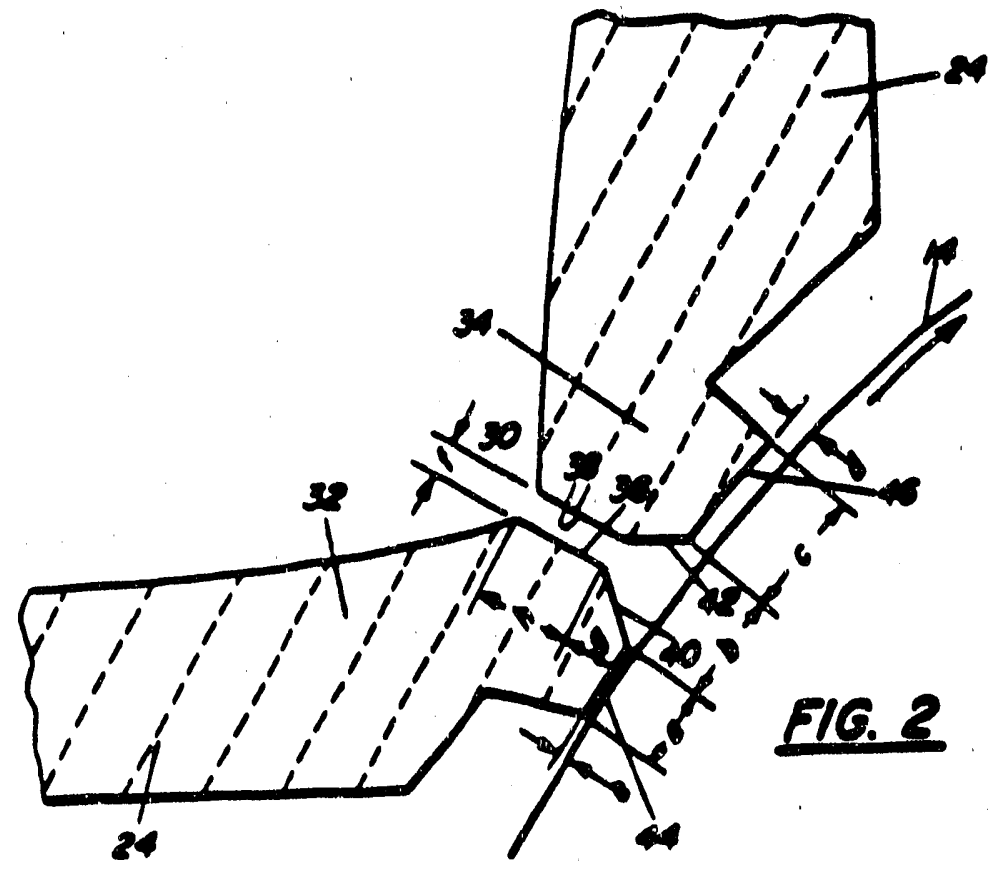

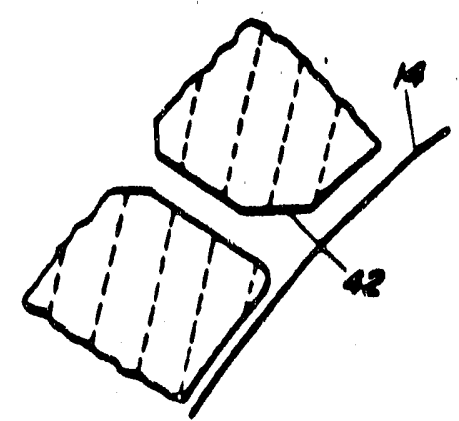

F16. 3

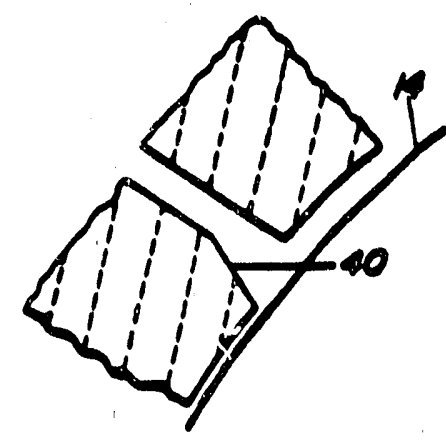

F16. 4

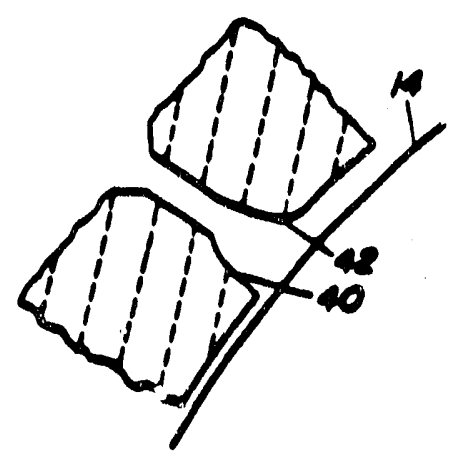

F795 


\section{U.S. Patent Dec. 4, 1984 Sheet 3 of $3 \quad 4,485,839$}

Fig.6.

Fig.7.

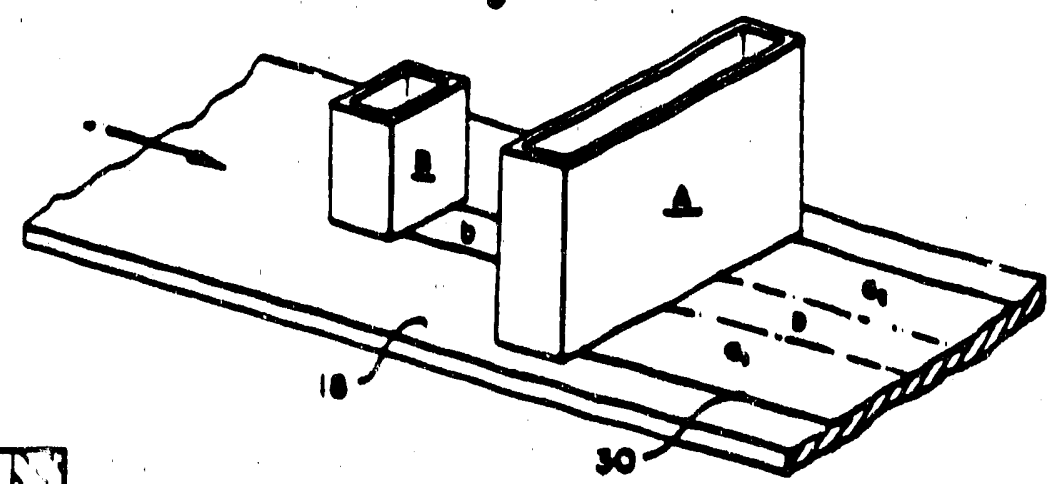

10

[i]

Sil

(1)

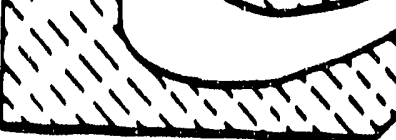

102

Fig. 10.

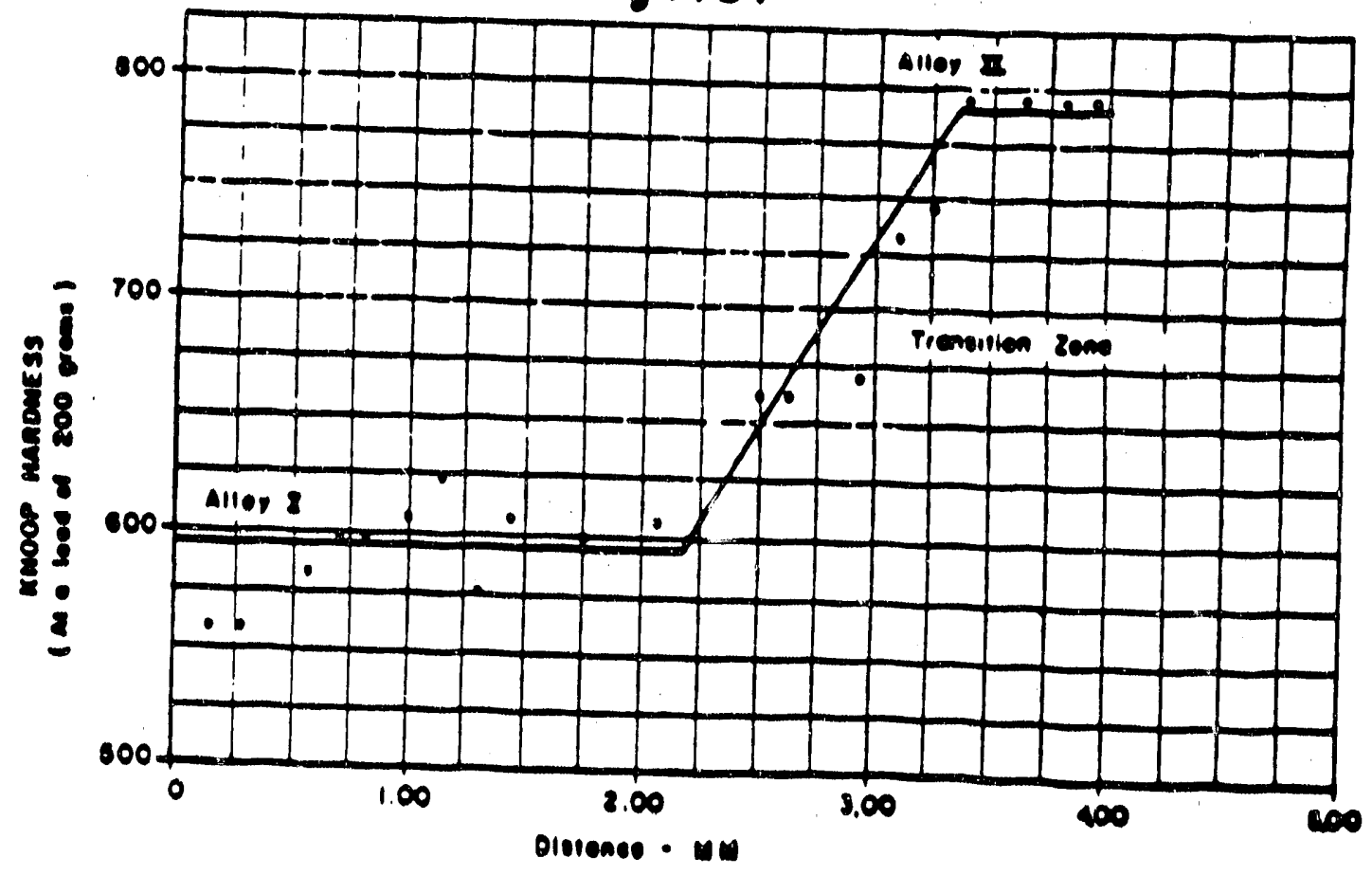


U.S. Patent Nov. 27, 1984 Shees 4 of $4 \quad 4,484,614$

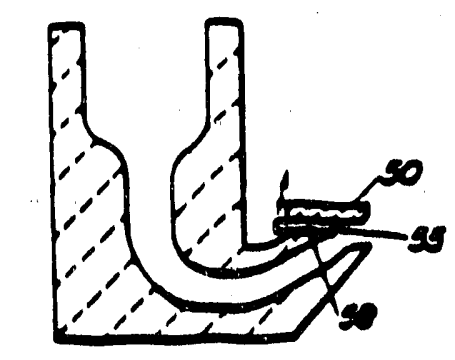

EF/G.12

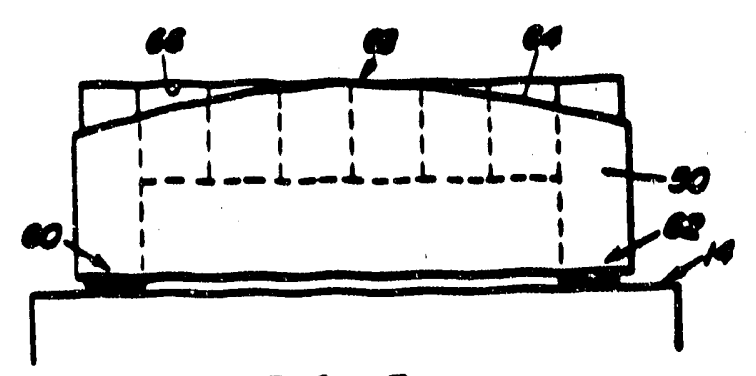

F/G. 13

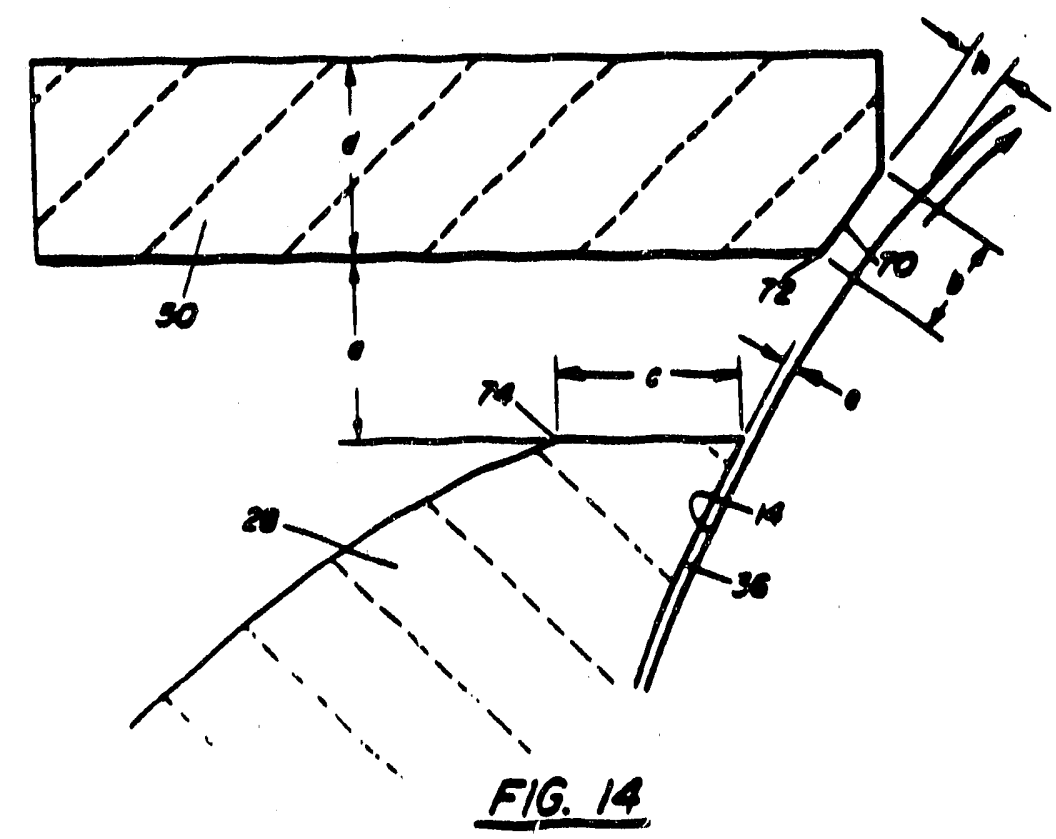

209 


\section{APPENDIX II}

\section{Detalls of Fater Modeling Results of Planar Flow Casting process}

lest $1 A$ - Diverging Nozzle with $G_{1}>G_{2}$. $\rho: 15^{\circ}, \beta: 90^{\circ}, G_{2}: 50 \mathrm{mils}, \alpha:+5^{\circ}, G_{1}: 100 \mathrm{mils}$.

At $5.5 "$ of head, $Q_{10}$ FPS was $3.5 \mathrm{GPM}$. This nozzle configuration exhibited very poor flow. A very complicated flow pattern was observed with no straight stream lines. The stream tended to pull in towards the center forming a thick rope of water about 2" out from the nozzle. This flow pattern persisted over the entire range of belt speeds.

At 11.5 " of head, $Q_{10}$ FPS increased to 5.0 GPM. Raising the head accented the flow pattern observed at 5.5" of head. The rope of water down the center of the belt reached a thickness of approximately $I^{\prime \prime}$. It was observed that $G_{2}$ was not completely filled.

Test $1 B$ - Diverging Nozzle with $G_{1}<G_{2}$. $\rho: 15^{\circ}, \beta: 90^{\circ}, \mathrm{G}_{2}: 50 \mathrm{mils}, \alpha:+5^{\circ}, \mathrm{G}_{1}: 25 \mathrm{mils}$.

At $5.5^{\prime \prime}$ of head, $Q_{10}$ FPS was 1.2 GPM. Decreasing $G_{2}$ restricted the flow out of the nozzle, though the flow pattern observed was still fairly complex. A series of smaller ropes of water formed at equal distances across the opening of the nozzle, fanning out and crisscrossing over one another as they moved away from the nozzle. Ropes formed as the water, adhering to the top of $\mathrm{G}_{2}$, pulled 
together upon exiting the nozzle. Lowering thr speed to 5 FPS caused increased spreading of the ropes and caused them to cross over closer in towards the nozzle. Further lowering the speed to 2.5 FPS, caused the nozzle to be flooded since the rate of water removal by the belt had dropped below the rate the water exited the nozzle.

A $11.5 "$ head gave a. $Q_{10}$ FPS of 2.2 GPM. As in test $1 \mathrm{~A}$, raising the head served to accent the flow pattern observed at the lower head. Here, the increased flow associated with the higher head, increased the number of ropes exiting the nozzle along with Increasing the level of severity of the spreading and crossing over of the ropes downstream from the nozzle. Lowering the speed to 5 FPS caused the crossing of the ropes to become quite severe and induced spreading of the stream edges. This was further exaggerated by lowering the speed to 2.5 FPS, where the stream exiting the $3^{\prime \prime}$ wide nozzle broadened to $4 "$ to $4.5^{\prime \prime}$ as it rode up the belt.

Test $2 \mathrm{~A}$ - Converging Nozzle with $\mathrm{G}_{1}>\mathrm{G}_{2}$. $\rho: 15^{\circ}, G_{2}: 50 \mathrm{mils}, \alpha: 5^{\circ}, G_{1}: 100 \mathrm{mils}$

At a head of $5.5 ", Q_{10}$ FPS was 2.5 GPM. The converging nozzle greatly improved upon the flow pattern when compared to the diverging nozzle of Test 1 . With this nozzle configuration, a smooth arrowhead plateau extended 4" out from the nozzle. The top of this plateau was laced with a crisscrossing quilted pattern of small standing waves. There appeared to be little spreading of the 
stream as the edges seemed to pull towards the centerline to form the arrow head. Ink injected into the flow passed through the wave form without a change in direction, indicating straight stream 1ines. Lowering the speed to 5 FPS and 2.5 FPS exaggerated the flow pattern and the arrowhead fell backward to about $3.5^{\prime \prime}$ and 2.5 " in front of the nozzle, respectively.

A head of $11.5 "$ increased $Q 10$ FPS to 3.3 GPM. This increased flow extended the arrowhead 6.5" from the nozzle, causing the flow to appear more elongated. Lowering the belt speed first to 5 FPS, then to 2.5 FPS brought the arrowhead back to 5" and 4.5 " from the nozzle. At the low speed of 2.5 FPS the stream started to spread, reaching $3.5 "$ in width as it moved up the belt.

Test 2B - Converging Nozzle with $G_{1}>G_{2}$. $\rho: 15^{\circ}, \beta: 90^{\circ}, G_{2}: 50 \mathrm{mils}, \alpha:-5^{\circ}, G_{1}: 25 \mathrm{mils}$.

A head of $5.5^{\prime \prime}$ gave a $Q_{10}$ FPS of 1.1 GPM. Where in test $1 B$ the smaller $G_{1}$ increased the number of ropes, here the reduced $G_{1}$ multiplied the number of arrowheads. This nozzle created a series of small arrowheads (pointing toward the nozzle) extending about l" out from the nozzle, where the stream flattened out keeping very straight streamlines as it is carried away up the belt. The restricting $G_{1}$ again appeared to improve the flow, though as in this case the flow rate was very low and $G_{2}$ was not filled. The single $V$ shaped arrowhead appeared as the speed was lowered to 5 FPS. The surface of the arrow head again resembled the quilted pattern of small crossing standing waves. Injecting ink into the 
stream showed however that the streamlines were not completely straight at this low flow. Where the surface standing wave pattern appeared to puld in to form the arrowhead, so to did the actual streamlines appear to be pulled in. A slight broadening of the stream also appeared to result from lowering the speed. Further lowering of the speed to 2.5 FPS, gave a very well defined arrowhead pattern extending to 2 " from the nozzle. The observation, that the actual streamlines were effected by the standing wave pattern became more obvious at this lower speed. The flow at these low speeds however proved to be very unstable and did not hold together going up the belt.

Raising the head to $11.5 "$ only increased Q Q before, increasing the head lengthened the flow pattern. The edge of the arrowhead extended 11.5" out from the nozzle forming a slight $V$ shaped standing wave form. The quilted pattern within the arrowhead elongated to form multiple smaller $\mathrm{V}$ shaped standing waves within the larger one. Injection of ink still indicated the connection between these surface wave forms and the actual streamlines. Lowering the speed to 5 FPS shortened the V to 8 ". Instability again occurred when the speed was lowered to 2.5 FPS.

Test $3 A$ - Diverging Nozzle with $G_{1}>G_{2}$. $\rho: 15^{\circ}, B: 60^{\circ}, G_{2}: 150 \mathrm{mils}, \alpha:+5^{\circ}, G_{1}: 200$ mils.

A 5.5" head produced a $Q_{10 F P S}$ of $5.4 \mathrm{GPM}$. Increasing $\mathrm{G}_{2}$ and $\mathrm{G}_{1}$ provided a greater supply of water through the nozzle but also produced a very complex wave pattern. The stream widened as it 
exited the nozzle and formed a complex bralded pattern with wandering streamilnes. The larger gaps provided a greater supply of water through the nozzle and produced a very complex wave pattern. The stream widened as it exited the nozzle and formed a complex braided pattern with wandering streamlines. $G_{2}$ did not appear to be filled. Lowering the speed to 5 FPS caused the edges to flatten, forming a large $V$ shaped standing wave mirrored by two more standing waves within the flrst. The formation of the V's appeared to be initiated at the corners of the nozzle. Lowering the speed to 2.5 FPS produced an unstable stream which broadened to 4 " wide; the V's retreated back towards the nozzle.

A $11.5 "$ head raised the $Q_{10 F P S}$ to $7.5 \mathrm{GPM}$ and increased the complexity of the flow. Again present were the $\mathrm{V}$ shaped standing waves and the braided, quilted pattern. The streamlines wavered as they passed over the standing waves. Lowering the speed increased the instability of the edges causing them to broaden out while the stream center maintained the $V$ standing wave pattern.

Test 3B - Diverging Nozzle with $G_{1}<G_{2}$. $p: 15^{\circ}, B: 60^{\circ}, G_{2}: 150$ mils, $\alpha:+5^{\circ}, G_{1}: 75 \mathrm{mils}$.

With a head of $5.5^{\prime \prime}$, the Q Q OFPS was 3.1 GPM. A stable flow was achieved with the reduction in $G_{1}$. There was still curling of the edges as they pulled in to form the arrowhead 4.5" from the nozzle. The curling progressed into roping of the edges as the stream moved up the belt. Lowering the speed again caused increased instability and collapsing of the wave pattern. 
The increased head of $11.5 "$ raised $Q_{10 F P S}$ TO 4.6 GPM. Flow from the nozzle appeared similar to that observed at the lower head although the increased rate of water out the nozzle lengthened the arrowhead to $6.5^{\prime \prime}$ and appeared to maintain stability longer at the lower speeds.

Tegt 3C - Diverging Nozzle with $G_{1}=G_{2}$. $\rho: 15^{\circ}, \beta: 60^{\circ}, \mathrm{G}_{2}: 75 \mathrm{mils}, \alpha:+5^{\circ}, \nabla_{1}: 75 \mathrm{mils}$.

A head of $5.5^{\prime \prime}$ produced a $Q_{\text {lofps }}$ of $2.5 \mathrm{GPM}$. The flow achieved with this configuration appeared to be much stabler than $3 A^{\prime}$ 's or 3B's having the appearance of a very stable standing wave pattern with a slight crossover appearance. The crisscrosising quilted pattern was again present within the standing waves. It appeared that where the large $V$ shaped standing waves and the outer edge of the arrowhead plateau are created by the corners of the nozzle, the quilted pattern is created by intermittent adhesion of the stream across the top of $G_{2}$. Lowering the speed to 5 FPS produced curling of the edges which began to spread when the speed was aropped to 2.5 FPS.

Test $4 \mathrm{~A}$ - Diverging Nozzle with $\mathrm{G}_{1}>\mathrm{G}_{2}$. $\rho: 15^{\circ}, \beta: 60^{\circ}, \mathrm{G}_{2}: 50 \mathrm{mils}, \alpha:+5^{\circ}, \mathrm{G}_{1}: 100 \mathrm{mils}$.

With a head of $5.5^{\prime \prime}$ and a Q QFPs of 4.1 , the flow pattern created by this nozzle was very complex. This nozzle configuration was similar to test l's, except the approach angle was decreased to $60^{\circ}$. It was likewise similar to tests $3 \mathrm{~A}$ and $3 \mathrm{~B}$ but used the smaller $50 \mathrm{mils} \mathrm{G}_{2}$. The stream again tended to form a rope toward 
the center of the belt as in test $1 \mathrm{~A} . \mathrm{G}_{2}$ seemed to fill, then unfill with the fluctuation of the roping action of the stream. Lowering the speed only seemed to aggravate the instability and spreading of the stream.

Ralsing the head to $11.5 "$ increased the $Q_{10 F P S}$ to 7 GPM and yielded very unstable flow, characterized by a great deal of turbulence and wandering in the stream. Again lowering the speed exaggerated the instability.

Test $4 B$ - Diverging Nozzle with $G_{1}<G_{2}$. $\rho: 15^{\circ}, B: 60^{\circ}, G_{2}: 50 \mathrm{mils}, \alpha:+5^{\circ}, G_{1}: 25 \mathrm{mils}$.

With the restricted $G_{1}$, the $5.5^{\prime \prime}$ head could only supply a Qlofps of $0.9 \mathrm{GPM}$. The stream surface exiting the nozzle contained countless small rivulets parallel to the direction of the belt. Lowering the speed initiated the formation of the crossing pattern of the $V$ shaped standing wave containing the quilted pattern. The flow appeared to be very stable with a slight pulling in of the edges as to form the $V$ standing waves. Stability was maintained as the speed was lowered to 2.5 FPS although a slight spreading of the stream was apparent.

No flow rate was recorded for the $11.5^{\prime \prime}$ head. The flow pattern appeared very similar to that at the 5.5" head. With straight flow lines at the high speed of 10 FPS and then the formation of the standing wave and quilted pattern at the lower speeds. The greater head again seemed to accent the flow's characteristics, extending 
and highlighting the standing wave pattern. Curling of the edges developed as standing waves formed.

It was observed with this nozzle that at the higher speed $\mathrm{G}_{2}$ was not filled and the stream maintained straight streamlines. As the speed decreased, $G_{2}$ became filled and the standing wave pattern formed. Since the larger standing waves appear to be the effect of the nozzle corners, it can be presumed that they are present at the higher speeds but are elongated to such an extent as to be indistinguishable from the series of rivulets. This was borne out by observing the elongation of the standing waves as the speed was increased. The quilted pattern was an effect produced only when $\mathrm{G}_{2}$ is filled.

Test 5A - Converging Nozzle with $G_{1}>G_{2}$. $0: 15^{\circ}, B: 60^{\circ}, G_{2}: 150 \mathrm{mils}, \alpha:-5^{\circ}, G_{1}: 200 \mathrm{mils}$.

The 5.5 " head produced a 6.5 GPM $Q_{10 F P S}$ of 6.5 GPM. This nozzle design duplicated test $3 A \& 3 B$ except that the secondary gap converged towards the exit. $G_{2}$ was filled and the flow exhibited the $\mathrm{V}$ standing wave with the associated quilted pattern. There was a slight amount of spreadin's with this nozzle which increased as the speed was lowered. Instability was present at 5 FPS with accented curling of the edges as they rolled up to form the standing wave. Roped edges and wandering of the stream were apparent at the low 2.5 FPS speed.

Raising the head to 105" maximized Q 10 FPS at 9.3 GPM. At 10 FPS the flow consisted of a combination of a vague $V$ shaped 
standing wave and very turbulent flow. There was definite spreading of the stream as the edges curled to shape the V. At 5 FPS the edges formed ropes; lowering the speed to 2.5 FPS merely increased the flow instability.

Test 5B - Converging Nozzle with $G_{1}<G_{2}$. $p: 15^{\circ}, B: 60^{\circ}, G_{2}: 150 \mathrm{mils}, \alpha:-5^{\circ}, G_{1}: 75 \mathrm{mils}$.

Decreasing $G_{1} 1 j$-ited $Q_{10 F P S}$ to $3.5 \mathrm{GPM}$ at the 5.5 " head and kept $G_{2}$ from appearing to be filled. The flow pattern again consisted of the $V$ standing wave and quilted pattern with rolling of the edges. Slowing the speed increased the wandering in the streamlines and broadened the stream.

At 11.5" of head, Q Q 1 FPS increased to $4.5 \mathrm{GPM}$ and exaggerated the lower head's flow pattern. The pattern appeared very complex with increased spreading. When the speed was lowered to 2.5 FPS, a twin $V$ pattern formed as the water attached itself to the top of $\mathrm{G}_{2}$. This attachment led to increased turbulence in the stream since it was not complete across the nozzle. This design seemed to increase the spreading of the stream.

Test 6A - Converging Nozzle with $G_{1}>G_{2}$. $\rho: 15^{\circ}, B: 60^{\circ}, G_{2}: 50 \mathrm{mils}, \alpha:-5^{\circ}, G_{1}: 100 \mathrm{mils}$.

Q lOFPS was $2.5 \mathrm{GPM}$ with 5.5 " of head using the nozzle geometry. For comparison, this geometry duplicated test 2 's with $B$ reduced to $60^{\circ}$, test $5^{\prime}$ 's with $G_{2}$ reduced to $50 \mathrm{mils}$, and test $4^{\prime} \mathrm{s}$ with a converging nozzle. The flow appeared very attractive exiting 
from this nozzle. A standing $V$ formed 4 " from the nozzle and the plateau which formed within appeared very flat. There was a slight curling of the edges due to the formation of the $V$ but the stream lines were very straight, even through the standing wave. Lowering the speed to 5 FPS produced a more rounded, smoother flow. The V retreated back to $3^{\prime \prime}$ in front of the nozzle and the stream tended to broaden slightly. Even at 2.5 FPS the stream appeared very stable though the curling of the edges increased.

At $11.5 "$ of head, $Q_{10 F P S}$ was $4.2 \mathrm{GPM}$ and the flow appeared much as it did at 5.5". The $V$ was elongated to 6" and edge curling produced edges about twice the height of the center. stability was maintained when the speed was dropped to 5 FPS, however the rolling of the edges increased causing spreading of the stream as it moved away from the nozzle. At 2.5 FPS the edge effect became even more pronounced and the streamlines started to wobble.

Test 6B - Converging Nozzle with $G_{1}<G_{2}$. $\rho: 15^{\circ}, \beta: 60^{\circ}, G_{2}: 50 \mathrm{mils}, \alpha:-5^{\circ}, G_{1}: 25 \mathrm{mils}$.

Reducing $G_{1}$ reduced $Q_{10 F P S}$ at $5.5^{\prime \prime}$ to $1.3 \mathrm{GPM}$. The low flow yielded a very smooth stream without any distinguishing standing waves. The quilted pattern was present and the streamlines were very straight. Lowering the speed to 5.5 FPS introduced the $V$ shaped standing wave though the streamlines remain straight. Further lowering the speed to 2.5 FPS introduced the curling edge effect. Increasing the speed back to 10 FPs resulted in the 
elongation of the standing wave until it once again became undetectable.

The flow pattern at $11.5^{\prime \prime}$ of head behaved similarly. The Increased head produced a $Q_{\text {IOFPS }}$ of 2.6 which slightly enhanced the pattern.

Test 7A - Converging Nozzle with $G_{1}>G_{2}$. $\rho: 15^{\circ}, \beta: 90^{\circ}, G_{2}: 150 \mathrm{mils}, \alpha:-5^{\circ}, G_{1}: 200 \mathrm{mils}$.

At 5.5", Q Q test $5^{\prime}$ 's except $\beta$ equaled $90^{\circ}$ and test $2^{\prime} \mathrm{s}$ with an increased $\mathrm{G}_{2}$ to 150 mils. Flow from this nozzle produced a very poor stream. Rolling of the edges and turbulence of the center produced a very complex flow pattern with poor streamlines. An elongated $V$, formed by the rolling edges, contained a rounded hill of water which sloped toward the edges. Lowering the speed to 5 FPS moved the V to 5" from the nozzle. The straam appeared to slope off from the $V$ then roll up again at the edges. At 2.5 FPS, the $V$ persisted but spreading of the stream became severe.

Raising the head to $11.5 "$ only exaggerated the poor flow pattern though the increased $Q_{10 F P S}$ OF 9.3 GPM pushed the hill of water further from the nozzle. This had the effect of making the flow look less turbulent by spreading out the $\mathrm{V}$. Lowering the speed brought the $\mathrm{V}$ back towards the nozzle and made the sloping of the stream from the center to the edges more dramatic. 
Test 7B - Converging Nozzle with $G_{1}<G_{2}$. $\rho: 15^{\circ}, B: 90^{\circ}, \mathrm{G}_{2}: 150 \mathrm{mils}, \alpha:-5^{\circ}, \mathrm{G}_{1}: 75 \mathrm{mils}$.

A 5.5 " head gave a $Q_{10 F P S}$ of 3.4 GPM. The smaller $G_{1}$ reduced the amount of turbulence and produced the arrowhead plateau pattern observed in test 2 , though the edge of the plateau was not very distinct. The stream appeared to fall off from the plateau to form humped edges. Reducing the speed brought the $V$ to $3^{\prime \prime}$ of the nozzle, increasing the rolling action at the edges. At 2.5 FPS, the $V$ retreated to $2^{\prime \prime}$ and the stream broke up completely at that point.

At 11.5", Q10FPS was $5 \mathrm{GPM}$ and the arrowhead plateau was again present. There was no distinguishable $V$ as the stream fell off to form the humped edges. The increased flow produced a greater degree of spreading which became worse as the speed was dropped. At 5 FPS, the rivulets composing the arrowhead became more turbulent. At 2.5 FPS, the edges began to rope and a $V$ was formed 5" ahead of the nozzle. As at the lower head the reduced speeds increased stream spreading.

Test 8A - Diverging Nozzle with $G_{1}>G_{2}$. $\rho: 15^{\circ}, \beta: 90^{\circ}, G_{2}: 150 \mathrm{mils}, \alpha:+5^{\circ}, G_{1}: 200 \mathrm{mils}$.

$Q_{\text {IOFPS }}$ was 5.1 GPM with $5.5^{\prime \prime}$ of head using this nozzle geometry. Again for comparison, this geometry was that used in test 3 with $B$ raised to $90^{\circ}$, in test 1 with $G_{2}$ opened to 150 mils, and in test 7 using a converging secondary gap. The flow pattern appeared much as it did in test 3 with distinct standing waves 
crossing in the midale of the stream to form the characteristic $V$. The quilted pattern again persisted within the $V$ and the stream appeared to slope down from the $V$ to form the rolling edges. Lowerling the speed from 10 FPS, to 5 FPS, then to 2.5 FPS, pulled the V from 6" from the nozzle to 5.5" to 5" with little change in the stream.

Maximum flow of $9.5 \mathrm{GPM}$ only allowed a maximum of 10 " of head. This flow produced was very turbulent, rlsing to $1 / 2 "$ thick on the belt and spreading 2 to 3 inches after leaving the nozzle. There appeared to be a $\mathrm{V}$ standing wave or arrowhead pattern containing the turbulent flow. Lowering the head increased the spreading as the turbulent flow was contained closer to the nozzle.

Test $8 B$ - Diverging Nozzle with $G_{1}<G_{2}$. $\rho: 15^{\circ}, \beta: 90^{\circ}, G_{2}: 150$ mils, $\alpha:+5^{\circ}, G_{1}: 75$ mils.

$5.5 "$ of head yielded a 1 IOFPS OF 3.4 GPM and produced a flat flow with a very distinct quilted pattern within a $\mathrm{V}$ extending out 7". The reduced flow allowed for good edge control with very little spreading. The pattern did not alter much as the speed was dropped to 5 FPS; however the V extended only 5". Spreading increased as the speed was lowered to 2.5 FPS. The V retreated to $4 "$ in front of the nozzle.

Raising the head to $11.5 ", Q_{10 F P S}$ of $4.6 \mathrm{GPM}$, did not alter the character of the flow. The stronger flow did push the $V$ to 8 " away from the nozzle at a belt speed of 10 FPS. Reducing the speed to 5 FPS only brought the $V$ back to $7 "$, where it appeared to remain even 
as the speed was further reduced to 2.5 FPS. The lower speeds produced a more distinct standing wave pattern with a visible edge effect at the lower speed. The edges curled up as the $V$ became more distinct.

Test $9 A$ - Diverging Nozzle with $G_{1}>G_{2}$. $\rho: 45^{\circ}, \beta: 60^{\circ}, G_{2}: 50 \mathrm{mils}, \alpha:+5^{\circ}, G_{1}: 100 \mathrm{mils}$.

At 5.5" of head and a Q10FPs of 4.5 GPM, the nozzle was completely flooded due to back flow down the belt. This nozzle design was that used in test 4 at a $\rho$ of $15^{\circ}$. The belt speed had to be increased to 15 FPS before a stream could be maintained from this $\rho$ of $45^{\circ}$. At 15 FPS, the flow exhibited a standing $V$ wave.

At 10", the maximum head allowed by the angle of the pouring box, Q10FPS was $6.5 \mathrm{GPM}$. At 10 FPS severe roping of the edges was present, rising $3 / 4 "$ on the belt. Shortly after leaving the nozzle the stream flooded the belt. At 5 FPS the nozzle was flooded. Raising to 15 FPS again produced a stream with roped edges $1 / 2$ " thick.

Checking the flow at the reduced head of $3.5 ", Q_{10 F P s}$ of 4.5 GPM, gave a stream that broke up just as it exited the nozzle with the belt speed at 10 FPS. At 15 FPS, the streamlines contained many rivulets near the nozzle. No standing wave pattern was visible. 
Test 9B - Diverging Nozzle with $G_{1}<G_{2}$. $\rho: 45^{\circ}, \beta: 60^{\circ}, G_{2}: 50 \mathrm{mlls}, \alpha:+5^{\circ}, G_{1}: 25 \mathrm{mlls}$

As in test 4 , reducing $G_{1}$ greatly restricted the flow rate, at 5.5" of head $Q_{10 F P S}$ was $1.5 \mathrm{GPM}$. The stream appeared very smooth at. this head with nice streamlines, though the strip was very thin. Seven to elgi.i l" long V's were present exlting the nozzle which crisscrossed as the stream moved away from the nozzle. A speed of 5 FPS caused the nozzle to flood. Increasing to 15 FPs produced a very flat, thin, straight stream. $G_{2}$ did not appear to be filled.

At $10 "$ of head, Q Q 10 FPs was $1.75 \mathrm{GPM}$ and the stream behaved much as it did at 5.5" of head. A belt speed of 9 FPS was required to produce a stream.

At $3.5 ", Q_{10 F P S}$ was again $1.5 \mathrm{GPM}$ and the stream again behaved as it did at $5.5 "$.

Test 10A - Converging Nozzle with $G_{1}>G_{2}$. $\rho: 45^{\circ}, R: 60^{\circ}, G_{2}: 50 \mathrm{mils}, \alpha:-5^{\circ}, G_{1}: 100 \mathrm{mils}$.

With the same geometry as test 6 , a head of $5.5^{\prime \prime}$ yielded a Q IOFPS Of $2.5 \mathrm{GPM}$. And as with test $6 \mathrm{~A}$, the stream produced exhibited very good flow characteristics. There was very little spreading of the stream which showed very straight streamlines when ink was injected. only a faint $V$ standing wave was visible which contained a very slight plateau, $G_{2}$ being completely filled. A speed of 7.5 FPS was required to keep the belt from flooding. Raising the speed to 15 FPS washed away the standing wave though 
the start of the $v$ could be distinguished at the corners of the nozzle.

A 10" head gave a more distinct standing wave pattern with a slightly higher plateau. The streamlines remained quite stralght. A speed of 7.3 FPS was still required to malntain the stream. And again, 15 FPS eliminated the standing wave.

The flow at 3.5 " was identical to that at $5.5 "$.

Test $10 B$ - Converging Nozzle with $G_{1}<G_{2}$. $\rho: 45^{\circ}, B: 600, G_{2}: 50 \mathrm{mlls}, \alpha:-5^{\circ}, G_{1}: 25 \mathrm{mils}$.

starting at $3.5^{\prime \prime}$ of head, Q10FPS was 1 GPM. With the reduced $G_{1}$ and low head, $G_{2}$ was unfilled and the flow out the nozzle appeared very thin and straight without standing waves. A speed of 7.1 FPS was required to keep the belt from flooding. 15 FPS produced a thinner stream.

Raising the head to $5.5 "$ increased $Q_{10 F P S}$ GPM and formed very slight $V$ standing waves $2 "$ in front of the nozzle. As at 3.5", there was very little spreading or edge effects. A speed of 7.3 FPS was needed to maintain the stream and the high speed of 15 FPS again flattened out the stream.

Raising the head up to the maximum of $10 "$, yielded a $Q_{10 F P S}$ of 2 GPM. The stream exhibited a slight $V$ which crossed 6 " out. Other than this, the flow behave much as it did at the lower heads. A belt speed of 7.4 FPS kept the stream from collapsing back on 
itself and the high speed of 15 FPS produced a thin, flat, straight stream.

Test 11A - Converglng Nozzle with $G_{1}>G_{2}$.

$\rho: 45^{\circ}, \beta: 90^{\circ}, G_{2}: 50 \mathrm{mlls}, \alpha:-5^{\circ}, G_{1}: 100 \mathrm{mLls}$.

Test 11 nozzle is the twin of test $2^{\prime} \mathrm{s}$ and provided a $Q_{10 F P S}$ of 2 GPM at $3.5^{\prime \prime}$ of head. A V formed 3 " from tie nozzle containing the crisscrossing quilted pattern as in lest 2. There was no spreading of the edges and the streamlines appeared to remain straight. 8.2 FPS was the lowest speed possible without flooding the belt. Again, 25 FPS produced uninterrupted stralght strlp with $G_{2}$ remaining filled.

No $Q_{10 F P S}$ was available for $5.5^{\prime \prime}$ of head though the flow looked slightly better. "The $V$ extended out to 4 " with minimal edge effects and still contained the quilted pattern which appears to be associated with a filled $G_{2}$. A speed under 8 FPS flooded the belt. and 15 FPS effected the stream as before.

10.5" of head provided a $Q_{10 F P S}$ OF $3.5 \mathrm{GPM}$ filling $\mathrm{G}_{2} \cdot$ slight curling of the edges accompanied the formation of the $V$ though the streamlines remained straight. The quilted pattern was still persistent within the $V$ giving it the raised arrowhead plateau appearance. Lowering the speed to 5 FPS caused the belt to flood but not the nozzle. As the speed was lowered the standing wave became more distinct. A speed of 7.5 FPS was required to keep the belt from flooding. The same effect as before was seen with the belt speed of 15 FPS. 
Test 11B - Converging Nozzle with $G_{1}<G_{2}$. $\rho: 45^{\circ}, B: 90^{\circ}, G_{2}: 50 \mathrm{mlls}, \alpha:-5^{\circ}, G_{1}: 25 \mathrm{mils}$.

Restricting the flow with $G_{2}$ reduced $Q_{\text {loFPS }}$ to $1 / 2$ GPM at $3.5 "$ of head. As observed in earlier tests the small $G_{1}$ oreated very flat flow with no edge effects or spreading. A belt speed of 7 FPS was required to keep the belt from flooding.

Ralsing the head to $5.5 "$ Increased $Q_{10 F P S}$ to $1.5 \mathrm{GPM}$ and produced very even flow with a hint of pulling in of the edges. This pattern could be maintained down to 5.5 FPS before the stream broke up.

At 10", Q loFPS was $1.7 \mathrm{GPM}$ and the flow was very similar to that observed at the lower heads. There appeared to be slightly more spreading and a more distinct quilted pattern with the increased flow provided by the higher head. A slightly higher speed of 5.8 FPS was required to keep the belt from flooding, possibly due to the increased spreading tendency with increased flow.

For each of the above three heads, a belt speed of 15 FPS produced the same thin, flat, straight stream as observed in the previous tests.

Test 12A - Converging Nozzle wit's $G_{1}>G_{2}$. $\circ: 45^{\circ}, B: 60^{\circ}, G_{2}: 150 \mathrm{mils}, \alpha:-5^{\circ}, G_{1}: 200 \mathrm{mils}$.

Using the same nozzle design used in test $5,3.5^{\prime \prime}$ of head yielded a QlofPs of $4.2 \mathrm{GPM}$. The nozzle was completely flooded at 
10 FPS and a stream could not be maintained over the top of the belt without back flow occurring even at the maximum speed of 20.3 FPS emptied $G_{2}$ and produced the flat stream characteristic of the 15 FPS belt speeds in the previous test. It was noted during these speed changes that increasing the belt speed increased the flow rate out of the nuzzle. The flow rate measured at 20.3 FPS was 4.6 GPM, slightly higher than the 4.2 GPM measured at 10 FPS.

Q IOFPS at $5.5 "$ of head was 5.4 GPM Indloating that changing the belt speed did not affect the flow rate as dramatically as changing the head. The effect of belt speed was again observed at 5.5 " of head by lowering the speed, with reading taken at 5 FPS and then at full stop. The flow rate decreased from 5.4 GPM to slightly less than $5 \mathrm{GPM}$ and finally to $4.6 \mathrm{GPM}$ when the belt was at full stop. The flow characteristics appeared similar to those at $3.5^{\prime \prime}$ of head.

Full stop flow at maximum head, 10", was 7.6 GPM. A Q10FPS was not recorded at this head. The flow consisted of crossing standing waves forming $a \mathrm{~V}$ and heavy spreading of the stream.

Test $12 B$ - Converging Nozzle with $G_{1}<G_{2}$. $p: 45^{\circ}, B: 60^{\circ}, G_{2}: 150 \mathrm{mils}, C:-5^{\circ}, G_{1}: 75 \mathrm{mils}$.

At $3.5 "$ of head, Q Q 1 FPS was $3.3 \mathrm{GPM}$ and the nozzle was flooded with a belt speed of 10 FPS. A stream still formed, however, as the belt moved the water away from the nozzle. Increasing the speed to 11.2 FPS cleared the nozzle and formed a V 2 " from the exit. Further increasing the speed to 15 FPS emptied $G_{2}$ and again produced a flat stream with no real standing waves. 
Raising the head to $5.5^{\prime \prime}$, increased Q10FPS to $3.5 \mathrm{GPM}$ and flooded the nozzle, as at $3.5^{\prime \prime}$ of head. The slightly higher flow seemed to increase the amount of spreading of the stream and curling of its edges. A speed of 13.5 FPS was required to clear the nozzle. Further increasing the speed to 15 FPS produced small. rivulets forming the orlssorossing quilted pattern atop the stream without the formation of the larger $V$ standing waves. $G_{2}$ did not empty until a speed of 18.9 FPS was reached. Once $G_{2}$ opened, however, it remained opened as the speed was derreased. Back at 10 FPS the stream exhibited the $V$ formed by the crossing of standing waves pulling in from the edges. $G_{2}$ did not refill untll the nozzle became flooded when the speed was dropped to 8.2 FPS.

At 10" head, Q10FPS increased to 4.9 GPM. Starting at 10 FPS, $\mathrm{G}_{2}$ was not filled. High rivulets formed across the nozzle crisscrossing into the quilted pattern. There appeared to be slight spreading of the stream as it approached the top of the belt. Lowering the speed to 4.2 FPS flooded the nozzle. The nozzle remained flooded even at the top belt speed of 20.3 FPS. The flow was characterized by rivulets forming from the flooded nozzle and roping of the edges, bejng similar to the flow produced in test 5, though flooding did not occur at the higher nozzle position. 
Test 13A - Diverging Nozzle with $G_{1}>G_{2}$. $\rho: 45^{\circ}, \beta: 90^{\circ}, G_{2}: 150$ mils, $\alpha:+5^{\circ}, G_{1}: 200$ mils.

Flooding of the belt occurred at all heads with this nozzle design which was that used during test 8 . Q Q was measured at 6.1 GPM. The flow was described by a flooded nozzle and spreading of the stream even at the maximum speed of 20.3 FPS. As the head was raised, turbulence of the stream increased.

Test 13B - Diverging Nozzle with $G_{1}<G_{2}$. $\rho: 45^{\circ}, \beta: 90^{\circ}, G_{2}: 150 \mathrm{mils}, \alpha:+5^{\circ}, G_{1}: 75 \mathrm{mils}$.

At $3.5 "$ of head, Q Q lofPS WAS $2.2 \mathrm{GPM}$. The reduction in $\mathrm{G}_{1}$ produced fair flow. There was a slight curling of the edges as they pulled in to form a standing $V$ wave. $G_{2}$ was not filled, ressulting in a $\mathrm{V}$ which was not as distinct as observed in other tests, its edges appearing more rounded, and no quilted pattern was present. This was similar to the flow in test 8 . Lowering the speed to 7.3 FPS flooded $G_{2}$. Increasing the speed back up to 10 FPS opened it back up again. Checking the streamlines with ink injection showed that the streamlines tended to jog out as they crossed over the edge of the $V$. This indicated that the actual flow of the stream was effected by surface conditions. Increasing the speed of the belt eliminated the $V$ and produced a thin stream with straight streamlines. 
At $5.5^{\prime \prime}$ of head, Q Q 10 PPS was $2.7 \mathrm{GPM}$, making the standing waves slightly more distinct, though $G_{2}$ was still empty. Lowering the speed to 7.3 FPS again flooded $G_{2}$, however, this time it remained flooded as the speed increased back to 10 FPS. The stream appeared to spread with rivulets forming across the nozzle and roping of the edges. Increasing the speed further to 12.1 FPS cleared the nozzle and returned the stream back to its initial condition.

Raising the head to 10", increased Q lOFPS to 3.7 GPM. $G_{2}$ seemed to be unfilled ind the stream exhibited a flat appearance with an arrowhead plateau sloping off to humped shoulders at the stream edges. A crisscrossing pattern was evident atop the plateau indicating that the surface of the stream was interacting with the nozzle within $G_{2}$, possibly forming a meniscus as the gap diverged. The gap appeared to remain open until the nozzle was flooded at a belt speed of 4.4 FPS. The nozzle remained flooded until a speed of 12 FPS was reached, opening $G_{2}$ and returning the stream to the initial state. Good flow seemed to only occur when the nozzle was not flooded and $G_{2}$ was open. It was noted that the flow rate appeared to increase slightly as the nozzle cleared.

Test $14 \mathrm{~A}$ - Diverging Nozzle with $G_{1}>G_{2}$. $\rho: 45^{\circ}, B: 60^{\circ}, G 2: 150$ mils, $\alpha:+5^{\circ}, G_{1}: 200 \mathrm{mils}$.

Q loFPS was not recorded at $3.5^{\prime \prime}$ of head. With the same design used in test 3 , the flow exiting the nozzle flooded the belt at this head even at the maximum speed of 20.3 FPS. Back wash flowed 
down the stream as it moved up on the belt. The edges resembled humped shoulders.

The nozzle remained flooded at 5.5" of head with a belt speed of 10 FPS. Raising the speed to 15 FPS cleared $G_{2}$ and permitted a standing $V$ wave to form in the stream. Flooding did not reoccur when the speed was reduced to 10 FPS. Instead the stream maintained the standing wave though it became very turbulent and spread out just ahead of the wave. Increasing the speed flattened out the turbulence and reproduced the stream as it had been before. With $\mathrm{G}_{2}$ unfilled, $Q_{10 F P S}$ was $4.6 \mathrm{GPM}$ at this head. Flooding $\mathrm{G}_{2}$ raised $Q_{10 F P S}$ to $6 \mathrm{GPM}$.

Q 10 FPS was not recorded at $10 "$ of head. The stream exhibited standing waves crossing $6 "$ " out from the nozzle. $G_{2}$ appeared to be opened and the edges did not have the raised shoulder appearance. slowing the speed of the belt made the standing wave pattern more distinct. At a speed of 2.5 FPS the stream exiting the nozzle was strong enough to prevent the nozzle from being flooded though the stream which had spread completely across the belt and back flowed around the nozzle. After flooding $G_{2}$ by stopping the belt, the speed was increased up to the maximum of 20.3 FPS. The nozzle failed to open again even at the maximum speed. 
Considering this test along with test 3 leads to the conclusion that this is a very poor nozzle design. In both tests the flow was very erratic and unstable. Whether $G_{2}$ was opened or flooded was a metastable condition depending on how the test was started.

Test 24B - Diverging Nozzle with $G_{1}<G_{2}$. $\rho: 45^{\circ}, \beta: 60^{\circ}, G_{2}: 150 \mathrm{mils}, \alpha:+5^{\circ}, G_{1}: 75$ mils.

As with test 3 , reducing $G_{1}$ stabilized the flow from the nozzle. At 3.5", Q Q OFPS was $2.6 \mathrm{GPM}$ and standing waves formed a $V$ 3" out from the nozzle. $G_{2}$ appeared emptied and there was still some slight back flow in the stream. The edges were wobbly but did not exhibit shoulders. Lowering the speed to 7.7 FPS flooded $\mathrm{G}_{2}$, where increasing the speed up to 9.8 FPS reopened it.

At $5.5^{\prime \prime}$ of head, a QlofPS of $4 \mathrm{GPM}$ was recorded. Such a large increase in flow seems unlikely and may be the result of an unstabilized head. At this head the $V$ moved out to $4.5^{\prime \prime}$ and became more distinct. No back flow was apparent and the flow exhibited good edges and streamlines. $G_{2}$ flooded when the speed was lowered to 7.4 FPS and reopened at 16 FPS, the increased flow apparently impeding the reopening of the nozzle. The flooded nozzle produced a stream with a smooth center in which a vague quilted pattern could be distinguished. The edge rolled up to form the shoulder. appearance observed with the larger $G_{2}$. On flooding the nozzle a second time, $G_{2}$ remained flooded even at maximum speed, again indicating the metastable nature of the flow. Increase in the flow rate was again observed with the flooding of the nozzle. 
$Q_{\text {IOFPS }}$ was $4.2 \mathrm{GPM}$ at $10 "$ of head. Crossing of the standing waves was pushed to 8" out with the stronger flow. A low speed of 3.0 FPS had to be reached before the nozzle flooded and only a speed of 11.5 was required to reopen 1t. Further increasing the speed erased the standing waves and produced straight streamlines.

Test 25A - Diverging Nozzle with $G_{1}>G_{2}$. $\rho: 45^{\circ}, \beta: 90^{\circ}, G_{2}: 50 \mathrm{mils}, \alpha:+5^{\circ}, G_{1}: 100 \mathrm{mils}$.

The nozzle design used for this test was that which exhibited the very poor flow characterized by the formation of a rolling hill in the stream's center in Test 1 . Q10FPs was 1.7 GPM through this nozzle at $3.5^{\prime \prime}$ of head. Similar flow to the poor flow of Test $1 \mathrm{~A}$ was observed. The stream tended to roll up towards the center partially filling $G_{2}$, while the flow did not fill the corners of the nozzle. The hill reached a height of nearly 1." before it flattened out as it moved out away from the nozzle. The edges curled up into shoulders, spreading out as they rode up the belt. The spreading created a long $\mathrm{V}$ wave form.

A speed of 7.6 FPS flooded the nozzle, where upon an increase in speed reopened it. An interesting characteristic of this nozzle was that the filled region of $G_{2}$ narrowed as the speed increased.

A head of 5.5 " produced the same flow pattern with the heavy flow towards the center and restricted flow at the edges. Flooding of the nozzle occurred at a higher speed of 8.4 FPS, most likely due to the increased supply of water at the higher head. Raising the speed reopened the nozzle as before. This was repeatable 
Indicating that this design did not possess the metastable nature of the previous test.

10" of head provided a $Q_{10 F P S}$ of 2.3 GPM. The increased flow flattened the ropey stream of water to $1 / 2$ " high off the belt though restricted flow out of the sides of $\mathrm{G}_{2}$ was still present.

Test 15B - Diverging Nozzle with $G_{1}<G_{2}$.

$\rho: 45^{\circ}, \beta: 90^{\circ}, G_{2}: 50 \mathrm{mils}, \alpha:+5^{\circ}, G_{1}: 25 \mathrm{mils}$.

starting with $10^{\prime \prime}$ of head, reducing $G_{1}$ produced nicer flow with the restricted $Q_{10 F P S}$ of $1.6 \mathrm{GPM}$. As in test 1 , the tighter $\mathrm{G}_{1}$ produced a quilted pattern with multiple standing wave, though not as rough. There was some curling to the edges as they pulled in slightly towards the center. Lowering the speed to 5.3 FPS flooded the nozzle which reopened when the speed was brought back up to 7.0 FPS. Increasing the speed to 15 FPS opened $G_{2}$ and produced straight, flat flow of nearly equal gauge across the width of the stream. The curling of the edges was dampened out at this high speed.

Decreasing the head to 5.5:1 lowered $Q_{10 F P S}$ to $1.2 \mathrm{GPM}$. The flow was very flat and streamlined with no edge effects. A low speed of 5.1 FPS was required to flood the nozzle which was reopened again with a flow of 7 FPS. 15 FPS produced the same type of stream as at the higher head.

Lowering the head to $3.5^{\prime \prime}$ produced a paper thin stream with Q IOFPS of $0.8 \mathrm{GPM}$. The stream appeared to have a very laminar flow 
with very straight streamlines. A speed of less than 5 FPS flooded the nozzle which reopened with speeds between 6 FPS and 7 FPS. The same very straight, very thin stream was produced by raising the speed to 15 FPS as with the higher heads.

Test 16A - Converging Nozzle with $G_{1}>G_{2}$. $\rho: 45^{\circ}, \mathrm{B}: 90^{\circ}, \mathrm{G}_{2}: 150 \mathrm{mils}, \alpha:-5^{\circ}, \mathrm{G}_{1}: 200 \mathrm{mlls}$.

Using the nozzle configuration as in test $7,3.5^{\prime \prime}$ of head yielded the high lofps of $5 \mathrm{GPM}$. As in test 7 , the flow produced with this nozzle was very poor with a great deal of flooding of both belt and nozzle. High belt speeds did not eliminate the flooding though rivulets could be seen in the stream exiting the nozzle and slight shoulders formed at the edges.

Flooding persisted at 5.5" of head with $Q_{10 F P S}$ equal to 6 GPM. Increasing the speed to 15 FPS pushed the flood away from the nozzle opening allowing an arrowhead plateau to form consisting of very turbulent rivulets. The edges tended to curl in to form the plateau. Increasing to 20 FPS lengthened the plateau slightly further from the nozzle along with the curled edges.

Raising the head to 10" yielded Q 10 FPS of 9 GPM and resulted in the plateau being pushed further out with an increase in the turbulence of the flow. 
Test 16B - Converging Nozzle with $\mathrm{G}_{1}<\mathrm{G}_{2}$. $\rho: 45^{\circ}, \beta: 90^{\circ}, \mathrm{G}_{2}: 150 \mathrm{mils}, \alpha:-5^{\circ}, \mathrm{G}_{1}: 75 \mathrm{mils}$.

No $Q_{10 F P S}$ was recorded for $3.5^{\prime \prime}$ of head. Again a reduction of Gl produced a smoother flow. At this head a nice flow with only slight curling of the edges emerged from a filled $G_{2}$. spreading of the edges produced a $\mathrm{V}$ wave form as the stream was carried away from the nozzle. Increasing the speed of the belt lengthened the V. At 17 FPS the $V$ had been swept away, though curling of the edges still persisted. Further increasing the speed to 18 FPS opened $G_{2}$ and produced a crisscrossing pattern on the surface of the stream. This pattern was the result of intermittent adhesion of the stream to the roof of $G_{2}$. Upon raising the speed to test for repeatability, it was observed that $G_{2}$ was open at 16 FPS. On a third trial, $G_{2}$ became unfilled at 11 FPS. This clearly indicated that the nature of $G_{2}$ was again metastable or depended on other factors other than belt speed. One such factor could be the vibration from the belt. The flow in $G_{2}$ may be very unstable over a range of speeds and could be jarred open by a peak in the vibration.

Q 1.0FPS was $2.7 \mathrm{GPM}$ at 5.5 " of head. The stream behavior was very similar to the $3.5^{\prime \prime}$ head's. Again increasing the speed elongated the $V$ wave form. At 20.3 FPS, the wave form had been erased and only the quilted pattern remained with slight curling of the edges. Slowing the belt down reformed tie $\mathrm{V}$ and moved it in towards the nozzle. The quilted pattern, enclosed in the $V$, became slightly more turbulent as the $V$ approached the nozzle. 
G2 was unfilled at 10" head. Q10Fps at $10 "$ of head was 5.5 GPM. The quilted pattern within the $V$ caused by the intermittent adhesion of the stream appeared to be composed of multiple $V$ standing waves interacting with one another as they exited the nozzle. Increase in the flow rate produced a thlcker stream which exaggerated this interaction and increased the roping of the edges. Reducing the speed to 5 FPS flooded the nozzle. Upon increasing the speed a flow pattern was produced similar to those caused by a full $G_{2}$ at $3.5 "$ and 5.5 " of head.

Test 17 - Converging Nozzle with $G_{1}=G_{2}$. $0: 45^{\circ}, \beta: 60^{\circ}, G_{2}: 50 \mathrm{mils}, \alpha:-5^{\circ}, G_{1}: 50 \mathrm{mils}, \operatorname{EXT}: 25 \mathrm{mils}$.

This test along with tests 18 and 19 were modifications of test $10 \mathrm{~A}$, test $10 \mathrm{~A}$ being observed to have exhibited the most acceptable flow of the first sixteen tests.

At 3.5 " of head the flow rate through the nozzle was $1.2 \mathrm{GPM}$ for the reference speed of 10 FPS. There appeared to be no standing wave pattern or spreading of the stream due to the low flow rate. A slight crisscrossing pattern was present on the surface of the stream. Increasing the head to 5.5, raised the flow to $1.5 \mathrm{GPM}$ and promoted the formation of a slight $V$ shaped plateau in the stream although the crisscrossing pattern persisted. Further raising the head to $10.5 "$ did not significantly alter the stream except for reinforcing the $V$ shaped plateau region. The flow rate increased to $2.75 \mathrm{GPM}$. 
Test 18 - Converging Nozzle with $G_{1}=1.5 * G_{2}$. $\rho: 450, \beta 600, G_{2}: 50 \mathrm{mils}, \alpha:-5^{\circ}, G_{1}: 75 \mathrm{mlls}$, EXT $37.5 \mathrm{mlls}$.

Test 18 used the exact nozzle conflguration as test 17 except $G_{1}$ had been opened from $50 \mathrm{inlls}$ to $75 \mathrm{mils}$.

Increasing $G_{1}$ appeared to lessen the restriction on the flow through th, nozzle. The flow rate increased to 2 GPM for $3.5^{\prime \prime}$ head and there was a silght rising of the stream near its' edges. This slight rise was the inftiation of the standing $V$ shaped platieau. The crisscrossing pattern observed in test 17 was again present. Increasing the head to 5.5 " raised the flow rate to $2.25 \mathrm{GPM}$ and created a slightly raised $V$ shaped plateau. The plateau's surface was level with the crisscrossing wave pattern. Further raising the head to 10.5" increased the flow to 3 GPM and as in test 17 enhanced the plateau region. The increased flow produced a series of standing waves crossing in from the edges although the flow remained stable.

Test 19 - Converging Nozzle with $G_{1}=2 * G_{2}$. $\rho: 45^{\circ}, \beta: 60^{\circ}, G_{2}: 50 \mathrm{mils}, \alpha:-5^{\circ}, G_{1}: 100 \mathrm{mils}$, EXT: $50 \mathrm{mils}$.

Test 19 again employed the same nozzle configuration as tests 17 but with $G_{1}$ opened from $50 \mathrm{mils}$ to $100 \mathrm{mils}$.

Under a 3.5" head the flow through the nozzle was $2.3 \mathrm{GPM}$. There was a more obvious edge effect and plateau formation than in tests 17 and 18. A crisscrossing pattern formed atop the plateau. The edges tended to be concave on exiting the nozzle, rising up to 
form the plateau, but turned convex shortly afterwards roling up into roped edges. The flat plateau dispersed at this point. Raising the head to 5.5" increased the rolling effect near the edges. The height of the plateau increased and took on the standing $V$ shaped wedge configuration. F'low rate increased to 2.5 GPM. Further raising the head to 10.5" lengthened the $\mathrm{V}$ shaped plateau to 6" from the nozzle. A sertes of standing $V$ waves of similar height as the plateau formed lmmedlately downstream from the plateau. In addition there appeared to be more spreading of the stream upon exiting the nozzle.

Test 20 - Converging Nozzle with $G_{1}=1.5 * G_{2}$ and Added Extension. $p: 45^{\circ}, \beta: 60^{\circ}, G_{2}: 50 \mathrm{mils}, \alpha:-5^{\circ}, G_{1}: 75 \mathrm{mils}$, EXT: $115 \mathrm{mils}$.

On comparing the flow patterns of test 17,18 , and 19, it was noted that the nozzle configuration used in test 18 appeared to exhibit smoother flow. It was also noted during these tests that an extension of the top of the nozzle opening past the nozzle exit helped promote a smoother flow. Hence, for this test, "e nozzle used in test 18 was fitted with a more prominent extension which extended the width of the nozzle.

With a head of $3.5 "$ and a reference speed of 10 FPS, the flow through the nozzle was measured at $2.1 \mathrm{GPM}$. Only slight spreading of the stream was observed as the water exited the nozzle. The stream edges tended to curve up slightly in a concave fashion to form a slightly raised plateau region across the center of the stream. The extension appeared to level out the stream. On 
raising the head to $5.5 "$, the flow rate increased to $2.5 \mathrm{GPM}$. There still appeared to be minimal spreading of the stream, though the stream did appear to spread slightly within the extension. It was noted that the extension seemed to aide in creating a stream which held a level profile longer. With a rise in head to roughly 10", there was a noted increase in stream spreading and the formation of a raised $V$ shaped plateau. The lncreased spreading occurred due to a small leak out the side of the nozzle. Water from this leak wetted the belt to the side of the stream, decreasing the surface tension at the stream edge. Otherwise, the stream edge remained very stable. The flow rate at this head was 3.4 GPM.

Test 21 - Weber/Reynolds Number Test. $\rho: 45^{\circ}, \beta: 60^{\circ}, G 2: 50$ mils, $\alpha:-5^{\circ}, G_{1}: 75$ mils, EXT: 115 mils.

This test was designed to model steel flow under a Weber number and Reynolds number relationship. As noted earlier, each of the previous tests used a Reynolds number and Froude number relationship. In order to create this relationship $140^{\circ} \mathrm{F}$ water was used as opposed to the $80^{\circ} \mathrm{F}$ water used for each of the previous tests. The nozzle used in test 20 was kept in place for this test.

At a 3.5" head, the stream appeared much as it did in test 20 . Very little spreading was observed and a slight standing $V$ wave pattern could be distinguished. The flow rate, however, was only $1.6 \mathrm{GPM}$ as opposed to $2.1 \mathrm{GPM}$ noted in test 20 for the same head level. Raising the head to 5.5 " increased the flow rate to 2.25 
GPM, still less than that observed in test 20 for a similar head. At this head there appeared to be slightiy more spreading of the stream, though the edge remained stable. Some rolling of the edge was noted and attributed to vibration in the belt and not related to the nozzle. A $V$ shaped standing wave was established with 1 ts tip about 5" from the nozzle's exit. Inoreasing the head to roughly 10.5" moved the tip of the wave to 7" from the nozzle. The $V$ standing wave formed a level plateau with a height of approximately 1/8". The edge of the stream had a height of about 1/16" off the belt. Flow rate at this head was 3 GPM. on letting the tank drain from this 10" head, the standing wave was observed to recede back towards the nozzle. Its tip had returned to 5" from the nozzle as the head lowered to 5.5". Upon the head reaching 3" the standing wave had dispersed leaving a level stream.

Test 22 - Secondary Gap Diverging Sides Test. $p: 45^{\circ}, \beta: 60^{\circ}, G_{2}: 50 \mathrm{mils}, \alpha:-5^{\circ}, G_{1}: 75 \mathrm{mils}$, EXT: $115 \mathrm{mils}$.

This test was run to evaluate the advantages of diverging the sides of the secondary gap in order to retain a constant cross sectional area as $G_{2}$ converged towards the exit. Initially, this test was performed with a extension which extended less than 1/4" on elther side of the nozzle. Having the corner of the extension in such close proximity to the stream appeared to cause the breakdown of the stream edge, enhancing stream spreading. Since the removal of the extension produced a smoother edge it was decided to repeat the test employing an extension which extended the width of the nozzle. 
The repeated test indicated that the diverging sides did enhance the spreading of the stream. At $3.5^{\prime \prime}$ of head, although the stream spread only slightly under the extension, upon leaving the extension the stream flared out to $1 / 2^{\prime \prime}$ on both sides of the nozzle. The edges curled slightly as the stream left the extension. There was no breakdown of the edges as seen earlier with the narrower extension. The extension again appeared to produce a flatter stream with a $V$ wave form extending out in front of the nozzle due to the spreading. It is Interesting to note that when the narrower extension was used, the breakdown of the edges prevented the formation of the $V$ at this head. A quilted pattern was observed atop the stream as 1 t exited from the filled $\mathrm{G}_{2}$.

Increasing the head to $5.5^{\prime \prime}$ produced flow similar to that at $3.5 "$ of head. A Q L LFPS of 2.5 GPM was measured at this head. Measurements with the narrower extension gave $Q_{10 F p s}$ values of 2.1 GPM and 2.3 GPM for the $3.5^{\prime \prime}$ and $5.5^{\prime \prime}$ heads, respectively. Increased flow accented the flow pattern in the stream. As the stream exited the nozzle it appeared concave, rising to form the plateau much as it did in earlier tests. It then turned convex and started to spread forming the $v$. Near the tip of the $v$, the curling of the edges allowed the edges to rise as the plateau sank under the crossing edges.

Raising the head to 10" increased QlOFPS to $3.2 \mathrm{GPM}$. The increased flow again served to accent the flow pattern observed at the lower heads. No distinct standing wave was apparent, though a smooth $V$ wave formed as the edges rolled in on the raised plateau. 
Both the spreading of the stream and the curling of the edges were enhanced by the increased flow out of the nozzle. The increased curling action broadened the stream to 6" in width from slightly wider than $3 " G_{2}$. The quilted pattern was still visible atop the plateau with the extension still appearing to maintain a more even surface.

Removal of the extension produced a more apparent $V$ standing wave pattern. It was the removal of the narrow extension used initially for this test that suggested that the extension's corners were effecting edge quality. Without the narrow extension, breakup of the edges ceased and the edge appeared smoother with less spreading as it formed the standing wave.

Test 23 - Weber/Froude Number Test. $\rho: 45^{\circ}, B: 60^{\circ}, G_{2}: 28$ mils, $\alpha:-5^{\circ}, G_{1}: 42$ mils, EXT: 115 mils.

Proportionally reducing $G_{1}$ and $G_{2}$ while keeping the rest of the nozzle's geometry the same allowed for modeling of the steel flow through the nozzle on a surface tension and gravitational basis. starting with a head of 2.5", QlofPs was less than 1 GPM. The flow appeared extremely smooth with no standing wave formed of any kind or spreading of the edges. Decreasing the belt speed to 5 FPS produced a faint $\mathrm{V}$ and allowed some back flow to occur. Raising the speed to 6 FPS eliminated this back flow and left a very smooth stream with a slight crossing wave enclosing a fine quilted pattern. 
Raising the head made the $V$ pattern more distinct. At 4.5 " of head with a $Q_{10 F P S}$ of 1 GPM the flow appeared much as it did in test 20 except with much less flow. The edges exited from under the extension in a concave fashion as the thin arrowhead plateau sloped down to the edges. As the stream rode out from the nozzle, the edge became convex and were pulled in to form the $\mathrm{V}$ standing wave which framed the plateal. At 10" of head, with a belt speed of 7.5 FPS, a distinct $V$ sh ed standing wave extended 7 " out from the nozzle. $G_{2}$ appeared to remain filled as the head was raised. Increasing the belt speed swept away the standing waves and gave the stream a very flat streamlined appearance.

Lowering the head collapsed the $\mathrm{V}$ back into the quilted pattern. At $0.5^{\prime \prime}$ head, $G_{2}$ opened allowing a very smooth, straight flow to exit the nozzle with a mirror like surface appearance. 


\section{APPENDIX III}

\section{Derinition of Terms in Melt overflow Btrip casting Log}

1. Heat wt.

2. Amount Cast

3. Final Heat Analysis

4. Ladle Preheat Temp.

5. Pour Box Temp.

6. Substrate

7. Nozzle Pos. WRT Wheel
- Welght of Melt in the Furnace.

- Approximate weight of strip produced plus metal left in pouring box.

- Analysis made from cast strip samples.

- Temperature in the ladle from the thermocouple located approximately 0.25 in. from refractory face just prior to tapping the melt from the furnace.

- Temperature in pouring box from thermocouple approx. 0.26 in. from refractory face in middle of box just prior to teeming neat from ladle.

- Chemistry of casting wheel.

- Position of the casting lip of the nozzle with respect to the wheel. 
8. Pool Depth

9. Initial Cast Speed

10. Aim Casting Temp.

12. Nozzle Gap

13. Nozzle Brick

14. Shroud Gas

15. Steel Transfer Temp.
- Height of the molten steel pool that contacts the wheel.

- starting rotational speed of casting wheel.

- Aim average temperature of steel in pouring box during casting.

- Aim operating gap between nozzle and casting substrate.

- Chemistry of refractory casting nozzle in contact with the steel.

- Gas atmosphere used to shroud the steel in the melt pool (up) and below the casting nozzle (down).

- Actual temperature of steel in ladle when transferred to the pouring box. 


\title{
APPENDIX IV
}

\section{BMALL WHEEL DATA ACQUISITION}

The small wheel data acquisition system based on an IBM PC-AT compatible computer was modifled to be more compatible with the existing acquisition and control system on the large wheel. Specifically, a MMAC-4000 I/O subsystem was mounted in the instrumentation cabinet at the small caster control pulpit and connected made to the signal lines. A small NEMA-12 electrical box mounted on the control pulpit was rewired to include indicator lights for low and high cooling water flows as determined by a turbine flow meter in the 2 in. feed line. A DATA ON push button with an adjacent indicator light was installed to allow easy activation of the data acquisition system.

\section{Analog inputs currently are:}

\author{
WHEEL BPEED \\ WATER INPUT TEMPERATURE \\ WATER OUTPUT TEMPERATURE \\ STEEL TEMPERATURE \\ POURING BOX TEMPERATURE \\ WATER FLOW
}




\title{
switch (digital) inputs are:
}

\author{
WHEEL HORIZONTAL POBITION \\ WHEEL VERTICAL POBITION \\ STRIPPER ACTIVATION \\ BRUBH ACTIVATION \\ STRIPPER GAB \\ DATA ON PUBH BUTTON \\ STEPPER MOTOR LINE DONE \\ RATCHET (currently inactive)
}

Digital outputs are:

\begin{abstract}
DATA ACQUIBITION ON LAMP (pulpit control box)
DATA BTORE LAMP (neON lamp no. O ON MMAC 1020 )
\end{abstract}

A new device $\mathrm{ZC}$ : was added to the $\mathrm{RSX}-11 / \mathrm{M}$ Plus operating system to allow direct support of the new MMAC front-in. A dedicated 9600 baud serial line for the UMAC and a second serial line for a local terminal were installed to the computer room. supporting software, written in FORTRAN, was installed on the Digital PDP $11 / 73$ computer in the control room. This software includes:

BMALL.T8K A task. which collects data from the sensors and switches. When the DATA ON button is depressed for the first time, the program turns on the DATA ON panel light and begins to collect data. Data is stored either when a switch input changes state or on a time basis. These criteria are active simultaneously, i.e., 
the data is stored whenever elther of the conditions are met. The timed storage operates at two speeds: slow which is every minute; and fast, where each data point is stored as it is taken. The casting condition determines the speed selected. Fast data acquisition is reserved for the casting state, $i . e .$, the time from when the wheel is brought to casting condition just before metal is fed into the pouring box until the cast is done. Casting state is established by the wheel position, stripper activation, and stripper gas states. Once in cast state, the fast data acquisition rate is maintained as long as either the original cast conditions are met or the melt thermocouple reading exceeds $2600^{\circ} \mathrm{F}$. This prevents dropping out of fast mode if attempts are made to clear a frozen nozzle or the operator decides to make an in-flight change in the cast such as turning off the stripper gas. Data is stored on a file named SMALL.DAT, with new data creating new versions of the same file name. File creation dates are used to connect data files to specific heats. Storing of data is stopped and the data file closed ready for processing whenever the DATA ON button is depressed a second time. The task SMALL continues, constantly printing the current input values in engineering units on the local terminal at the small caster and ready for a new data collection cycle when the DATA ON button is depressed again.

SMAPLT.TSK A task which plots the data in the latest version of the file SMALL.DAT according to the channel information contained in the file. sMAPLT.DAT. The format of SMAPLT.DAT includes a provision on the first line for specifying the start 
time and duration in seconds from the initial data point, or alternatively, to start the plot at the initial CASTING data point (i.e., skip the preheat portion). Other lines consist of a data channel specification including range and labeling information. Analog channels are plotted as continuous lines. Digital (switch) inputs are plotted as an upward arrow when going from off-to-on, and a down arrow when turning off. The source flle, SMAPLT.FTN contains comments which explain the format of SMAPLT.DAT in detail. A sample plot is shown in Fig. 36 .

BMABCK.TBK A task to 'play back' the data from SMALL.DAT on the console terminal in case a specific data point is required. This is primarlly useful in problem solving.

The system startup command file $[1,2]$ STARTUP. CMD was modified so that the task SMALL would be initiated upon startup unless blocked by the operator. 

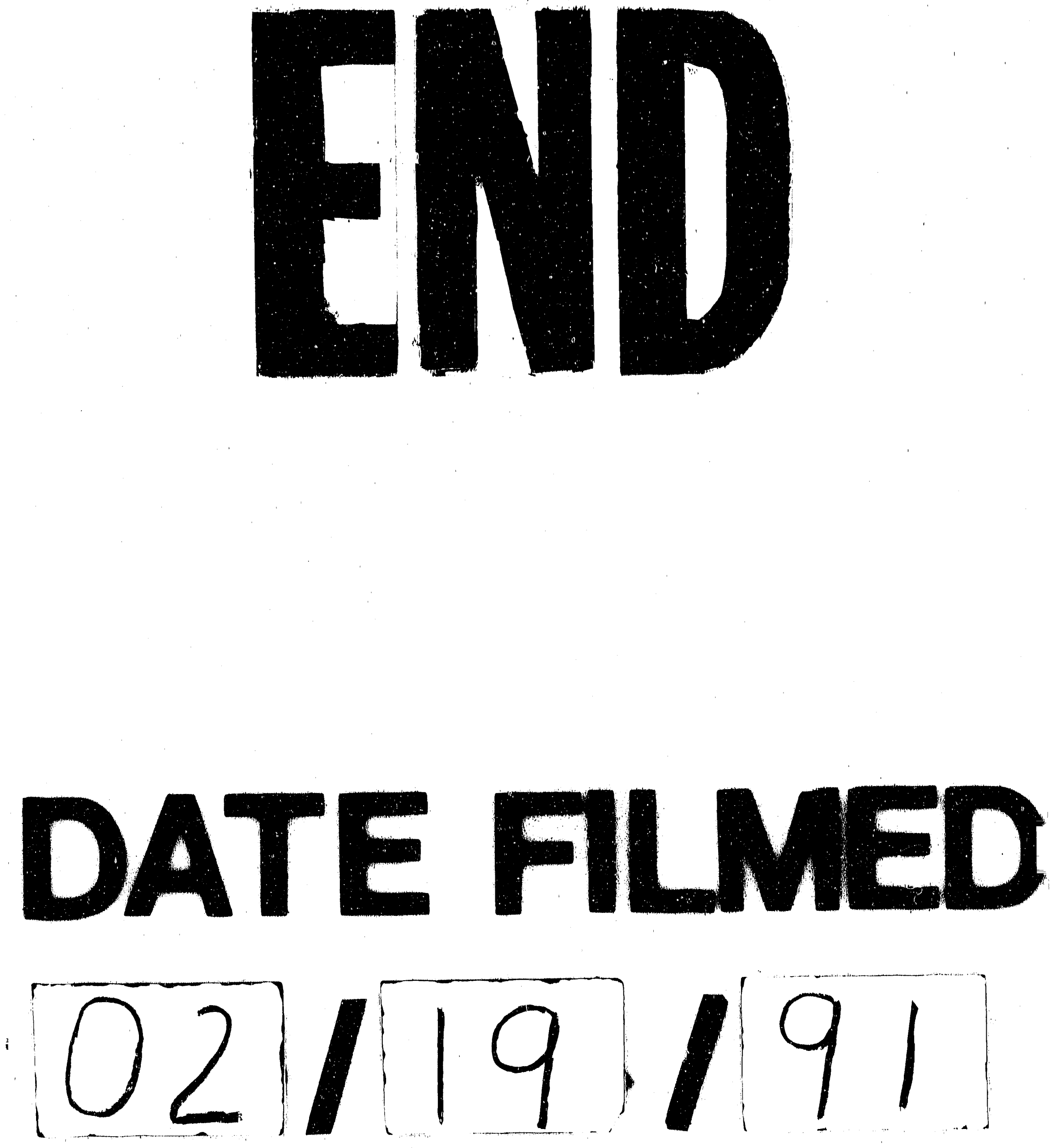
